UNIVERSIDADE DE SÃO PAULO

ESCOLA DE ENGENHARIA DE SÃO CARLOS

DEPARTAMENTO DE ENGENHARIA DE ESTRUTURAS

RAFAELLA MOREIRA LIMA GONDIM RESENDE

Avaliação dos efeitos da danificação e da acustoelasticidade sobre a velocidade de pulso ultrassônico em corpos de prova de concreto submetidos a compressão uniaxial 



\title{
Avaliação dos efeitos da danificação e da acustoelasticidade sobre a velocidade de pulso ultrassônico em corpos de prova de concreto submetidos a compressão uniaxial
}

\author{
VERSÃO CORRIGIDA
}

A versão original encontra-se na Escola de Engenharia de São Carlos

\begin{abstract}
Dissertação apresentada ao
Departamento de Engenharia de

Estruturas da Escola de Engenharia de

São Carlos, Universidade de São Paulo, como parte dos quesitos necessários para obtenção do título de Mestre em Engenharia Civil (Estruturas).

Orientador: Prof. Dr. Vladimir Guilherme Haach
\end{abstract}


AUTORIZO A REPRODUÇÃO TOTAL OU PARCIAL DESTE TRABALHO, POR QUALQUER MEIO CONVENCIONAL OU ELETRÔNICO, PARA FINS DE ESTUDO E PESQUISA, DESDE QUE CITADA A FONTE.

Ficha catalográfica elaborada pela Biblioteca Prof. Dr. Sérgio Rodrigues Fontes da EESC/USP com os dados inseridos pelo(a) autor(a).

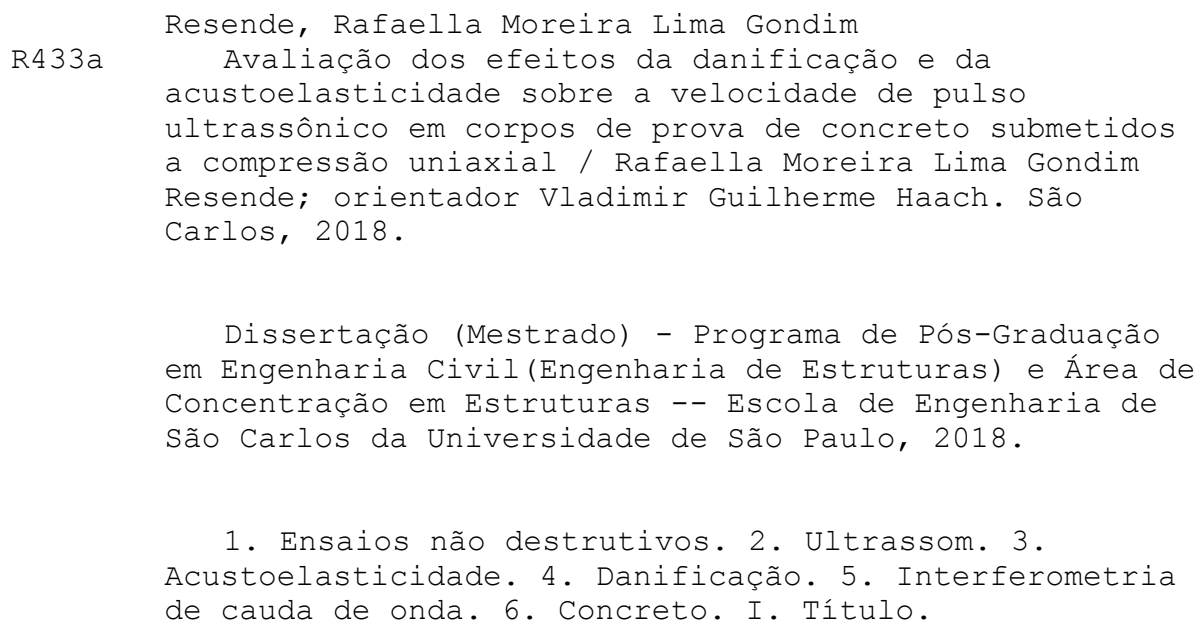




\section{FOLHA DE JULGAMENTO}

Candidata: Engenheira RAFAELLA MOREIRA LIMA GONDIM RESENDE.

Título da dissertação: "Avaliação dos efeitos de danificação e da acustoelasticidade sobre a velocidade de pulso ultrassônico em corpos de prova de concreto submetidos a compressão uniaxial".

Data da defesa: 23/04/2018.

Comissão Julgadora:

Resultado:

Prof. Dr. Vladimir Guilherme Haach (Orientador)

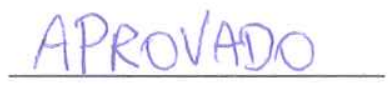

(Escola de Engenharia de São Carlos/EESC)

Prof. Dr. Luiz Carlos de Almeida

APROUAPO

(Universidade Estadual de Campinas/UNICAMP)

Prof. Dr. José Luiz Antunes de Oliveira e Sousa

ATROVADT

(Universidade Estadual de Campinas/UNICAMP)

Coordenador do Programa de Pós-Graduação em Engenharia Civil (Engenharia de Estruturas):

Prof. Titular Humberto Breves Coda

Presidente da Comissão de Pós-Graduação:

Prof. Associado Luís Fernando Costa Alberto 



\section{AGRADECIMENTOS}

Ao professor e orientador Vladimir pela disponibilidade, atenção e tranquilidade ao longo de todo o trabalho.

Ao meu marido, Ranyere, pelo amor, compreensão e apoio nos últimos dez anos. Obrigada pelo incentivo e por me fazer feliz!

À minha mãe e aos meus irmãos, Ludmilla e Matheus, por todo o amor e pela paciência com a distância.

Ao Yagho, pela amizade e por fazer com que as longas horas de estudo e trabalho fossem mais felizes!

Ao Tito, pelo companheirismo e pela amizade.

Aos amigos que entraram no Mestrado comigo, Giovane, Alex, Emerson, Fabiana, Francielle e Felipi.

Às amigas da D6, Mariana, Maria, Lisiane e Aline, e aos demais colegas do SET.

Aos técnicos do laboratório, Jorge, Amaury, Romeu, Vareda e Fabiano, por todo o suporte durante as concretagens e os ensaios.

Aos professores do IFMA e do SET, por terem ajudado na minha formação como engenheira.

À CAPES, pela bolsa de mestrado concedida. 

"Mas o que importa a eternidade da danação a quem encontrou num segundo o infinito da fruição?" (Charles Baudelaire) 



\section{RESUMO}

RESENDE, R. M. L. G. Avaliação dos efeitos da danificação e da acustoelasticidade sobre a velocidade de pulso ultrassônico em elementos de concreto. 2018. 133p. Dissertação (Mestrado em Engenharia Civil (Estruturas)) Escola de Engenharia de São Carlos, Universidade de São Paulo, São Carlos, 2018.

A teoria da acustoelasticidade relaciona a variação de velocidade de propagação de ondas mecânicas à variação de tensão em um meio sólido. Em materiais frágeis como concreto, a danificação altera a velocidade de propagação paralelamente ao efeito acustoelástico. O objetivo deste trabalho é identificar e quantificar como a danificação e o efeito acustoelástico agem sobre a Velocidade de Pulso Ultrassônico (VPU) em corpos de prova de concreto submetidos a compressão uniaxial. Para tanto, foram realizadas três fases de ensaio. A primeira fase objetivou gerar dados para a análise da aplicação da interferometria de cauda de onda (Coda Wave Interferometry - CWI). Duas variações deste método foram estudadas e comparadas, com o propósito de determinar-se qual gera melhores resultados e quais parâmetros devem ser adotados para as análises. Para tal, um código computacional foi desenvolvido utilizando a linguagem Python 3.6.0. Foi constatado que a técnica do alongamento apresenta resultados melhores que a técnica tradicional da interferometria de cauda de onda. $A$ segunda etapa foi dedicada ao estudo da variação de velocidade de propagação devido à recuperação de dano do corpo de prova. A terceira fase abordou a influência da geometria da amostra e da composição do concreto sobre a resposta do material à acustoelasticidade. Além disso, definiu-se um Índice de Dano (D) baseado na redução do módulo de elasticidade devido ao carregamento, a fim de isolar a variação de velocidade causada pelo efeito acustoelástico. Quanto ao estudo da recuperação de dano ao longo do tempo, a variação relativa de velocidade nas primeiras 24 horas após a retirada do carregamento se mostrou muito pequena em relação às variações geradas pelas condições de temperatura e umidade. Concluiu-se também que as amostras cilíndricas apresentaram respostas mais uniformes ao efeito acustoelástico que as amostras prismáticas. Por fim, o Índice de Dano se mostrou eficaz para isolar os efeitos da danificação e da acustoelasticidade sobre a VPU.

Palavras-chave: Ensaios não destrutivos. Ultrassom. Acustoelasticidade. Danificação. Interferometria de Cauda de onda. Concreto. 



\begin{abstract}
RESENDE, R. M. L. G. Evaluation of damaging and acoustoelastic effect over ultrasonic pulse velocity in concrete elements. 2018. 133 p. Dissertation (M. Sc. in Civil Engineering (Structures)) - School of Engineering of São Carlos, University of São Paulo, São Carlos, 2018.

The acoustoelasticity theory relates the variation in propagation velocity of mechanical waves to the stress variation in a solid medium. In brittle materials such as concrete, damage affects the propagation velocity parallel to the acoustoelastic effect. This research aims to identify and quantify how damage and acoustoelastic effect act on Ultrasonic Pulse Velocity (UPV) in concrete samples subjected to uniaxial compression. In order to do so, three phases of testing were performed. The first one focused on generating data to analyze the application of the Coda Wave Interferometry $(\mathrm{CWI})$. Two variations of this method were studied and compared, to the purpose of determining which variation shows better results and which parameters should be adopted in the analysis. To enable the analysis, a computational code using Python 3.6.0 language was developed. It was verified that the stretching technique shows better results than the traditional coda wave interferometry technique. The second phase was dedicated to study the variation in propagation velocity due to damage recovery in the sample. The third phase addressed the influence of the sample geometry and the concrete composition over the response from the material to the acoustoelasticity. Furthermore, a Damage Index (D) was defined based on the elastic modulus reduction due to loading, in order to isolate the variation of velocity due solely to the acoustoelastic effect. Regarding the study of damage recovery over time, the relative velocity variation in the first 24 hours following the withdrawal of the loading showed to be too little when compared to the variations caused by temperature and humidity conditions. It was also concluded that the cylindrical samples showed more uniform responses to the acoustoelastic effect than the prismatic samples. Finally, the Damage Index proved itself to be a reliable tool to isolate the effects of damage and acoustoelasticity over the UPV.
\end{abstract}

Keywords: Nondestructive testing. Ultrasound. Acoustoelasticity. Damage. Coda Wave Interferometry. Concrete. 



\section{LISTA DE FIGURAS}

Figura 2.1 - Propagação de onda longitudinal ................................................. 33

Figura 2.2 - Propagação de onda de cisalhamento ......................................... 34

Figura 2.3 - Propagação de onda Rayleigh ..................................................... 34

Figura 2.4 - Esquema do ensaio de velocidade de pulso ultrassônica .....................38

Figura 2.5 - Posições relativas entre os dois transdutores ................................... 39

Figura 2. 6 - Velocidade de onda de superfície $x$ tensão aplicada .........................43

Figura 2. 7 - Comparação entre valores teóricos e experimentais obtidos para ponte

em construção.

Figura 2. 8 - Variação da frequência de ressonância dos modos de vibração: (a) torcional e (b) longitudinal ....................................................................... 46

Figura 2. 9 - Velocidade de onda de superfície $x$ tensão aplicada .........................49

Figura 2. 10 - Esquema simplificado do carregamento aplicado por Zhang et al.

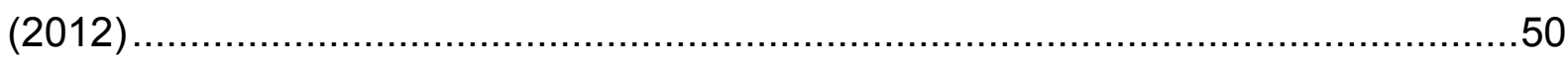

Figura 2. 11 - Ondas registradas em amostras de granito a $45^{\circ} \mathrm{C}$ (azul) e $50^{\circ} \mathrm{C}$ (vermelho)

Figura 3. 1 - Concretagem das amostras: (a) betoneira utilizada e (b) realização do ensaio de abatimento

Figura 3. 2 - Equipamentos utilizados: (a) aparelho de ultrassom PunditLab+e (b) transdutores de cisalhamento de $250 \mathrm{kHz}$

Figura 3. 3 - Peças utilizadas para que a aplicação do carregamento não danifique os transdutores: (a) metálica e (b) de isopor. 60

Figura 3. 4 - Calibração: (a) procedimento e (b) equipamento calibrado. 60 Figura 3. 5 - Equipamentos utilizados: (a) pórtico de reação com cilindro hidráulico e célula de carga e (b) equipamento P3. 60

Figura 3. 6 - Ensaios preliminares: (a) configuração do ensaio e (b) detalhe do posicionamento do corpo de prova

Figura 3. 7 - Esquema simplificado do carregamento do primeiro tipo de ensaio da segunda etapa.

Figura 3.8 - Esquema simplificado do carregamento do segundo tipo da segunda etapa

Figura 3. 9 - Posicionamento do transdutor LVDT durante a terceira etapa de ensaios

Figura 3. 10 - Esquema simplificado do carregamento na terceira etapa de ensaios

Figura 3. 11 - Configuração da terceira etapa de ensaios 67

Figura 4. 1 - Interface do programa de Interferometria de cauda de onda .70 
Figura 4.2 - Resultados obtidos com as medidas de 14 janelas sem sobreposição:

(a) média e (b) dispersão

Figura 4. 3 - Detalhe do sinal da onda sem carregamento mostrando o intervalo de chegada das ondas longitudinais e de cisalhamento .72

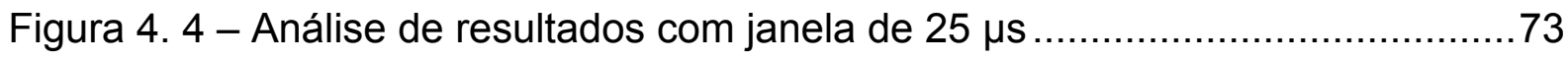

Figura 4. 5 - Análise de resultados com janela de 50 s .....................................73

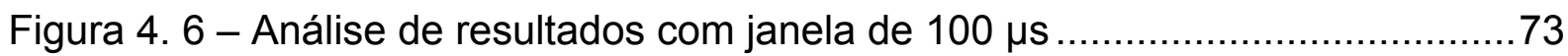

Figura 4.7 - Dispersão de resultados para a janela de $100 \mu$ s e ponto central

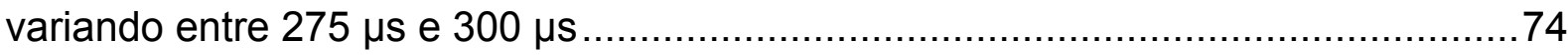

Figura 4. 8 - Dispersão de resultados para a janela de $100 \mu$ s e ponto central variando entre $300 \mu$ s e $325 \mu$ s.

Figura 4. 9 - Variação de velocidade para cada ponto central com carregamento de $20 \%$ e janela de $100 \mu$ s

Figura 4. 10 - Variação de velocidade para cada ponto central com carregamento de $20 \%$ e janela de $100 \mu s$

Figura 4. 11 - Dispersão de resultados para a janela de $50 \mu$ s e ponto central variando entre $275 \mu$ s e $300 \mu$ s.

Figura 4. 12 - Dispersão de resultados para a janela de $50 \mu$ s e ponto central variando entre $300 \mu$ s e $325 \mu$ s

Figura 4. 13 - Variação de velocidade para cada ponto central com carregamento de $30 \%$ e janela de $50 \mu \mathrm{s}$

Figura 4. 14 - Variação de velocidade para cada ponto central com carregamento de $30 \%$ e janela de $50 \mu \mathrm{s}$

Figura 4. 15 - Detalhe da sobreposição dos sinais sem carregamento (onda azul) e com carregamento de $20 \%$ da tensão de ruptura (onda vermelha) .... .75

Figura 4. 16 - Detalhe da sobreposição dos sinais sem carregamento (onda azul) e com carregamento de $30 \%$ da tensão de ruptura (onda vermelha)

Figura 4. 17 - Detalhe da sobreposição dos sinais sem carregamento (onda azul) e com carregamento de $40 \%$ da tensão de ruptura (onda vermelha) .........................76

Figura 4. 18 - Sobreposição dos sinais de todos os níveis de carregamento...........76

Figura 4. 19 - Detalhe 'a' da sobreposição dos sinais .................................... 77

Figura 4. 20 - Detalhe 'b' da sobreposição dos sinais ......................................77

Figura 4. 21 - Dispersão de resultados para a janela de $50 \mu$ s e ponto central

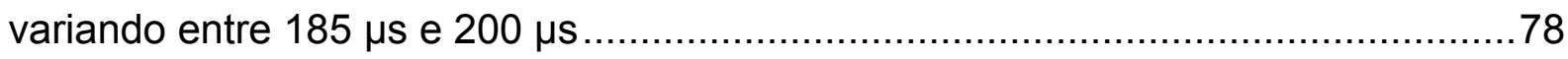

Figura 4. 22 - Dispersão de resultados para a janela de $50 \mu$ s e ponto central variando entre $200 \mu$ s e $225 \mu$ s.

Figura 4. 23 - Dispersão de resultados para a janela de $50 \mu$ s e ponto central variando entre $225 \mu$ s e $250 \mu s$

Figura 4. 24 - Dispersão de resultados para a janela de $50 \mu$ s e ponto central variando entre $250 \mu \mathrm{s}$ e $275 \mu \mathrm{s}$ 
Figura 4. 25 - Dispersão de resultados para a janela de $100 \mu$ s e ponto central variando entre $185 \mu$ s e $200 \mu$ s.

Figura 4. 26 - Dispersão de resultados para a janela de $100 \mu$ s e ponto central variando entre $200 \mu$ s e $225 \mu$ s.

Figura 4. 27 - Dispersão de resultados para a janela de $100 \mu$ s e ponto central variando entre $225 \mu$ s e $250 \mu$ s.

Figura 4. 28 - Dispersão de resultados para a janela de $100 \mu$ s e ponto central variando entre $250 \mu$ s e $275 \mu$ s.

Figura 4. 29 - Resultados avaliados com o alongamento (janela de $50 \mu \mathrm{s}$ )

Figura 4. 30 - Dispersão de resultados com o ponto central variando entre $200 \mu \mathrm{s}$ e $225 \mu \mathrm{s}$

Figura 4. 31 - Dispersão de resultados com o ponto central variando entre $225 \mu \mathrm{s}$ e $250 \mu \mathrm{s}$

Figura 4. 32 - Dispersão de resultados com o ponto central variando entre $250 \mu \mathrm{s}$ e

$275 \mu \mathrm{s}$

Figura 4. 33 - Onda emitida com ganho e voltagem de excitação máximos;

$\mathrm{t}=108.1 \mu \mathrm{s}$

Figura 4. 34 - Onda emitida com ganho e voltagem de excitação máximos;

$\mathrm{t}=103.7 \mu \mathrm{s}$

Figura 4. 35 - Interface do programa para avaliação do tempo de chegada de ondas longitudinais

Figura 5. 1 - Prismas após a concretagem .88

Figura 5. 2 - Resultados obtidos no Ensaio 1: (a) variação de velocidade sem correção; (b) variação de velocidade obtida no controle; e (c) variação de velocidade com correção

Figura 5. 3 - Resultados obtidos no Ensaio 2: (a) variação de velocidade sem correção; (b) variação de velocidade obtida no controle íntegro: (c) variação de velocidade obtida no controle danificado; (d) detalhe da variação de velocidade obtida no controle íntegro; (e) detalhe da variação de velocidade obtida no controle danificado; (f) variação de velocidade com correção (controle íntegro); e (g) variação de velocidade com correção (controle danificado)

Figura 5.4 - Resultados obtidos no Ensaio 1 durante o carregamento: (a) variação de velocidade sem correção; (b) variação de velocidade obtida no controle: (c) variação de velocidade com correção

Figura 5. 5 - Dispersão de resultados do prisma 1 - ondas longitudinais, direção 195 Figura 5. 6 - Dispersão de resultados do cilindro 1 - ondas longitudinais, direção 1

Figura 5.7 - Dispersão de resultados do prisma 2 - ondas longitudinais, direção 195 Figura 5. 8 - Dispersão de resultados do cilindro 2 - ondas longitudinais, direção 1 
Figura 5. 9 - Dispersão de resultados do prisma 3 - ondas longitudinais, direção 195 Figura 5. 10 - Dispersão de resultados do cilindro 3 - ondas longitudinais, direção 1

Figura 5. 11 - Dispersão de resultados do prisma 1 - ondas de cisalhamento, direção 1

Figura 5. 12 - Dispersão de resultados do cilindro 1 - ondas de cisalhamento, direção 1

Figura 5. 13 - Dispersão de resultados do prisma 2 - ondas de cisalhamento, direção 1

Figura 5. 14 - Dispersão de resultados do cilindro 2 - ondas de cisalhamento, direção 1

Figura 5. 15 - Dispersão de resultados do prisma 3 - ondas de cisalhamento, direção 1

Figura 5. 16 - Dispersão de resultados do cilindro 3 - ondas de cisalhamento, direção 1

Figura 5.17 - Dispersão de resultados do prisma 2 - ondas longitudinais, direção 2

Figura 5. 18 - Dispersão de resultados do cilindro 2 - ondas longitudinais, direção 2

Figura 5. 19 - Dispersão de resultados do prisma 3 - ondas longitudinais, direção 2

Figura 5. 20 - Dispersão de resultados do cilindro 3 - ondas longitudinais, direção 2

Figura 5. 21 - Dispersão de resultados para o traço 2, ondas longitudinais, direção 1: (a) cilindro 1; (b) cilindro 2; e (c) cilindro 3. 100 Figura 5. 22 - Dispersão de resultados para o traço 3, ondas longitudinais, direção 1: (a) cilindro 1; (b) cilindro 2; e (c) cilindro 3. 101

Figura 5. 23 - Comparação entre as médias obtidas para cada cilindro (ondas longitudinais 1).

Figura 5. 24 - Dispersão de resultados para o traço 2, ondas de cisalhamento, direção 1: (a) cilindro 1; (b) cilindro 2; e (c) cilindro 3 102 Figura 5. 25 - Dispersão de resultados para o traço 3, ondas de cisalhamento, direção 1: (a) cilindro 1; (b) cilindro 2; e (c) cilindro 3 103

Figura 5. 26 - Comparação entre as médias obtidas para cada cilindro (ondas de cisalhamento)

Figura 5. 27 - Dispersão de resultados para o traço 2, ondas longitudinais, direção 2:

(a) cilindro 1; (b) cilindro 2; e (c) cilindro 3. 104

Figura 5. 28 - Dispersão de resultados para o traço 3, ondas longitudinais, direção 2:

(a) cilindro 1; (b) cilindro 2; e (c) cilindro 3. 105 
Figura 5. 29 - Comparação entre as médias obtidas para cada cilindro (ondas longitudinais 2)....

Figura 5. 30 - Prisma 1, traço 1: (a) Índice de Dano; (b) Variação relativa de velocidade devido à danificação; (c) Variação relativa de velocidade devido à acustoelasticidade; (d) influência da danificação sobre a variação de velocidade .. 110 Figura 5. 31 - Prisma 2, traço 1: (a) Índice de Dano; (b) Variação relativa de velocidade devido à danificação; (c) Variação relativa de velocidade devido à acustoelasticidade; (d) influência da danificação sobre a variação de velocidade ...111 Figura 5. 32 - Prisma 3, traço 1: (a) Índice de Dano; (b) Variação relativa de velocidade devido à danificação; (c) Variação relativa de velocidade devido à acustoelasticidade; (d) influência da danificação sobre a variação de velocidade...112 Figura 5. 33 - Cilindro 1, traço 1: (a) Índice de Dano; (b) Variação relativa de velocidade devido à danificação; (c) Variação relativa de velocidade devido à acustoelasticidade; (d) influência da danificação sobre a variação de velocidade ..113 Figura 5. 34 - Cilindro 2, traço 1: (a) Índice de Dano; (b) Variação relativa de velocidade devido à danificação; (c) Variação relativa de velocidade devido à acustoelasticidade; (d) influência da danificação sobre a variação de velocidade ..114 Figura 5. 35 - Cilindro 3, traço 1: (a) Índice de Dano; (b) Variação relativa de velocidade devido à danificação; (c) Variação relativa de velocidade devido à acustoelasticidade; (d) influência da danificação sobre a variação de velocidade ..115 Figura 5. 36 - Cilindro 1, traço 2: (a) Índice de Dano; (b) Variação relativa de velocidade devido à danificação; (c) Variação relativa de velocidade devido à acustoelasticidade; (d) influência da danificação sobre a variação de velocidade ..116 Figura 5. 37 - Cilindro 2, traço 2: (a) Índice de Dano; (b) Variação relativa de velocidade devido à danificação; (c) Variação relativa de velocidade devido à acustoelasticidade; (d) influência da danificação sobre a variação de velocidade...117 Figura 5. 38 - Cilindro 3, traço 2: (a) Índice de Dano; (b) Variação relativa de velocidade devido à danificação; (c) Variação relativa de velocidade devido à acustoelasticidade; (d) influência da danificação sobre a variação de velocidade...118 Figura 5. 39 - Cilindro 1, traço 3: (a) Índice de Dano; (b) Variação relativa de velocidade devido à danificação; (c) Variação relativa de velocidade devido à acustoelasticidade; (d) influência da danificação sobre a variação de velocidade...119 Figura 5. 40 - Cilindro 2, traço 3: (a) Índice de Dano; (b) Variação relativa de velocidade devido à danificação; (c) Variação relativa de velocidade devido à acustoelasticidade; (d) influência da danificação sobre a variação de velocidade ..120 Figura 5. 41 - Cilindro 3, traço 3: (a) Índice de Dano; (b) Variação relativa de velocidade devido à danificação; (c) Variação relativa de velocidade devido à acustoelasticidade; (d) influência da danificação sobre a variação de velocidade ..121 Figura 5. 42 - Variação de velocidade para a amostra descarregada: (a) prisma 1; e (b) cilindro T1C1 



\section{LISTA DE TABELAS}

Tabela 2.1 - Correções de velocidade de pulso devido à variação de temperatura .40

Tabela 2. 2 - Distância mínima entre transdutores ..................................................41

Tabela 3. 1 - Quantidade de corpos de prova ensaiados.......................................57

Tabela 3. 2 - Descrição das composições de concreto utilizadas ...........................58

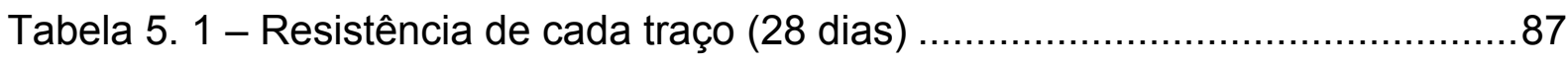

Tabela 5. 2 - Coeficientes acustoelásticos ………….....................................106 



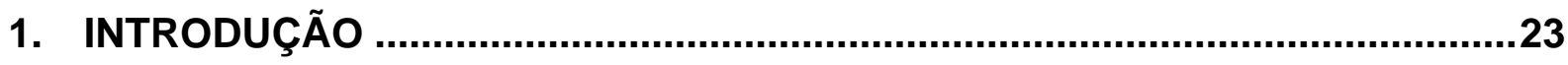

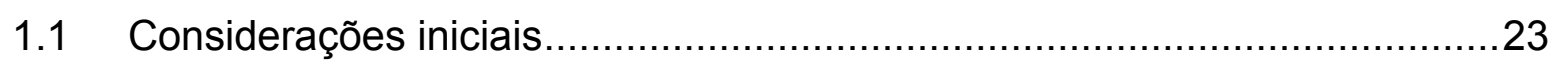

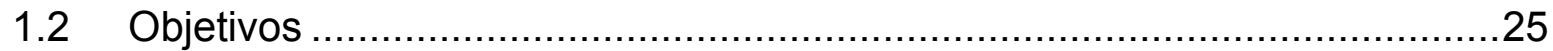

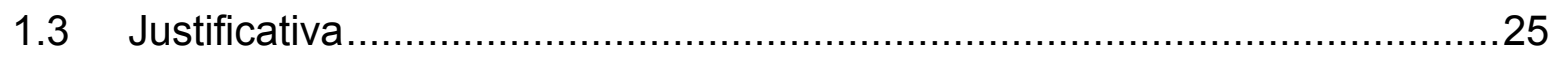

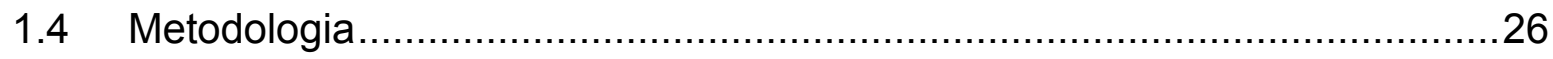

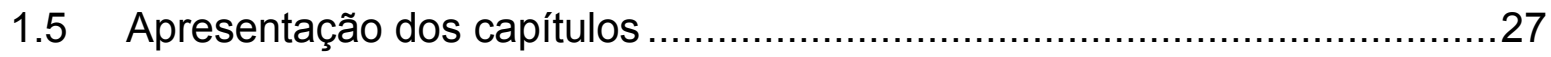

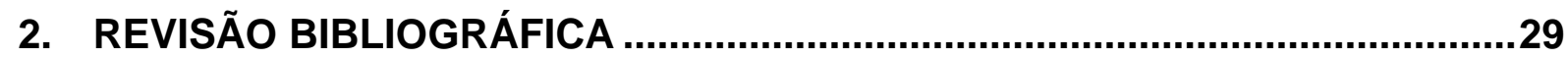

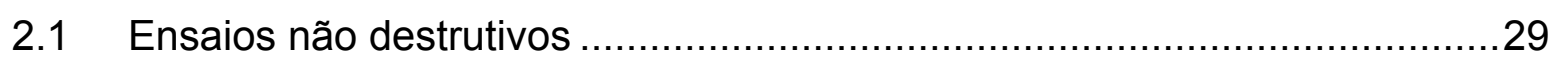

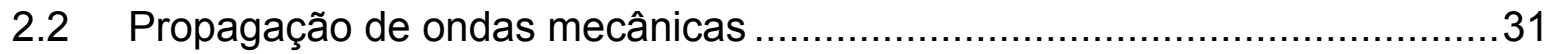

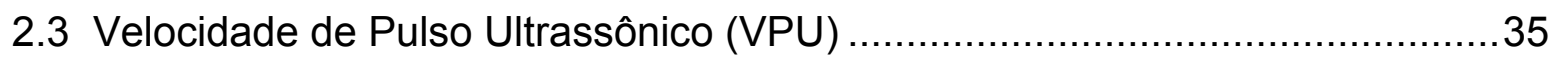

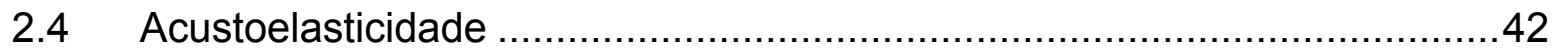

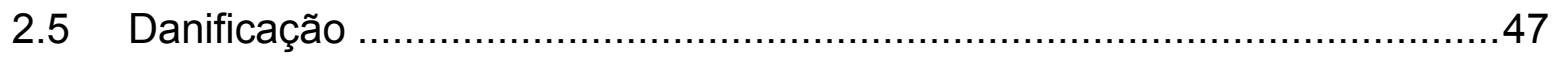

2.6 Interferometria de Cauda de Onda (Coda Wave Interferometry - CWI) .......51

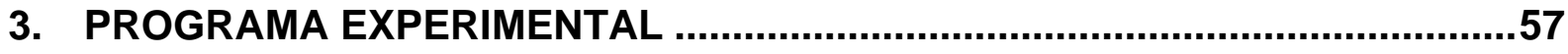

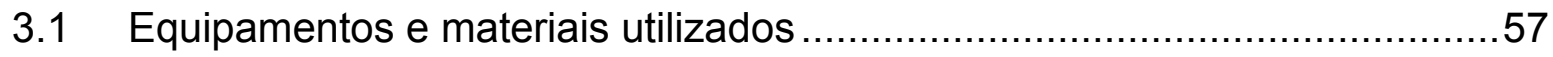

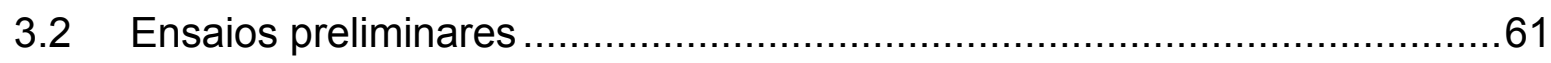

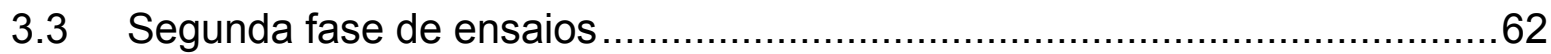

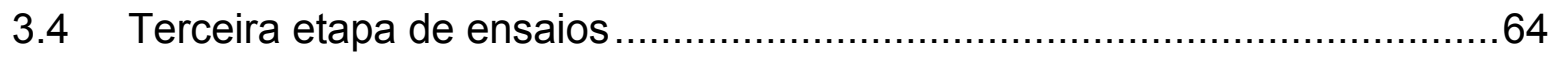

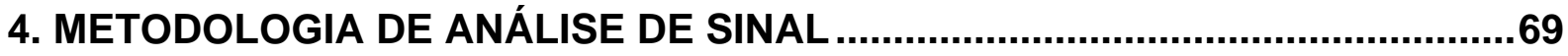

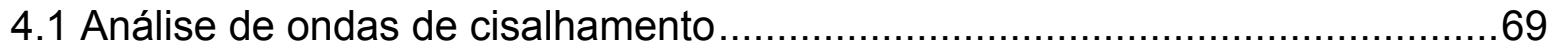

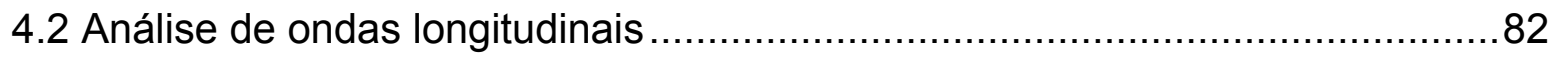

5. RESULTADOS

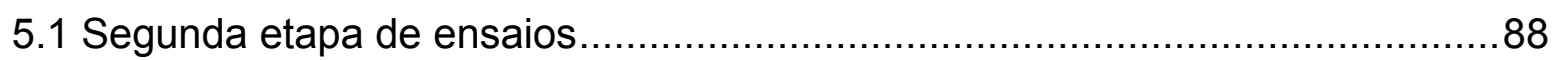

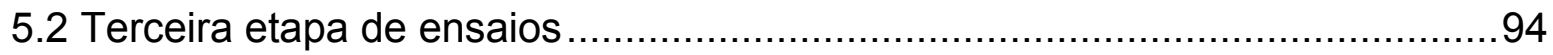

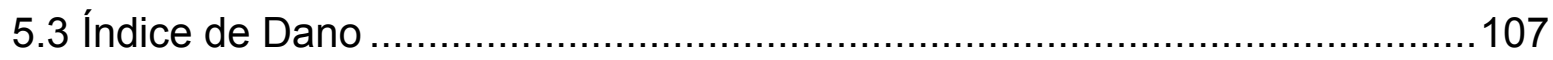

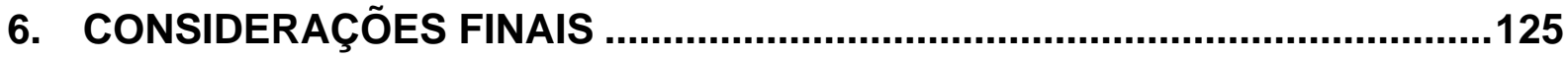

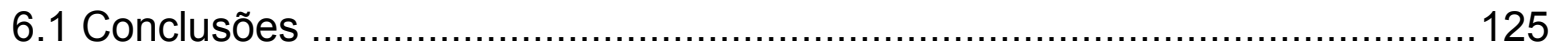

6.2 Sugestões para trabalhos futuros.......................................................126

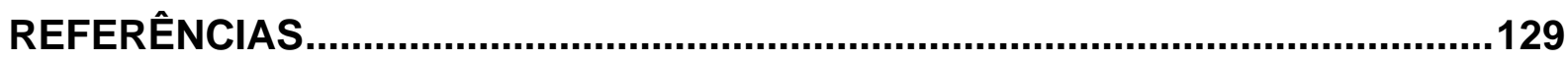





\section{INTRODUÇÃO}

\subsection{Considerações iniciais}

Para garantir a durabilidade de estruturas de concreto em serviço, faz-se necessário monitorar as propriedades desta estrutura durante sua construção e utilização. Neste sentido, ensaios não destrutivos (ENDs) oferecem uma excelente alternativa à avaliação de estruturas, uma vez que se caracterizam por causar pouco ou nenhum dano à estrutura avaliada.

Por não causarem danos à estrutura, os ENDs apresentam ainda a possibilidade de monitoração das características de um mesmo elemento estrutural ao longo do tempo. Além disso, uma vez que não é necessário fazer grandes reparos na estrutura após a execução dos ensaios, os ENDs apresentam custo menor que ensaios destrutivos.

A International Atomic Energy Agency (2002) lista as seguintes situações em que ENDs são recomendados:

- Monitoração do ganho de resistência nas primeiras idades para remoção de forma;

- Controle de qualidade de elementos pré-moldados;

- Localização de defeitos e descontinuidades no concreto, tais como fissuras ou falhas de concretagem;

- Determinação da uniformidade do concreto;

- Localização de armaduras e determinação de área de aço;

- Aumento da confiança em ensaios destrutivos quando não for possível extrair uma quantidade significativa de amostras;

- Estudo da deterioração do concreto após incêndios ou aplicação de carregamentos excepcionais;

- Estudo de durabilidade do concreto;

- Análise da variação das propriedades do material ao longo do tempo. 
Embora ENDs já sejam utilizados corriqueiramente na indústria de produção de aço estrutural, seu uso em concreto ainda não é uma prática difundida. Malhotra (2004) explica que o desenvolvimento de técnicas de ENDs para concreto é mais lento devido à heterogeneidade do material. O autor afirma que um dos métodos construtivos mais utilizado em estruturas de concreto, a moldagem in-loco, contribui para aumentar a variabilidade do material e dificultar a obtenção de parâmetros para a padronização de ensaios não destrutivos.

Ensaios não destrutivos, em sua maioria, não fazem medição direta da propriedade desejada do material. Como exemplo, podemos citar os ENDs para obtenção da resistência de elementos de concreto. Neste tipo de ensaio, são feitas medições indiretas que devem ser correlacionadas à resistência por meio de curvas ou tabelas. Daí a dificuldade gerada pela variabilidade do concreto. Para que os ENDs tenham um bom nível de confiança, o ideal é que sejam geradas equações de correlação específicas para o traço do concreto avaliado.

O ensaio utilizado neste trabalho é o de Velocidade de Pulso Ultrassônico (VPU), que se baseia em medir a velocidade de propagação de ondas ultrassônicas. No Brasil, este ensaio é regulamentado pela ABNT NBR 8802:2013 e pode ser utilizado para verificar a homogeneidade do concreto; identificar falhas de concretagem e determinar profundidade de fissuras; e monitorar variações nas propriedades do concreto ao longo do tempo.

O presente trabalho propõe a utilização deste ensaio para a investigação dos efeitos da acustoelasticidade e da danificação sobre a velocidade de pulso ultrassônico em corpos de prova de concreto submetidos a compressão uniaxial.

A acustoelasticidade é uma propriedade que determina a variação da velocidade de propagação de ondas mecânicas quando o estado de tensões do meio é alterado. No entanto, o estudo deste fenômeno no concreto é dificultado pela fragilidade do material. Quando submetido à tensão, o concreto tende a fissurar. $O$ surgimento e propagação dessas descontinuidades no material também afetam a velocidade de propagação. 


\subsection{Objetivos}

Este trabalho teve como objetivo geral avaliar os efeitos da danificação e da acustoelasticidade sobre a velocidade de pulso ultrassônico em corpos de prova de concreto submetidos a compressão uniaxial.

A fim de alcançar o objetivo geral, foram determinados os seguintes objetivos específicos:

$\checkmark$ Analisar o uso da técnica interferometria de cauda de onda para determinar variações de velocidade de propagação;

$\checkmark$ Avaliar a viabilidade de utilização do Índice de Dano para separar quantitativamente a variação relativa de velocidade devido à danificação e ao efeito acustoelástico;

$\checkmark$ Estudar como a velocidade de propagação varia devido à recuperação de dano após a aplicação de um carregamento ao concreto;

$\checkmark$ Avaliar a influência da geometria do corpo de prova sobre a resposta da amostra ao efeito acustoelástico;

$\checkmark$ Avaliar o efeito acustoelástico em diferentes composições de concreto;

$\checkmark$ Desenvolver um procedimento padronizado de ensaio que permita a avaliação das variações de velocidade.

\subsection{Justificativa}

Avaliar o nível de tensão ao qual elementos estruturais de concreto estão submetidos é de interesse em várias situações corriqueiras da engenharia. Alguns exemplos são estruturas de grande porte que tenham sofrido redistribuição de 
esforços devido a um recalque diferencial; estruturas em que haja suspeita de risco de colapso; elementos protendidos, a fim de verificar perdas de protensão; estruturas que sofreram ação de um incêndio.

Por outro lado, o uso de técnicas não destrutivas é vantajoso para avaliação de elementos estruturais em serviço por permitir a obtenção de dados sem perturbação ou necessidade de posterior manutenção da estrutura. Esta propriedade é ainda mais desejável se houver suspeita de risco de colapso da estrutura. Neste sentido, é interessante a avaliação do nível de tensões em elementos estruturais de concreto por meio de ensaios ultrassônicos.

A técnica da avaliação do nível tensão por meio de ondas ultrassônicas se baseia na teoria da acustoelasticidade. Entretanto, devido à fragilidade do material, o concreto sofre abertura e propagação de fissuras conforme o seu nível de tensão aumenta. Esta danificação interage com a velocidade de pulso ultrassônica e dificulta a obtenção do nível de tensão da estrutura por meio da referida teoria.

Embora vários trabalhos analisem danificação e efeito acustoelástico, a quantificação da variação de velocidade devido à cada um dos fatores ainda não foi esclarecida. Neste sentido, este trabalho busca dar a sua contribuição à compreensão do fenômeno.

\subsection{Metodologia}

A fim de atingir os objetivos traçados, foram realizadas as seguintes etapas:

Revisão bibliográfica: nesta etapa, foi pesquisado o estado da arte de temas relativos a este trabalho, como: ensaios não destrutivos, propagação de ondas mecânicas, o método da Velocidade de Pulso Ultrassônico, efeito acustoelástico e avaliação de tensões e danificação usando ensaios ultrassônicos.

Estudo da interferometria de cauda de onda: esta etapa correspondeu ao estudo da aplicação da interferometria de cauda de onda à análise da variação de velocidade entre ondas ultrassônicas. Ensaios preliminares foram realizados a fim de fornecer dados para a validação do método e para otimização dos parâmetros que 
regem o mesmo. Ademais, um código computacional foi desenvolvido para aplicação da técnica do alongamento, uma variação do método tradicional. Então, os resultados obtidos pelas duas técnicas foram comparados para determinação da metodologia de análise de sinais a ser adotada posteriormente na pesquisa.

Etapa experimental: os ensaios desta etapa foram realizados no Laboratório de Estruturas da Escola de Engenharia de São Carlos (LE-EESC). Além dos ensaios preliminares para estudo da interferometria de cauda de onda, a etapa experimental apresentou ainda outras duas fases. A primeira teve o objetivo de quantificar a danificação em função do carregamento máximo aplicado utilizando o ensaio de Velocidade de Pulso Ultrassônico. A segunda etapa objetivou estudar a influência da geometria da amostra e da composição do concreto sobre o efeito acustoelástico. A partir da terceira etapa de ensaios, foi possível também isolar as parcelas de variação de velocidade devido ao efeito acustoelástico e à danificação. Todos os carregamentos aplicados foram incrementais de compressão uniaxial. A cada incremento, a força aplicada foi mantida constante para a realização do ensaio de VPU.

Análise de resultados: esta etapa consistiu na análise e discussão dos resultados obtidos na etapa experimental. As variações de velocidade foram obtidas por meio da interferometria de cauda de onda, no caso de ondas de cisalhamento, e pelo programa desenvolvido por Schiavon (2015), no caso de ondas longitudinais. Ainda, definiu-se o Índice de Dano para cada nível de carregamento e sugeriu-se um método para isolar os efeitos da danificação e da acustoelasticidade.

\subsection{Apresentação dos capítulos}

O presente trabalho se dividiu em seis capítulos: introdução, revisão bibliográfica, programa experimental, metodologia de análise de sinais, resultados e considerações finais.

O capítulo 2, referente à revisão bibliográfica, discorreu sobre os ensaios não destrutivos e sobre os conceitos de propagação de ondas necessários à compreensão 
deste trabalho. O capítulo trouxe ainda a descrição da metodologia para execução do ensaio de Velocidade de Pulso Ultrassônico. Por fim, o capítulo mostrou o estado da arte das pesquisas relacionadas a acustoelasticidade, estudo da danificação por meio de ensaios ultrassônicos e avaliação de sinais com a interferometria de cauda de onda.

O capítulo 3 descreveu inicialmente os equipamentos e materiais utilizados ao longo do programa experimental. A seguir, foram descritos os procedimentos adotados em laboratório para a realização dos ensaios.

O capítulo 4 descreveu os métodos adotados para avaliação dos sinais obtidos em ensaio. Neste capítulo, discutiu-se a adequação da interferometria de cauda de onda para a avaliação do efeito acustoelástico e descreveu-se a metodologia para obtenção do tempo de chegada de ondas longitudinais.

O capítulo 5 mostrou os resultados encontrados e as discussões desenvolvidas.

O capítulo 6 trouxe as considerações finais incluindo as conclusões acerca da pesquisa desenvolvida e as sugestões para trabalhos futuros. 


\section{REVISÃO BIBLIOGRÁFICA}

Neste capítulo, foram apresentadas as revisões correspondentes aos tópicos principais abordados neste trabalho. Inicialmente, foi realizada uma revisão dos ensaios não destrutivos mais utilizados na engenharia, dentre os quais está inserido o método da Velocidade de Pulso Ultrassônico (Ultrasonic Pulse Velocity - UPV). A seguir, foram abordados os itens específicos do ensaio ultrassônico, tais como a teoria da aplicação do método, a teoria de propagação de ondas mecânicas e como executar o ensaio.

Uma vez expostos os ensaios, foram abordados os fenômenos estudados com o uso do ensaio UPV: acustoelasticidade e danificação. Nestes itens, foram relatados os trabalhos encontrados na literatura que foram relevantes ao planejamento deste estudo.

Por fim, foi discutido o método utilizado para análise dos resultados dos ensaios, a Interferometria de Cauda de Onda. Neste item, foram mostrados trabalhos que já aplicaram esta técnica para a avaliação de danificação e acustoelasticidade em elementos de concreto.

\subsection{Ensaios não destrutivos}

Por ser o material de construção mais usado no mundo, o concreto exige o desenvolvimento de técnicas capazes de avaliar seu desempenho em serviço. Neste contexto, os ensaios não destrutivos se mostram vantajosos pela capacidade de obtenção de dados com pouca ou nenhuma danificação da estrutura. Logo, este tipo de ensaio apresenta uma opção prática e de baixo custo para a caracterização de estruturas. Os principais tipos de ensaios não destrutivos utilizados atualmente são:

- Métodos de Dureza Superficial (esclerometria): este método é utilizado para estimar a resistência à compressão do concreto. O mesmo também consiste em uma boa ferramenta de avaliação de uniformidade do concreto e comparação entre duas amostras. A precisão do ensaio é afetada pela 
rugosidade da superfície; tamanho, forma e rigidez dos elementos; idade e umidade da peça; tipo do agregado graúdo e do cimento utilizados; e presença de carbonatação da superfície. (MALHOTRA, 2004)

- Técnicas de Resistência à Penetração: este método é utilizado para estimar a resistência à compressão do concreto e para comparar a resistência em pontos distintos da estrutura. O resultado pode ser afetado pela presença de armaduras ou agregados graúdos próximos à superfície. (MALHOTRA; CARETTE, 2004)

- Ensaio de arrancamento: este ensaio consiste em arrancar um elemento metálico de formato especial inserido no concreto durante a moldagem. A força necessária para tal extração é correlacionada à resistência à compressão do concreto. O ensaio pode ser usado para determinar o tempo de desforma insitu. No entanto, este método apresenta a desvantagem de precisar ser planejado anteriormente à moldagem da estrutura. (MEHTA; MONTEIRO, 2008)

- Ensaio Break-off: este método é usado para estimar a resistência à compressão de elementos de concreto. A técnica é aplicada principalmente para determinar o tempo de desforma e de aplicação de protensão na estrutura. (NAIK, 2004)

- Método da Maturidade: este método só é aplicável para estruturas em fase de cura. Logo, o mesmo deve ser planejado antes da concretagem da estrutura. Nesta avaliação, surge o conceito de maturidade, que é função do tempo e da temperatura de cura. A maturidade pode ser correlacionada à resistência à compressão do concreto. (MEHTA; MONTEIRO, 2008)

- Frequência de ressonância: este método consiste em encontrar a frequência natural de vibração do material. A mesma pode ser utilizada para estimar o módulo dinâmico de elasticidade, a densidade e o coeficiente de Poisson da amostra. Além disso, em ensaios de durabilidade, o método pode ser usado para monitorar o grau de deterioração do concreto. (MALHOTRA; SIVASUNDARAM, 2004)

- Método da Velocidade de Pulso Ultrassônico: este método consiste na determinação da velocidade de propagação de ondas ultrassônicas por um meio sólido. A técnica é utilizada para obtenção do módulo de elasticidade e 
da resistência à compressão do material. Este ensaio ainda pode ser usado para detecção de fissuras. (NAIK; MALHOTRA; POPOVICS, 2004)

- Eco-impacto e Eco-pulso: estes métodos se baseiam no efeito que a estrutura tem sobre a propagação de ondas sônicas para determinar as propriedades do concreto. Os usos mais tradicionais incluem determinação da espessura de elementos de concreto e identificação de danificação. (NAIK; MALHOTRA; POPOVICS, 2004)

- Métodos Eletromagnéticos: estes métodos podem ser usados para localização de armaduras; determinação da espessura do cobrimento, da umidade e do potencial de corrosão da amostra; e localização de defeitos e de corrosão. (LAUER, 2004)

- Métodos de Radar de Ondas Curtas: este método é utilizado principalmente para encontrar defeitos no concreto. Outros usos potenciais incluem acompanhamento da hidratação do cimento e ganho de resistência nas primeiras idades, análise do efeito de aditivos, determinação da umidade e da espessura de elementos de concreto. (CLEMEÑA, 2004)

- Termografia Infra-vermelho: é utilizada para identificar defeitos e anomalias no interior do elemento de concreto. É baseada na teoria de que a existência de um defeito altera o fluxo de calor na estrutura. (WEIL, 2004)

- Emissão Acústica: esta técnica consiste em captar e avaliar as emissões acústicas naturais do concreto quando o mesmo é danificado. Este ensaio é usado para monitoração do surgimento e propagação de fissuras. (MINDESS, 2004)

\subsection{Propagação de ondas mecânicas}

Ondas sonoras se caracterizam por serem ondas mecânicas. Ou seja, são ondas que precisam de um meio para propagação. Os sons perceptíveis ao ouvido humano são aqueles com frequência entre $20 \mathrm{~Hz}$ e $20 \mathrm{kHz}$. Ondas com frequência inferior a $20 \mathrm{~Hz}$ são chamadas de infrassom. Ondas com frequência superior a $20 \mathrm{kHz}$ são chamadas de ultrassom (ANDREUCCI, 2016). 
A Amplitude (A) é definida como a máxima deflexão das partículas de sua posição de repouso. $O$ comprimento de onda $(\lambda)$ corresponde à distância percorrida pela onda entre duas cristas adjacentes. O tempo necessário para percorrer esta distância é o período da onda $(\bar{T})$. Quando a onda percorre um comprimento de onda, a mesma completa um ciclo.

A frequência (f) corresponde à quantidade de ciclos que a onda realiza em um período de tempo e, portanto, corresponde ao inverso do período. A unidade de frequência utilizada comumente é o Hertz $(\mathrm{Hz})$, ou quantidade de ciclos por segundo.

$A$ velocidade de propagação $(V)$ de uma onda corresponde à distância percorrida pela onda em um período de tempo. Segundo Naik, Malhotra e Popovics (2004), a relação entre velocidade de propagação, frequência e comprimento de onda é dada pela equação 2.1 .

$V=\lambda f$

A velocidade de propagação de onda em um sólido é função das características do meio. Logo, para um mesmo material, a frequência de propagação e o comprimento de onda são inversamente proporcionais. O controle do comprimento de onda por meio da variação da frequência é de particular interesse no estudo de propagação de ondas em meios não homogêneos.

Em materiais heterogêneos, surge o fenômeno da atenuação, que reduz a amplitude da onda. Krautkrämer e Krautkrämer (1990) explicam que, quando a onda se propaga pela fronteira entre dois materiais de densidade ou velocidade de propagação diferentes, há uma variação da impedância acústica que dispersa parte da energia da onda. Para evitar a atenuação, Krautkrämer e Krautkrämer (1990) sugerem que se aumente o comprimento de onda de modo que as heterogeneidades não sejam detectadas pela mesma.

Naik, Malhotra e Popovics (2004) afirmam que a atenuação será mais intensa se a heterogeneidade tiver dimensão igual ou superior ao comprimento de onda. Os autores indicam o valor máximo de frequência de $500 \mathrm{kHz}$ para ensaios de velocidade de pulso ultrassônico em concreto. Naik, Malhotra e Popovics (2004) declaram ainda que ondas com frequências menores conseguem percorrer uma distância maior no concreto. Enquanto ondas de frequência $500 \mathrm{kHz}$ se propagam por alguns 
centímetros, ondas de $20 \mathrm{kHz}$ de frequência podem atravessar cerca de $10 \mathrm{~m}$ de concreto.

Em um ensaio para medir a velocidade do pulso ultrassônico, podem ser utilizados os três tipos de onda a seguir:

- Ondas longitudinais (Fig. 2.1): estas ondas se propagam na mesma direção do movimento das partículas. Estas ondas também são chamadas de ondas $P$ (primárias) ou ondas de compressão. Estas são as ondas que se propagam mais rapidamente dentro de um meio. Segundo Andreucci (2016), as ondas longitudinais podem se propagar por meios sólidos, líquidos ou gasosos.

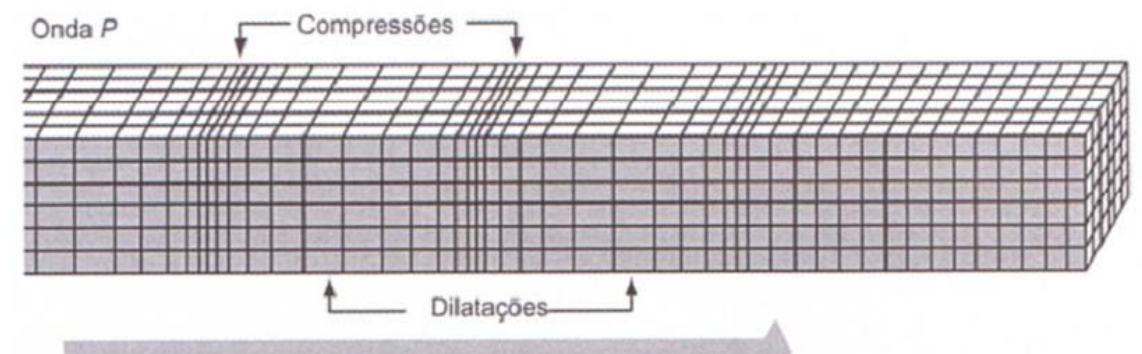

Figura 2.1- Propagação de onda longitudinal Fonte: Mehta; Monteiro (2008)

- Ondas transversais (Fig. 2.2): estas ondas se propagam perpendicularmente à direção de movimento das partículas. Estas também são chamadas de ondas S (secundárias) ou ondas de cisalhamento. A onda de cisalhamento sempre será mais lenta que a onda longitudinal e mais rápida que as ondas de superfície. A relação entre as velocidades de ondas primárias e secundárias é descrita pela equação 2.2 (MEHTA; MONTEIRO, 2008).

$\frac{V_{p}}{V_{s}}=\sqrt{\frac{2(1-v)}{1-2 v}}$

Como o valor máximo do coeficiente de Poisson (v) é igual a 0,5, a expressão dentro do radical sempre será maior que 1. Segundo Andreucci (2016), ondas de cisalhamento se propagam apenas em meios sólidos. Meios líquidos e gasosos não permitem a propagação deste tipo de ondas porque não têm resistência ao 
cisalhamento. Logo, não ocorre a movimentação das partículas na direção perpendicular à propagação da onda.

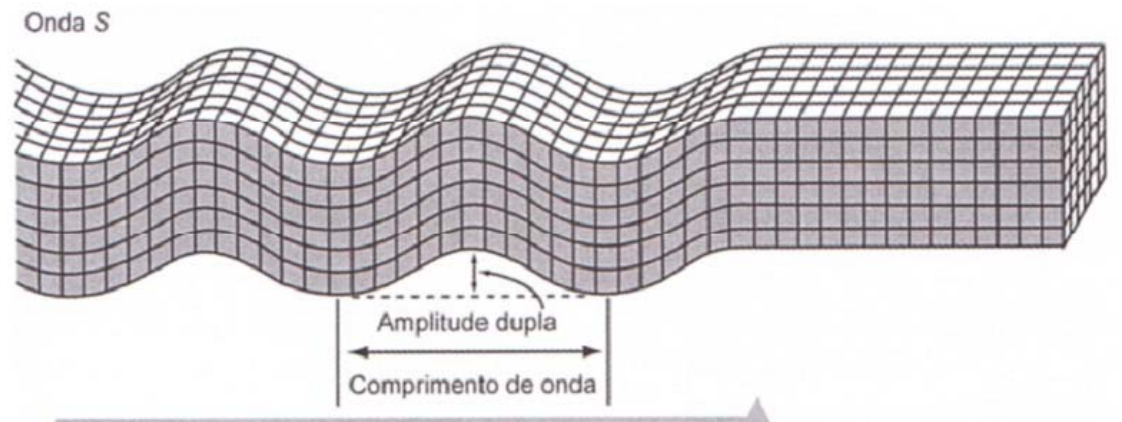

Figura 2.2 - Propagação de onda de cisalhamento Fonte: Mehta; Monteiro (2008)

- Ondas Rayleigh (Fig. 2.3): são ondas de superfície que são geradas a partir da combinação de ondas longitudinais e de cisalhamento. O movimento das partículas gerado por esta onda é elíptico. Ondas Rayleigh se caracterizam por serem ondas mais lentas que as longitudinais e transversais mas de maior amplitude.

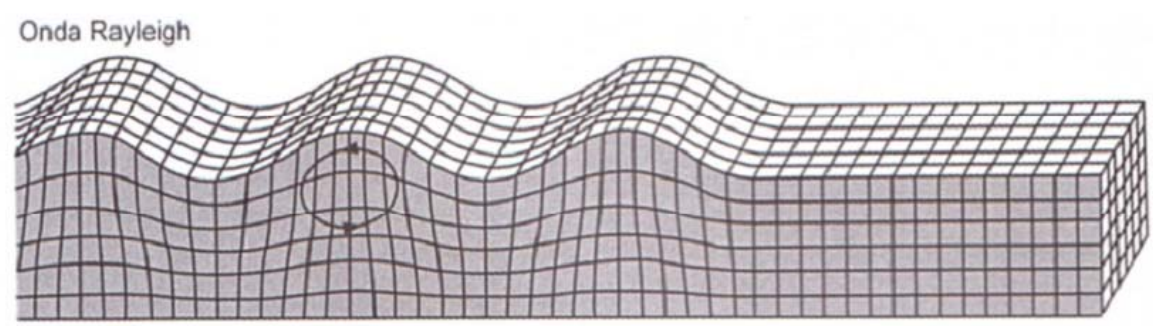

Figura 2.3 - Propagação de onda Rayleigh

Fonte: Mehta; Monteiro (2008)

Schneider (1997) traz equação 2.3 para relacionar as velocidades de propagação de ondas Rayleigh e ondas de cisalhamento:

$V_{R}=V_{s} \frac{0,87+1,12 v}{1+v}$ 


\subsection{Velocidade de Pulso Ultrassônico (VPU)}

Um dos métodos não-destrutivos mais utilizados é o método da Velocidade de Pulso Ultrassônico. A avaliação estrutural por meio deste método é vantajosa devido ao seu baixo custo, à simplicidade de execução do ensaio e por não causar danos à estrutura. O método consiste em propagar um pulso ultrassônico por um meio de comprimento conhecido e medir o tempo entre a emissão da onda e a chegada da mesma ao receptor.

Tradicionalmente, o método do ultrassom é utilizado para determinação das constantes elásticas do material, tais como módulo volumétrico $(\mathrm{K})$, módulo de elasticidade transversal $(G)$, módulo de elasticidade $(E)$ e coeficiente de Poisson (v). Mehta e Monteiro (2008) apresentam as equações 2.4 a 2.7 para obtenção das constantes elásticas em materiais isotrópicos:

$$
\begin{aligned}
& V_{p}=\sqrt{\frac{K+4 / 3 G}{\rho}} \\
& V_{s}=\sqrt{\frac{G}{\rho}} \\
& V_{p}=\sqrt{\frac{E(1-v)}{\rho(1-2 v)(1+v)}} \\
& V_{s}=\sqrt{\frac{E}{2 \rho(1+v)}}
\end{aligned}
$$

Onde,

$V_{p}=$ velocidade de onda primária;

$V_{s}=$ velocidade de onda secundária;

$\rho=$ densidade do material.

Em alguns casos, como materiais cujo processo de fabricação pode levar à existência de tensões residuais, estruturas que sofreram recalque diferencial e em elementos protendidos, pode ser de interesse avaliar o nível de tensão ao qual um elemento estrutural está submetido. Esta avaliação poderia ser feita por meio do efeito 
acustoelástico, que é a variação na velocidade de propagação de uma onda atravessando um meio sólido devido à alteração do nível de tensão ao qual este meio está submetido. As formulações matemáticas (equações 2.8 a 2.12) deste fenômeno foram propostas por Hughes e Kelly (1953).

$$
\begin{aligned}
& \rho V_{11}^{2}=\bar{\lambda}+2 \mu+\frac{\sigma_{11}}{3 K}\left[2 l+\bar{\lambda}+\frac{\bar{\lambda}+\mu}{\mu}(4 m+4 \bar{\lambda}+10 \mu)\right] \\
& \rho V_{12}^{2}=\rho V_{13}^{2}=\mu+\frac{\sigma_{11}}{3 K}\left[m+\frac{\bar{\lambda} n}{4 \mu}+4 \bar{\lambda}+4 \mu\right] \\
& \rho V_{22}^{2}=\rho V_{33}^{2}=\bar{\lambda}+2 \mu+\frac{\sigma_{11}}{3 K}\left[2 l-\frac{2 \bar{\lambda}}{\mu}(m+\bar{\lambda}+2 \mu)\right] \\
& \rho V_{21}^{2}=\rho V_{31}^{2}=\mu+\frac{\sigma_{11}}{3 K}\left[m+\frac{\bar{\lambda} n}{4 \mu}+\bar{\lambda}+2 \mu\right] \\
& \rho V_{23}^{2}=\rho V_{32}^{2}=\mu+\frac{\sigma_{11}}{3 K}\left[m-\frac{\bar{\lambda}+\mu}{2 \mu} n-2 \bar{\lambda}\right]
\end{aligned}
$$

Onde,

$V_{i j}=$ velocidade de onda que tem direção de propagação $\mathrm{i}$ e direção de polarização da onda j;

$\sigma_{11}=$ tensão de compressão aplicada ao longo da direção 1 ;

$l, m, n=$ constantes apresentadas por Murnaghan (1937) ao desenvolver formulações da mecânica do contínuo considerando grandes deformações;

$\bar{\lambda}, \mu=$ constantes de Lamé, definidas pelas propriedades elásticas do material. As constantes de Lamé são definidas por relações entre o módulo de elasticidade (E) e o coeficiente de Poisson (v), de acordo com a equação 2.13.

$$
\bar{\lambda}=\frac{v E}{(1+v)(1-2 v)}
$$

Estas equações foram desenvolvidas para meios elásticos, sólidos, homogêneos e isotrópicos. Blanco (2015) argumenta que, apesar de nenhuma destas 
considerações ser verdadeira para o concreto, é possível admitir estas aproximações com um erro pequeno devido às razões listadas abaixo.

O concreto é um material heterogêneo a nível macroscópico, devido à presença dos agregados. Ademais, o material apresenta vazios e fissuras a nível microscópico. No entanto, desde que estas heterogeneidades sejam menores que um comprimento de onda, o meio pode ser tratado como homogêneo.

O concreto não é completamente sólido por ter vazios preenchidos com líquido e ar. Novamente, se o comprimento de onda tiver dimensão superior aos vazios, a propagação não será prejudicada pela presença de outras fases e o material pode ser suposto sólido.

Ainda de acordo com Blanco (2015), as interfaces entre agregado, zona de transição e pasta não têm grande influência sobre o caminho, modo ou frequência de propagação da onda e, por isso, o concreto pode ser considerado isotrópico.

Para níveis baixos de tensão, o concreto apresenta comportamento aproximadamente elástico. Logo, a teoria da acustoelasticidade será mais precisa neste intervalo.

Segundo Lillamand (2010), as equações que regem o efeito acustoelástico podem ser tratadas como funções lineares simplificadas (eq. 2.14).

$$
V_{i j}^{\sigma}=V_{i j}^{0}\left(1+A_{i j} \sigma_{11}\right)
$$

Onde,

$V_{i j}^{\sigma}=$ velocidade de onda que tem direção de propagação i e direção de polarização da onda j submetida a uma tensão uniaxial na direção 1;

$V_{i j}^{0}=$ velocidade de onda que tem direção de propagação i e direção de polarização da onda j sem aplicação de tensão;

$A_{i j}=$ constante acustoelástica que depende das constantes de Lamé e Murnaghan (1937).

Os equipamentos básicos necessários à execução do ensaio de velocidade de pulso ultrassônico são os transdutores, o aparelho de ultrassom e os cabos coaxiais. O aparelho é formado por um gerador de pulsos, um circuito para medição do tempo, 
um amplificador e uma tela para exibição do resultado. O esquema do ensaio é mostrado na figura 2.4 .

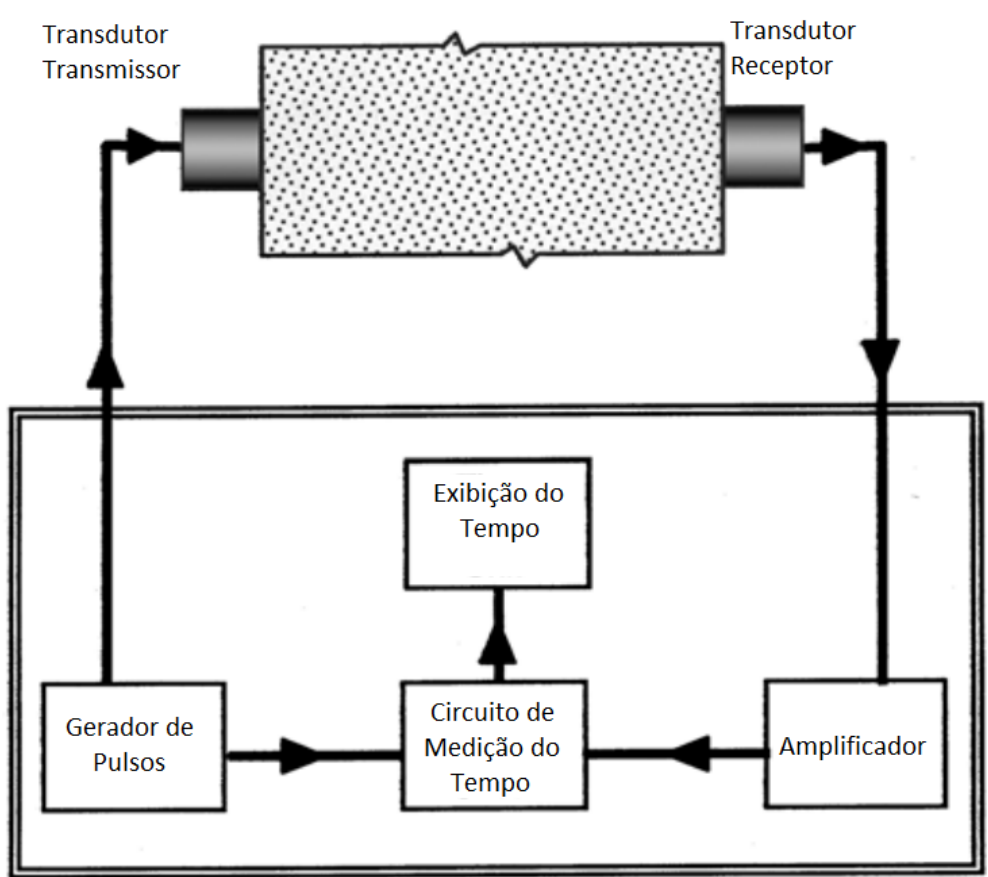

Figura 2.4 - Esquema do ensaio de velocidade de pulso ultrassônica Fonte: ASTM C597-09 (2009)

O posicionamento dos transdutores pode ser feito de três maneiras diferentes (figura 2.5): transmissão direta, transmissão indireta ou transmissão semidireta.

A transmissão direta é a mais recomendada porque este é o arranjo de transdutores que tem a menor perda de energia entre a transmissão e a recepção do sinal (Naik; Malhotra; Popovics, 2004). Outra vantagem deste arranjo é a maior facilidade para determinar a distância percorrida pela onda.

Segundo a ABNT NBR 8802:2013, a transmissão semidireta "só deve ser utilizada quando não houver a possibilidade de acesso a duas faces opostas de um corpo de prova ou componente de concreto e a única face acessível não tiver comprimento suficiente para se utilizar o arranjo de transmissão indireta". Naik, Malhotra e Popovics (2004) afirmam que este arranjo de transdutores é recomendado quando se deseja evitar uma região com concentração de armaduras.

A transmissão indireta é recomendada quando se tem acesso a apenas um lado do corpo de prova ou elemento a ser ensaiado. Naik, Malhotra e Popovics (2004) defendem que este arranjo é mais suscetível a erros porque a onda irá se propagar nas camadas mais próximas à superfície do concreto (cobrimento). Os autores afirmam que esta região pode apresentar características diferentes do concreto no 
interior do elemento. Logo, os resultados encontrados para a superfície podem não ser válidos para o interior da amostra.
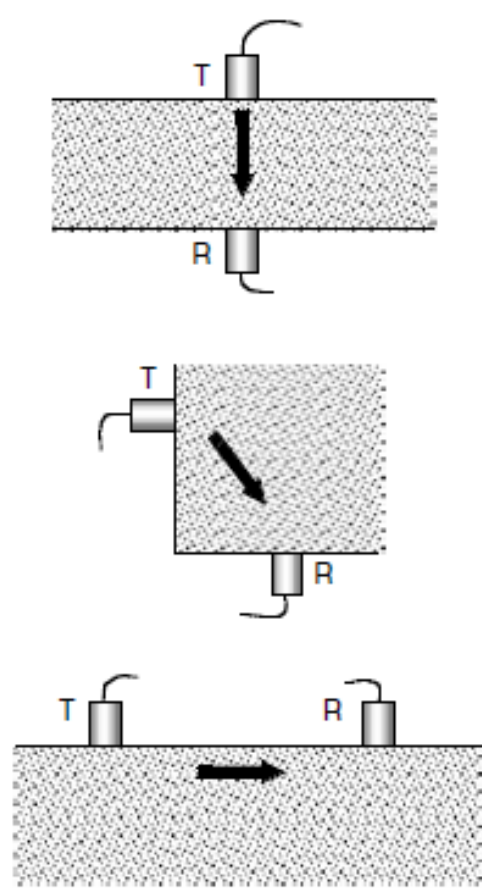

$\mathrm{T}=$ transmissor

$\mathrm{R}=$ receptor

Figura 2.5 - Posições relativas entre os dois transdutores

Fonte: Naik; Malhotra; Popovics (2004)

\section{Transmissão}

direta

Transmissão semidireta

\section{Transmissão}

indireta
Os transdutores contêm cristais piezoelétricos, que são os dispositivos responsáveis pela geração das ondas ultrassônicas. Quando uma corrente elétrica é aplicada no transmissor, o cristal piezoelétrico transforma esta energia elétrica em energia mecânica. A energia mecânica se manifesta por meio de vibração e a onda gerada por ela se propaga pela amostra. Do outro lado, o receptor recebe a energia mecânica e a converte de novo em energia elétrica. Esta corrente é detectada pelo aparelho de ultrassom, que reconstrói o sinal da onda. Segundo Andreucci (2016), a frequência nominal do transdutor é determinada pela espessura do cristal piezoelétrico que o compõe. De acordo com o autor, cristais de menor espessura produzem frequências de vibração maiores.

É importante a utilização de um acoplante adequado entre o transdutor e a amostra. A presença de ar entre o transdutor e o concreto pode acarretar em erros no ensaio devido a dispersão da onda. Segundo Abraham et al. (2012), o coeficiente de transmissão de onda na interface entre ar e concreto é de cerca de 1\%. Naik, Malhotra e Popovics (2004) recomendam que a camada de acoplante seja tão fina quanto 
possível para que a mesma não introduza erros de leitura. Crawford (1997) sugere que sejam obtidas várias medidas para um mesmo ponto até que se obtenha um valor mínimo de tempo para garantir que o resultado não seja afetado pelo acoplante. $A$ escolha da substância utilizada para acoplamento depende do tipo de onda utilizada, do material e da conformidade superficial da amostra.

Durante a aplicação do ensaio de Velocidade de Pulso Ultrassônico, existem diversos fatores que podem influenciar o resultado do mesmo e prejudicar a sua precisão. Os principais são: temperatura, estado de tensões, distância entre transdutores, umidade e a presença de armaduras.

Jones e Facaoaru (1969) descrevem como a temperatura afeta a VPU. Os autores afirmam que no intervalo de temperatura entre $5^{\circ} \mathrm{C}$ e $30^{\circ} \mathrm{C}$, a velocidade de propagação não sofre alteração. Entretanto, acima de $30^{\circ} \mathrm{C}$, o concreto começa a sofrer microfissuração devido à alta temperatura, reduzindo assim a velocidade da onda. Por outro lado, quando a temperatura se aproxima de $0^{\circ} \mathrm{C}$, a água presente nos poros do material se aproxima do estado sólido e provoca o aumento da VPU. Os autores sugerem que, quando o ensaio de VPU for relacionado fora do intervalo de temperatura ideal, os valores de velocidade sejam corrigidos pelos fatores listados na tabela 2.1 .

Tabela 2.1 - Correções de velocidade de pulso devido à variação de temperatura

\begin{tabular}{|c|c|c|}
\hline \multirow{2}{*}{ Temperatura $\left({ }^{\circ} \mathrm{C}\right)$} & \multicolumn{2}{|c|}{ Correção (\%) } \\
\hline & Concreto seco ao ar & Concreto saturado \\
\hline 60 & +5 & +4 \\
\hline 40 & +2 & +1.7 \\
\hline 20 & 0 & 0 \\
\hline 0 & -0.5 & -1 \\
\hline Abaixo de -4 & -1.5 & -7.5 \\
\hline
\end{tabular}

Fonte: Jones; Facaoaru (1969)

A variação na velocidade de pulso devido ao estado de tensões e ao histórico de carregamento se relaciona aos fenômenos da acustoelasticidade e da danificação, temas principais deste trabalho. Portanto, a influência destes dois fatores será discutida nos tópicos subsequentes em maior profundidade. 
A princípio, a distância entre transdutores não deveria influenciar a velocidade de pulso. Entretanto, existe uma separação mínima entre os mesmos que deve ser respeitada para que o resultado obtido seja válido. Esta distância é igual a um comprimento de onda. Conforme foi mostrado na equação 2.1 , a velocidade é dada pelo produto entre o comprimento e a frequência da onda. Logo, podemos dizer que o comprimento de onda é função do material analisado e da frequência do transdutor adotado. Naik, Malhotra e Popovics (2004) afirmam que a velocidade de pulso ultrassônico em concreto tipicamente varia entre 3000 m/s e 5000 m/s. Assumindo estes valores, podemos encontrar as distâncias mínimas para frequências usuais de transdutores mostradas na tabela 2.2 .

Tabela 2. 2 - Distância mínima entre transdutores

\begin{tabular}{ccc}
\hline \multirow{2}{*}{ Frequência (Hz) } & \multicolumn{2}{c}{ Distância mínima (cm) } \\
\cline { 2 - 3 } & $\mathbf{V}=\mathbf{3 0 0 0} \mathbf{~ m / s}$ & $\mathbf{V}=\mathbf{5 0 0 0} \mathbf{~ m} / \mathbf{s}$ \\
\hline 24 & 12,5 & 20,8 \\
54 & 8,1 & 13,5 \\
82 & 5,6 & 9,3 \\
150 & 3,7 & 6,1 \\
200 & 2,0 & 3,3 \\
220 & 1,5 & 2,5 \\
250 & 1,4 & 2,3 \\
500 & 1,2 & 2,0 \\
& 0,6 & 1,0 \\
\hline
\end{tabular}

Bungey, Millard e Grantham (2006) afirmam que a velocidade de pulso pode chegar a ser $5 \%$ maior em um concreto saturado em comparação a um concreto seco. Os autores afirmam também que a diferença de comportamento será menor quanto maior a resistência do concreto. O aumento da umidade implica em aumento da velocidade de propagação porque parte do ar nos vazios do concreto é substituído por água. A velocidade de propagação de ondas longitudinais é cerca de 4,5 vezes maior na água que no ar. Por isso o concreto com maior volume de vazios e, consequentemente, menor resistência apresenta maior sensibilidade à variação de umidade. 
Quanto às armaduras, Bungey, Millard e Grantham (2006) declaram que estas devem ser evitadas uma vez que introduzem incertezas no ensaio de VPU. A primeira dificuldade discutida pelos autores é a incerteza com relação ao caminho percorrido pela onda. Por ter uma maior velocidade de propagação, o aço se torna um "caminho preferencial" para a onda ultrassônica. Portanto, fica difícil prever como a armadura desvia a onda de seu percurso. Ademais, como a onda não se propaga pelo concreto, pode não ser possível obter informações sobre este material. Segundo os autores, outra dificuldade presumível é a presença de uma quantidade maior de vazios no concreto ao redor da armadura. Entre a armadura e a forma, há uma dificuldade de penetração e compactação do concreto que pode fazer com que o mesmo fique mais poroso nesta região, principalmente se houver uma densidade alta de armaduras. Portanto, informações obtidas com o ensaio de VPU nesta região podem não representar o material presente no interior da estrutura.

\section{$2.4 \quad$ Acustoelasticidade}

Carmo et al. (2007) utilizaram a técnica da birrefringência acústica para identificar as regiões de tração e compressão em uma barra de aço estrutural submetida a flexão. Segundo a teoria da acustoelasticidade, as áreas submetidas a tração devem ter velocidade de propagação reduzida, enquanto as áreas comprimidas têm aumento de velocidade. O autor explica este efeito a nível molecular. Quando o material está comprimido, ocorre aproximação entre os átomos, facilitando a passagem da onda entre eles. Na tração, ocorre o fenômeno oposto.

Gokhale (2007) estudou a aplicação do efeito acustoelástico para determinação de tensão em trilhos continuamente soldados. O autor desenvolveu modelos para ondas longitudinais, de cisalhamento, Rayleigh e Lamb. Foi concluído que ondas de superfície possuem maior sensibilidade ao efeito acustoelástico em trilhos de aço. $O$ autor ressalta que o tipo de onda mais sensível pode variar com o material.

Shokouhi, Zoëga e Wiggenhauser (2010) investigaram o efeito acustoelástico em corpos de prova de concreto submetidos a ensaios de compressão uniaxial. Neste trabalho, foram utilizadas ondas sônicas de superfície para análise de variação de velocidade de propagação. Além da presença do efeito acustoelástico, os autores 
concluíram que a danificação da amostra tem grande influência sobre a velocidade do pulso ultrassônico.

Shokouhi, Zoëga e Wiggenhauser (2010) analisaram o comportamento do gráfico velocidade de onda $x$ tensão e identificaram a existência de três fases distintas no comportamento da curva (Fig. 2.6). As diferenças entre as fases é explicada pela interação entre efeito acustoelástico e danificação.

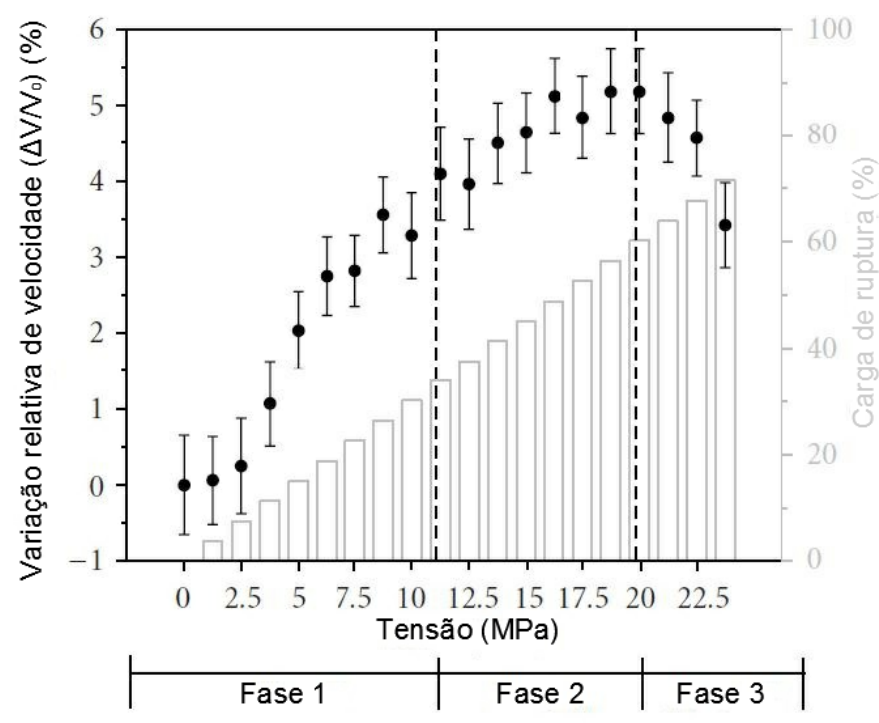

Figura 2. 6 - Velocidade de onda de superfície $x$ tensão aplicada Fonte: adaptada de Shokouhi; Zoëga; Wiggenhauser (2010)

A primeira fase é caracterizada por tensões inferiores a $30 \%$ da resistência à compressão do material. Nesta fase, o concreto ainda tem comportamento aproximadamente elástico e a danificação que existe é decorrência da microestrutura heterogênea do material. Neste nível de carregamento, a compressão tende a fechar esta microfissuração sem gerar a abertura de novas fissuras. Logo, a acustoelasticidade é o efeito dominante e a relação velocidade $x$ tensão é linear.

A segunda fase corresponde ao carregamento entre 30 e $60 \%$ do carregamento último. Nesta etapa, a velocidade continua crescendo com o carregamento. No entanto, como também ocorrem a abertura e propagação de fissuras, o aumento da velocidade nesta etapa é menor que na fase anterior. O fim deste estágio corresponde ao máximo valor de velocidade de onda.

$\mathrm{Na}$ terceira fase, o carregamento varia entre 60 e 100\% do carregamento de ruptura. Para estes níveis de tensão, o efeito da fissuração é dominante sobre o efeito acustoelástico. Logo, apesar do aumento da tensão, a velocidade de propagação da onda diminui. 
Lillamand et al. (2010) demonstraram o efeito acustoelástico em concreto. O autor ensaiou corpos de prova de concreto submetidos a compressão uniaxial e mostrou que a velocidade de propagação de uma onda ultrassônica é dependente do nível de tensão ao qual a amostra está submetida. Neste trabalho, a tensão máxima aplicada aos corpos de prova correspondeu a menos da metade da resistência à compressão das amostras. Para estes níveis de carregamento, a relação entre velocidade e tensão foi linear, em concordância com a teoria da acustoelasticidade.

Analisando ondas longitudinais, Lillamand et al. (2010) encontraram uma variação de até $92 \mathrm{~m} / \mathrm{s}$ para um aumento de tensão de $16 \mathrm{MPa}$. Estes dados mostram que o concreto pode ter uma sensibilidade ao efeito acustoelástico 10 vezes superior à sensibilidade do aço. Lillamand et al. (2010) também demonstraram que ondas longitudinais e de cisalhamento polarizadas na direção do carregamento apresentam maior sensibilidade à variação de tensão que ondas polarizadas em outras direções.

Kleitsa et al. (2010) estudaram o efeito acustoelástico em cabos de protensão instalados em uma contenção. Devido à dificuldade de acesso aos cabos, a variação de velocidade de propagação foi estudada na região das placas de ancoragem. Os autores compararam simulações numéricas a dados experimentais. Inicialmente, simulou-se ausência de contato entre os cabos e o meio (cabos cercados por ar). Posteriormente, a rigidez do meio foi gradativamente aumentada até chegar à rigidez do cabo.

Com isso, os autores mostraram que, em um sólido heterogêneo, o caminho percorrido pela onda depende da diferença de rigidez entre os meio pelos quais ela se propaga. Se houver uma grande diferença entre eles, a onda vai desviar do meio de menor rigidez, caminhando pela superfície de contato entre os dois.

Stähler, Sens-Schöfelder e Niederleithinger (2011) usaram o efeito acustoelástico para monitorar a tensão em vigas de uma ponte em construção. A técnica de construção utilizada foi o método de lançamentos incrementais. Neste método, a superestrutura da ponte é montada na cabeceira e empurrada até sua posição final. Logo, ao longo da construção, a tensão na superestrutura varia conforme as vigas se movimentam sobre os pilares da ponte. Utilizou-se interferometria de cauda de onda para determinação da variação de velocidade.

As variações de velocidade obtidas com o ultrassom foram comparadas a resultados analíticos obtidos com um software de simulação em diferenças finitas. Os autores ressaltam que não foi possível obter o nível de tensão real na estrutura para 
comparação. Para relacionar a variação de velocidade de pulso ultrassônico à variação da tensão na viga, foram utilizadas constantes acustoelásticas obtidas em laboratório para o mesmo traço de concreto. A comparação de resultados mostrou boa concordância, como pode ser visto na figura 2.7 .

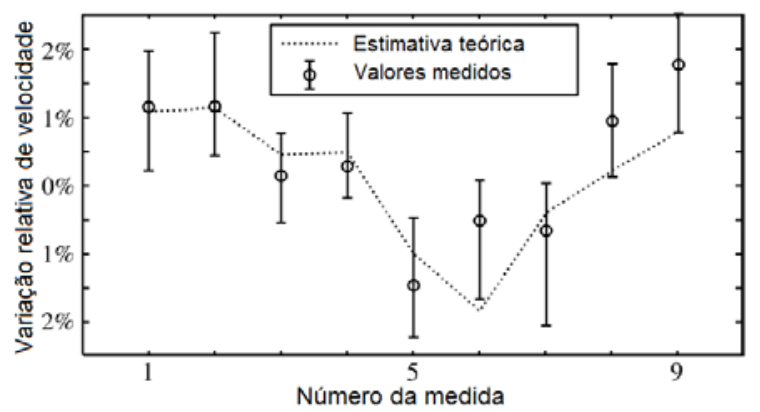

Figura 2. 7 - Comparação entre valores teóricos e experimentais obtidos para ponte em construção Fonte: adaptada de Stähler; Sens-Schöfelder; Niederleithinger (2011)

Lundqvist e Rydén (2012) avaliaram a relação entre efeito acustoelástico e ensaios de ressonância acústica. Para tanto, os autores ensaiaram vigas de concreto protendido. Foram feitas quatro vigas de concreto. Todas as vigas foram moldadas com uma cordoalha no meio da seção. Então, três das quatro vigas foram protendidas e, posteriormente, a protensão foi retirada. O ensaio de ressonância acústica foi feita ao longo da aplicação e da retirada de tensão para determinar os modos de vibração longitudinal e torcional.

Lundqvist e Rydén (2012) mostraram que as frequências de ressonância dos modos de vibração longitudinal e torcional aumentaram com o aumento da tensão de forma análoga à variação de velocidade de pulso ultrassônico (Fig. 2.8). Os autores afirmam que as frequências de ressonância de todos os modos de vibração aumentam quando a tensão é aplicada no elemento.

Shokouhi et al. (2012) utilizaram ondas sônicas de superfície, ensaios de emissão acústica e um medidor óptico de deformação para medir o efeito acustoelástico e a danificação em prismas de concreto submetidos a compressão uniaxial. Os autores submeteram a amostras a ciclos de carregamento e descarregamento para avaliação da variação de velocidade ultrassônica.

Os autores observaram que a diminuição percentual de velocidade diminuiu a cada ciclo. Uma vez que o efeito acustoelástico depende apenas do carregamento, a menor variação de velocidade indica que, a cada carregamento, menos danificação é gerada. Este comportamento pode ser explicado pelo efeito Kaiser. Segundo esta 
teoria, só será gerada nova danificação em uma amostra de concreto se o carregamento exceder a maior tensão já aplicada àquele elemento.

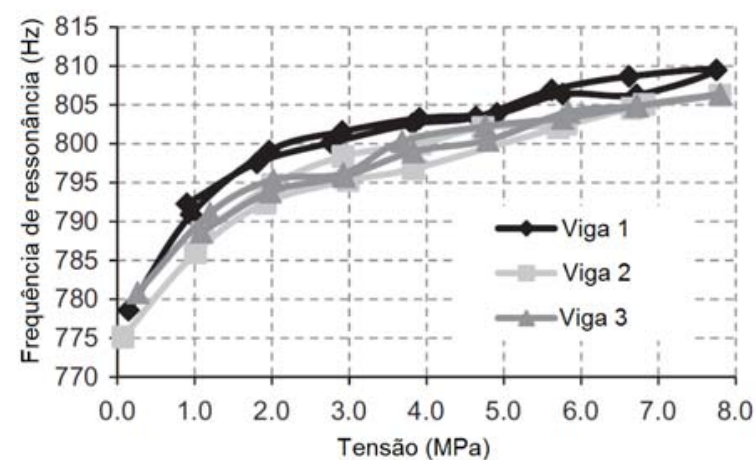

(a)

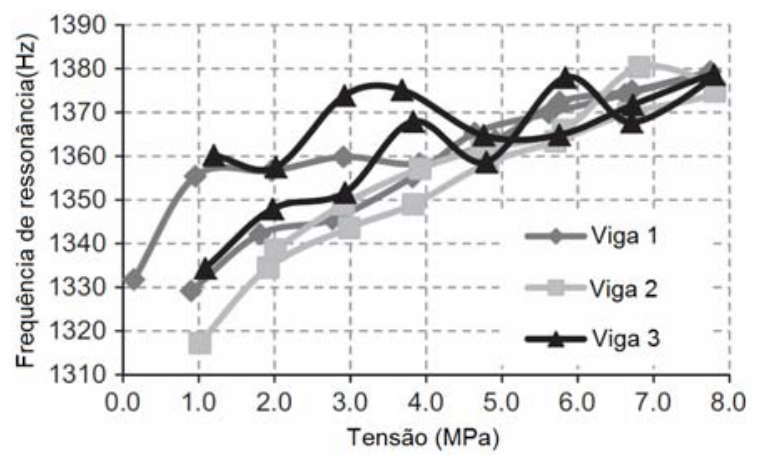

(b)

Figura 2. 8 - Variação da frequência de ressonância dos modos de vibração: (a) torcional e (b) longitudinal

Fonte: adaptada de Lundqvist; Rydén (2012)

Foi definido que, se a variação de velocidade fosse medida durante o descarregamento, esta já seria equivalente à variação gerada somente pelo efeito acustoelástico, uma vez que, pelo efeito Kaiser, não haveria danificação nova sendo gerada no descarregamento. Os autores defendem também que a variação de velocidade gerada pelo dano irreversível é dada pela diferença entre as curvas de velocidade $\mathrm{x}$ tensão no carregamento e descarregamento de um mesmo ciclo.

Embora os autores defendam que a variação de velocidade medida no descarregamento seja equivalente à causada apenas pelo efeito acustoelástico, os mesmos afirmam também que, a partir do carregamento de $80 \%$ da tensão de ruptura, a velocidade começa a diminuir porque o efeito da danificação é predominante sobre a acustoelasticidade.

A ideia de que não existe danificação no descarregamento é corroborada pelo baixo número emissões acústicas durante este período. No entanto, como a velocidade de pulso ultrassônico diminui com o aumento da tensão, fica claro que ocorre uma modificação na estrutura do concreto que o ensaio de emissão acústica não é capaz de identificar. Daí a necessidade de se criar uma metodologia alternativa para isolar os efeitos da acustoelasticidade e da danificação.

Por fim, Shokouhi et al. (2012) revisaram o trabalho de Shokouhi, Zoëga e Wiggenhauser (2010) a fim de incluir uma quarta fase no gráfico variação relativa de velocidade por tensão aplicada, com carregamentos inferiores a $15 \%$ da resistência à 
compressão da amostra. Para este nível de carregamento, a velocidade de pulso ultrassônico se mantém constante.

Schiavon (2015) também estudou o efeito acustoelástico em prismas de concreto submetidos a compressão uniaxial. A autora relata que, após o descarregamento das amostras, novas medições de velocidade de propagação foram realizadas a fim de comparar estes resultados com as velocidades encontradas anteriormente ao carregamento. Foi constatado que as velocidades continuaram sofrendo alterações mesmo após a retirada completa do carregamento. Como a amostra não estava submetida a tensão, esta variação de velocidade não pode ser justificada pelo efeito acustoelástico. Logo, podemos admitir que esta variação de velocidade se deve a uma parcela de danificação reversível.

\subsection{Danificação}

Aggelis et al. (2009) utilizaram ensaios de emissão acústica e velocidade de pulso ultrassônico para verificar danificação em elementos de concreto. Foram moldados elementos de concreto simples e elementos que continham uma camada de concreto simples na parte superior e uma camada de concreto reforçado com fibras na parte inferior. Todos os corpos de prova foram reforçados com duas barras de 13 $\mathrm{mm}$ na parte inferior e submetidos a ensaios de flexão.

O ensaio de emissão acústica foi feito com 12 transdutores de $60 \mathrm{kHz}$ espalhados pela superfície da amostra. Quando ocorre o surgimento de uma fissura, há uma liberação de energia que atinge os sensores. O número de ocorrências e a amplitude deste sinal são armazenados no ensaio.

O ensaio de velocidade de pulso ultrassônico foi feito com vários níveis de carregamento. Durante o ensaio, a tensão era mantida constante. O ensaio foi feito para todas as combinações de caminho possíveis para os 12 sensores instalados na amostra. Os resultados foram utilizados para montar uma tomografia nas três dimensões do elemento.

Os autores afirmam que as duas técnicas mostraram boa correspondência de resultados, demonstrando a confiabilidade de ambas na detecção e localização de dano. Aggelis et al. (2009) também afirmaram que o ideal seria utilizar as duas 
técnicas de forma complementar, uma vez que a velocidade de pulso ultrassônico não consegue identificar fissuras pequenas e a emissão acústica não detecta fissuras inativas.

Schurr et al. (2009) estudaram o uso da interferometria de cauda de onda, técnica de processamento de sinais, para detecção do efeito acustoelástico e verificação da alteração de velocidade de propagação devido a dano mecânico e dano térmico em prismas de concreto. Todas as amostras foram submetidas a um carregamento de $4 \mathrm{MPa}$. As amostras submetidas a dano térmico ficaram por $3 \mathrm{~h}$ em uma câmara a $120^{\circ} \mathrm{C}$. Este procedimento foi repetido três vezes. As amostras que sofreram dano mecânico foram carregadas em 10 ciclos, com carregamento variando de 0 a 4 MPa.

Os autores mostraram que a inclinação da curva de variação de velocidade após o dano térmico aumentou conforme a amostra passou mais horas na câmara térmica, demonstrando que a interferometria de cauda de onda é adequada para avaliar danificação por variação de temperatura.

As amostras submetidas a dano mecânico mostraram uma tendência crescente de variação de velocidade nos primeiros ciclos e depois se estabilizaram. Os autores sugerem que tenha ocorrido uma "saturação" de dano mecânico, ou seja, que a amostra tenha atingido uma danificação máxima para o nível de carregamento. Os autores afirmam que isto é possível porque a tensão utilizada foi muito baixa para causar propagação das fissuras.

Mirmiran e Wei (2001) utilizaram o ensaio de velocidade de pulso ultrassônico para estudar a danificação em elementos de concreto reforçado com fibras poliméricas quando submetidos a carregamento mecânico. Os autores ensaiaram cilindros de concreto simples e tubos de concreto reforçado com fibras preenchidos com concreto simples. Para quantificar o dano, os autores utilizaram o índice de dano (D) descrito na equação 2.15, conforme definido por Daponte, Maceri e Olivito (1990).

$$
D=1-\frac{X}{X_{0}}
$$

Este índice de dano é definido em função da velocidade de propagação, sendo $X_{0}$ a velocidade na amostra íntegra e $X$ a velocidade na amostra danificada. 
Mirmiran e Wei (2001) perceberam que a variação de velocidade de propagação é mais acentuada a partir do carregamento correspondente a $30 \%$ da tensão de ruptura. Os autores identificaram três regiões no gráfico da figura 2.9 que foram encontradas em todas as amostras. Este gráfico mostra o índice de dano por nível de tensão em elementos de concreto reforçado com fibras preenchidos com concreto simples submetidos a carregamento cíclico. A primeira fase corresponde à danificação para o carregamento de até $30 \%$ da resistência à compressão do elemento; nesta faixa de tensão, o dano evolui lentamente. A segunda fase corresponde ao carregamento de $30 \%$ a $50 \%$ da tensão de ruptura; nesta fase o dano evolui rapidamente, a uma proporção 8,5 vezes maior que a da primeira fase. A última fase corresponde ao carregamento de $50 \%$ a $100 \%$ da tensão de ruptura. Os autores mostram que, durante o primeiro carregamento, o índice de dano atinge um valor máximo entre 0,22 e 0,25 e volta a diminuir mesmo com o aumento do carregamento. A partir do segundo ciclo de carregamento, o comportamento do gráfico foi semelhante para todos os outros ciclos e mostrou uma tendência mais linear. Os autores afirmam que o índice de dano apresenta resultados melhores na faixa de tensão que vai de 0 a $50 \%$ da resistência à compressão do elemento. Mirmiran e Wei (2001) afirmam ainda que esta é a faixa de trabalho da maioria das estruturas em serviço e, portanto, a metodologia utilizada é adequada para verificação do dano em estruturas de concreto.

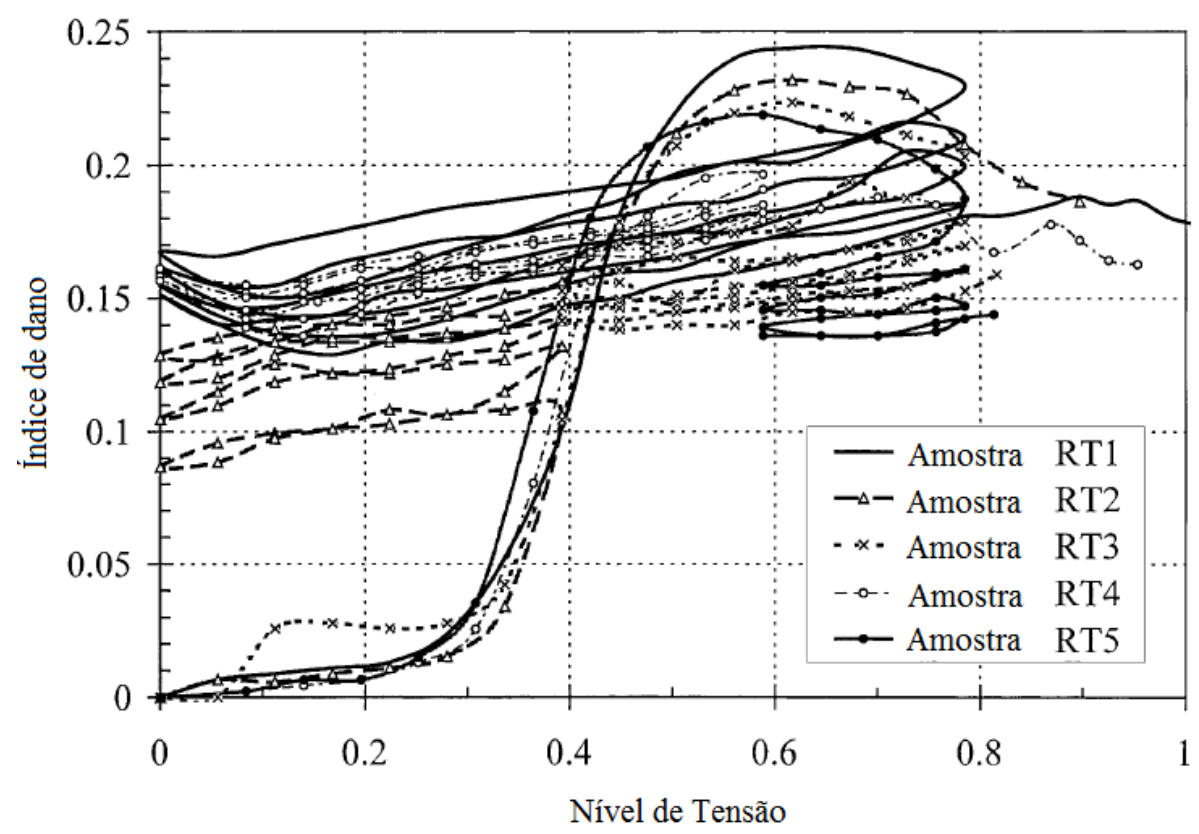

Figura 2. 9 - Velocidade de onda de superfície $x$ tensão aplicada Fonte: adaptada de Mirmiran; Wei (2001) 
Zhang et al. (2012) estudaram a variação de velocidade de propagação em corpos de prova de concreto submetido a tração uniaxial com a consideração do efeito da fluência. Após ciclos de carregamento, as amostras eram submetidas a carregamento constante durante $20 \mathrm{~h}$ e, após este período, $18 \mathrm{~h}$ sem tensão. Um esquema simplificado do carregamento utilizado é mostrado na figura 2.10. Para evitar que a variação de temperatura tivesse influência sobre a velocidade de propagação do elemento, um corpo de prova exposto às mesmas condições ambientais foi mantido sem solicitações mecânicas. As variações de velocidade encontradas neste corpo de prova eram descontadas dos outros resultados.

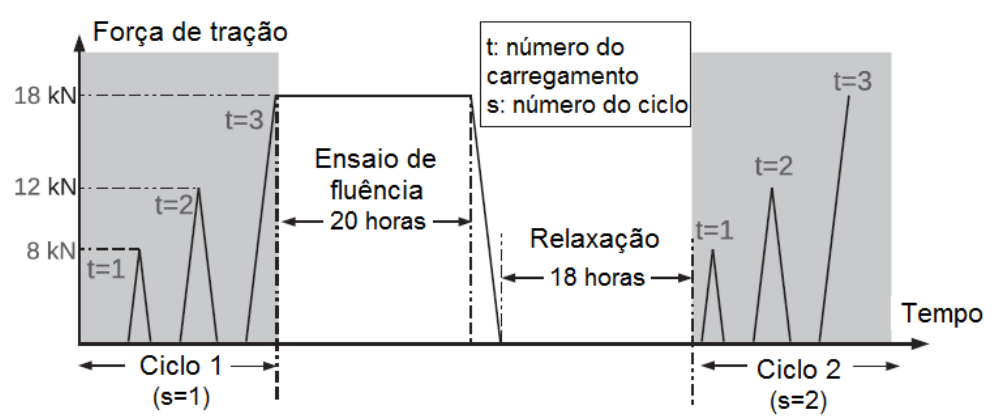

Figura 2. 10 - Esquema simplificado do carregamento aplicado por Zhang et al. (2012) Fonte: adaptada de Zhang et al.(2012)

No período de relaxação, mesmo sem a aplicação de carregamento, ocorreu um aumento na velocidade de propagação, o que sugere que parte do dano foi revertido. $\mathrm{O}$ autor afirma que o mecanismo de recuperação deste dano seria a reação de clínquer não-hidratado presente na pasta com água proveniente das fissuras de carregamento.

Zhang et al. (2012) também afirmam que uma parte da redução de velocidade fica permanentemente na amostra após cada ciclo de carregamento. Com isso, o autor mostra a existência de uma parcela irreversível de danificação no corpo de prova.

Saint-Pierre et al. (2016) criou o índice CQD (Concrete Quality Designation) para avaliar a danificação em estruturas de concreto in situ por meio da Velocidade de Pulso Ultrassônico. Este índice analisa a velocidade de pulso encontrada na estrutura deteriorada ( $V_{\text {insitu }}$ ) e a compara com a velocidade encontrada para uma amostra íntegra do mesmo material extraída do elemento estrutural $\left(V_{l a b}\right)$, segundo a equação 2.16 . 


$$
C Q D=\frac{V_{\text {insitu }}-V_{\text {ref }}}{V_{\text {lab }}-V_{\text {ref }}} \times 100
$$

O trabalho de Saint-Pierre et al. (2016) verifica O CQD em barragens e os autores sugerem que, para obras hidráulicas, se utilize como velocidade de referência a velocidade de propagação de ondas mecânicas na água $(1500 \mathrm{~m} / \mathrm{s})$. Esta velocidade corresponde ao total comprometimento da estrutura.

Os autores defendem que a adoção do índice CQD é uma medida mais precisa da danificação que o uso direto da Velocidade de Pulso Ultrassônico pois, uma vez que a velocidade de controle é extraída da própria estrutura, não é necessário que se conheça previamente as características do concreto original.

\subsection{Interferometria de Cauda de Onda (Coda Wave Interferometry - CWI)}

O método da Interferometria de Cauda de Onda foi utilizado para realizar as análises dos resultados dos ensaios de ultrassom executados ao longo da pesquisa.

A cauda de onda, ou ondas Coda, é caracterizada por ser composta de ondas de chegada tardia. Segundo Planès e Larose (2013), o nome Coda vem da sismografia e corresponde à parte final do sismograma após um terremoto. Sempre que uma onda ultrassônica encontra uma heterogeneidade no meio de propagação, parte da energia da onda é desviada. A cauda de onda é formada a partir da interação de várias ondas atenuadas. Apesar de seu processo de formação ser aleatório, a cauda de onda tem grande repetibilidade.

Segundo Planès e Larose (2013), uma grande vantagem do uso da cauda de onda é a grande sensitividade destas ondas à mudanças no meio. Os autores explicam que, como a cauda de onda é o resultado de múltiplas atenuações, estas ondas passam mais tempo viajando pelo meio em comparação com as ondas que passam diretamente de um transdutor a outro. Logo, a cauda de onda tem maior "memória" das mudanças ocorridas no meio.

Grêt, Snieder e Scales (2006) mostram a diferença da sensibilidade das ondas mais rápidas e da cauda de onda à danificação. A figura 2.11 mostra dois sinais de 
ondas ultrassônicas se propagando em uma amostra de granito. O gráfico azul mostra a onda registrada para a temperatura de $45^{\circ} \mathrm{C}$ e o gráfico vermelho mostra a onda registrada para $50^{\circ} \mathrm{C}$.

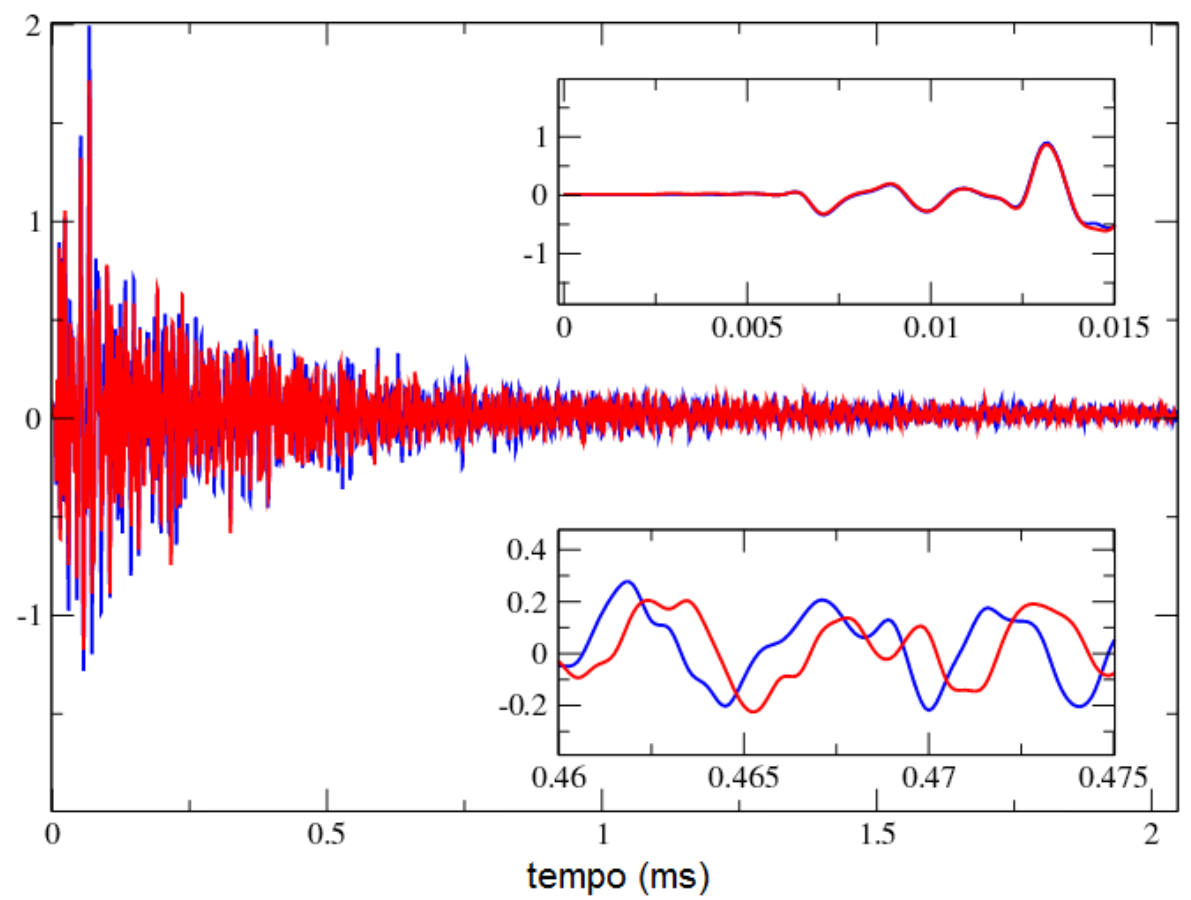

Figura 2. 11 - Ondas registradas em amostras de granito a $45^{\circ} \mathrm{C}$ (azul) e $50^{\circ} \mathrm{C}$ (vermelho) Fonte: Grêt, Snieder e Scales (2006)

Como pode ser visto na figura 2.11, o início do sinal é praticamente coincidente para as duas temperaturas. Na primeira parte do sinal, a diferença de $5^{\circ} \mathrm{C}$ provoca alterações de velocidade que não podem ser detectadas. No entanto, as caudas dos sinais apresentam diferença significativa.

O método da interferometria de cauda de onda é utilizado para detectar variações no meio de propagação por meio da análise da variação do sinal antes e após a perturbação. Quando aplicada ao problema da acustoelasticidade, esta técnica permite encontrar a variação relativa da velocidade de propagação entre amostras com níveis de tensão diferentes.

Snieder et al. (2002) mostraram a formulação matemática do método. Os autores afirmam que a mudança no meio de propagação pode ser analisada pela função de correlação entre o sinal anterior e posterior à perturbação.

A função de correlação descreve a similaridade entre dois sinais quando um deles sofre uma transposição no eixo do tempo. Para cada intervalo que um dos sinais é atrasado ou adiantado, é calculado um valor para a função correlação. Quanto maior 
a similaridade entre os sinais, maior será o valor da função correlação. A função correlação cruzada aplicada em um trecho do sinal, adaptada de Snieder et al. (2002), é dada pela equação 2.17 .

$$
C C^{(t, T)}(\Delta t)=\frac{\int_{t-T}^{t+T} u_{n p}\left(t^{\prime}\right) u_{p}\left(t^{\prime}+\Delta t\right) d t^{\prime}}{\sqrt{\int_{t-T}^{t+T} u_{n p}^{2}\left(t^{\prime}\right) d t^{\prime} \int_{t-T}^{t+T} u_{p}^{2}\left(t^{\prime}\right) d t^{\prime}}}
$$

Onde $t$ e $T$ definem o intervalo do sinal em que a função será aplicada. A janela de aplicação tem tamanho $2 T$ e ponto central $t$. O sinal não perturbado é dado por $u_{n p}$ e o sinal perturbado é $u_{p}$.

Uma vez determinada a função correlação cruzada, para aplicação do método, é necessário determinar o valor da variação de tempo $\Delta t$ que leva ao valor máximo desta função. Com o valor de $\Delta t$ e o ponto central da janela $t$, é possível calcular a variação de velocidade relativa de acordo com a demonstração simplificada de Grêt, Snieder e Scales (2006). Segundo os autores, para uma variação constante de velocidade e heterogeneidades fixas, o caminho de propagação é dado por $l=V t$. Para uma mudança homogênea de velocidade e mesmo caminho de propagação, são válidas as equações 2.18 a 2.22 .

$$
\begin{aligned}
& l=(V+\delta V)(t+\delta t) \\
& V t=(V+\delta V)(t+\delta t) \\
& V t=V t+V \delta t+\delta V t+\delta V \delta t
\end{aligned}
$$

Como os produtos $V t$ se anulam e a parcela $\delta V \delta t$ tem valor desprezível:

$$
\delta V t=-V \delta t
$$

Por fim, fazendo $V=V_{0}$, encontramos a seguinte expressão simplificada:

$$
\frac{d V}{V_{0}}=-\frac{\Delta t}{t}
$$


Uma outra vantagem do método é que torna-se desnecessário calcular a velocidade inicial da amostra não perturbada, uma vez que é possível obter a variação de velocidade relativa diretamente da variação de tempo.

Payan et al. (2009) utilizaram o CWI para determinar o efeito acustoelástico em corpo de prova cilíndricos de concreto com carregamento correspondente a até $30 \%$ da tensão de ruptura. Os autores relataram que o tempo de chegada da onda longitudinal foi $14 \mu$ s e que sinal foi considerado até o tempo de $260 \mu$ s porque a dispersão dos dados foi muito grande em porções mais atrasadas do sinal. Os autores explicam que essa dispersão é aumentada devido à contribuição das regiões próximas à aplicação da tensão, que apresentam tensão elevada.

$\mathrm{Na}$ prática, o valor da variação relativa de velocidade tem uma pequena variação conforme se altera o ponto central da janela. Grêt, Snieder e Scales (2006) indicam como escolher o valor correto. Os autores utilizaram 20 janelas de duração 50 us para fazer a correlação cruzada e escolheram o ponto central destas de modo que não ocorresse sobreposição entre elas. É importante que as janelas não se cruzem para garantir que as medidas de variação de velocidade são independentes entre si. A variação de velocidade determinada pelo método corresponde à média do valor encontrado nestas 20 janelas. Os autores também recomendam que se calcule o desvio-padrão das medidas para verificar a confiabilidade do ensaio.

Grêt, Snieder e Scales (2006) ressaltam ainda que a sensibilidade da cauda de onda é mais acentuada em ondas de cisalhamento que em ondas longitudinais. Os autores explicam que a variação de velocidade da cauda de onda é dividida de acordo com a equação 2.23 .

$$
\frac{\delta V}{V} \approx 0,09 \frac{\delta V_{P}}{V_{P}}+0,91 \frac{\delta V_{S}}{V_{S}}
$$

Larose e Hall (2009) conseguiram detectar variações de velocidade da ordem de $10^{-5}$ usando o método da interferometria de cauda de onda. Segundo os autores, para atingir este nível de precisão, foi necessário utilizar uma frequência de $500 \mathrm{kHz}$. Foi considerada "cauda de onda" a parte do sinal que teve tempo de chegada entre 50 e $500 \mu s$.

Como a cauda de onda é o resultado da interação da onda atenuada com várias direções de polarização, Planès e Larose (2013) afirmam que a constante 
acustoelástica medida por este procedimento corresponde à média das constantes acustoelásticas em todas as direções de propagação e polarização.

A metodologia adotada para análise de sinais a partir da interferometria de cauda de onda é mostrada no capítulo 4. 


\section{PROGRAMA EXPERIMENTAL}

Neste capítulo, foram apresentados os equipamentos e materiais utilizados ao longo desta pesquisa. Além disso, foram apresentados também o programa experimental para investigação da acustoelasticidade e da danificação em elementos de concreto a partir do ensaio de Velocidade de Pulso Ultrassônico, com descrição das três etapas experimentais realizadas.

\subsection{Equipamentos e materiais utilizados}

As duas primeiras etapas de ensaio foram realizadas em corpos de prova prismáticos de $15 \mathrm{~cm} \times 15 \mathrm{~cm} \times 50 \mathrm{~cm}$. Na terceira etapa, os ensaios foram realizados em prismas de mesmas dimensões e cilindros de diâmetro $15 \mathrm{~cm}$ e altura $50 \mathrm{~cm}$, conforme descrito na tabela 3.1 .

Tabela 3. 1 - Quantidade de corpos de prova ensaiados

\begin{tabular}{ccc}
\hline Tipo de ensaio & $\begin{array}{r}\text { Quantidade de prismas } \\
\mathbf{1 5 \times 1 5 \times 5 0} \mathbf{c m}^{\mathbf{3}}\end{array}$ & $\begin{array}{c}\text { Quantidade de cilindros } \\
\mathbf{\phi 1 5} \mathbf{~ c m \times 5 0 ~} \mathbf{~ c m}\end{array}$ \\
\hline Ensaios preliminares & 1 & 0 \\
Segunda etapa & 2 & 0 \\
Terceira etapa & 3 & 9 \\
\hline
\end{tabular}

Todos as composições de concreto utilizadas na pesquisa foram sugeridas por Haach, Juliani e Roz (2015). Durante as duas primeiras etapas experimentais, adotouse somente o traço 1. Para avaliação da terceira etapa de ensaios, foram realizados experimentos em cilindros dos três traços, a fim de se avaliar a influência da composição do concreto sobre o efeito acustoelástico. Os traços utilizados são descritos na tabela 3.2.

As concretagens foram realizadas no Laboratório de Estruturas (LE-EESC) (Figura 3.1a). A quantidade de água utilizada foi determinada em função do slump 
desejado (Figura 3.1b). Foi utilizado cimento do tipo CP V - ARI. Como agregados, foram utilizadas areia média e brita 1.

Tabela 3. 2 - Descrição das composições de concreto utilizadas

\begin{tabular}{ccccc}
\hline Traço & Composição & $\begin{array}{c}\text { Relação } \\
\text { água/cimento }\end{array}$ & Slump (mm) & $\begin{array}{c}\text { Resistência } \\
\text { esperada } \\
\text { (MPa) }\end{array}$ \\
\hline 1 & $1: 2,06: 2,94$ & 0,63 & 150 & 39,61 \\
2 & $1: 1,30: 2,20$ & 0,43 & 150 & 50,35 \\
3 & $1: 2,83: 3,87$ & 0,84 & 150 & 29,08 \\
\hline
\end{tabular}

Fonte: Adaptada de Haach, Juliani e Roz (2015)

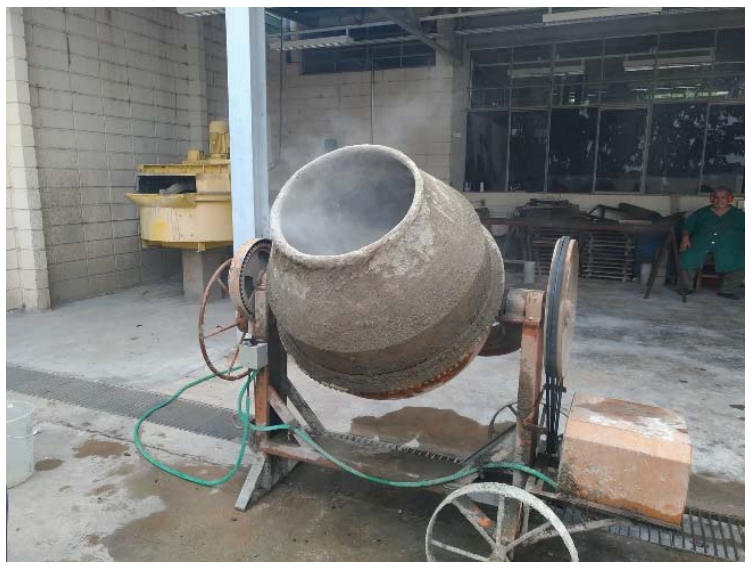

(a)

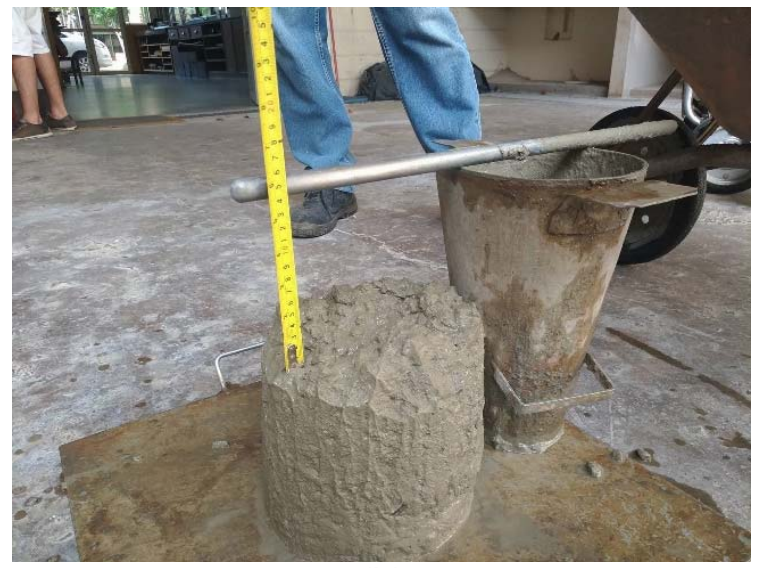

(b)

Figura 3. 1 - Concretagem das amostras: (a) betoneira utilizada e (b) realização do ensaio de abatimento

O equipamento utilizado para a realização do ensaio de Velocidade de Pulso Ultrassônico foi o aparelho Pundit Lab+, desenvolvido pela empresa Proceq ${ }^{\circledR}$. O equipamento tem medida de resolução de 0,1 $\mu$ s e pode ser usado com transdutores de frequência nominal de $24 \mathrm{kHz}$ a $500 \mathrm{kHz}$. O equipamento pode ser conectado a um computador para visualização e armazenamento do sinal da onda por meio do software Punditlink, também desenvolvido pela Proceq ${ }^{\circledR}$. Os transdutores adotados foram emissores de ondas de cisalhamento, com frequência nominal de $250 \mathrm{kHz}$. O aparelho de ultrassom e os transdutores são mostrados na figura 3.2.

Para garantir o acoplamento entre o corpo de prova e os transdutores de cisalhamento, foi utilizado um material acoplante produzido pela Echo Ultrasonics ${ }^{\circledR}$, próprio para a transmissão de ondas de cisalhamento de incidência normal à 
superfície. O fabricante recomenda que o produto seja utilizado no intervalo de temperatura entre $4^{\circ} \mathrm{C}$ e $32^{\circ} \mathrm{C}$.

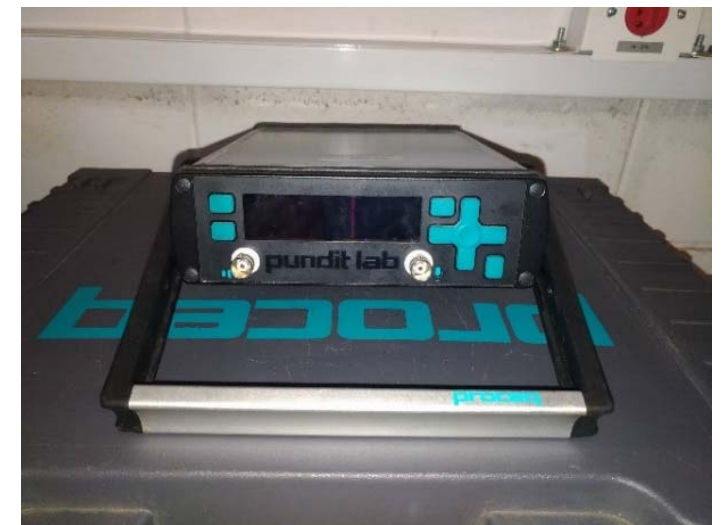

(a)

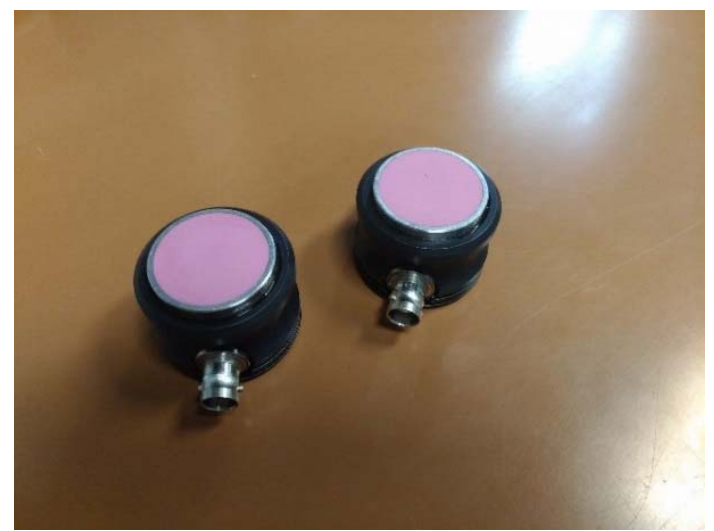

(b)

Figura 3. 2 - Equipamentos utilizados: (a) aparelho de ultrassom PunditLab+e (b) transdutores de cisalhamento de $250 \mathrm{kHz}$

Os transdutores de ondas longitudinais não foram utilizados devido à sua geometria. Enquanto os transdutores de cisalhamento possuem conectores laterais para o encaixe dos cabos coaxiais (Figura 3.2b), os transdutores de onda longitudinal têm formato cilíndrico com uma altura maior e conector no sentido longitudinal. Em razão disso, os mesmos não podem ser encaixados entre o corpo de prova e o atuador dos ensaios.

Para possibilitar a aplicação do carregamento no corpo de prova sem danificar os transdutores, uma peça de aço em forma de $U$ (Figura 3.3a) foi posicionada entre a base do prisma e a laje de reação, bem como entre o topo do prisma e o atuador hidráulico. Transdutores instalados nas faces inferior e superior do corpo de prova foram colocados na parte vazada da peça e, durante os ensaios preliminares, mantidos na sua posição fixa por uma peça de isopor (Figura 3.3b). Nos outros ensaios, as peças de isopor não foram utilizadas. Isto se deve à maior duração dos experimentos, que exigia que o gel acoplante fosse substituído algumas vezes ao longo do ensaio.

Antes de realizar qualquer medição com o aparelho de ultrassom, é necessário calibrar o aparelho. O fabricante fornece um cilindro de calibração de $10 \mathrm{~cm}$ de comprimento. A calibração é garantida quando o tempo necessário para que a onda atravesse o cilindro é de $25,4 \mu \mathrm{s}$. O referido processo está ilustrado na Figura 3.4.

Para a realização dos ensaios, um pórtico (figura 3.5a) foi montado e fixado a uma das lajes de reação do Laboratório de Estruturas. O carregamento foi aplicado 
por um cilindro hidráulico ligado a uma célula de carga. Para visualizar a força aplicada, foi utilizado um equipamento indicador de deformação da marca Vishay ${ }^{\circledR}$, modelo P3 (figura 3.5b).

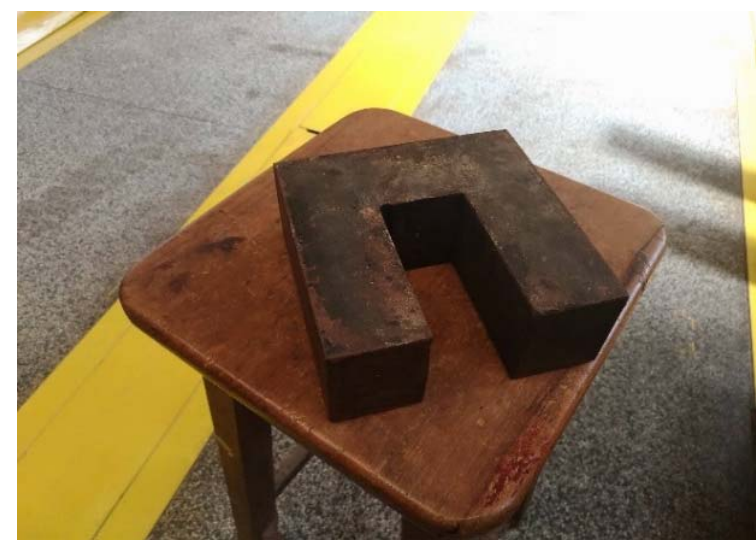

(a)

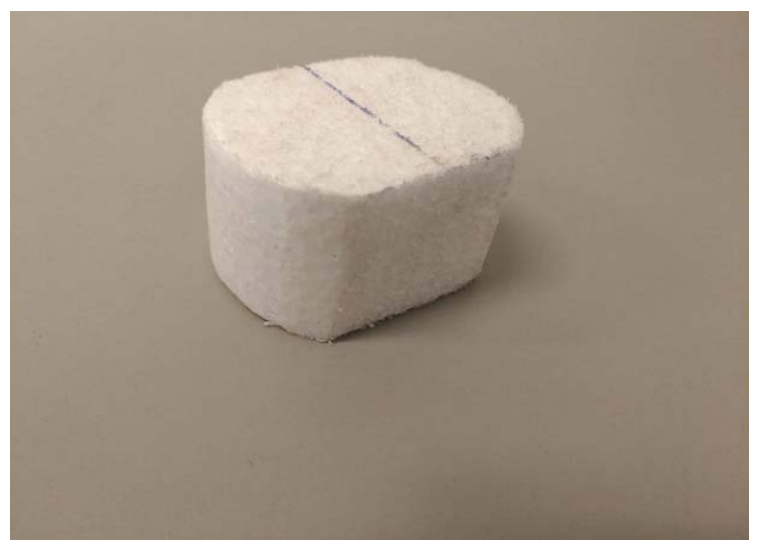

(b)

Figura 3. 3 - Peças utilizadas para que a aplicação do carregamento não danifique os transdutores:

(a) metálica e (b) de isopor

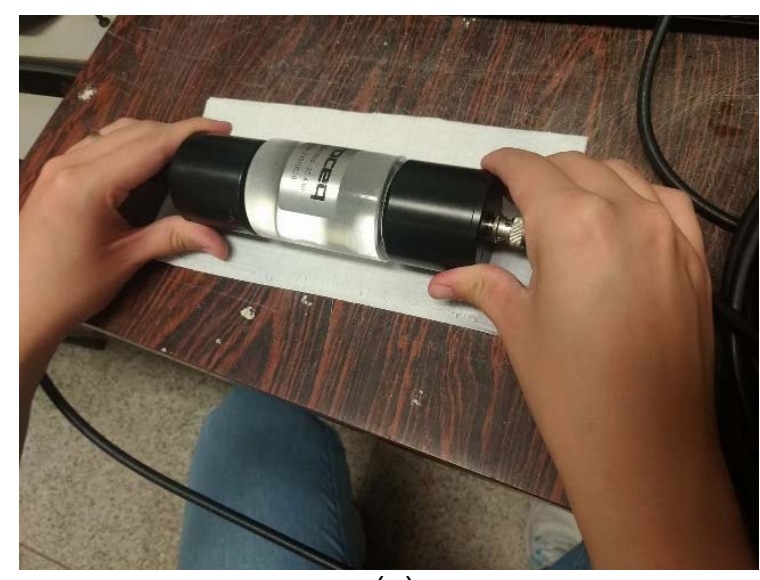

(a)

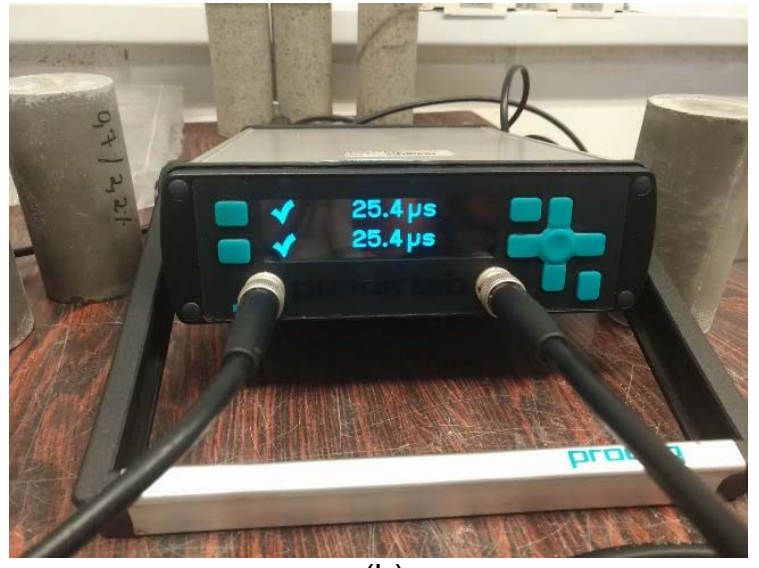

(b)

Figura 3. 4 - Calibração: (a) procedimento e (b) equipamento calibrado

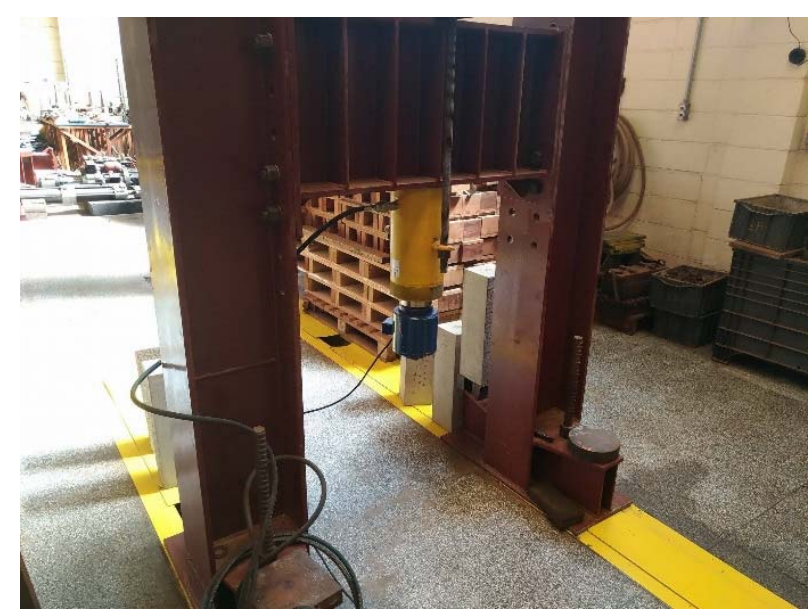

(a)

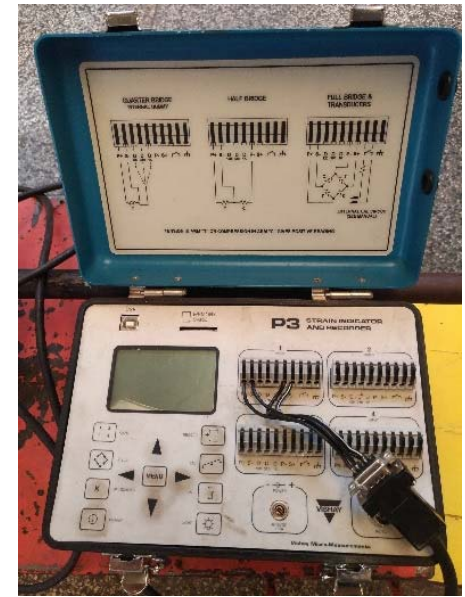

(b)

Figura 3. 5 - Equipamentos utilizados: (a) pórtico de reação com cilindro hidráulico e célula de carga e (b) equipamento P3 
Todos os ensaios foram realizados no pórtico de reação. A variação entre os métodos de ensaio se deu pelo esquema de carregamento e pontos de carregamento em que o ensaio de Velocidade de Pulso Ultrassônico foi realizado.

\subsection{Ensaios preliminares}

Os ensaios preliminares foram realizados em um prisma de concreto de $15 \mathrm{~cm}$ x $15 \mathrm{~cm}$ x $50 \mathrm{~cm}$. O prisma foi carregado até 10\%, 20\%, 30\%, 40\%, 50\%, 60\% e 65\% da sua carga de ruptura. O limite de $65 \%$ do carregamento foi adotado pelo limite de força que o cilindro hidráulico poderia aplicar ao prisma.

Para cada um dos níveis de carregamento listados, o ensaio de Velocidade de Pulso Ultrassônico foi realizado. Nesta etapa, foram emitidas apenas ondas de cisalhamento na direção 1, ou seja, na direção de aplicação do carregamento. Durante estes ensaios, os transdutores foram fixados em sua posição por meio da peça de isopor mostrada na figura 3.3b. Quando um dos níveis de carregamento desejados era atingido, a força aplicada era mantida constante para que fossem emitidos dez pulsos ultrassônicos. A onda final para o nível de carregamento é dada pela média das amplitudes destas ondas. A configuração do ensaio é mostrada na figura 3.6.

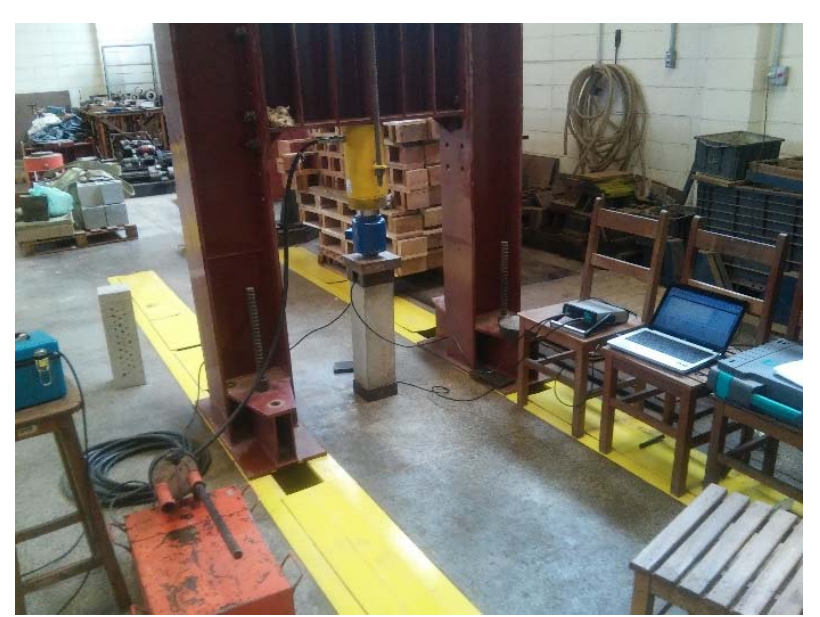

(a)

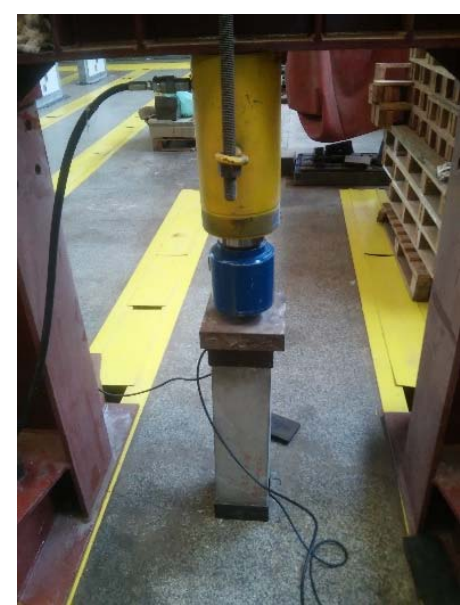

(b)

Figura 3. 6 - Ensaios preliminares: (a) configuração do ensaio e (b) detalhe do posicionamento do corpo de prova 
Durante a execução do ensaio, as informações das ondas eram gravadas por meio do software PunditLink e armazenadas para análise posterior. Os métodos de análise de resultados serão discutidos nos capítulos 5 e 6 .

\subsection{Segunda fase de ensaios}

Esta etapa de ensaios correspondeu ao estudo da efeito da danificação reversível sobre a velocidade de pulso ultrassônico. Nesta fase, os ensaios visaram verificar como o concreto se comporta após sofrer um carregamento. Neste sentido, estes experimentos verificaram a variação relativa de velocidade em amostras de concreto nas primeiras 24 horas após a retirada do carregamento

Inicialmente, se pensou em dividir esta etapa experimental em dois tipos de ensaio. O primeiro tipo verificaria o efeito da danificação em carregamentos de curta duração. Já o segundo tipo verificaria o mesmo efeito em carregamentos de média duração.

Os primeiros ensaios seriam realizados para verificar a recuperação da variação de velocidade de pulso ultrassônica após um carregamento de curta duração. Seriam aplicados carregamentos de 30\%, 40\%, 50\% e 60\% da tensão de ruptura do corpo de prova e a variação de velocidade seria avaliada por um período de 24 horas. O esquema simplificado do carregamento é mostrado na figura 3.7 .

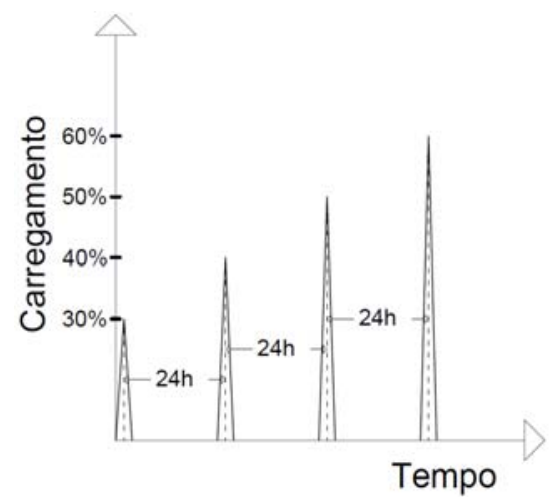

Figura 3. 7 - Esquema simplificado do carregamento do primeiro tipo de ensaio da segunda etapa

Apesar de ter sido planejado, o ensaio com carregamento de curta duração não foi realizado. Esta etapa de ensaios foi iniciada com carregamentos de média duração e, após a realização deste ensaio em dois corpos de prova, constatou-se que a 
variação de velocidade no período de tempo analisado era muito próxima da precisão mínima do aparelho de ultrassom. Logo, os ensaios posteriores desta etapa foram suspendidos.

Nos ensaios de carregamento de média duração, os corpos de prova foram submetidos a ciclos de carregamento de 24 horas sob tensão constante. Após o período de carregamento, a amostra passou 24 horas sem tensão. A variação de velocidade foi monitorada nos períodos de tempo em que o prisma esteve descarregado. O esquema simplificado do carregamento deste tipo de ensaio é mostrado na Figura 3.8.

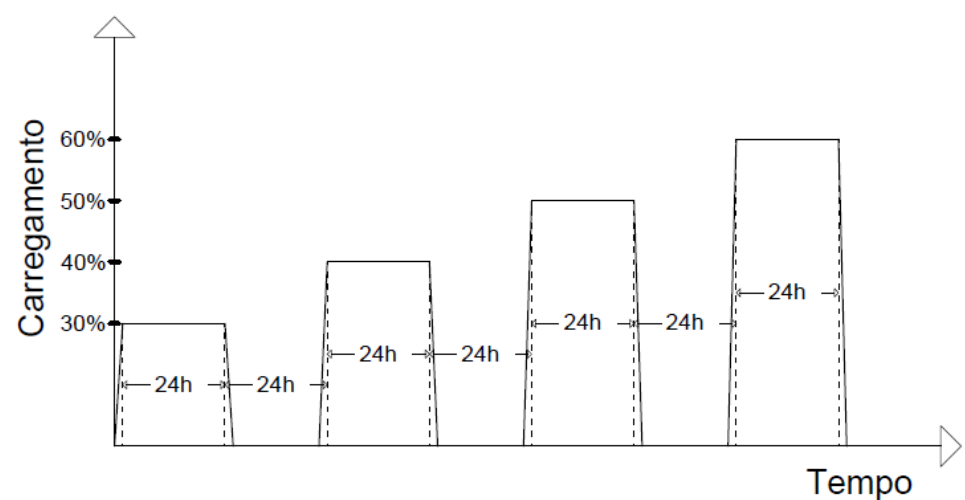

Figura 3. 8 - Esquema simplificado do carregamento do segundo tipo da segunda etapa

Os níveis de carregamento constante aplicados foram 30\%, 40\%, 50\% e 60\% da tensão de ruptura do prisma. Cada nível de carregamento foi aplicado em um ciclo correspondente a um dia de carregamento e um dia sem tensão.

Os ensaios de Velocidade de Pulso Ultrassônico foram realizados em intervalos de tempo regulares. Considerando o tempo zero como o da retirada do carregamento, as medidas foram realizadas a cada dez minutos na primeira hora e a cada hora nas primeiras seis horas. Por fim, o ensaio de VPU foi realizado após 24 horas. Escolheuse o limite das primeiras seis horas devido ao limite do horário de funcionamento do laboratório.

No segundo ensaio, verificou-se a necessidade de obtenção de maiores informações sobre o comportamento do material entre as seis e 24 horas após a remoção do carregamento. Portanto, estendeu-se o tempo de verificação a cada hora para as primeiras 13 horas de descarregamento. 
Neste ensaio, foram avaliadas apenas as ondas de cisalhamento emitidas na direção do carregamento. Para cada ponto de medida, dez ondas eram emitidas a fim de que a onda analisada fosse a média das emitidas.

Devido ao longo período de duração do ensaio, verificou-se a necessidade de avaliação da influência da variação das condições ambientais sobre a velocidade de pulso ultrassônico. Para tanto, um corpo de prova íntegro foi mantido no ambiente do ensaio e, a cada medida realizada na amostra em ensaio, uma medida foi realizada no corpo de prova de controle. No segundo ensaio, adotou-se, além da amostra íntegra de controle, uma amostra danificada para avaliação da influência das condições ambientais.

Os transdutores não foram fixados ao longo do ensaio em razão da longa duração do mesmo. Como a amostra passou períodos de 24 horas sob tensão constante, havia o risco de que a mesma viesse a romper com um carregamento menor que o previsto, tanto pela diminuição da resistência causada pela fluência como pela possibilidade de que um dos corpos de prova apresentasse resistência abaixo da média. Consequentemente, a fim de se evitar que uma possível ruptura do concreto danificasse os transdutores, os mesmos não foram deixados presos ao corpo de prova. Posteriormente, a necessidade de avaliação das amostras de controle com os mesmos transdutores usados no ensaio também foi um fator para que os mesmos não fossem fixados.

Nesta etapa, as variações relativas de velocidade foram estudadas na ausência de carregamento. Logo, podemos assumir que todos os valores encontrados foram decorrentes da danificação do corpo de prova. Uma vez que a velocidade continua variando com o tempo após a retirada da tensão aplicada, assumiu-se que a variação de velocidade seria devido ao corpo de prova se recuperando parcialmente do dano sofrido.

\subsection{Terceira etapa de ensaios}

A terceira etapa de ensaios correspondeu à determinação das parcelas de variação de velocidade devido ao efeito acustoelástico e à danificação dos elementos submetidos à compressão uniaxial. 
Foram realizados 12 ensaios nesta fase, sendo três ensaios em prismas e três em cilindros de concreto do traço 1; três ensaios em cilindros do traço 2; e três ensaios em cilindros do traço 3.

Nesta etapa, os transdutores foram posicionados na direção do carregamento e perpendicularmente ao mesmo. Em cada posição, foram emitidas ondas longitudinais e ondas de cisalhamento. Foram utilizados transdutores de cisalhamento de $250 \mathrm{kHz}$ para a emissão dos dois tipos de onda. Para emitir ondas longitudinais com os transdutores de cisalhamento, seguiu-se a recomendação de Schiavon (2015) de ajustar-se as configurações de amplitude e ganho do aparelho de ultrassom para o valor máximo.

Inicialmente, o ensaio de VPU seria realizado nas duas direções com o auxílio de um osciloscópio que foi adquirido ao longo da pesquisa e, portanto, ambos os pares de transdutores poderiam ser fixados em sua posição. Entretanto, devido ao longo prazo de entrega do equipamento, optou-se por realizar o ensaio com apenas um par de transdutores a fim de se cumprir o cronograma da pesquisa. Ademais, durante a execução do ensaio, percebeu-se que era necessário remover o transdutor para reaplicar o acoplante após alguns ciclos de carregamento. Acredita-se que a necessidade de reaplicação constante do produto esteja relacionada à alta temperatura nos dias em que os ensaios foram realizados, acima do intervalo de operação recomendado pelo fabricante. Portanto, em face dos motivos expostos, os transdutores não foram fixados em sua posição neste ensaio.

As amostras foram instrumentadas com transdutores do tipo LVDT (Linear Variable Differential Transformer) a fim de se determinar os deslocamentos dos mesmos durante a aplicação do carregamento. Foram fixados dois transdutores em faces laterais opostas dos corpos de prova. A distância inicial entre os fixadores dos transdutores foi de $25 \mathrm{~cm}$. Como as amostras tinham altura de $50 \mathrm{~cm}$, os fixadores foram afastados $12,5 \mathrm{~cm}$ das bordas superior e inferior da face lateral. A fixação dos transdutores LVDT nos corpos de prova é mostrada na figura 3.9. Os transdutores foram ligados a um sistema de aquisição que incluía também a determinação do carregamento aplicado. Logo, na terceira etapa de ensaios, o indicador de deformação P3 não foi utilizado. 


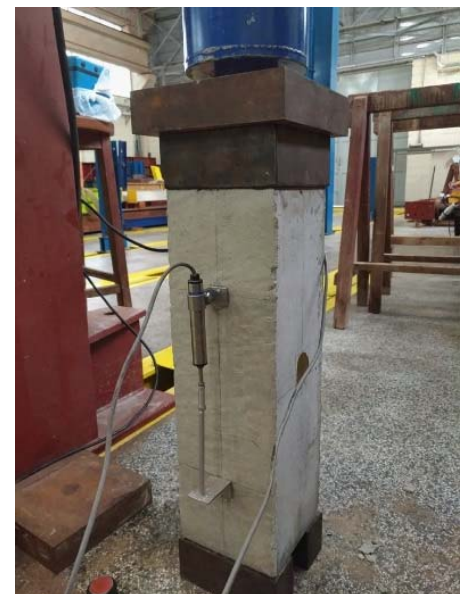

Figura 3. 9 - Posicionamento do transdutor LVDT durante a terceira etapa de ensaios

A obtenção dos deslocamentos das amostras ao longo do ensaio foi necessária para determinação do módulo de elasticidade do material. Por sua vez, o módulo de elasticidade foi utilizado na determinação do Índice de Dano (D), uma medida proposta para auxiliar na quantificação dos efeitos da danificação e da acustoelasticidade sobre a variação relativa de velocidade ultrassônica. A descrição matemática do Índice e os resultados obtidos são discutidos no capítulo 5 .

O esquema simplificado do carregamento aplicado aos corpos de prova é mostrado na figura 3.10 .

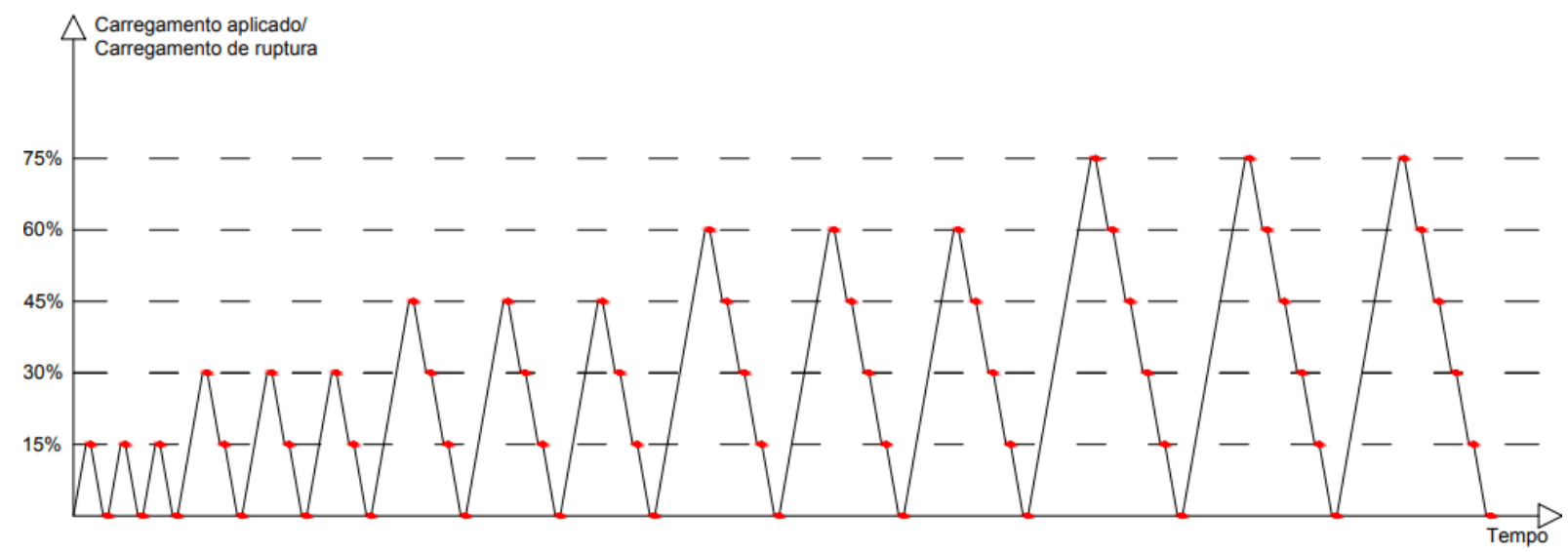

Figura 3. 10 - Esquema simplificado do carregamento na terceira etapa de ensaios

Como pode ser visto na Figura 3.10, foram aplicados 15 ciclos de carregamento e descarregamento aos corpos de prova. Cada um dos pontos vermelhos na figura indicam os pontos em que a tensão foi mantida constante para que o ensaio de Velocidade de Pulso Ultrassônico fosse realizado. Em cada ponto, dez pulsos ultrassônicos foram emitidos e a onda analisada correspondeu à média destes. $O$ limite de $75 \%$ da tensão de ruptura foi determinado a fim de evitar que a amostra 
rompesse enquanto em contato com os transdutores de cisalhamento e danificassem o equipamento.

As medidas foram efetuadas durante o descarregamento da amostra seguindo a recomendação de Shokouhi et al. (2012) para estudo do efeito acustoelástico.

A configuração desta etapa experimental é mostrada na Figura 3.11 aplicada em uma amostra cilíndrica.

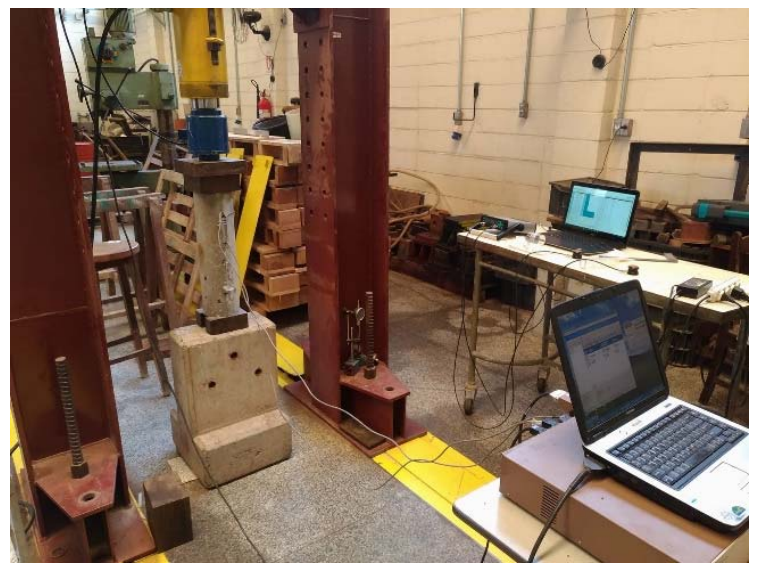

Figura 3. 11 - Configuração da terceira etapa de ensaios

A base de concreto sob o corpo de prova mostrada na Figura 3.11 é composta por um concreto de resistência superior à da amostra em ensaio sendo ainda reforçada com aço. Portanto, a mesma não interferiu nos resultados apresentados. Seu posicionamento teve a função de otimizar a ergonomia do ensaio. 


\section{METODOLOGIA DE ANÁLISE DE SINAL}

Neste capítulo, foram apresentadas as metodologias para análise da variação de velocidade entre os sinais. A abordagem dependeu do tipo de onda escolhida. Quando a análise realizada utilizou ondas de cisalhamento, foi usado o método da Interferometria de Cauda de Onda. Para a avaliação de ondas longitudinais, a velocidade de cada onda foi calculada a partir do seu tempo de chegada a fim de se determinar a variação de velocidade entre os sinais.

\subsection{Análise de ondas de cisalhamento}

A fim de definir qual método de avaliação seria utilizado nos experimentos subsequentes, os resultados de um mesmo ensaio foram analisados por meio da Interferometria de Cauda de Onda tradicional e por uma variação do método chamada "stretching" ou alongamento.

Para avaliar a aplicação da técnica da interferometria tradicional, utilizou-se programa CWI elaborado por Haach (2016). A interface do programa é mostrada na figura 4.1. Como dados de entrada do programa, são necessários dois arquivos de extensão .txt. Cada arquivo deve conter as informações de amplitude de uma das duas ondas que desejamos analisar. Ademais, o usuário deve informar o ajuste do tempo de calibração, a frequência de aquisição do sinal, o tamanho $T$ da janela e a posição central da janela.

O ajuste do tempo de calibração é informado pelo aparelho de ultrassom durante a execução do ensaio. Este ajuste é necessário para descontar o tempo em que a onda percorre os cabos coaxiais que ligam o aparelho de ultrassom aos transdutores. A frequência de aquisição também é informada pelo aparelho de ultrassom. Estas duas informações são necessárias para possibilitar a reconstrução do sinal.

Os outros parâmetros necessários à execução do programa (tamanho da janela e ponto central) são necessários para o cálculo da correlação cruzada entre os sinais. 
A janela corresponde ao trecho do sinal que será analisado. Para que o trecho a ser utilizado seja definido, é preciso que se indique o tamanho do mesmo (tamanho da janela) e em que ponto do sinal (ponto central) o trecho se localiza.

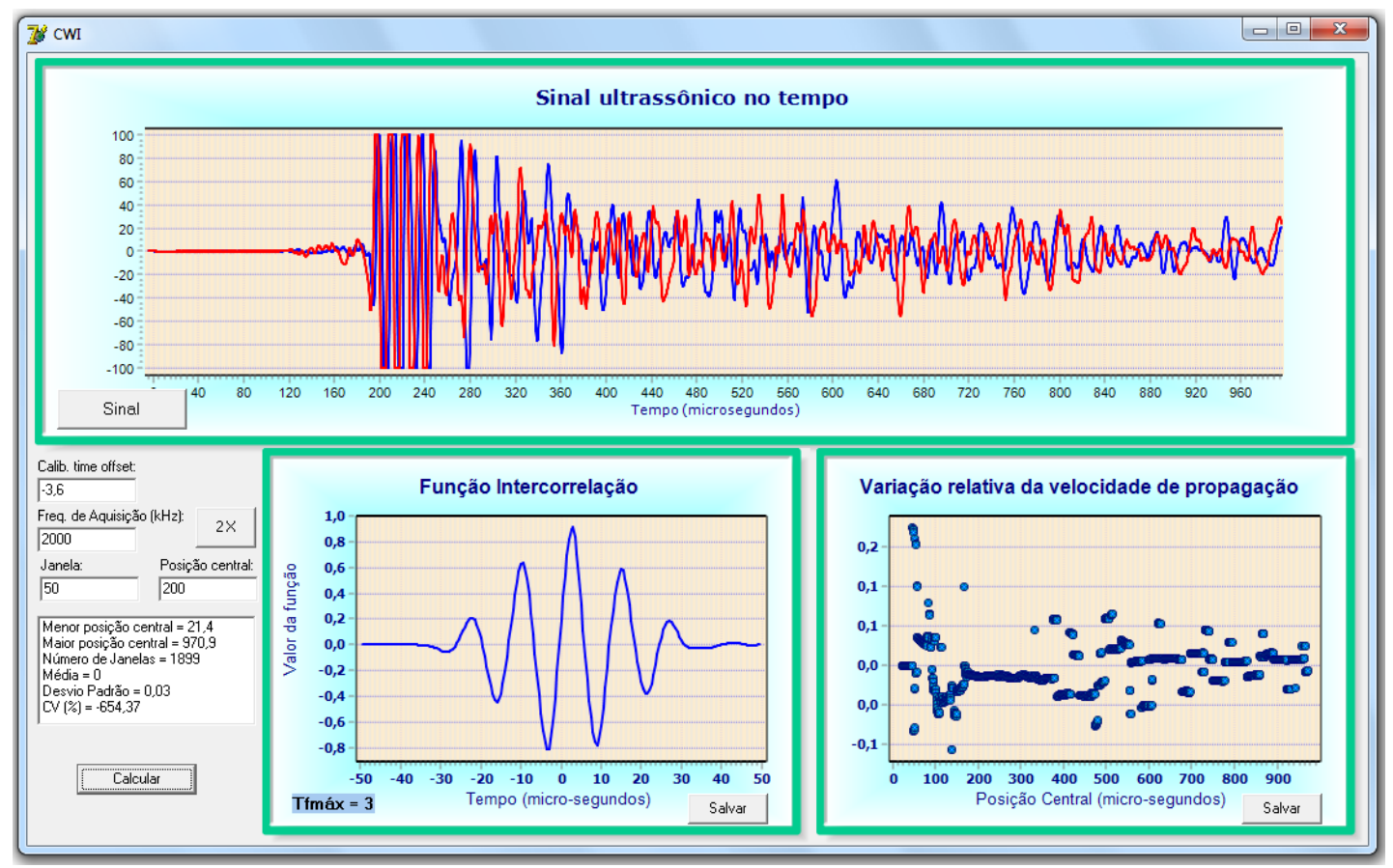

Figura 4. 1 - Interface do programa de Interferometria de cauda de onda Fonte: Haach (2016)

Uma vez que todos os dados de entrada são fornecidos, a função correlação cruzada é calculada e seu valor máximo é informado ao usuário. Além disso, é mostrado um gráfico da variação relativa da velocidade de propagação para um dado tamanho de janela com a variação do ponto central ao longo do sinal. O gráfico da variação relativa de velocidade também pode ser exportado como um arquivo de extensão .txt.

Para um dado tamanho de janela, o valor da correlação cruzada varia conforme se altera o ponto central da janela. De acordo com a teoria da interferometria de cauda de onda, a variação da correlação cruzada é proporcional à variação do ponto central da janela. Portanto, a variação relativa de velocidade deveria tender a um valor e variar pouco com a mudança do ponto central. Na prática, existe uma grande flutuação do valor da variação de velocidade.

Então, torna-se necessário decidir qual ponto central deve ser considerado para obtenção da variação de velocidade. A cauda de onda é definida como o trecho do 
sinal de chegada tardia. Logo, qualquer trecho do sinal que ocorra após a chegada da onda de cisalhamento pode ser usado para aplicação do método.

Inicialmente, utilizou-se o procedimento proposto por Grêt, Snieder e Scales (2006). Foram utilizadas janelas de 50 us e escolhidos pontos centrais que resultassem em 14 janelas sem sobreposição. A variação relativa de velocidade para cada valor de carregamento foi igualada à média entre as medidas.

A figura 4.2 mostra que este procedimento não é adequado para a análise dos resultados destes ensaios. O gráfico da esquerda mostra valores negativos de variação de velocidade para os carregamentos de $40 \%$ e $50 \%$ da força última, o que não faz sentido pela teoria da acustoelasticidade. Já o gráfico da direita mostra que as medidas tiveram valores altíssimos de dispersão. A dispersão alta explica os resultados ruins obtidos com as médias. No entanto, para entender a alta dispersão, devemos voltar à figura 4.1 e observar o gráfico na parte inferior direita da imagem.

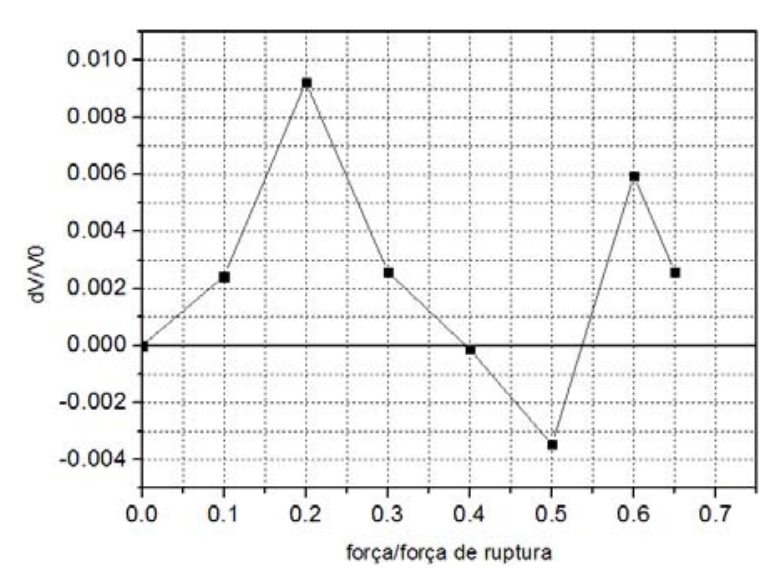

(a)

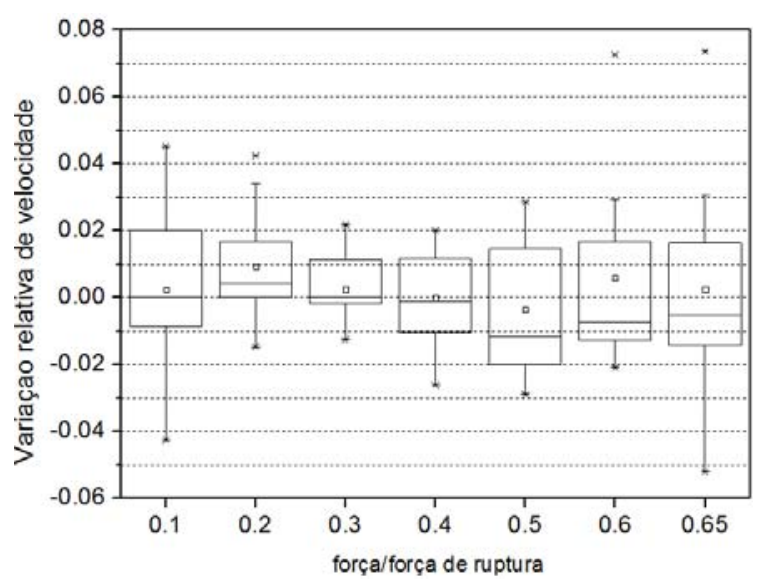

(b)

Figura 4. 2 - Resultados obtidos com as medidas de 14 janelas sem sobreposição: (a) média e (b) dispersão

Pelo gráfico, a variação relativa de velocidade apresenta bom comportamento na região em que o tempo do ponto central varia entre cerca de $200 \mu$ s e $300 \mu$ s. Conforme o ponto central se afasta dessa região, a dispersão aparece. Quando o sinal avança no tempo, a amplitude da onda que chega ao transdutor receptor diminui. Logo, a presença de ruído tem um efeito maior sobre a qualidade do sinal para tempos de chegada maiores. Daí a grande dispersão que ocorre para tempos próximos e acima de $400 \mu \mathrm{s}$.

Para evitar o trecho do sinal que está permeado de ruído, foram realizadas novas análises considerando pontos centrais mais próximos do tempo de chegada da 
onda de cisalhamento. Embora seja difícil determinar o tempo exato de chegada da onda, é visível na figura 4.3 que isto ocorre entre alguns microssegundos antes dos 200 us. Para este ensaio, foi admitido que o tempo de chegada da onda de cisalhamento seria de cerca de $185 \mu$ s.

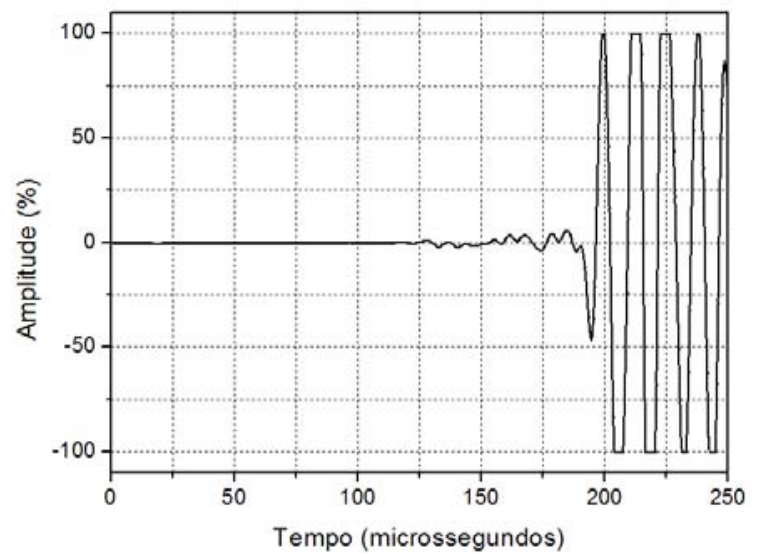

Figura 4. 3 - Detalhe do sinal da onda sem carregamento mostrando o intervalo de chegada das ondas longitudinais e de cisalhamento

A fim de encontrar o trecho do sinal que oferece o melhor resultado, foram estudados trechos com os pontos centrais variando entre $185 \mu \mathrm{s}$ e $200 \mu \mathrm{s}$; $200 \mu \mathrm{s}$ e

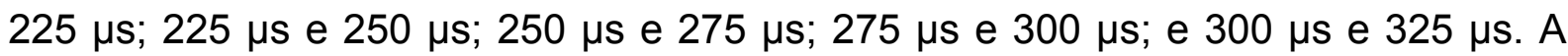
influência do tamanho da janela nos resultados também foi estudada. Para cada um dos trechos listados, resultados foram gerados com janelas de $25 \mu \mathrm{s}, 50 \mu \mathrm{s}$ e $100 \mu \mathrm{s}$. A qualidade dos resultados foi avaliada a partir da dispersão das medidas e do comportamento esperado pela teoria da acustoleasticidade.

Conforme mostrado nas figuras 4.4 a 4.6 , as janelas de $50 \mu$ e $100 \mu s$ proporcionaram curvas bem próximas para todos os intervalos de ponto central estudado, à exceção de alguns pontos isolados. Por outro lado, os resultados obtidos com a janela de $25 \mu$ s apresentaram uma variação bem maior nas suas curvas.

Com exceção de alguns pontos isolados, os gráficos acima mostram que a variação de velocidade relativa é praticamente a mesma para os pontos centrais estudados nas janelas de $50 \mu$ s e $100 \mu$ s.

A fim de entender porque os pontos relativos ao carregamento de $30 \%$ na janela de $50 \mu$ s e ao carregamento de $20 \%$ na janela de $100 \mu$ s ficaram fora da curva quando o ponto central variou de 275 s a $325 \mu$ s, foram estudadas suas dispersões. 


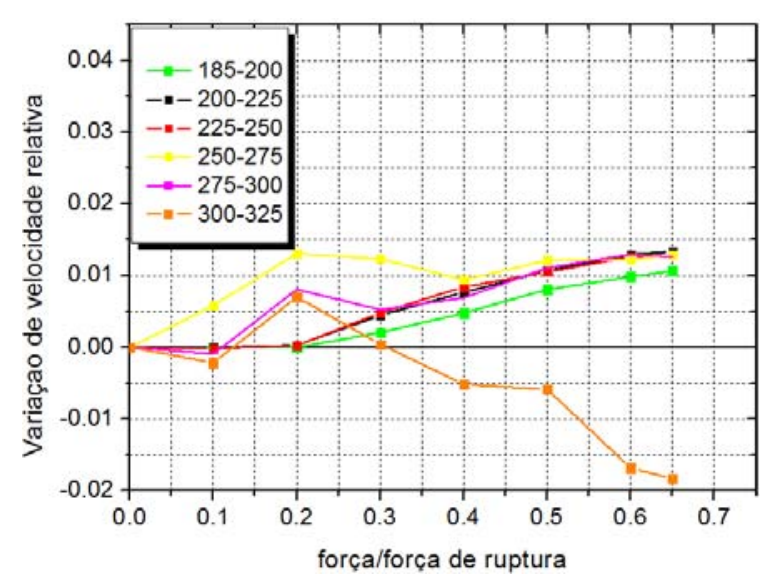

Figura 4. 4 - Análise de resultados com janela de $25 \mu \mathrm{s}$

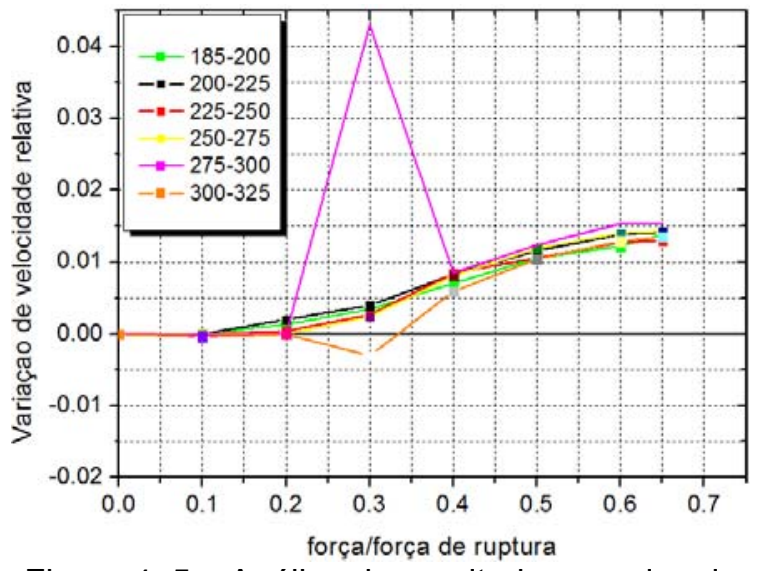

Figura 4. 5 - Análise de resultados com janela de $50 \mu \mathrm{s}$

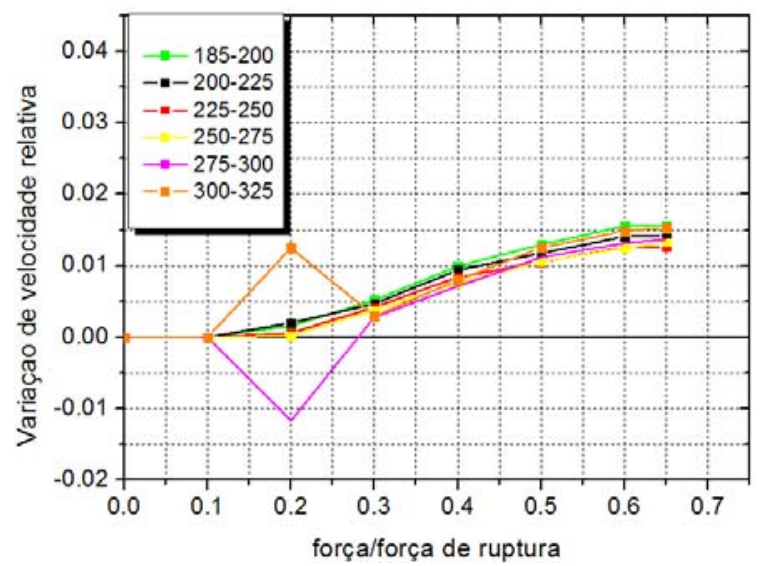

Figura 4. 6 - Análise de resultados com janela de $100 \mu \mathrm{s}$

A dispersão é mostrada em dois tipos de gráfico: gráficos de linhas relacionando a variação de velocidade e o ponto central para um mesmo carregamento e tamanho de janela; e gráficos box-plot.

O gráfico box-plot é um recurso visual estatístico para mostrar a dispersão de dados em uma análise. Nos gráficos a seguir, os pontos indicados por um $\mathrm{x}$ correspondem aos pontos de valor máximo e mínimo da distribuição. O ponto representado por um quadrado corresponde à média da distribuição. Por fim, os valores indicados pelos lados superior e inferior do retângulo correspondem ao primeiro e terceiro quartil. Imaginando que a distribuição dos dados esteja organizada de forma crescente, o primeiro quartil corresponde ao valor superior ao primeiro quarto desta distribuição. O terceiro quartil corresponde ao valor superior a $75 \%$ da distribuição.

Como pode ser observado nas figuras 4.7 a 4.14 houve uma grande diferença entre os pontos de máxima e mínima variação de velocidade. Para buscar a origem 
desta dispersão, é necessário verificar como os sinais que geraram estes resultados se apresentam.

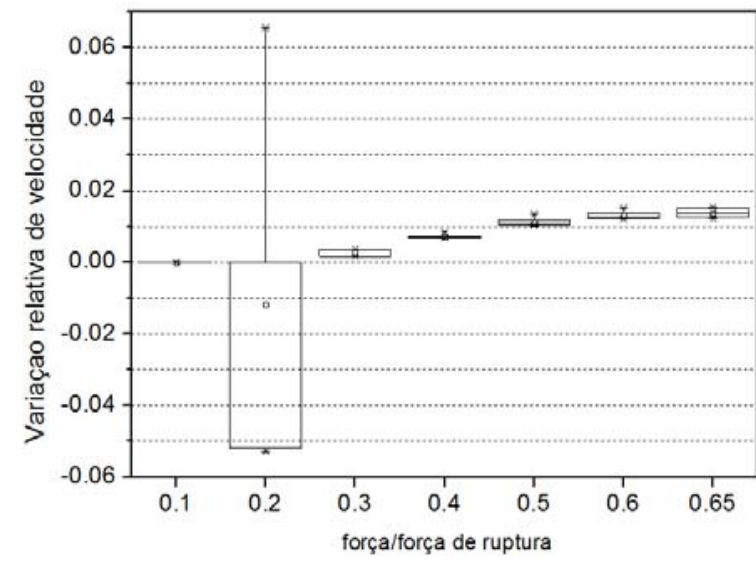

Figura 4. 7 - Dispersão de resultados para a janela de $100 \mu$ s e ponto central variando entre $275 \mu \mathrm{s}$ e $300 \mu \mathrm{s}$

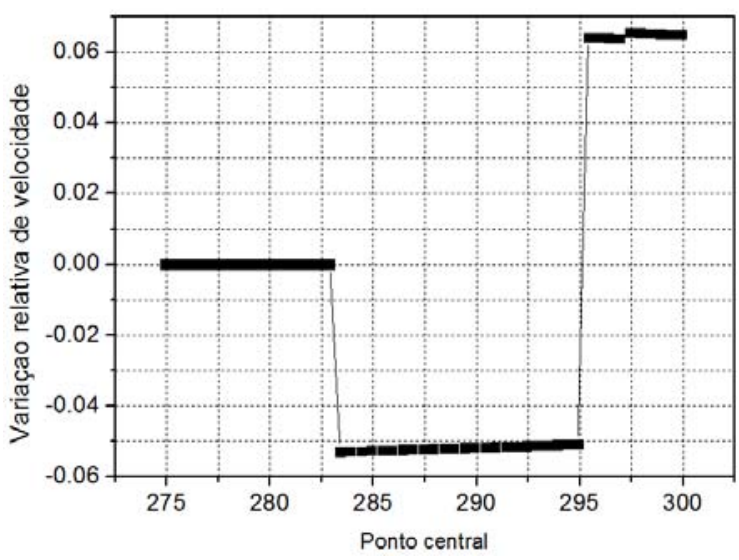

Figura 4. 9 - Variação de velocidade para cada ponto central com carregamento de $20 \%$ e janela de $100 \mu \mathrm{s}$

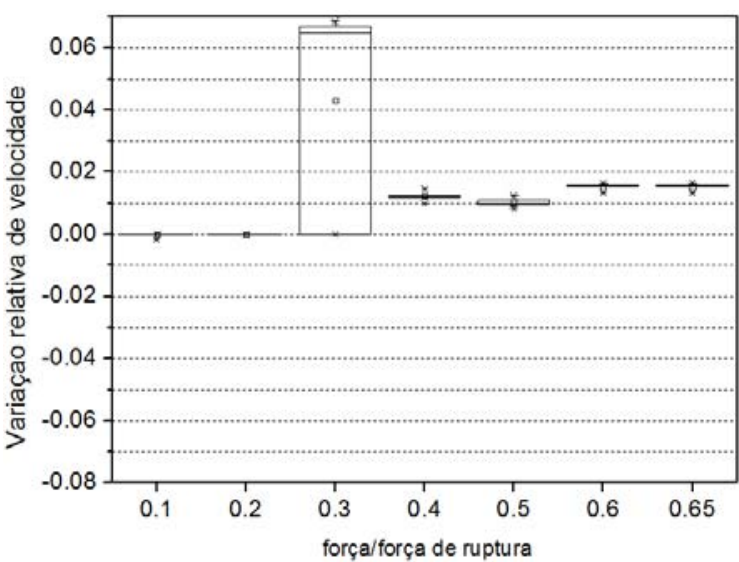

Figura 4. 11 - Dispersão de resultados para a janela de $50 \mu$ s e ponto central variando entre $275 \mu \mathrm{s}$ e $300 \mu \mathrm{s}$

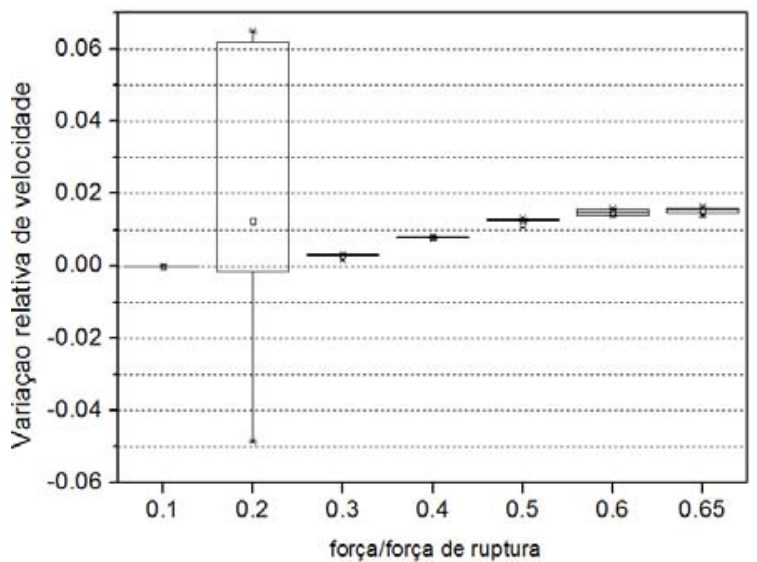

Figura 4. 8 - Dispersão de resultados para a janela de 100 us e ponto central variando entre $300 \mu \mathrm{s}$ e $325 \mu \mathrm{s}$

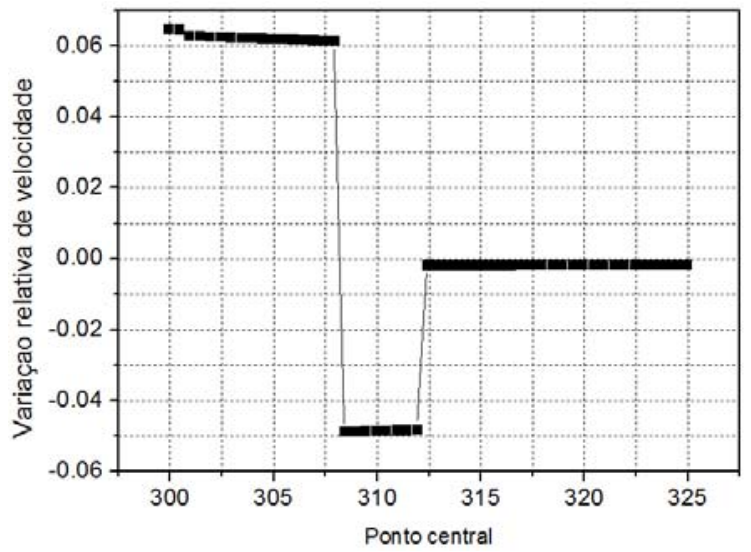

Figura 4. 10 - Variação de velocidade para cada ponto central com carregamento de $20 \%$ e janela de $100 \mu \mathrm{s}$

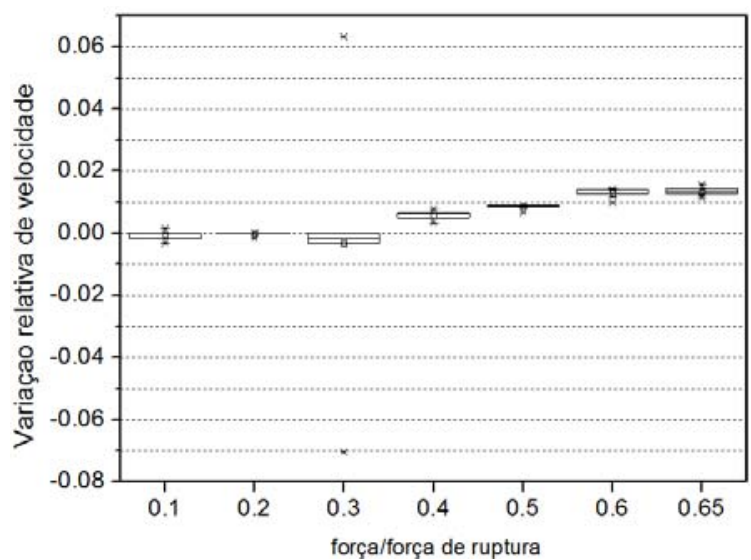

Figura 4. 12 - Dispersão de resultados para a janela de $50 \mu$ s e ponto central variando entre $300 \mu \mathrm{s}$ e $325 \mu \mathrm{s}$ 


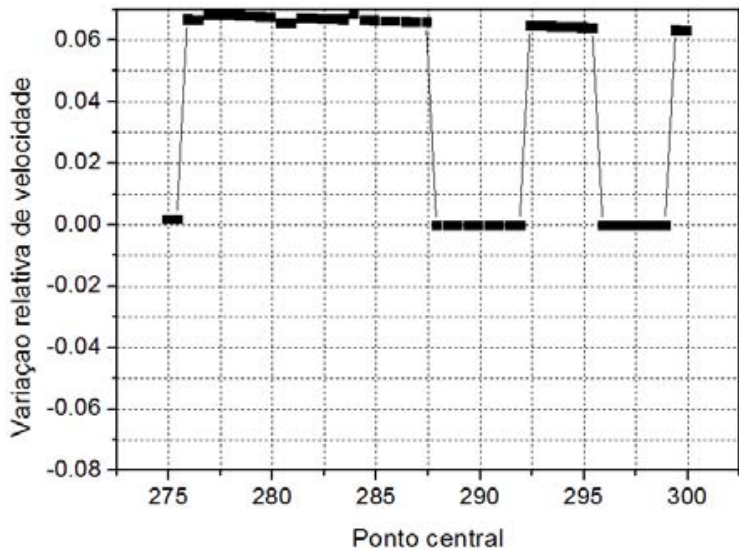

Figura 4. 13 - Variação de velocidade para cada ponto central com carregamento de $30 \%$ e janela de $50 \mu \mathrm{s}$

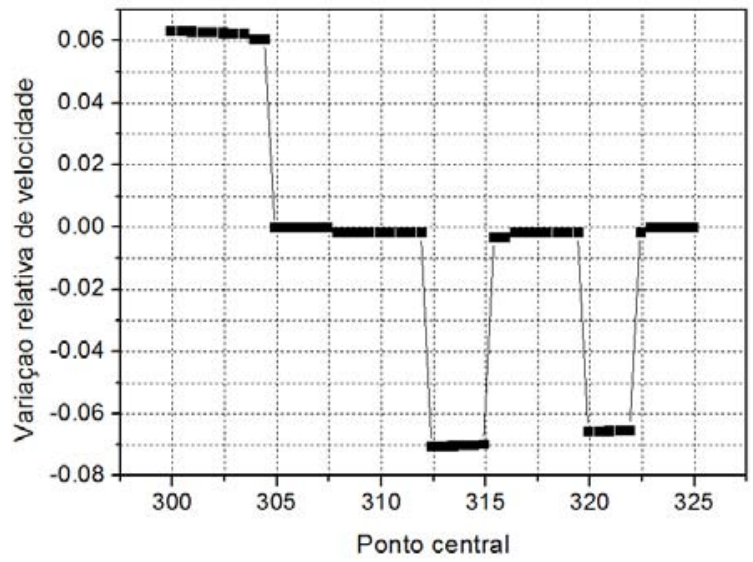

Figura 4. 14 - Variação de velocidade para cada ponto central com carregamento de $30 \%$ e janela de $50 \mu \mathrm{s}$

Nas figuras 4.15 a 4.17 , são mostrados os sinais obtidos para o carregamento de $20 \%, 30 \%$ e $40 \%$. O sinal da onda com carregamento de $40 \%$ da tensão de ruptura apresentou bom comportamento em todos os trechos analisados com as janelas de $50 \mu \mathrm{s}$ e $100 \mu \mathrm{s}$.

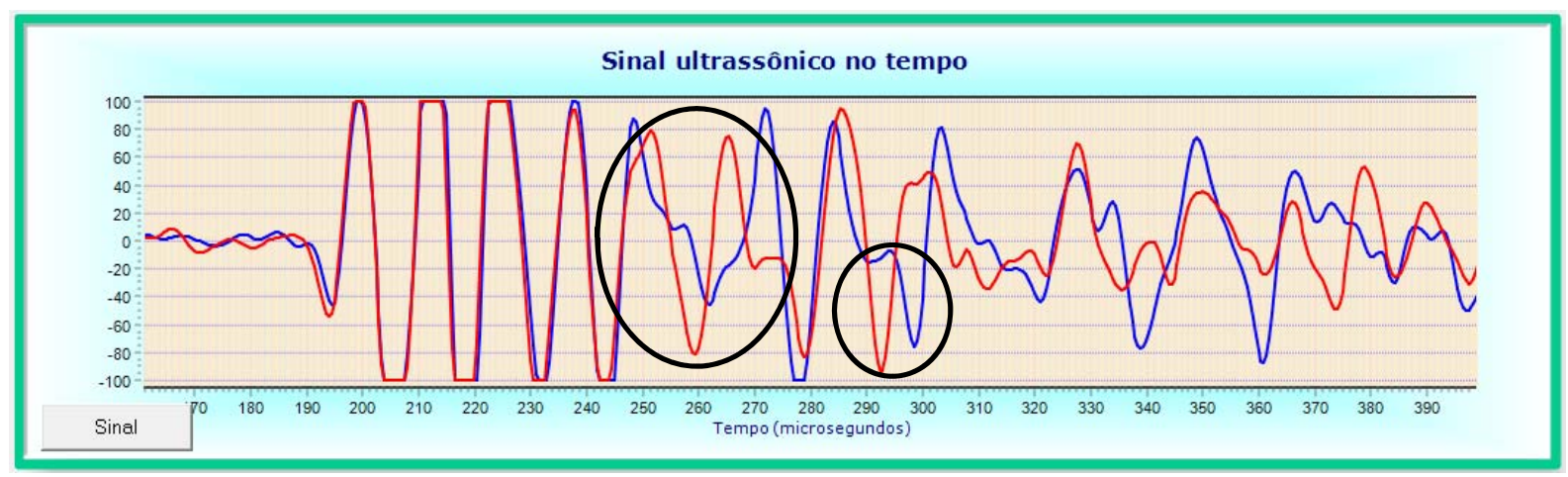

Figura 4. 15 - Detalhe da sobreposição dos sinais sem carregamento (onda azul) e com carregamento de $20 \%$ da tensão de ruptura (onda vermelha)

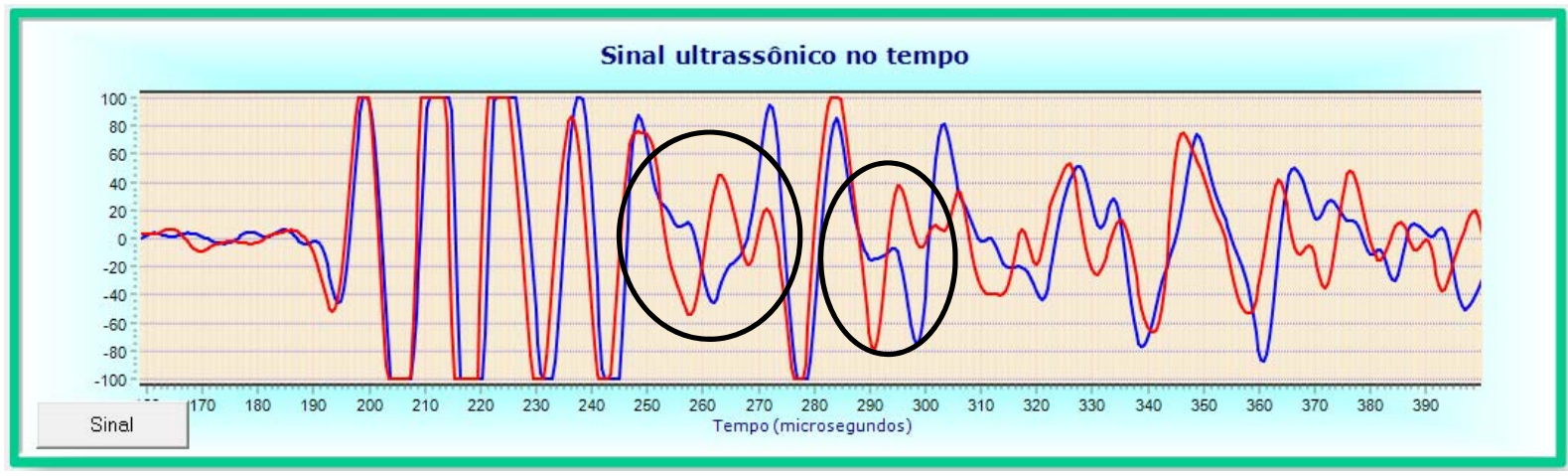

Figura 4. 16 - Detalhe da sobreposição dos sinais sem carregamento (onda azul) e com carregamento de $30 \%$ da tensão de ruptura (onda vermelha) 


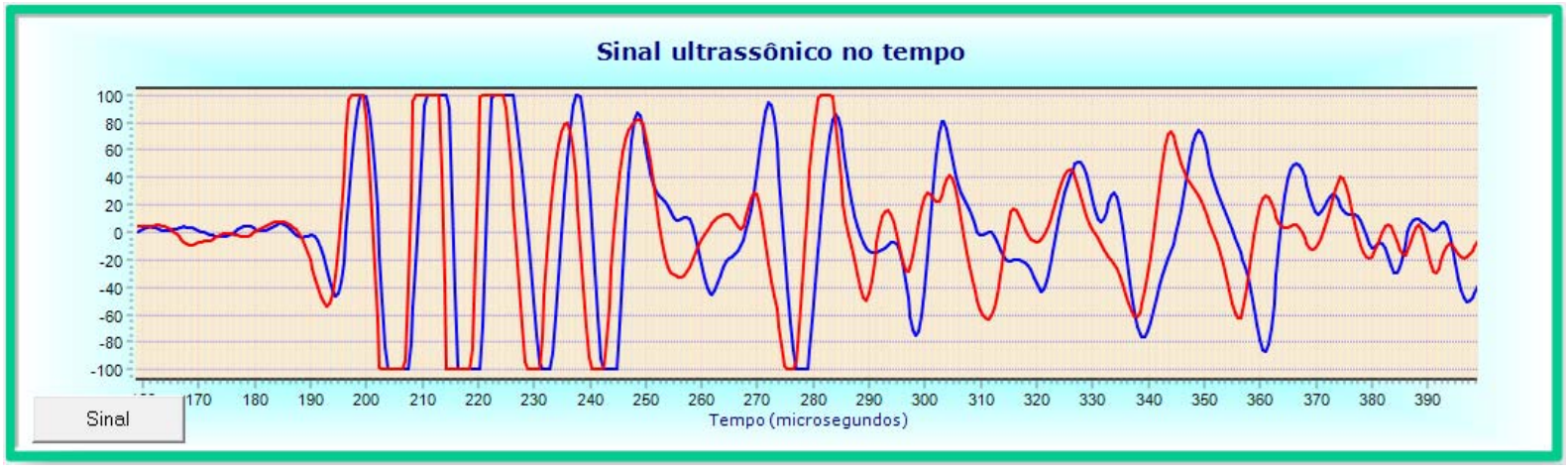

Figura 4. 17 - Detalhe da sobreposição dos sinais sem carregamento (onda azul) e com carregamento de $40 \%$ da tensão de ruptura (onda vermelha)

Nos detalhes circulados, podemos perceber que existem variações nos formatos das ondas, com a formação de alguns picos que não existiam no sinal original (obtido na ausência de carregamento). Uma vez que a grande dispersão de resultados se deve à variação do sinal, é necessário refletir sobre quais aspectos podem influenciar o formato da onda.

$\mathrm{Na}$ figura 4.18 , é feita a sobreposição de sinais para todos os níveis de carregamento. Neste gráfico, foram destacados os pontos em que as ondas correspondentes aos carregamentos de 20\% (cor azul) e de 30\% (cor verde) apresentaram picos muito deslocados em relação às demais ondas. O detalhe "a" é mostrado na figura 4.19 e o detalhe "b" na figura 4.20 .

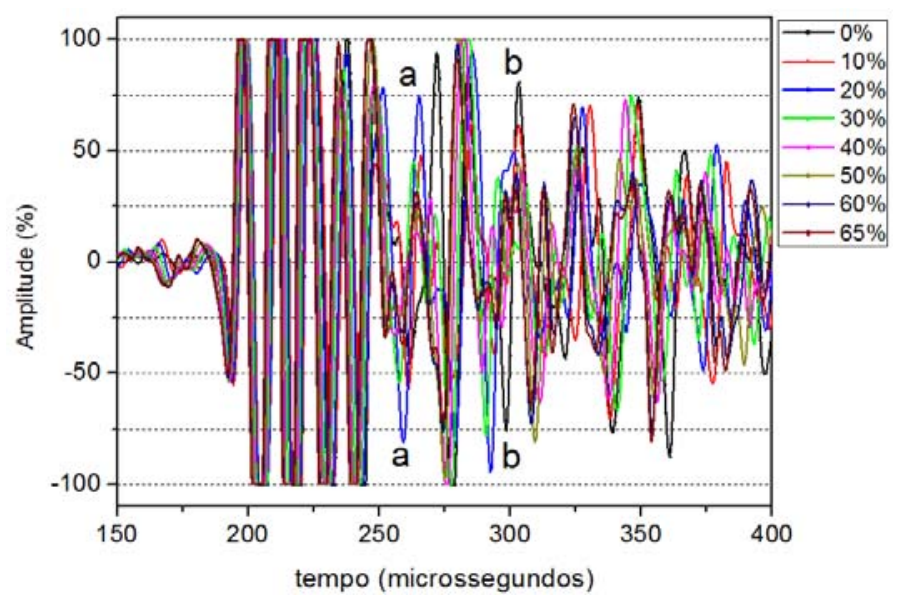

Figura 4. 18 - Sobreposição dos sinais de todos os níveis de carregamento 


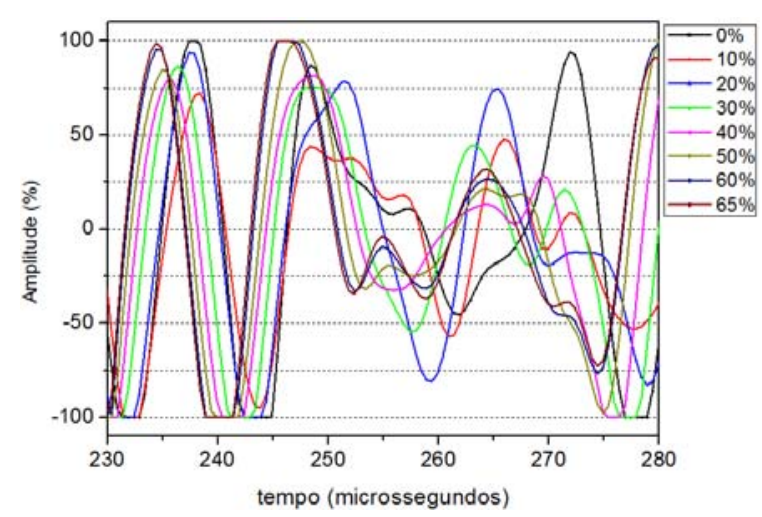

Figura 4. 19 - Detalhe 'a' da sobreposição dos sinais

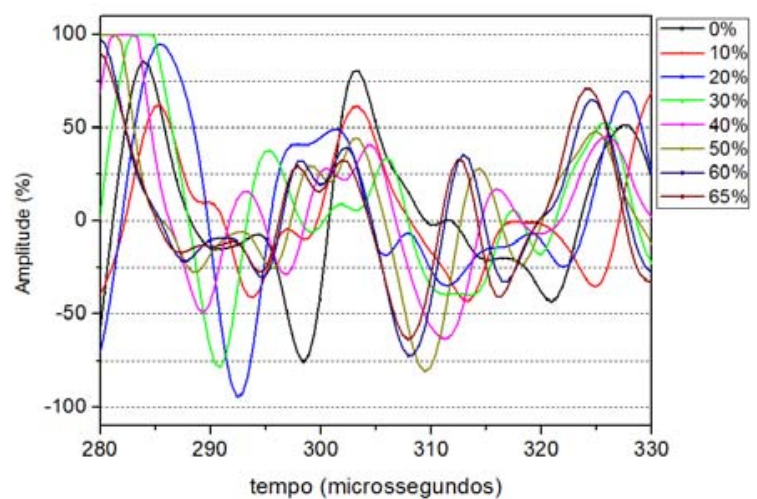

Figura 4. 20 - Detalhe 'b' da sobreposição dos sinais

Quando um fator altera a velocidade de propagação da onda, ocorre o deslocamento do sinal ao longo do eixo do tempo e uma compressão ou dilatação do sinal. Para alterar a repetibilidade do sinal, é necessário que haja uma alteração no seu caminho de propagação. Logo, o fator mais comum para explicar este fenômeno seria a danificação do corpo de prova.

Com o surgimento ou propagação de novas fissuras, há uma mudança na forma como a onda se dispersa. Durante a sua propagação, a tendência da onda é seguir em linha reta. No entanto, a presença de heterogeneidades (agregados, fissuras) faz com que parte da energia da onda seja desviada. Estas porções desviadas compõem o sinal após a chegada da onda. Durante o ensaio, a posição dos agregados tem pouquíssima alteração dentro do corpo de prova. Portanto, a melhor explicação para a alteração da amostra é a presença de dano no concreto.

Voltando aos gráficos com as curvas de variação de velocidade por carregamento, todas as variações relativas de velocidade para as janelas de $50 \mu \mathrm{s} e$ $100 \mu$ s com ponto central entre $185 \mu$ s e $275 \mu$ s apresentam resultados consistentes. Para encontrar o melhor intervalo de ponto central e tamanho de janela para nossas análises, foram realizados estudos de dispersão dos dados para cada intervalo estudado.

Os gráficos de dispersão de resultados com janela de $50 \mu$ s são mostrados nas figuras 4.21 a 4.24 . Entre $185 \mu \mathrm{s}$ e $275 \mu \mathrm{s}$, a ordem de grandeza dos resultados foi a mesma e a dispersão para os diversos intervalos de ponto central foi parecida. No entanto, as diferenças entre o terceiro e o primeiro quartil foram um pouco menores no intervalo de ponto central entre $225 \mu \mathrm{s}$ e $250 \mu \mathrm{s}$. Logo, este será considerado o melhor intervalo para uma janela de $50 \mu$ s. 
Os gráficos de dispersão para as janelas de $100 \mu$ s (Fig. 4.25 a 4.28) mostram que todos os intervalos tiveram dispersões parecidas. Este resultado já era esperado uma vez que, neste intervalo, todos os pontos de média estavam próximos. Com as janelas de $100 \mu$ s, as menores dispersões ocorreram no intervalo entre $200 \mu$ s e 225 $\mu \mathrm{s}$.

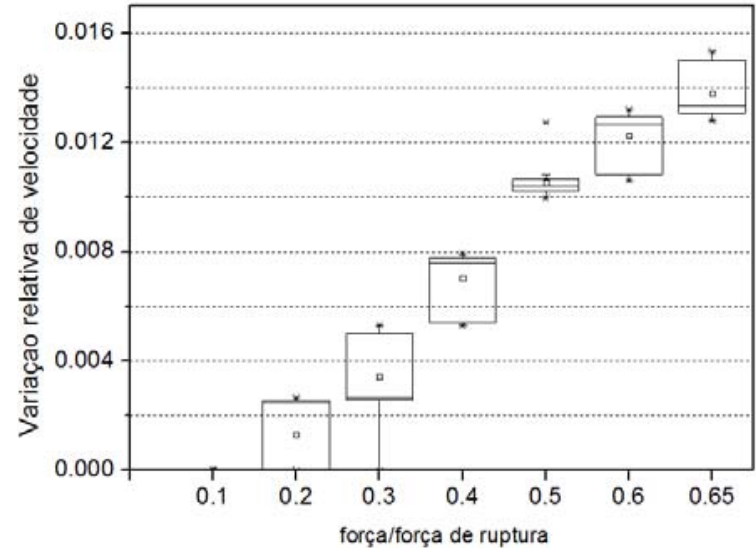

Figura 4. 21 - Dispersão de resultados para a janela de $50 \mu$ s e ponto central variando entre $185 \mu \mathrm{s}$ e $200 \mu \mathrm{s}$

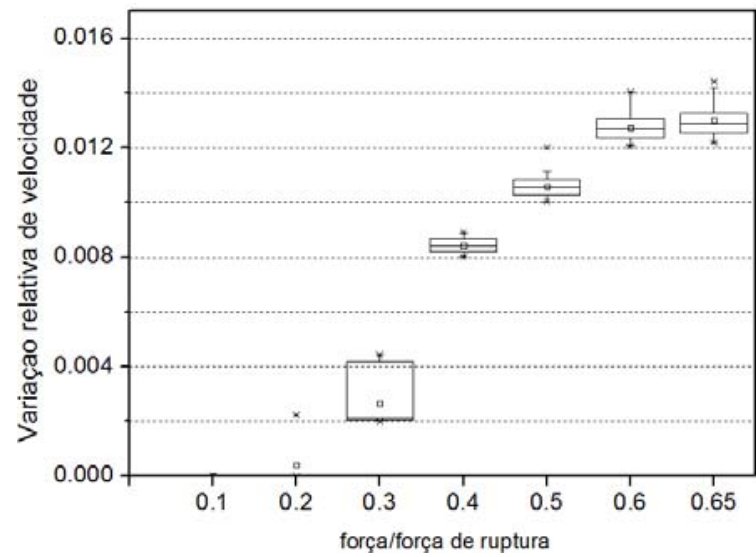

Figura 4. 23 - Dispersão de resultados para a janela de 50 us e ponto central variando entre $225 \mu \mathrm{s}$ e $250 \mu \mathrm{s}$

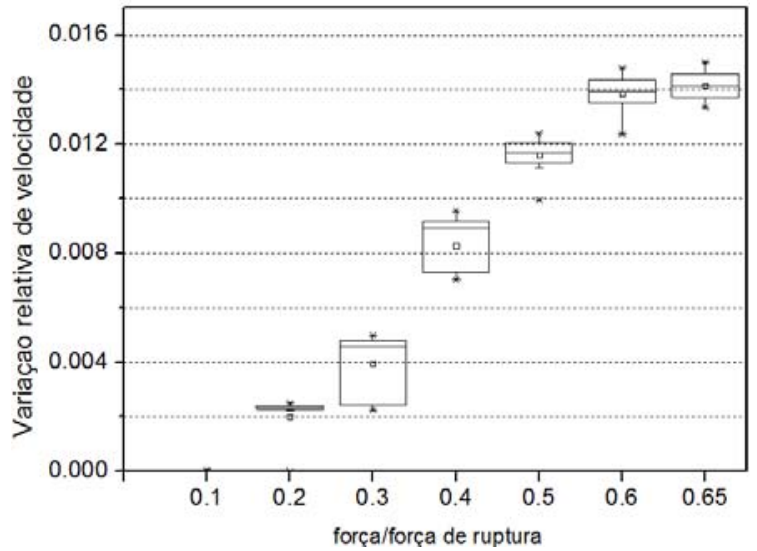

Figura 4. 22 - Dispersão de resultados para a janela de $50 \mu$ s e ponto central variando entre $200 \mu \mathrm{s}$ e $225 \mu \mathrm{s}$

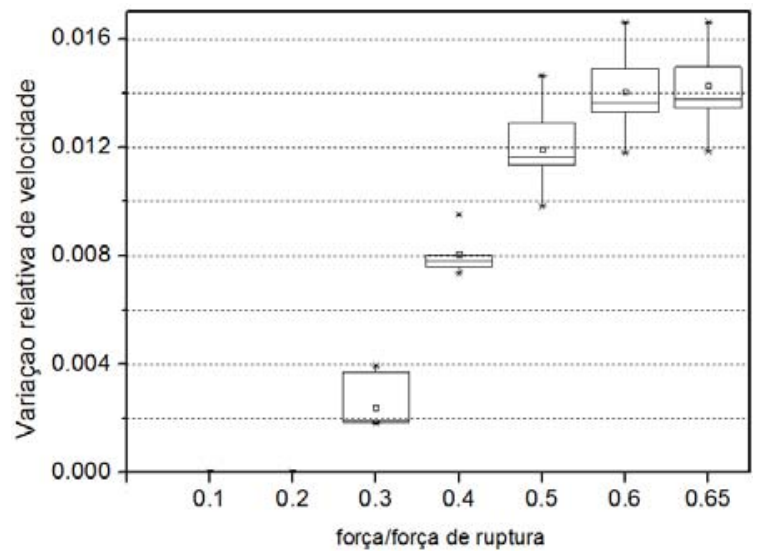

Figura 4. 24 - Dispersão de resultados para a janela de 50 us e ponto central variando entre $250 \mu \mathrm{s}$ e $275 \mu \mathrm{s}$

De modo geral, as janelas de $100 \mu$ s apresentaram uma dispersão ligeiramente menor que as janelas de $50 \mu \mathrm{s}$.

Além do uso da técnica tradicional da interferometria de cauda de onda para obtenção da variação de velocidade de propagação, os resultados também foram avaliados por meio de uma variação do método, o alongamento. Enquanto a técnica tradicional admite que a variação da velocidade se dá por meio da translação do sinal 
no eixo do tempo, o alongamento considera o quanto o sinal se dilata ou se contrai quando o meio é alterado.

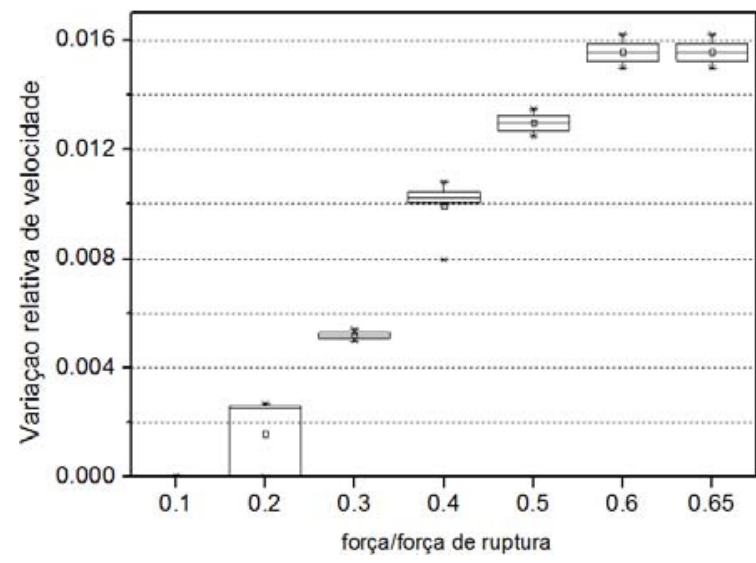

Figura 4. 25 - Dispersão de resultados para a janela de 100 us e ponto central variando entre $185 \mu \mathrm{s}$ e $200 \mu \mathrm{s}$

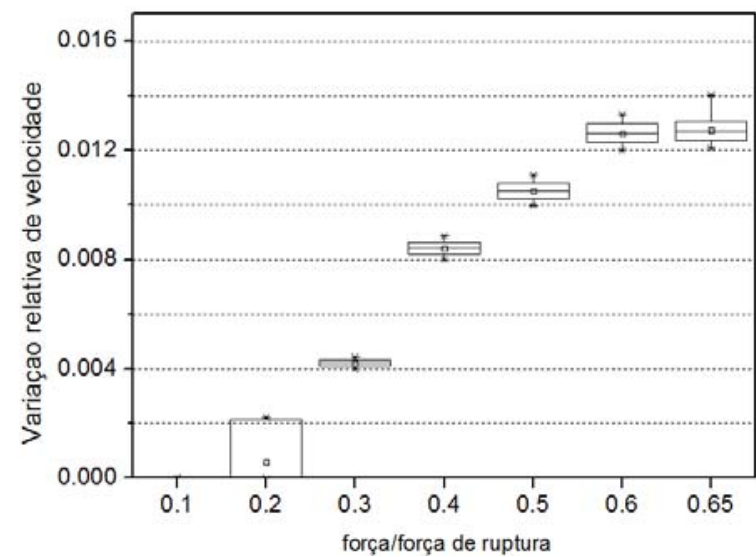

Figura 4. 27 - Dispersão de resultados para a janela de $100 \mu$ s e ponto central variando entre $225 \mu \mathrm{s}$ e $250 \mu \mathrm{s}$

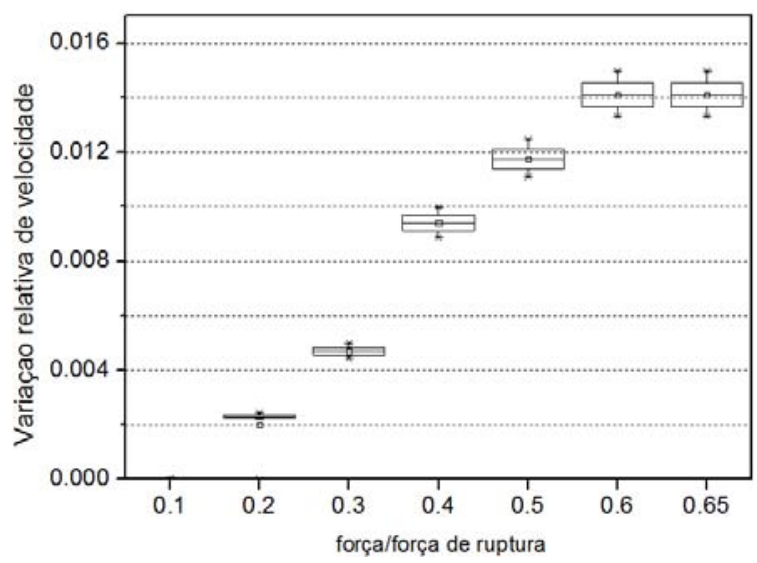

Figura 4. 26 - Dispersão de resultados para a janela de 100 us e ponto central variando entre $200 \mu \mathrm{s}$ e $225 \mu \mathrm{s}$

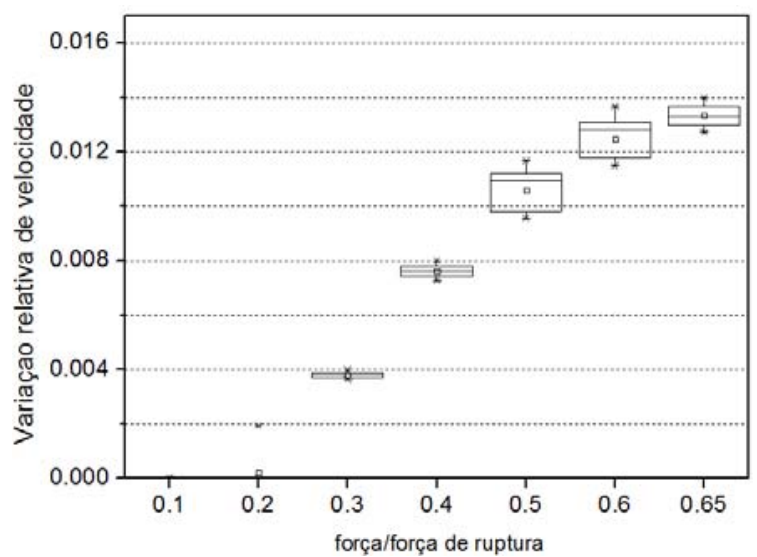

Figura 4. 28 - Dispersão de resultados para a janela de $100 \mu$ s e ponto central variando entre $250 \mu \mathrm{s}$ e $275 \mu \mathrm{s}$

O alongamento já foi usado por Sens-Schönfelder e Larose (2008) para analisar variações no solo lunar devido a eventos sísmicos; por Schurr et al. (2011) para avaliar danificação em elementos de concreto; e por Zhang et al. (2012) para avaliar o efeito acustoelástico em concreto submetido a tração.

Assim como na interferometria de cauda de onda tradicional, o alongamento também determina a variação relativa de velocidade por meio do valor máximo da função correlação cruzada. No entanto, enquanto a técnica tradicional é descrita em função do $\Delta \mathrm{t}$, que é a variação do segundo sinal do eixo do tempo, nesta variação a equação é escrita em função do fator de alongamento $\tau$, que pode ser positivo ou 
negativo. A correlação cruzada é calculada entre o primeiro sinal multiplicado por 1+ $\tau$ e o segundo sinal inalterado, conforme mostrado na equação 4.1.

$$
C C_{\left(h_{0}, h_{1}\right)}^{\left(t_{1}, t_{2}\right)}(\tau)=\frac{\int_{t_{1}}^{t_{2}} h_{0}(t(1+\tau)) \cdot h_{1}(t) d t}{\sqrt{\int_{t_{1}}^{t_{2}} h_{0}^{2}(t(1+\tau)) d t \int_{t_{1}}^{t_{2}} h_{1}^{2}(t) d t}}
$$

Onde $h_{0}$ e $h_{1}$ são os sinais obtidos antes e depois da perturbação, respectivamente, e $t_{1}$ e $t_{2}$ são os limites da janela em que a correlação cruzada é calculada. Para realizar a análise dos resultados por meio do alongamento, um código computacional foi desenvolvido utilizando a linguagem Python 3.6.0.

As informações de entrada necessárias ao funcionamento do código são os dois sinais em arquivos separados de extensão .txt, a frequência de aquisição do sinal, o fator de calibração e o tamanho da janela da correlação cruzada. É preciso determinar ainda qual os valores máximo e mínimo de fator de alongamento a serem utilizados e o incremento deste valor a cada iteração.

A cada iteração, todo o sinal é multiplicado pelo fator de alongamento adotado para aquele passo e, por interpolação linear, são encontrados os pontos intermediários que correspondem aos tempos originais. Este processo é necessário para que a correlação cruzada possa ser calculada entre o sinal dilatado e reconstruído e o outro sinal. Uma vez calculada a correlação cruzada, este valor é comparado ao máximo obtido até então para aquele ponto central. Se o valor recémcalculado for maior que o armazenado, este se torna o máximo e o valor do fator de dilatação é armazenado. Após esta comparação, o valor do fator de alongamento é incrementado e a iteração é repetida.

Os dados de saída correspondem a um arquivo de extensão .txt que relaciona cada ponto central ao longo do sinal com o fator de alongamento que gera o valor máximo da função correlação cruzada.

A análise dos resultados utilizando o alongamento é mostrado na figura 4.29 para a janela de $50 \mu$ s e ponto central entre $200 \mu$ s e $275 \mu \mathrm{s}$. A análise da dispersão dos resultados é mostrada nas figuras 4.30 a 4.32 .

Como pode ser visto na figura 4.29, os resultados obtidos com o alongamento tiveram a mesma magnitude dos resultados obtidos com a técnica tradicional da 
interferometria de cauda de onda. Por outro lado, o alongamento se mostrou vantajoso por não apresentar a mesma sensibilidade a ruídos no sinal, uma vez que não houve pontos fora da curva no intervalo estudado. Uma outra vantagem do alongamento é a sua maior precisão para perturbações pequenas. Com a técnica tradicional a variação de velocidade relativa foi igual a zero com o carregamento aplicado de $10 \%$ da força de ruptura. Com a variação do método, a análise apresentou um resultado positivo mesmo para este nível de carregamento.

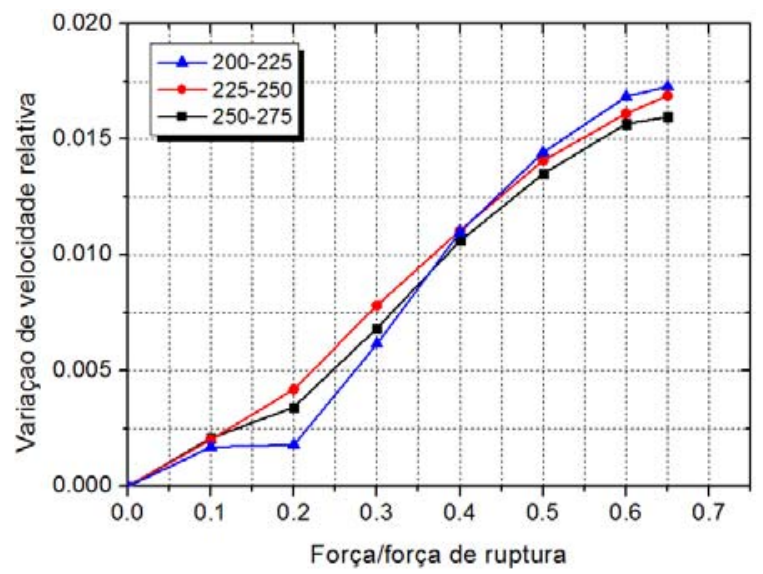

Figura 4. 29 - Resultados avaliados com o alongamento (janela de $50 \mu \mathrm{s}$ )

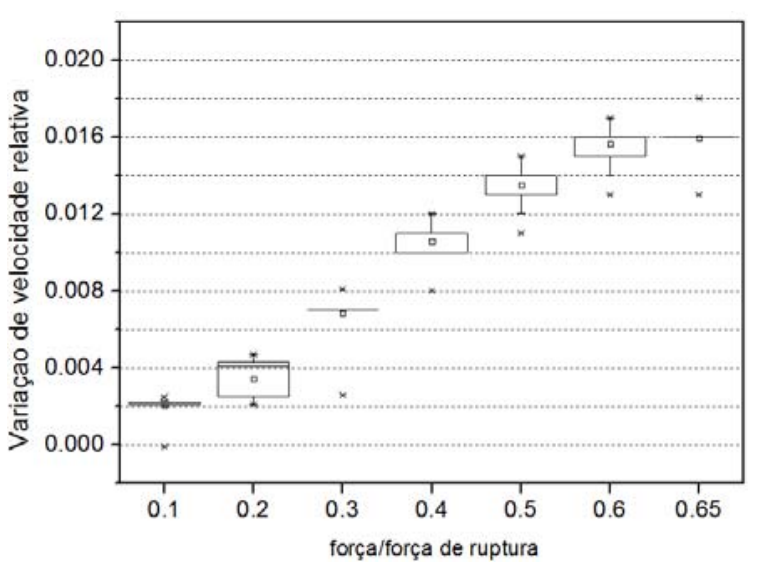

Figura 4. 30 - Dispersão de resultados com o ponto central variando entre $200 \mu$ s e $225 \mu s$

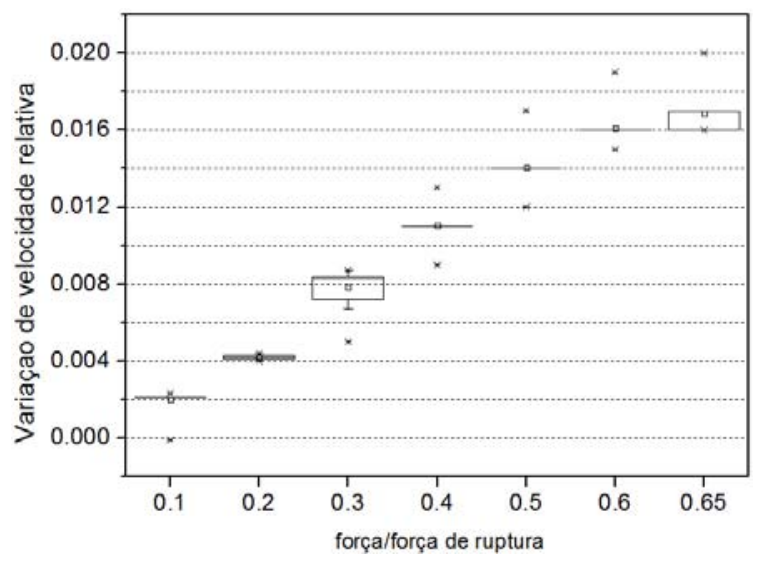

Figura 4. 31 - Dispersão de resultados com o ponto central variando entre $225 \mu$ s e $250 \mu \mathrm{s}$ 


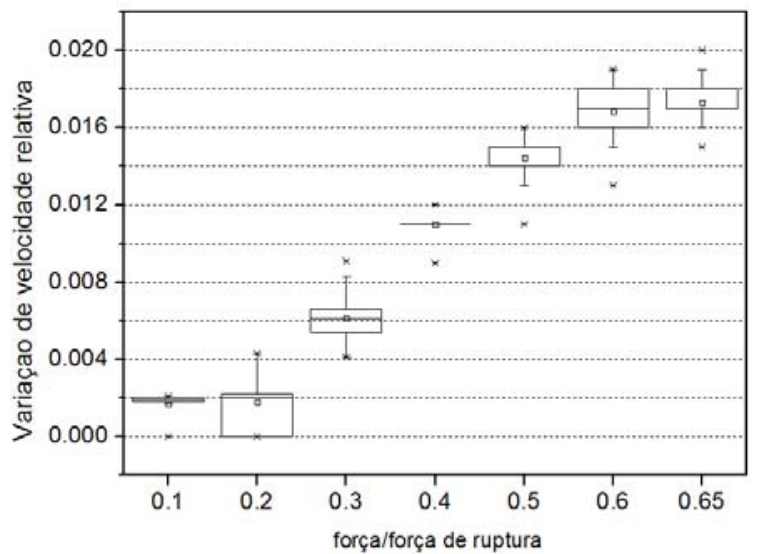

Figura 4. 32 - Dispersão de resultados com o ponto central variando entre $250 \mu$ s e $275 \mu$ s

O uso da janela de $100 \mu$ s foi desconsiderado devido ao alto tempo de processamento demandado pelo programa para realizar a análise, uma vez que o uso da janela de $50 \mu$ s exige menor tempo de processamento e já é capaz de gerar resultados satisfatórios.

Por fim, definiu-se que as análises por meio da interferometria de cauda de onda seriam feitas com a janela de $50 \mu$ s e ponto central entre $225 \mu$ s e $250 \mu s$, usando a técnica do alongamento.

\subsection{Análise de ondas longitudinais}

A análise de resultados envolvendo ondas longitudinais consistiu em identificar os tempos de chegada de cada onda, a fim de se determinar a sua velocidade e, posteriormente as variações relativas de velocidade desejadas.

Os ensaios foram realizados com transdutores de cisalhamento de $250 \mathrm{kHz}$. Logo, para que o tempo de chegada das ondas emitidas se aproximasse do tempo de chegada das ondas longitudinais, as configurações do aparelho foram ajustadas para máxima voltagem de excitação e máximo ganho, conforme sugerido por Schiavon (2015).

Para cada ponto de medida, 10 ondas longitudinais foram emitidas. A onda analisada correspondeu à média destas 10 ondas. Embora o programa Punditlink ${ }^{\circledR}$ forneça o tempo de chegada da onda, este nem sempre é preciso. As Figuras 4.33 e 4.34 mostram duas ondas emitidas em um mesmo ponto de medição. Comparando 
as duas imagens, fica claro que as duas ondas mostram o mesmo sinal, entretanto, o programa aponta tempos de chegada diferentes devido a alguma instabilidade no segundo sinal. Para evitar este problema, utilizou-se o programa desenvolvido por Schiavon (2015) para determinação do tempo correto (Figura 4.35).

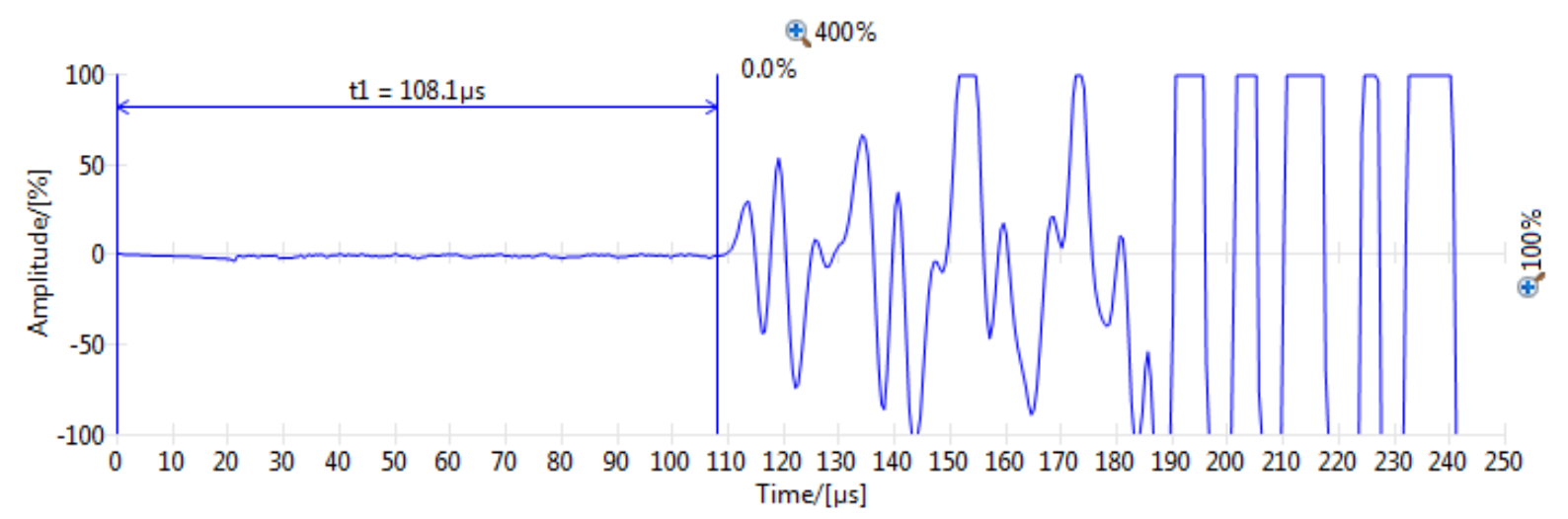

Figura 4. 33 - Onda emitida com ganho e voltagem de excitação máximos; $t=108.1 \mu \mathrm{s}$

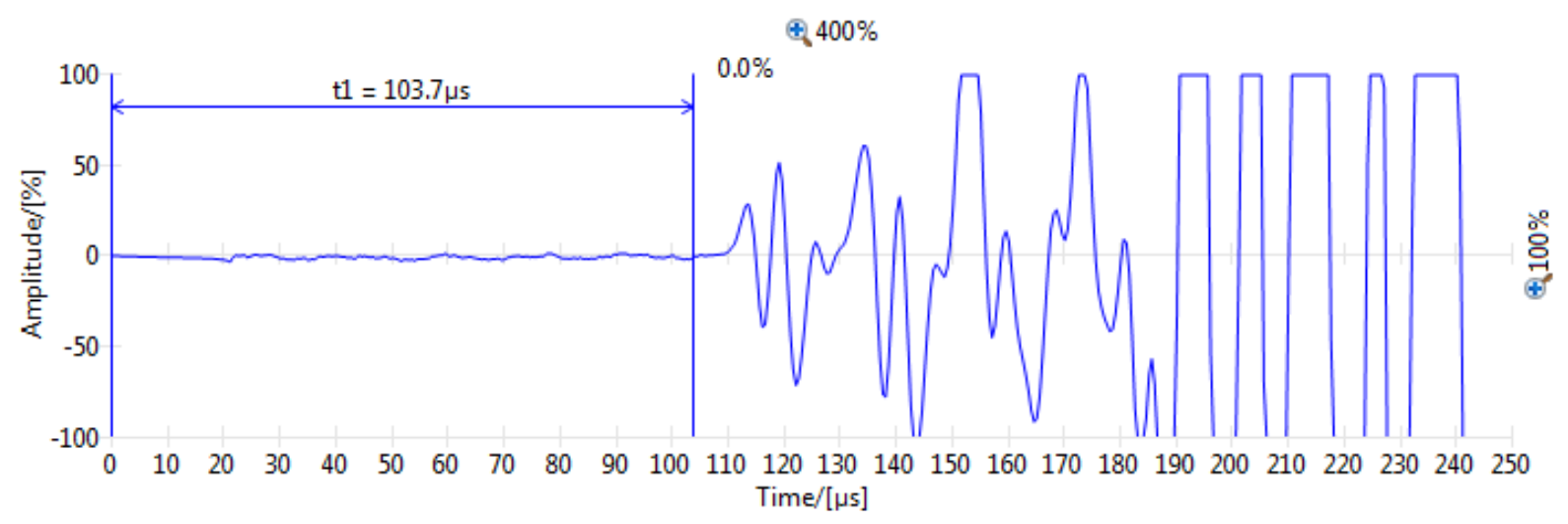

Figura 4. 34 - Onda emitida com ganho e voltagem de excitação máximos; $t=103.7 \mu \mathrm{s}$

Os arquivos de entrada necessários para a determinação do tempo de chegada das ondas longitudinais correspondem ao arquivo contendo as amplitudes do sinal na extensão .txt e ao tempo de calibração fornecido pelo aparelho de ultrassom. A saída do programa corresponde ao gráfico do sinal com linhas vermelhas e verdes indicando os possíveis tempo de chegada e a lista dos valores de tempo em que estas linhas aparecem no sinal. 


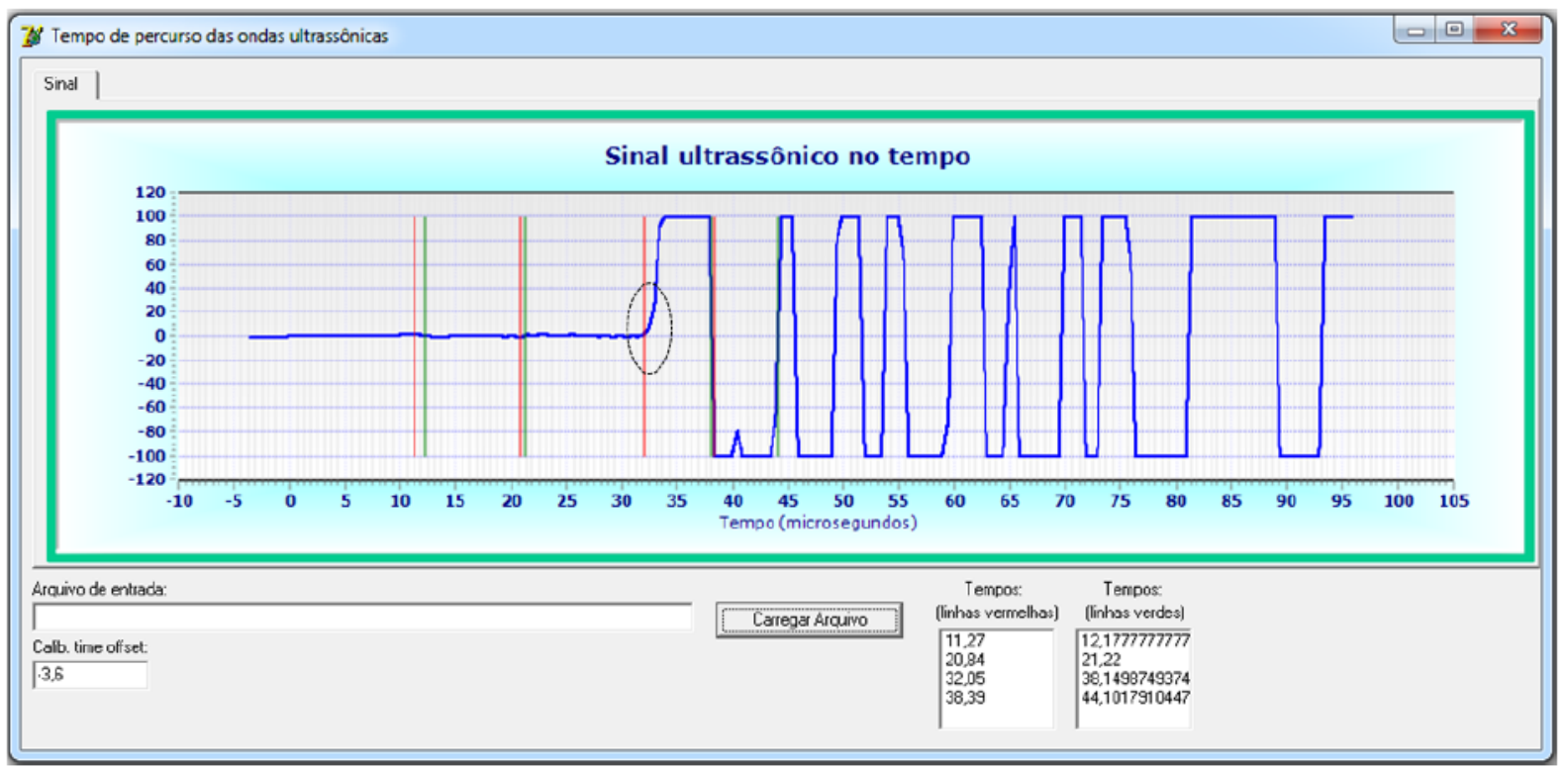

Figura 4. 35 - Interface do programa para avaliação do tempo de chegada de ondas longitudinais Fonte: Schiavon (2015)

A seguir, o funcionamento do programa de análise do tempo de percurso de ondas ultrassônicas é desenvolvido. Toda a descrição é adaptada de Schiavon (2015).

A primeira operação do programa corresponde a aumentar a quantidade de pontos do sinal. O aparelho de ultrassom utilizado tem frequência de aquisição de 2 $\mathrm{MHz}$, que equivale a um valor de amplitude a cada $0,5 \mu \mathrm{s}$. O programa cria então uma nova lista de pontos de amplitude a cada 0,1 $\mu$ s. Os pontos são obtidos por interpolação linear entre os pontos medidos. Esta nova lista é chamada "amplitude 2".

A partir da lista "amplitudes 2", uma nova lista chamada "absoluto" é gerada. Nesta lista, são gravados os módulos do sinal "amplitude 2". A seguir, é criada uma lista com o mesmo número de elementos de "amplitudes 2" e "absoluto" e esta é preenchida com zeros.

Para cada posição (i) da lista, o valor de "auxiliar" [i-1] é comparado ao de "absoluto" [i]; o valor de "auxiliar" [i] é então definido como o maior dos dois valores. Deste modo, o vetor auxiliar mostra o valor de amplitude máximo já apresentado pelo sinal até aquele tempo.

Elabora-se então o vetor "derivada", que calcula e grava os valores da derivada do vetor auxiliar, de acordo com a equação 4.2.

$$
\text { derivada }[i]=\frac{\text { auxiliar }[i+1]-\text { auxiliar }[i]}{0,01}
$$


Podemos perceber que o vetor derivada só vai apresentar valores não nulos quando o valor de auxiliar[i+1] for diferente de auxiliar[i]. Logo, o vetor derivada mostra em quais pontos o sinal atinge um novo valor máximo de amplitude ao longo do tempo. A princípio, todos os pontos que aparecem no vetor "derivada" são candidatos a pontos de chegada da onda. No entanto, logo após a chegada da onda, há uma sucessão de valores de amplitude crescentes e não seria correto que o programa marcasse todos os pontos sequenciais como possíveis tempos de chegada. Portanto, os valores de derivada são agrupados sempre que houver mais de um valor positivo em sequência e apenas o primeiro da sequência é marcado como possível tempo de chegada.

Por fim, é emitida a lista com todos os possíveis tempos de chegada e os mesmos são marcados por uma linha vermelha na representação gráfica do sinal. Para cada linha vermelha, é marcada também uma linha verde, que representa o primeiro ponto no tempo após a linha vermelha em que a amplitude do sinal se tornou igual a zero. Os pontos no tempo em que a linha verde é marcada também são listados. 


\section{RESULTADOS}

Neste capítulo, foram apresentados os resultados obtidos após a execução do plano experimental e suas respectivas discussões. O capítulo foi dividido em três partes: a primeira subdivisão abordou os resultados obtidos com a segunda etapa de ensaios; a segunda e a terceira partes trouxeram as discussões acerca dos ensaios da terceira etapa e a tentativa de quantificar a danificação nas amostras por meio de um Índice de Dano proposto.

A solicitação em todos os experimentos realizados foi definida como uma porcentagem da tensão de ruptura. Portanto, antes da realização dos ensaios de Velocidade de Pulso Ultrassônico, foi necessário definir a tensão de ruptura das amostras (Tabela 5.1). Para obtenção da resistência média de cada traço, três prismas de $15 \mathrm{~cm} \times 15 \mathrm{~cm} \times 50 \mathrm{~cm}$ foram comprimidos até a ruptura com o auxílio da máquina servo-hidráulica. Os ensaios de compressão foram realizados aos 28 dias

\begin{tabular}{ccc}
\multicolumn{3}{c}{ Tabela 5. 1 Resistência de cada traço (28 dias) } \\
\hline \multirow{2}{*}{ Traço } & $\begin{array}{c}\text { Resistência } \\
\text { esperada (MPa) }\end{array}$ & $\begin{array}{c}\text { Resistência obtida } \\
\text { (MPa) }\end{array}$ \\
\hline 1 & 39,61 & 29,53 \\
2 & 50,35 & 30,62 \\
3 & 29,08 & 23,16 \\
\hline
\end{tabular}

A opção por prismas com as mesmas dimensões dos que seriam ensaiados posteriormente se deve à influência da geometria da amostra sobre a resistência à compressão. Na referência, as amostras ensaiadas eram cilíndricas de dimensões $\phi 10 \mathrm{~cm} \times 20 \mathrm{~cm}$. Nos prismas, a geometria desfavorece a resistência devido à maior esbeltez da amostra. Além disso, os prismas são moldados com o concreto sendo lançado lateralmente (Figura 5.1), enquanto os cilindros são preenchidos longitudinalmente. Com isso, ocorre maior exsudação em uma das faces laterais do prisma, aumentando a não-linearidade do material. Portanto, há uma maior flexocompressão no prisma que no cilindro e daí a ruptura com uma tensão menor. 
A importância de se definir corretamente a tensão de ruptura da amostra em ensaio se deve ao fato de que a resposta acustoelástica é investigada em função da razão entre a força aplicada e a de ruptura.

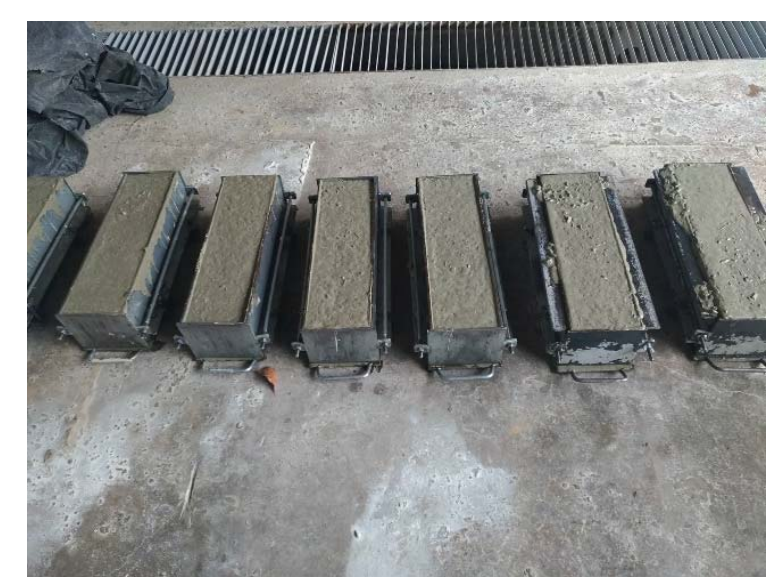

Figura 5. 1 - Prismas após a concretagem

\subsection{Segunda etapa de ensaios}

Este experimento objetivou esclarecer o comportamento do concreto após sofrer um carregamento, a fim de identificar a variação relativa de velocidade causada pela danificação reversível. Neste ensaio, foi analisada apenas a onda de cisalhamento emitida na direção do carregamento. Todos os resultados apresentados foram obtidos com a janela de $50 \mu$ s e ponto central variando entre $225 \mu$ s e $250 \mu \mathrm{s}$.

A figura 5.2 mostra os resultados obtidos com o primeiro ensaio desta etapa. As amostras foram submetidas a 24 horas de carregamento constante. As variações de velocidade mostradas na figura 5.2 mostram como a amostra se comportou nas primeiras 24 horas após a remoção do carregamento. A legenda indica o nível de tensão ao qual a amostra havia sido submetida nas 24 horas anteriores, em relação à tensão de ruptura. 


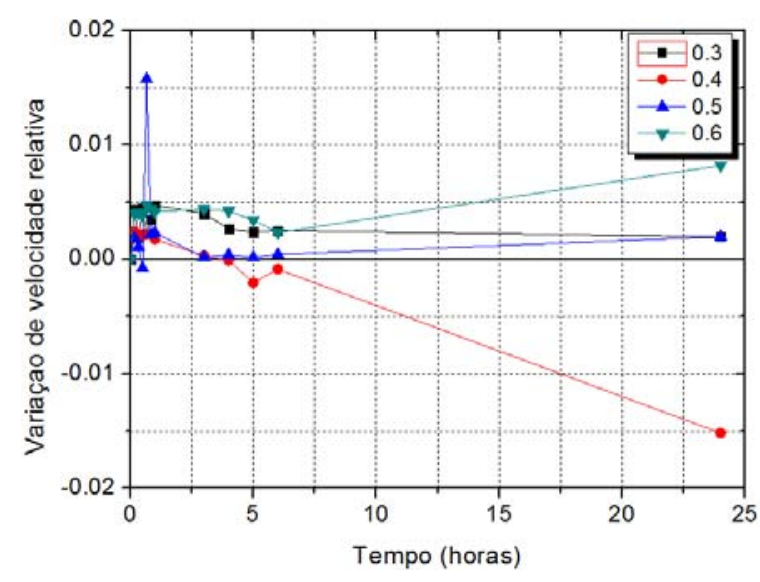

(a)

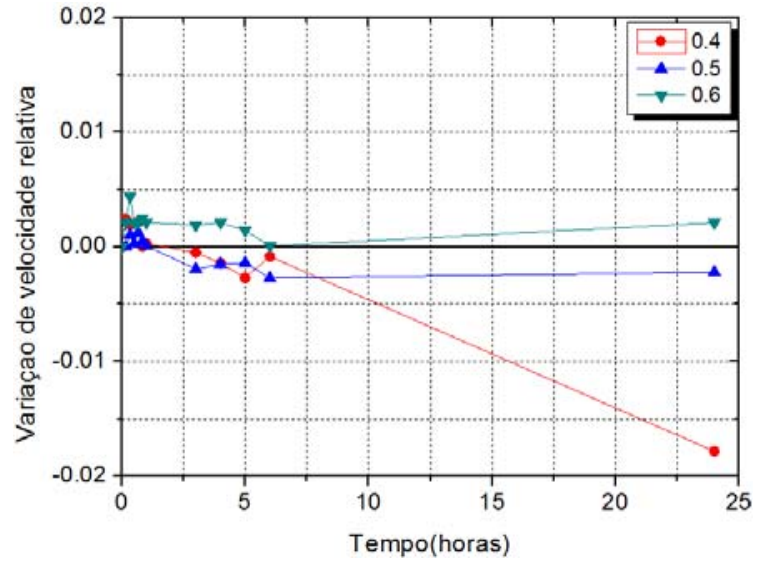

(b)

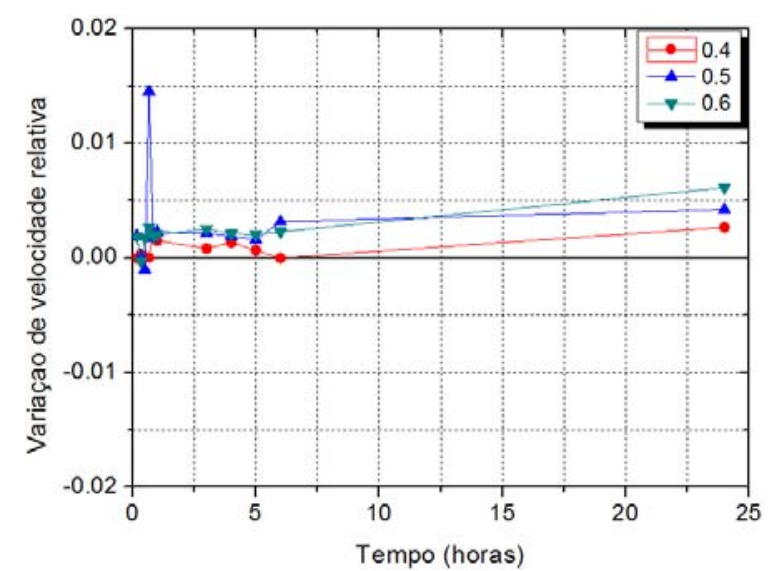

(c)

Figura 5. 2 - Resultados obtidos no Ensaio 1: (a) variação de velocidade sem correção; (b) variação de velocidade obtida no controle; e (c) variação de velocidade com correção

Após a realização deste ensaio para o carregamento de $30 \%$ da tensão de ruptura, verificou-se a necessidade de avaliar a influência da variação das condições ambientais sobre o resultado do ensaio.

As condições de umidade e temperatura têm influência sobre a Velocidade de Pulso Ultrassônico e a cidade de São Carlos se caracteriza pela grande amplitude térmica diária, que pode ultrapassar $15^{\circ} \mathrm{C}$ (VASCONCELOS, SOUZA e TEIXEIRA, 2013).

O aumento da temperatura ambiente diminui a velocidade de pulso ultrassônico por provocar microfissuração no concreto. Por outro lado, a variação da umidade ambiente gera variação no preenchimento dos poros do concreto; sendo a velocidade do som maior na água que no ar, um aumento na umidade gera um aumento na velocidade de propagação da onda no concreto. Embora estes efeitos sejam pequenos e tenham ordem de $10^{-2}$, segundo Bungey, Millard e Grantham (2006), os mesmos precisam ser considerados uma vez que a recuperação do dano provoca 
uma variação relativa de velocidade de ordem $10^{-3}$, conforme pode ser visto na Figura 5.2 .

Logo, nos ciclos de carregamento subsequentes, o ensaio de VPU foi realizado simultaneamente em um prisma descarregado, a fim de ser utilizado como controle. Os resultados obtidos com o prisma de controle e a correção do ensaio são mostrados nas figuras $5.2 \mathrm{~b}$ e $5.2 \mathrm{c}$.

Após a realização do ensaio de VPU no corpo de prova de controle, foi possível observar que as variações de temperatura e umidade são significativas em comparação com a variação devido à recuperação do dano. Uma vez realizada a correção da variação de velocidade considerando o controle, observou-se que a variação de velocidade é praticamente constante nas primeiras horas após a remoção do carregamento e é ligeiramente maior no tempo de $24 \mathrm{~h}$. No entanto, não é possível afirmar que esta relação é linear entre as 6 h e 24 h. Logo, no segundo ensaio, foram efetuados mais pontos de medição. A Figura 5.3 mostra os resultados obtidos neste ensaio.

As variações de umidade e temperatura alteram a velocidade de propagação por agirem sobre a microestrutura do concreto. Durante o primeiro ensaio, utilizou-se um prisma íntegro como controle, entretanto, especulou-se que a magnitude da ação das condições ambientais sobre a velocidade de propagação poderia variar entre o corpo de prova íntegro e o danificado pelo ensaio.

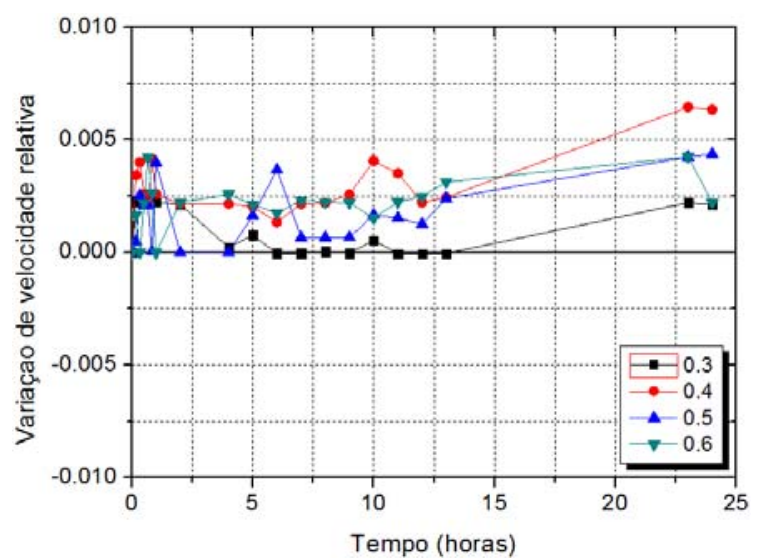

(a) 


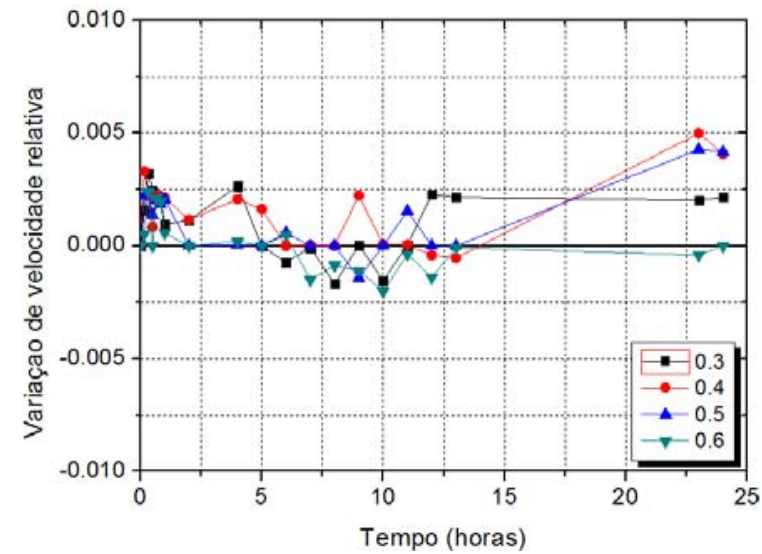

(b)

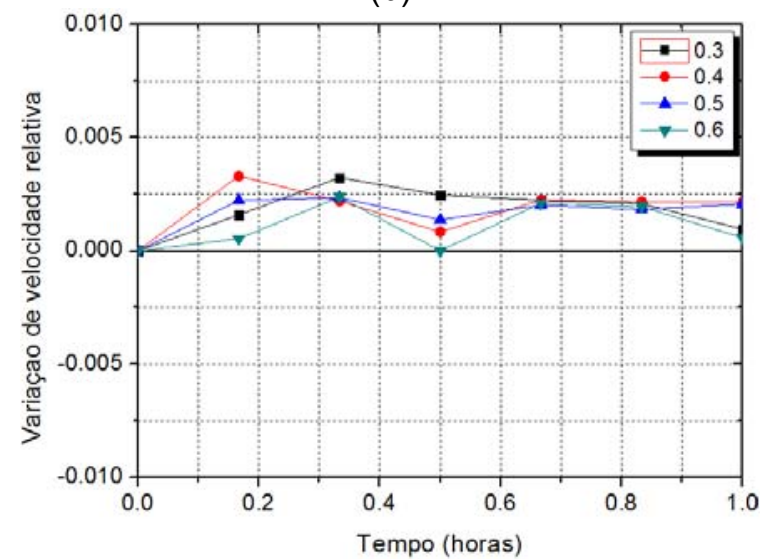

(d)

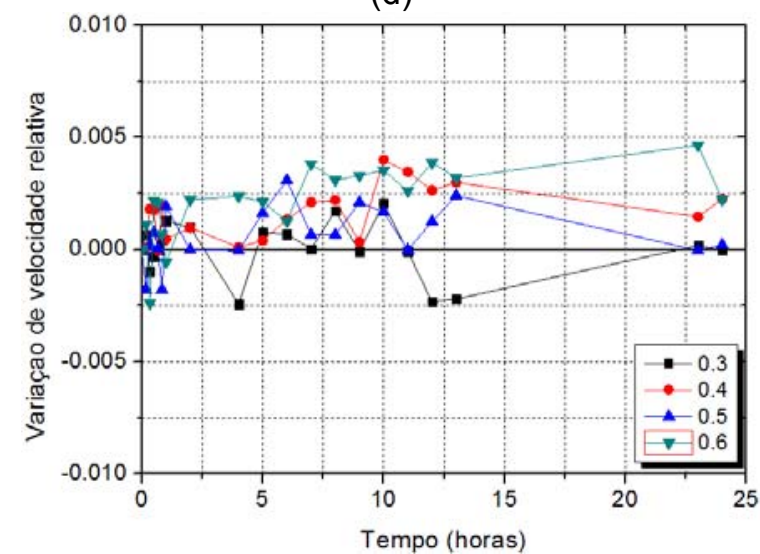

(f)

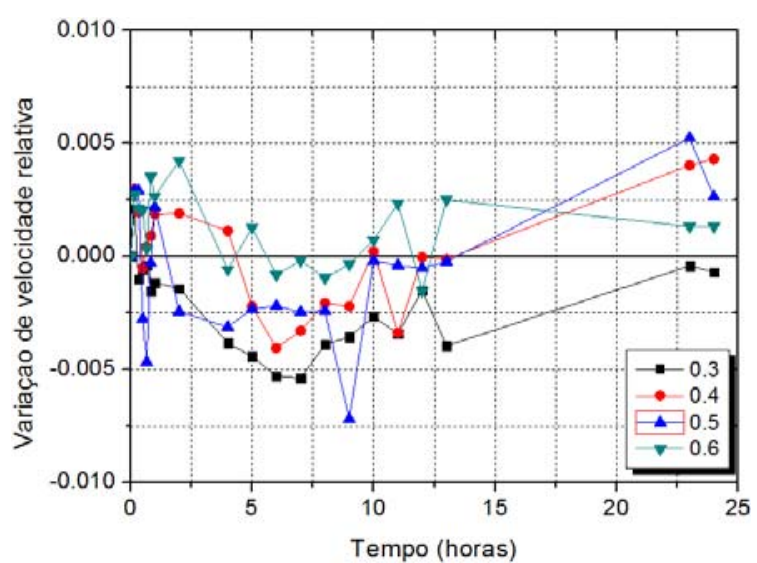

(c)

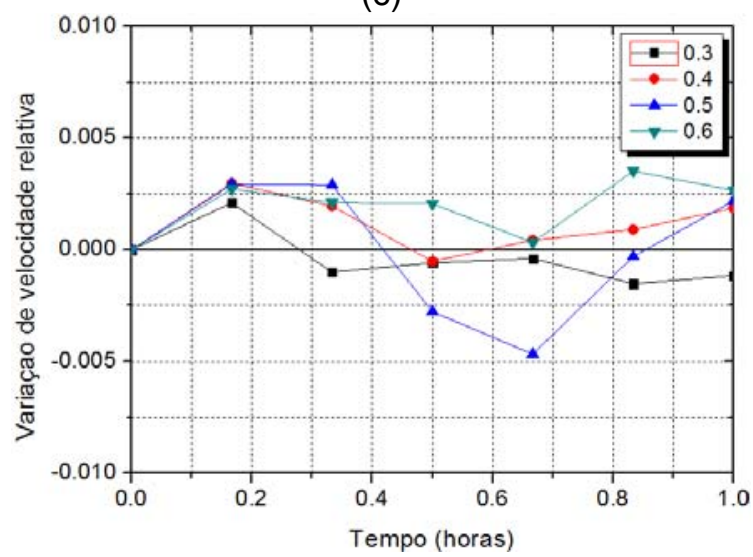

(e)

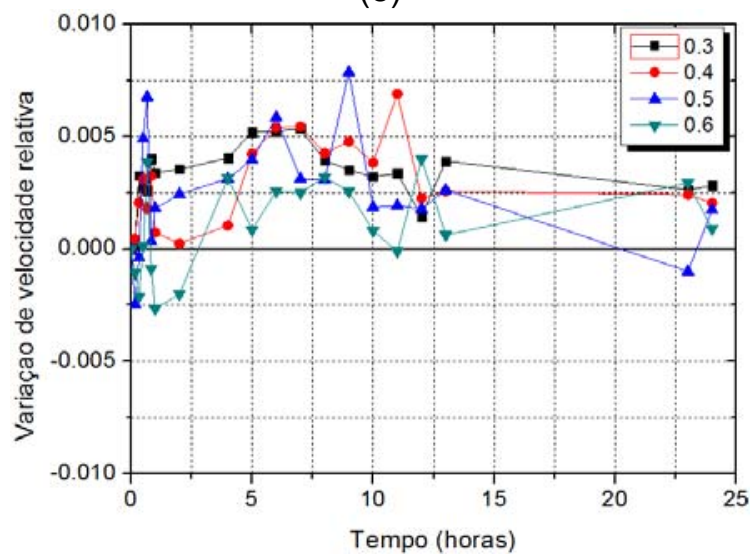

(g)

Figura 5. 3 - Resultados obtidos no Ensaio 2: (a) variação de velocidade sem correção; (b) variação de velocidade obtida no controle íntegro: (c) variação de velocidade obtida no controle danificado; (d) detalhe da variação de velocidade obtida no controle íntegro; (e) detalhe da variação de velocidade obtida no controle danificado; (f) variação de velocidade com correção (controle íntegro); e (g) variação de velocidade com correção (controle danificado)

A variação de velocidade devido ao aumento da temperatura deveria ser menor na amostra danificada, uma vez que a microfissuração seria desprezível em comparação ao dano causado pelo carregamento. Por outro lado, a variação devido a umidade seria maior no elemento danificado, uma vez que o mesmo seria mais poroso que o íntegro. Logo, com o objetivo de aproximar as condições da amostra de 
controle do prisma em ensaio, foram adotados um controle íntegro e um controle já danificado (prisma utilizado no primeiro ensaio).

As figuras $5.3 \mathrm{~b}$ e $5.3 \mathrm{c}$ mostram os resultados obtidos com os controles íntegro e danificado. Comparando estas figuras, é possível perceber que as variações do ambiente tiveram uma influência maior sobre o controle danificado que sobre o controle íntegro. Isto indica que a abertura de fissuras devido ao carregamento e, consequentemente, a maior porosidade potencializam a variação relativa de velocidade devido a variações climáticas.

As figuras 5.3d e 5.3e mostram o detalhe da variação de velocidade nos prismas de controle durante a primeira hora de ensaio.

Analisando os detalhes das Figuras 5.3d e 5.3e, vemos que, em um intervalo de tempo de 20 minutos, a variação relativa de velocidade chegou a 0.00323 no controle íntegro e a 0.00757 no controle danificado. Bungey, Millard e Grantham (2006) afirmam que a velocidade de propagação pode ser até 5\% maior em um concreto saturado comparado a um concreto seco. Portanto, assumindo uma relação linear, uma variação de $0,7 \%$ na velocidade de propagação significaria uma variação de $15 \%$ na umidade ambiente em cerca de 20 minutos.

Observando as Figuras 5.3f e 5.3g, não é possível distinguir uma tendência de comportamento entre as curvas traçadas para cada nível de carregamento. Era esperado que, com a retirada do carregamento, parte do dano fosse recuperado e a velocidade de propagação aumentasse.

Este ensaio foi realizado sem monitoração dos deslocamentos ocorridos no corpo de prova. Logo, é possível que, após a remoção do carregamento, parte do deslocamento por fluência tenha sido revertido e o aumento da distância entre os transdutores tenha interferido com os resultados. Embora a variação da distância devido ao deslocamento seja desprezível quando o efeito acustoelástico é avaliado, este valor pode ser significativo em comparação ao estudado neste ensaio.

É necessário discutir também a precisão do aparelho para realizar a medida da variação da velocidade devido à recuperação do dano. Uma variação de $10^{-3}$ avaliada com ponto central de $200 \mu$ s equivale a $0,2 \mu \mathrm{s}$, valor próximo à precisão mínima do aparelho, de 0,1 $\mu$ s. É possível que a falta de padrão identificável entre as medidas e as grandes variações de velocidade em um curto período de tempo sejam explicadas pela limitação do aparelho. 
Embora o efeito da variação das condições ambientais sobre a velocidade de pulso ultrassônico seja comparável ao da danificação reversível, o mesmo é desprezível quando comparado à variação devido à acustoelasticidade e à danificação total. A Figura 5.4 mostra as variações relativas de velocidade medidas durante o carregamento das amostras no ensaio 1 . A legenda indica a tensão à qual o material estava submetido em relação à tensão de ruptura.

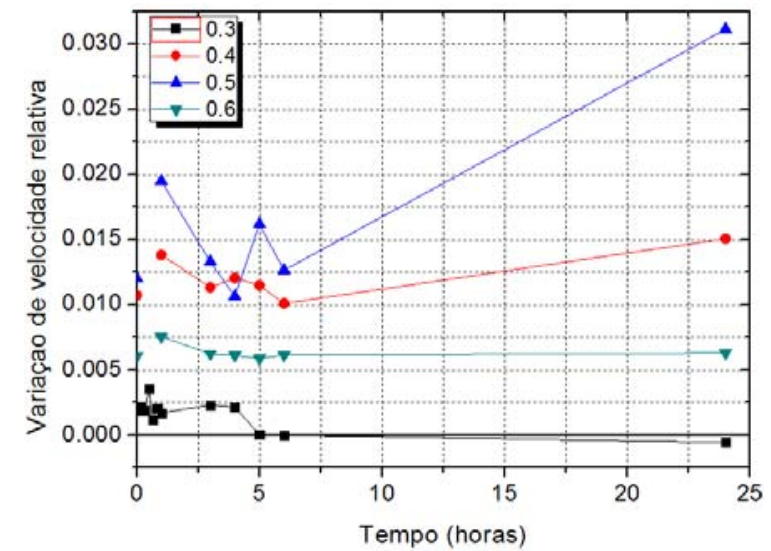

(a)

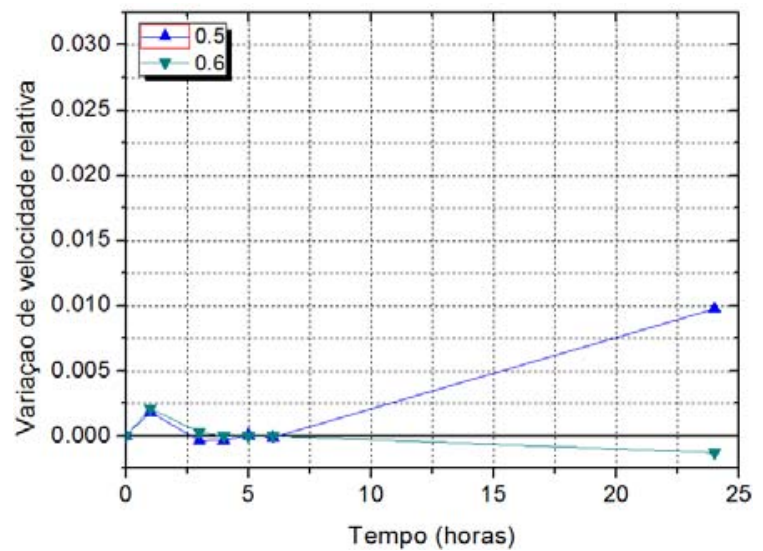

(b)

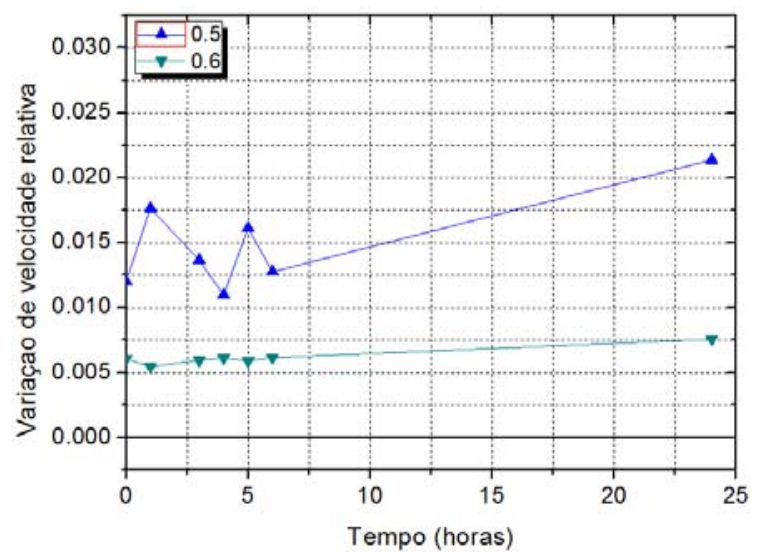

(c)

Figura 5. 4 - Resultados obtidos no Ensaio 1 durante o carregamento: (a) variação de velocidade sem correção; (b) variação de velocidade obtida no controle: (c) variação de velocidade com correção

As figuras 5.4b e 5.4c só mostram a variação de velocidade para os níveis de carregamento de $50 \%$ e $60 \%$ porque o controle só passou a ser adotado a partir do descarregamento do nível de $40 \%$ da tensão máxima suportada pelo prisma. Como pode ser visto nos gráficos, apenas quando o material estava carregado a $30 \%$ da sua tensão de ruptura, a variação de velocidade medida foi de magnitude semelhante à variação causada por fatores ambientais. A variação de velocidade no controle só mostrou valor não desprezível em um dos pontos avaliados. No caso, a variação ocorreu após 24 horas de avaliação. Portanto, podemos considerar que, para ensaios 
curtos com a amostra carregada, os efeitos da variação de temperatura e umidade sobre a velocidade de pulso podem ser desprezados.

\subsection{Terceira etapa de ensaios}

Inicialmente, foi mostrada a análise da influência da geometria da amostra sobre a resposta do elemento ao efeito acustoelástico. Para tanto, foram comparados três prismas de $15 \mathrm{~cm} \times 15 \mathrm{~cm} \times 50 \mathrm{~cm}$ e três cilindros de $15 \mathrm{~cm}$ de diâmetro e $50 \mathrm{~cm}$ de altura de mesmo traço.

Nesta etapa de ensaios, as variações de velocidade causadas por alterações de umidade e temperatura foram desprezadas. Embora esta etapa experimental tenha sido formada por ensaios de longa duração, a variação de velocidade foi avaliada por ciclo de carregamento. Isto é, a variação de velocidade foi calculada entre a onda obtida no nível de carregamento desejado e a onda obtida com a amostra descarregada ao fim do ciclo. Portanto, o tempo máximo de intervalo de emissão entre duas ondas comparadas foi de cerca de 45 minutos, nos últimos ciclos de carregamento.

A seguir, foram apresentados os resultados obtidos com os três prismas e três cilindros de mesmo traço. A variação relativa de velocidade foi analisada a partir da propagação de ondas longitudinais e de cisalhamento na direção do carregamento (direção 1) e da propagação de ondas longitudinais na direção perpendicular ao carregamento (direção 2). As figuras 5.5 a 5.10 mostram os resultados obtidos com a utilização de ondas longitudinais emitidas na direção 1. As figuras 5.11 a 5.16 mostram os resultados obtidos com ondas de cisalhamento emitidas na direção 1. Por fim, as figuras 5.17 a 5.20 mostram os resultados obtidos com ondas longitudinais emitidas na direção 2. 


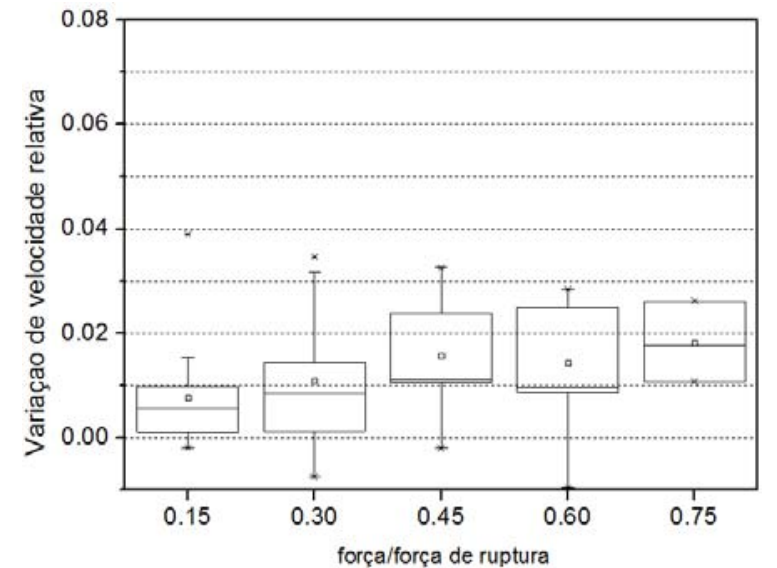

Figura 5.5 - Dispersão de resultados do prisma 1 - ondas longitudinais, direção 1

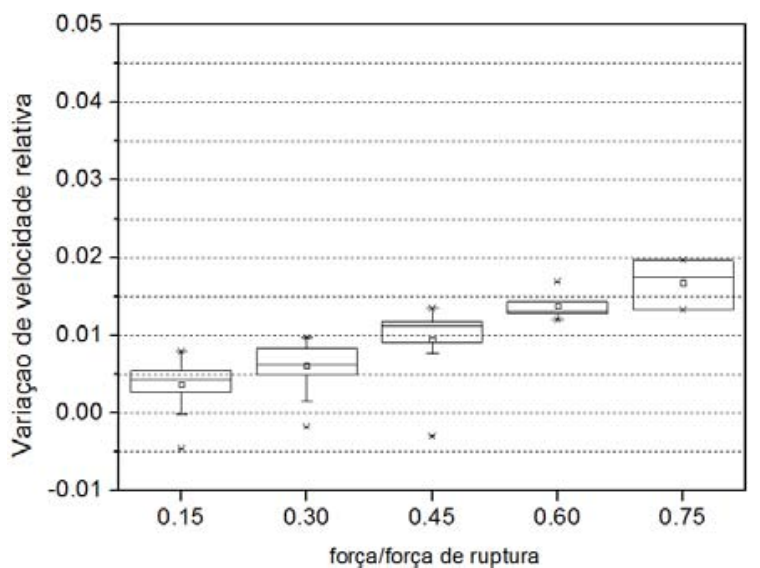

Figura 5.7 - Dispersão de resultados do prisma 2 - ondas longitudinais, direção 1

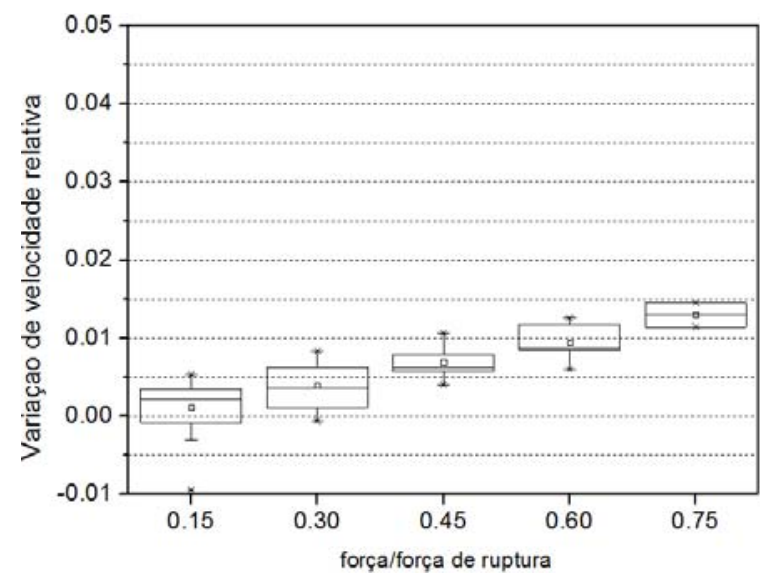

Figura 5. 9 - Dispersão de resultados do prisma 3 - ondas longitudinais, direção 1

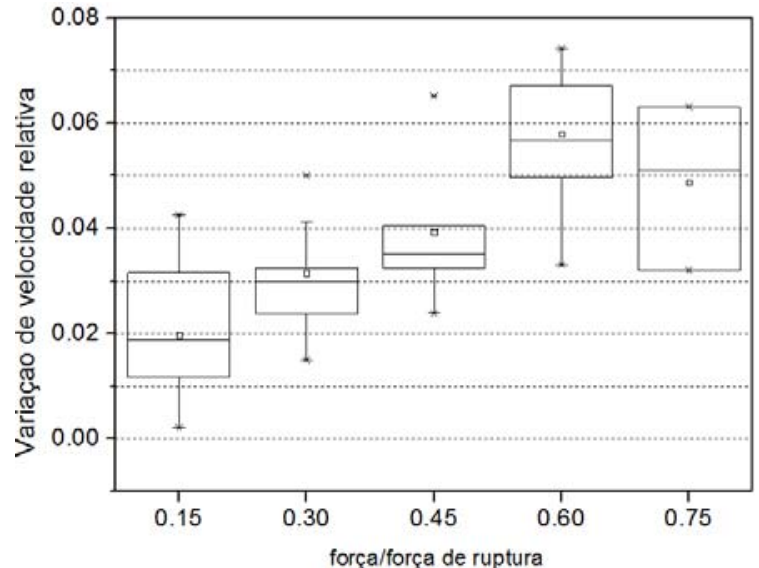

Figura 5. 6 - Dispersão de resultados do cilindro 1 - ondas longitudinais, direção 1

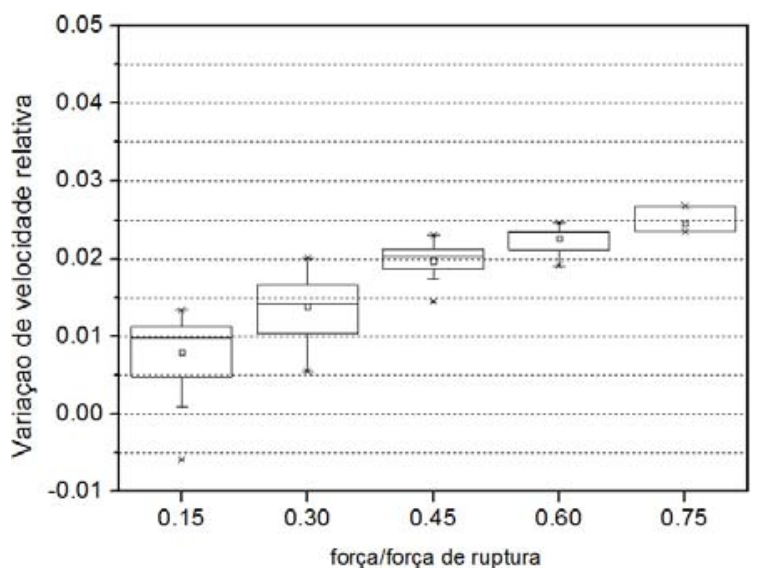

Figura 5.8 - Dispersão de resultados do cilindro 2 - ondas longitudinais, direção 1

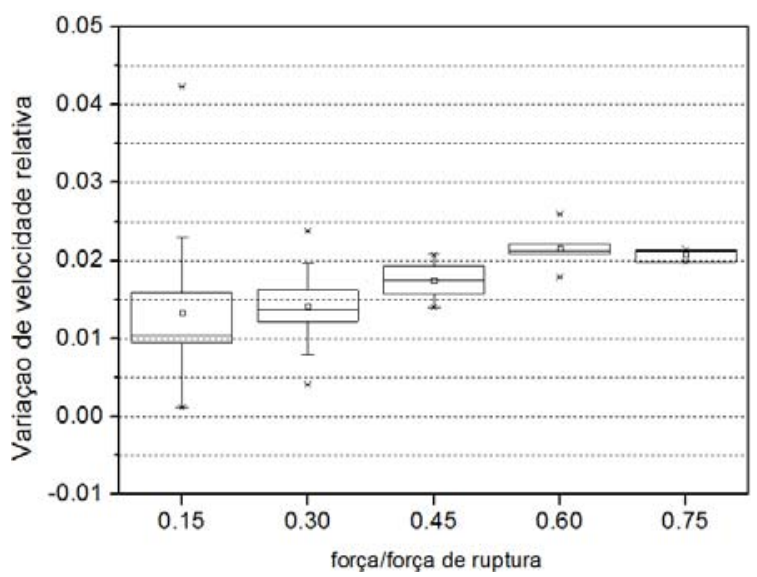

Figura 5. 10 - Dispersão de resultados do cilindro 3 - ondas longitudinais, direção 1

Durante os ensaios, foram emitidas também ondas de cisalhamento na direção 2. No entanto, não foram obtidos resultados significativos para estas ondas com a utilização da interferometria de cauda de onda. Acredita-se que isto se deva à necessidade de otimizar os valores dos parâmetros tamanho da janela e ponto central 
para este tipo de sinal. Como a direção 2 tem dimensão muito inferior à dimensão 1 , o sinal chega muito mais rapidamente e tem uma duração menor. Logo, os parâmetros da correlação têm que ser adaptados.

Analisando as figuras 5.5 a 5.10, podemos perceber que as médias das variações de velocidade tiveram aproximadamente a mesma grandeza nos prismas 2 e 3 e cilindros 2 e 3 . No prisma 1 e cilindro 1, as variações de resultados foram ligeiramente maiores. Estes dois ensaios foram feitos na máquina servo-hidráulica.

Inicialmente, todos os ensaios seriam realizados nesta máquina. No entanto, devido ao grande volume de pesquisas sendo realizadas no LE-EESC e ao tempo necessário para a execução do ensaio, optou-se por realizar os ensaios no pórtico equipado com uma célula de carga. Observou-se também que o atuador manual tinha capacidade de manter o carregamento de forma mais constante que o atuador servohidráulico sendo possível, portanto, que a diferença entre os desvios seja explicada pela diferença no atuador.

Pode ser observado que, entre os prismas, houve mais resultados negativos (inconsistentes com a teoria da acustoelasticidade) que entre os cilindros. Acredita-se que os corpos-de-prova cilíndricos apresentam uma melhor distribuição de tensões que os corpos-de-prova prismáticos e que isso provoque a melhor resposta ao efeito acustoelástico.

Por fim, é importante destacar que, em algumas amostras, a variação entre o primeiro e o terceiro quartil nos gráficos aumenta conforme o carregamento aumenta. Isto se deve à forma como o ensaio foi planejado, com ciclos crescentes de carregamento. Nos três primeiros ciclos, o corpo de prova foi carregado até $15 \%$ de sua tensão de ruptura e, portanto, a velocidade de pulso ultrassônico foi medida apenas para este nível de carregamento. Nos três ciclos seguintes, o corpo de prova foi carregado até $30 \%$ da tensão de ruptura e, portanto, o ensaio de VPU foi realizado para os níveis de carregamento de $15 \%$ e $30 \%$ e assim sucessivamente. O gráfico mostra a média dos valores encontrados para a variação relativa de velocidade em cada dos pontos em que o ensaio foi realizado.

Logo, o gráfico mostra a distribuição de 15 valores de variação de velocidade relativa para carregamento de 15\%, 12 valores para o carregamento de $30 \%, 9$ valores para o carregamento de $45 \%, 6$ valores para o carregamento de $60 \%$ e 3 valores para o carregamento de $75 \%$. 
A partir dos gráficos mostrados nas figuras 5.11 a 5.16 , podemos observar que a tendência de comportamento apresentado nos ensaios é similar ao comportamento bilinear registrado por Shokouhi, Zoëga e Wiggenhauser (2010), com uma declividade maior até cerca de $45 \%$ da tensão de ruptura.

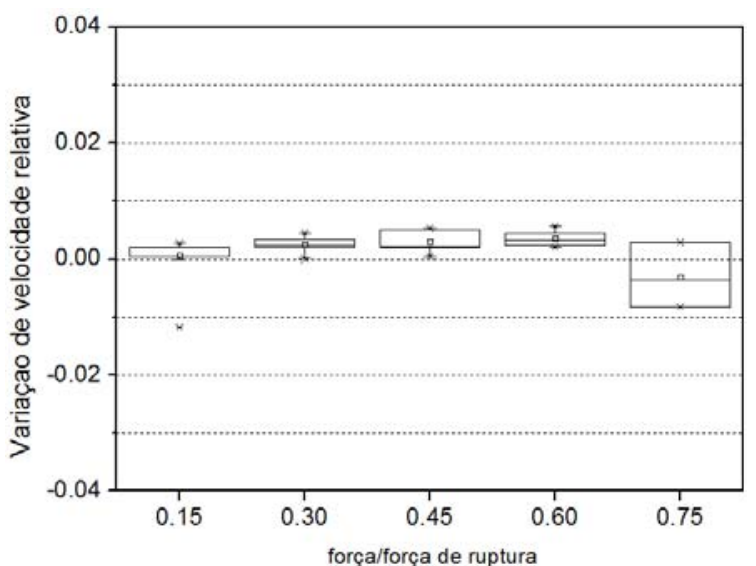

Figura 5. 11 - Dispersão de resultados do prisma 1 - ondas de cisalhamento, direção 1

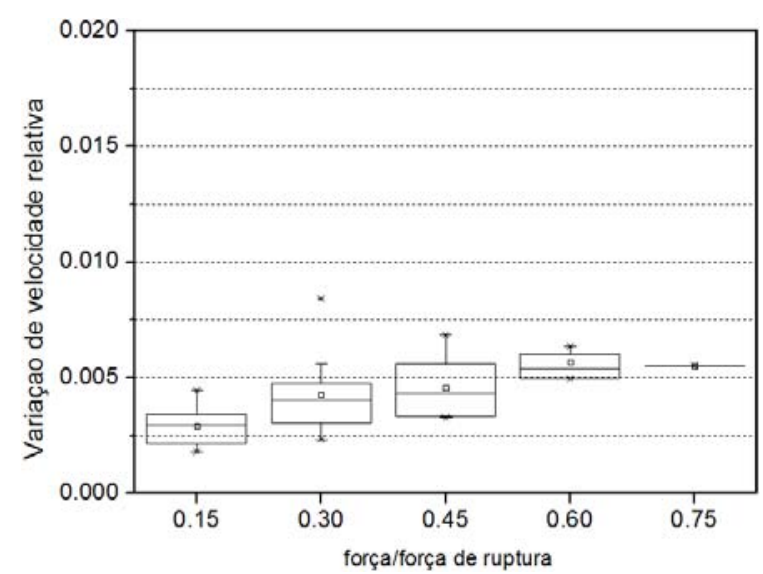

Figura 5. 13 - Dispersão de resultados do prisma 2 - ondas de cisalhamento, direção 1

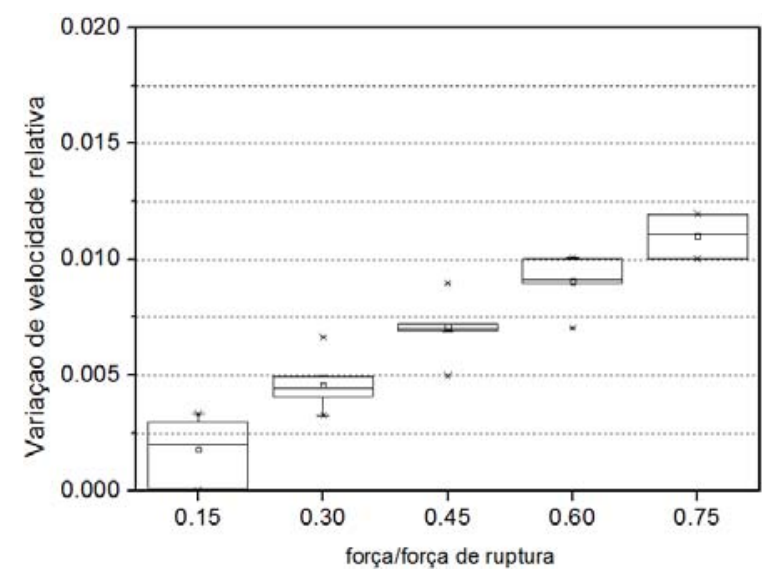

Figura 5. 15 - Dispersão de resultados do prisma 3 - ondas de cisalhamento, direção 1

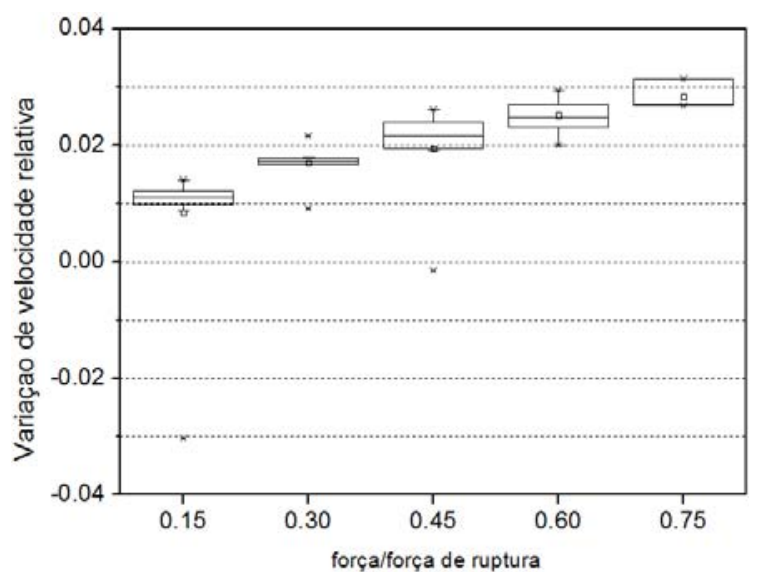

Figura 5. 12 - Dispersão de resultados do cilindro 1 - ondas de cisalhamento, direção 1

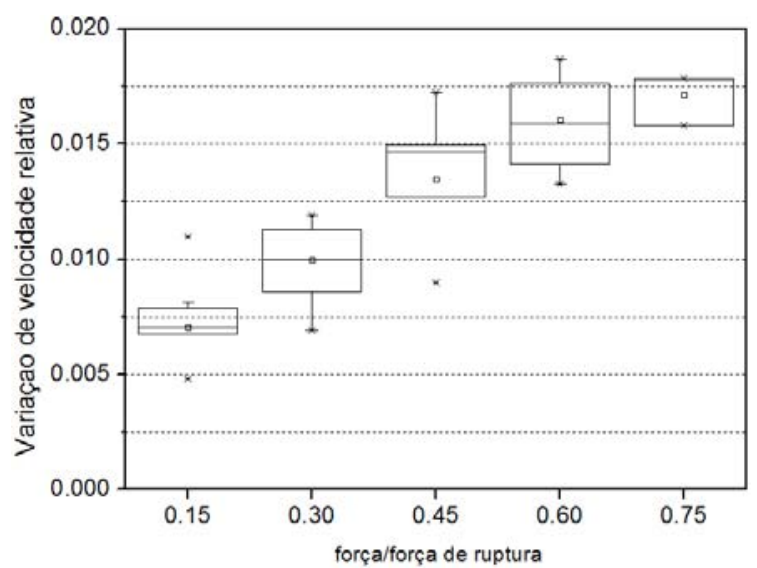

Figura 5. 14 - Dispersão de resultados do cilindro 2 - ondas de cisalhamento, direção 1

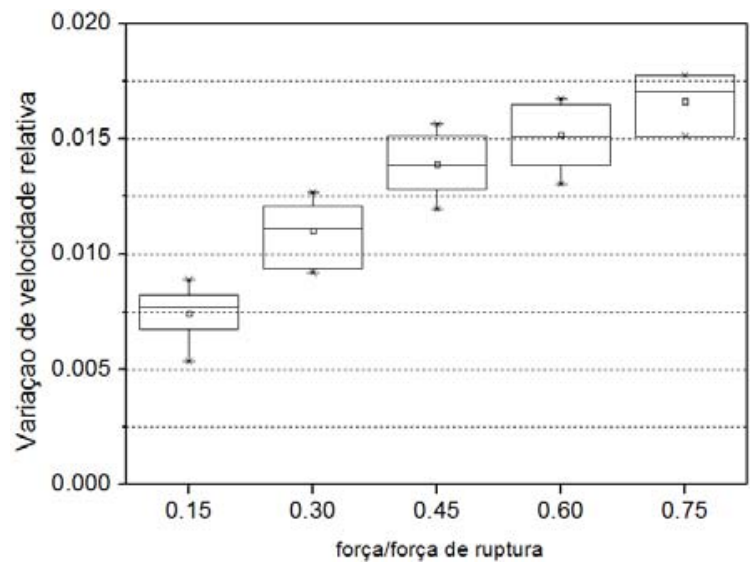

Figura 5. 16 - Dispersão de resultados do cilindro 3 - ondas de cisalhamento, direção 1 
Embora os prismas e os cilindros tenham apresentado variações de velocidade de mesma ordem de grandeza $\left(10^{-2}\right)$, de modo geral, a variação de velocidade foi maior nos cilindros que nos prismas. É possível que essa diferença ocorra devido à diferença na distribuição de tensões devido à forma do corpo-de-prova.

Em comparação aos resultados obtidos com ondas longitudinais, é possível perceber que as ondas de cisalhamento apresentam variação relativa de velocidade ligeiramente menor, porém as medidas possuem menor variabilidade. É possível perceber também que o comportamento das curvas é mais parecido entre os vários cilindros e prismas quando a onda estudada é a de cisalhamento.

As ondas longitudinais são mais sensíveis ao efeito acustoelástico que as ondas de cisalhamento, por terem direção de propagação e vibração iguais à direção de carregamento. Portanto, é esperado que a variação de velocidade seja maior com este tipo de onda. Porém, o comportamento da onda não justifica que os resultados obtidos com estas ondas tenham maior variabilidade que os obtidos com ondas de cisalhamento.

A análise da variação de velocidade de ondas longitudinais consiste em encontrar o tempo exato de chegada da onda, para assim obter o valor da velocidade. Por outro lado, a análise da variação relativa de velocidade das ondas de cisalhamento é feita diretamente pela interferometria de cauda de onda. Acredita-se que a menor discrepância nos resultados das ondas de cisalhamento se deva à menor variabilidade do método de ensaio.

Como pode ser observado nas figuras 5.17 a 5.20 , as análises obtidas com as ondas longitudinais emitidas na direção 2 tiveram menor variação de velocidade que as ondas longitudinais emitidas na direção do carregamento. Este comportamento era esperado, uma vez que o efeito acustoelástico é mais influente quando a direção de propagação e a de vibração da onda são iguais à direção de carregamento.

É possível perceber também que a variabilidade dos resultados foi maior nos cilindros que nos prismas. Uma possível explicação para este fenômeno é a maior dificuldade em posicionar o transdutor devido à forma do cilindro. No prisma, a lateral da amostra é plana e toda a face do transdutor entra em contato com o concreto. No cilindro, apenas uma parte do transdutor fica em contato com o concreto e mesmo a inclinação do transdutor pode influenciar significativamente a variação de velocidade, uma vez que a distância percorrida e a variação no tempo de chegada da onda são muito pequenas. 


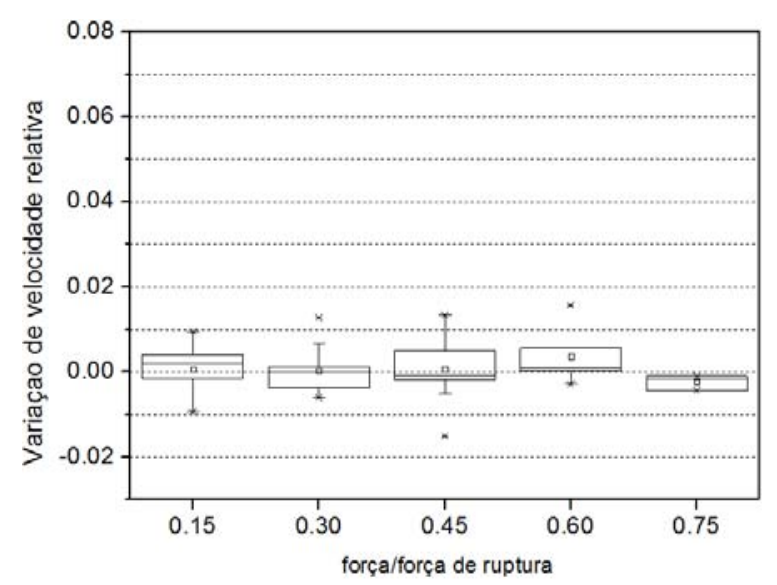

Figura 5. 17 - Dispersão de resultados do prisma 2 - ondas longitudinais, direção 2

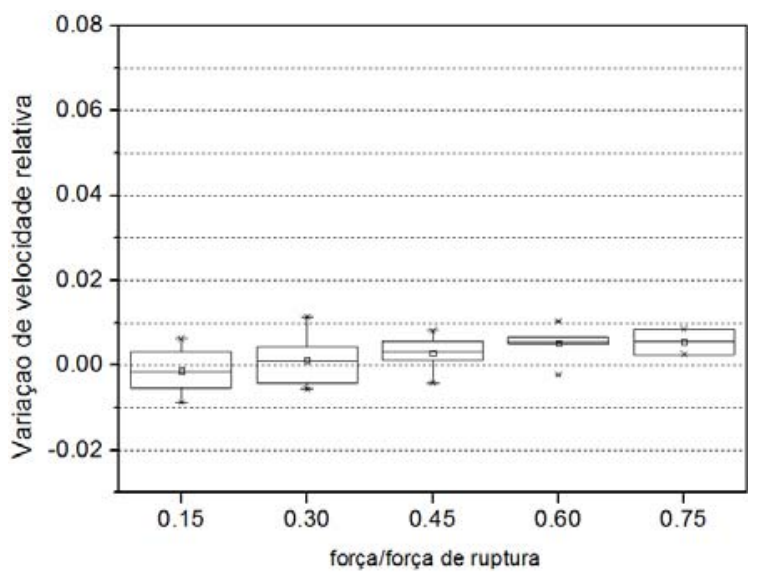

Figura 5. 19 - Dispersão de resultados do prisma 3 - ondas longitudinais, direção 2

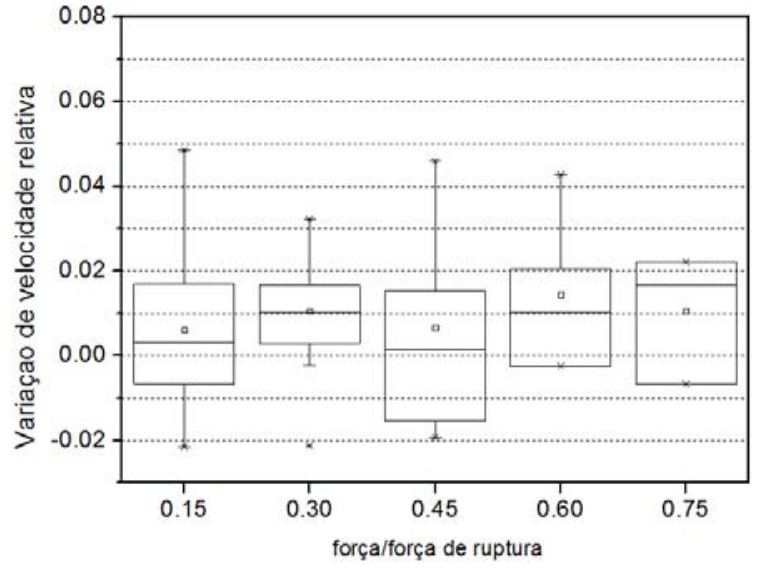

Figura 5. 18 - Dispersão de resultados do cilindro 2 - ondas longitudinais, direção 2

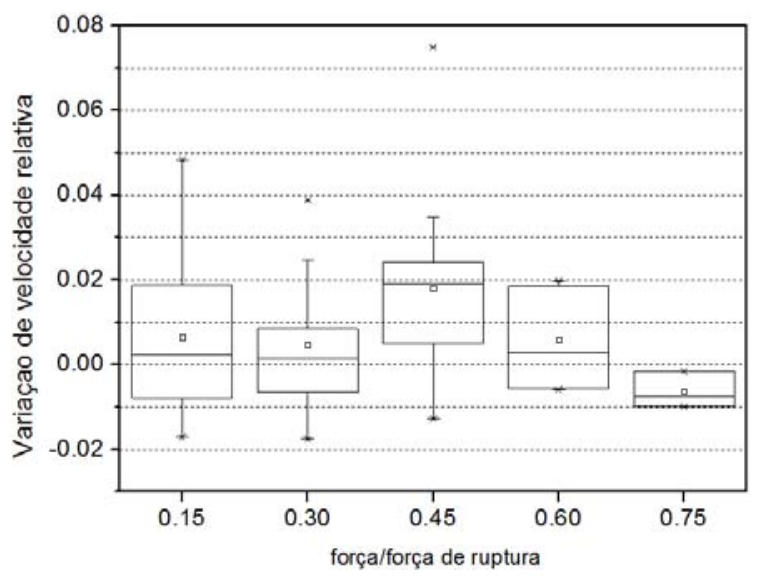

Figura 5. 20 - Dispersão de resultados do cilindro 3 - ondas longitudinais, direção 2

Nos ensaios com o cilindro 1 e o prisma 1 não foram avaliadas ondas emitidas na direção 2. Quando estes ensaios foram executados, planejava-se realizar os testes na direção 1 e 2 separadamente, a fim de que os transdutores pudessem ficar fixados ao longo do ensaio. No entanto, isto não foi possível porque, ao longo do ensaio (duração de cerca de $6 \mathrm{~h}$ ), o material utilizado para acoplamento perdia viscosidade e precisava ser substituído para que a onda fosse transmitida. Uma vez que constatouse que os transdutores não poderiam permanecer fixos, o ensaio nas duas direções foi unificado.

Uma vez realizada a análise da influência da geometria da amostra sobre o efeito acustoelástico, verificou-se que os cilindros geraram resultados mais consistentes que os prismas. Portanto, a análise da influência da composição do concreto será realizada apenas para corpos de prova cilíndricos.

As figuras 5.21 e 5.22 mostram as dispersões das análises de variação relativa de velocidade de ondas longitudinais nos cilindros dos traços 2 e 3. 


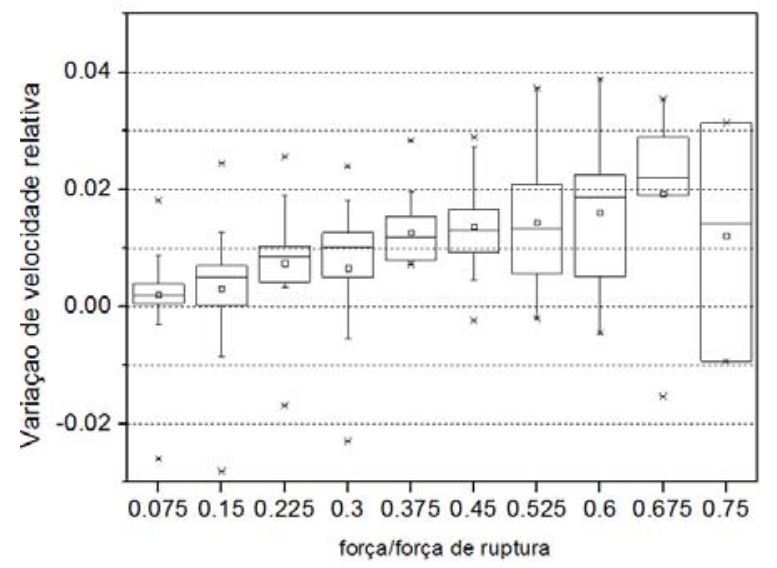

(a)

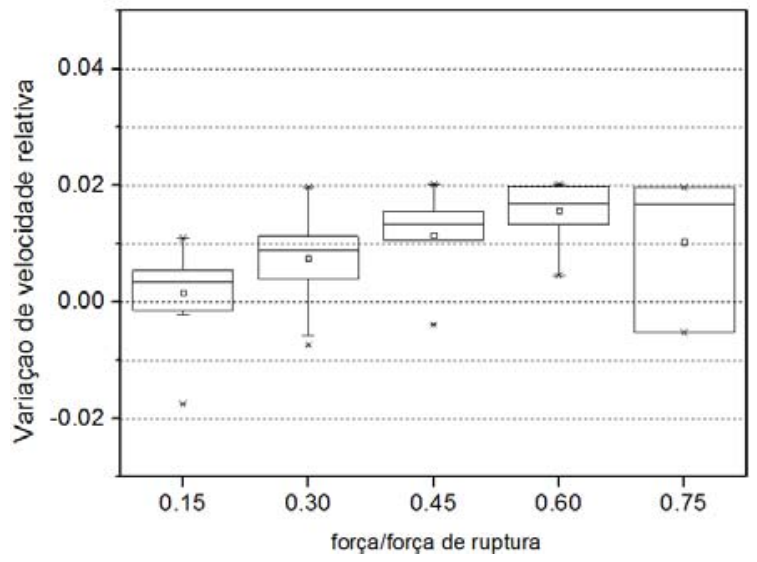

(b)

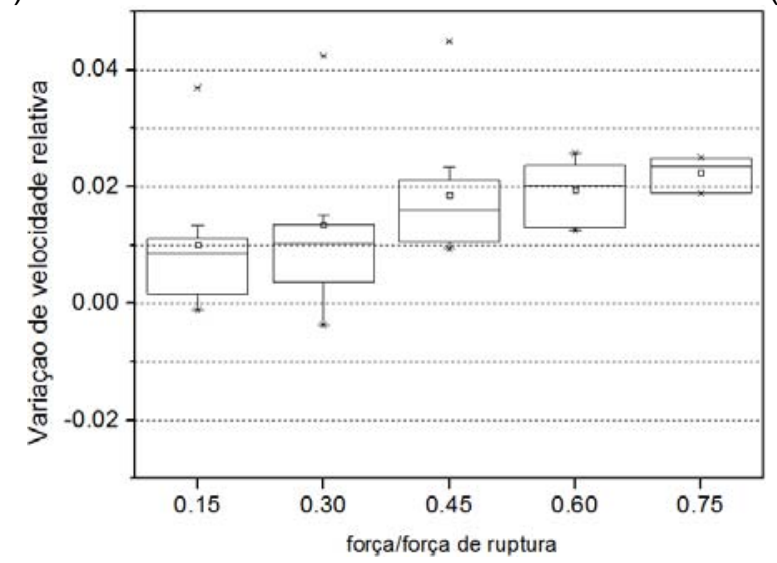

(c)

Figura 5. 21 - Dispersão de resultados para o traço 2, ondas longitudinais, direção 1: (a) cilindro 1; (b) cilindro 2; e (c) cilindro 3

Durante o ensaio do primeiro cilindro do segundo traço, houve uma tentativa de realizar mais ciclos de carregamento, a fim de se obter a variação relativa de velocidade para pontos intermediários do carregamento. O esquema de carregamento deste ensaio foi similar ao dos outros experimentos, com a repetição de 3 ciclos de carregamento a cada nível máximo de força atingido. Como foram planejadas as análises de 10 níveis de força, foram necessários 30 ciclos de carregamento e descarregamento. Este esquema não foi repetido nos ensaios subsequentes devido ao longo tempo exigido para a realização do ensaio. Enquanto os ensaios com 15 ciclos demandam um dia útil do laboratório para sua execução, o ensaio com 30 ciclos exigiu três dias para sua realização. Este tempo mais longo de execução implica em maiores variações climáticas ao longo da realização do ensaio e, portanto, insere maior variabilidade nos resultados, como pode ser visto na figura 5.21a. 


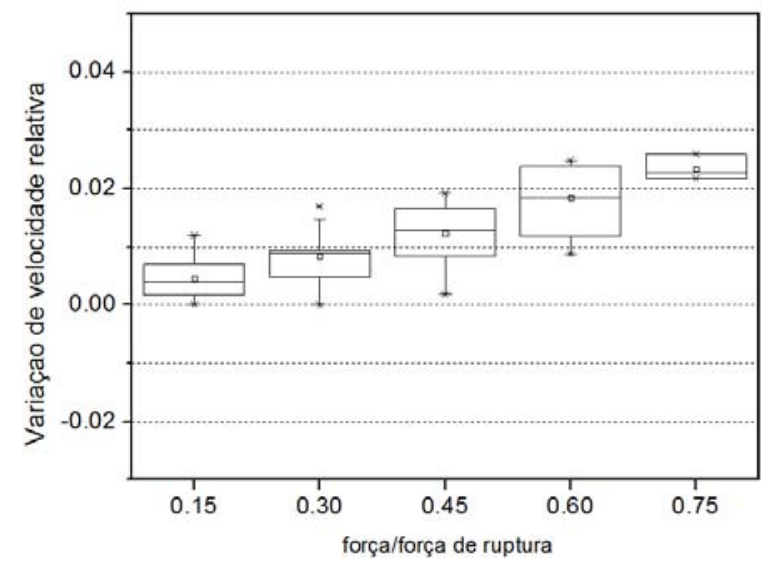

(a)

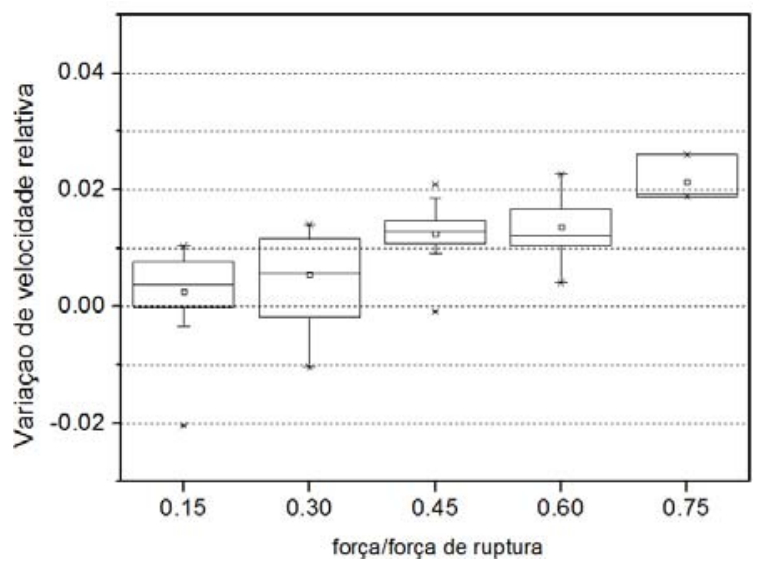

(b)

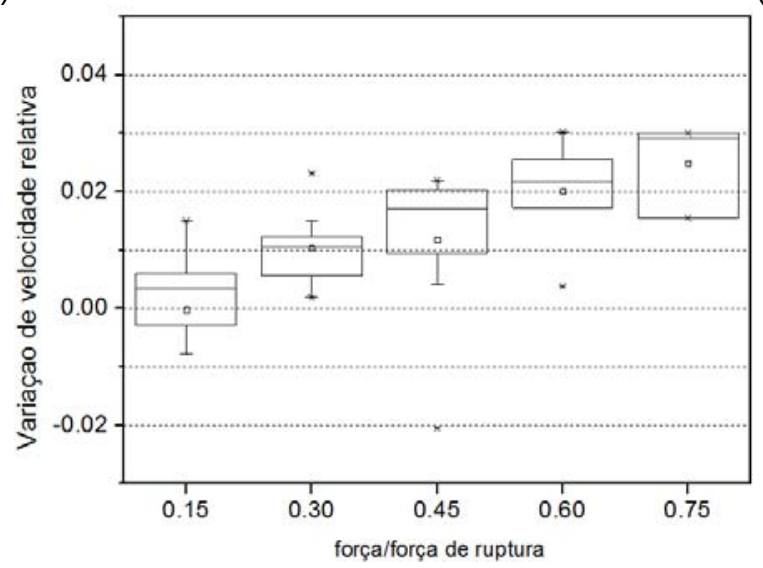

(c)

Figura 5. 22 - Dispersão de resultados para o traço 3, ondas longitudinais, direção 1: (a) cilindro 1; (b) cilindro 2; e (c) cilindro 3

A figura 5.23 mostra a comparação das médias dos cilindros dos três traços. Nesta figura, a legenda é apresentada na forma TxCy, onde x corresponde ao número do traço e y ao número do cilindro.

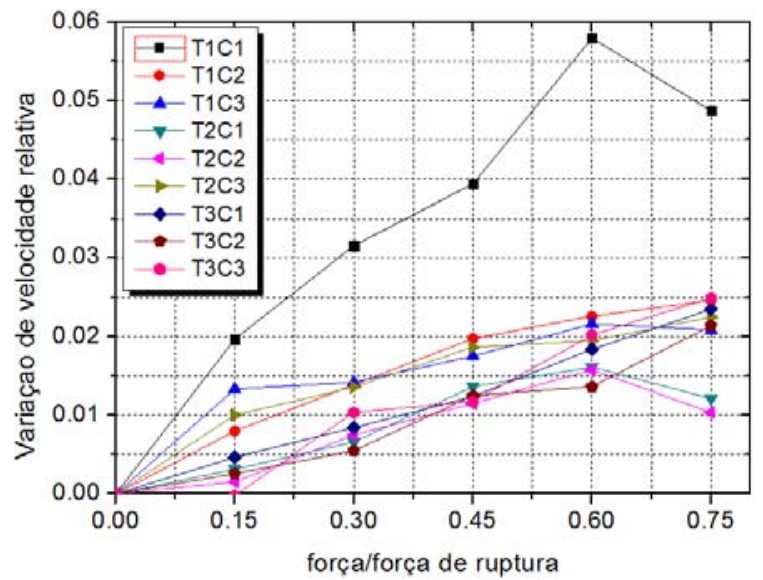

Figura 5. 23 - Comparação entre as médias obtidas para cada cilindro (ondas longitudinais 1)

Observando o gráfico da figura 5.23, podemos perceber que a única amostra que apresenta médias discrepantes em relação aos demais é a T1C1. Essa diferença 
não pode ser explicada pela composição do concreto, uma vez que o comportamento varia significativamente do apresentado pelos outros cilindros de mesmo traço. Logo, é razoável supor que a diferença se deve a falhas de vibração e moldagem durante a concretagem.

A tensão aplicada nos corpos de prova foi determinada a partir da ruptura de três prismas de mesmo traço. Assumindo-se que o cilindro T1C1 sofreu com falhas de vibração, o mesmo apresentaria tensão de ruptura inferior à das outras duas amostras de mesmo traço. Logo, se este cilindro tem resistência inferior aos outros de mesma composição, a relação entre força aplicada e força de ruptura seria superior à mostrada na Figura 5.23 e, portanto, geraria valores mais altos de variação relativa de velocidade.

Embora as curvas dos cilindros dos três traços estejam bem próximas, pode ser destacado que as amostras se agrupam e se tornam quase coincidentes para um mesmo traço (T1C2 e T1C3; T2C1 e T2C2; os três cilindros do terceiro traço).

As figuras 5.24 e 5.25 mostram as análises de dispersões obtidas com ondas de cisalhamento se propagando na direção do carregamento.

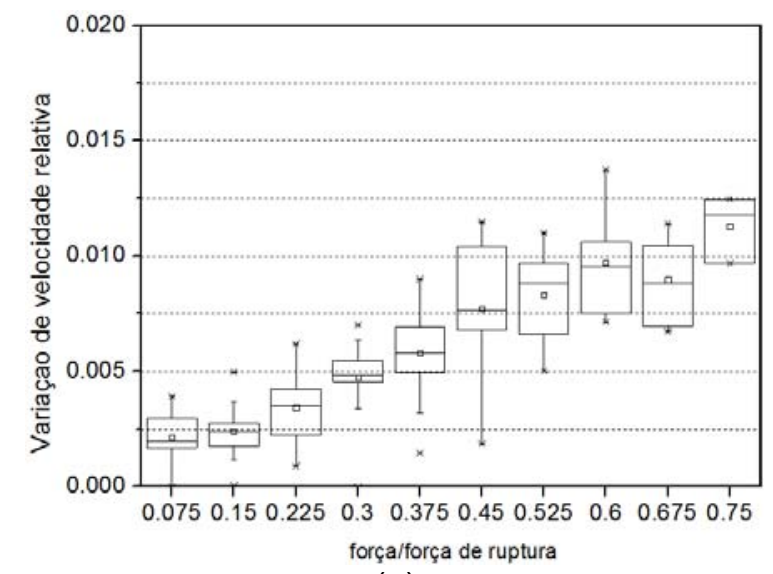

(a)

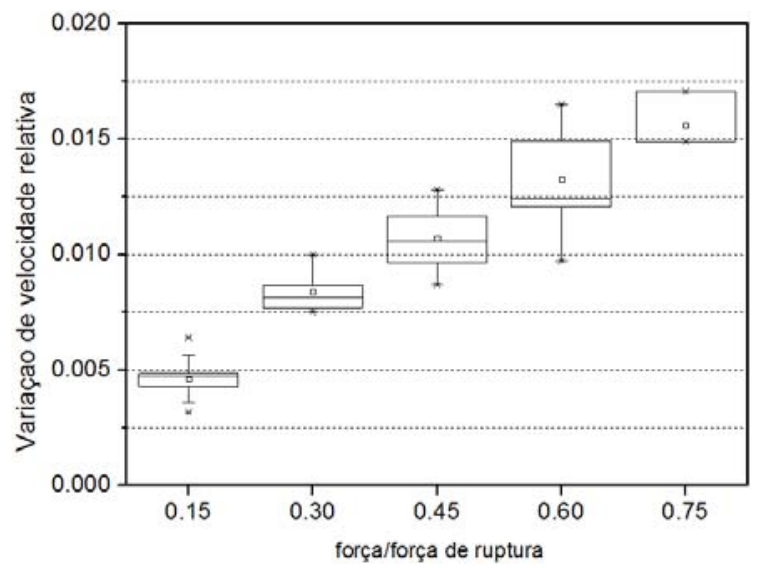

(b)

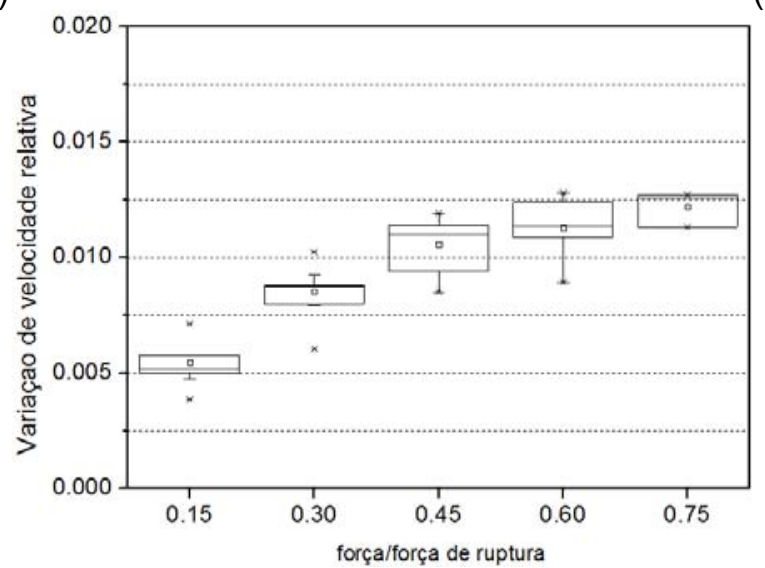

(c)

Figura 5. 24 - Dispersão de resultados para o traço 2, ondas de cisalhamento, direção 1: (a) cilindro 1; (b) cilindro 2; e (c) cilindro 3 


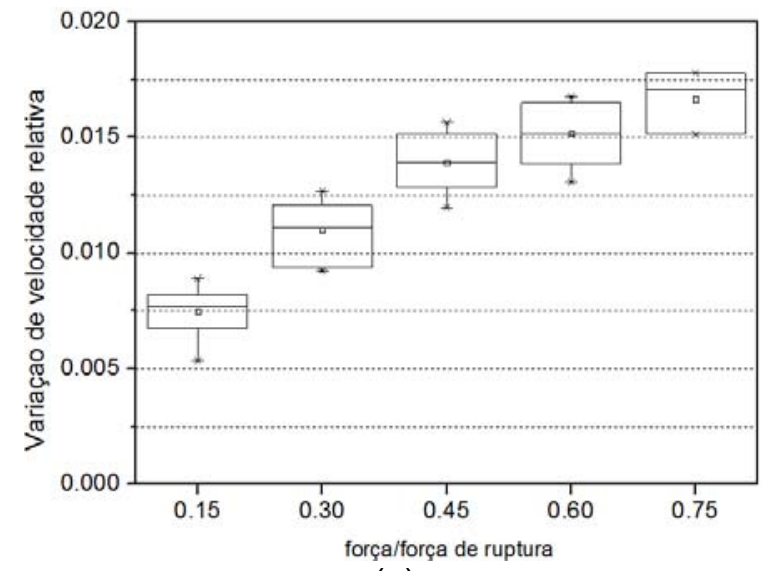

(a)

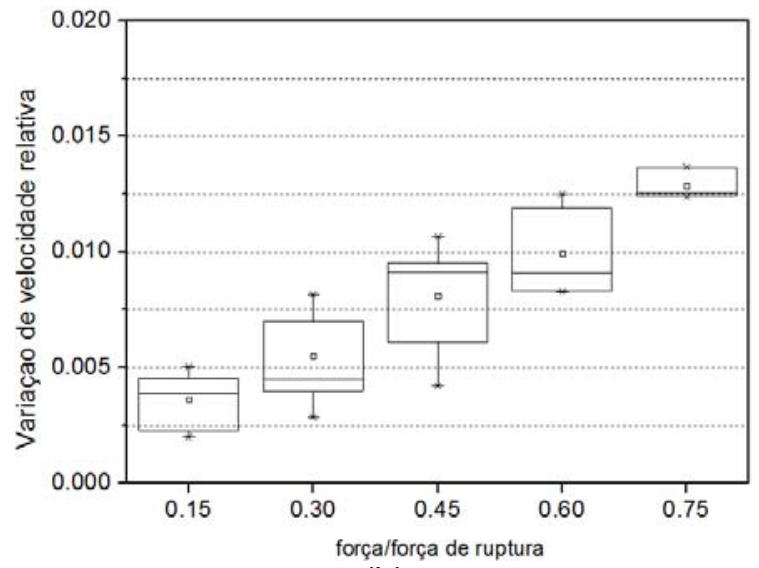

(b)

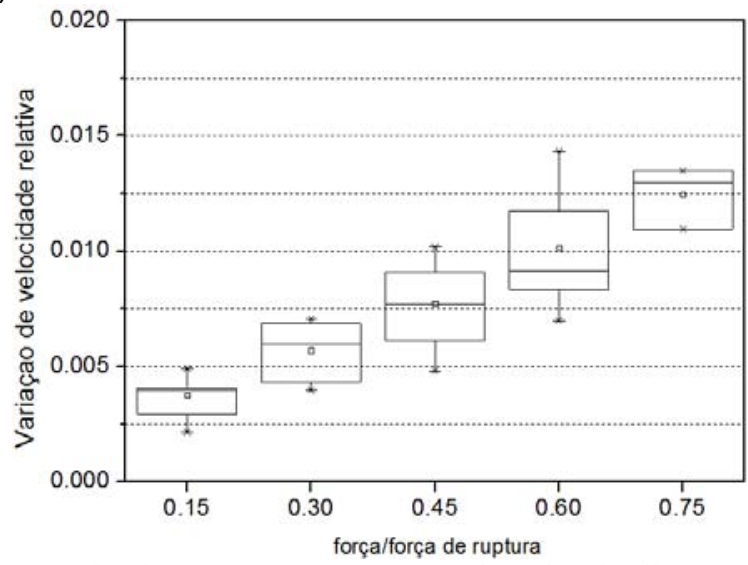

Figura 5. 25 - Dispersão de resultados para o traço 3, ondas de cisalhamento, direção 1: (a) cilindro 1; (b) cilindro 2; e (c) cilindro 3

A figura 5.26 apresenta as médias das variações relativas de velocidade de cada traço.

Não foi possível observar uma grande influência da composição do concreto sobre a dispersão dos resultados. Entretanto, observando a figura 5.26, é possível perceber que as curvas se sobrepõem para um mesmo traço, tendo valores maiores para a primeira composição e valores menores para a terceira. As exceções ocorrem para o T1C1 e para o T2C1. Acredita-se que este comportamento se deve à dispersão própria do material devido ao processo de moldagem. 


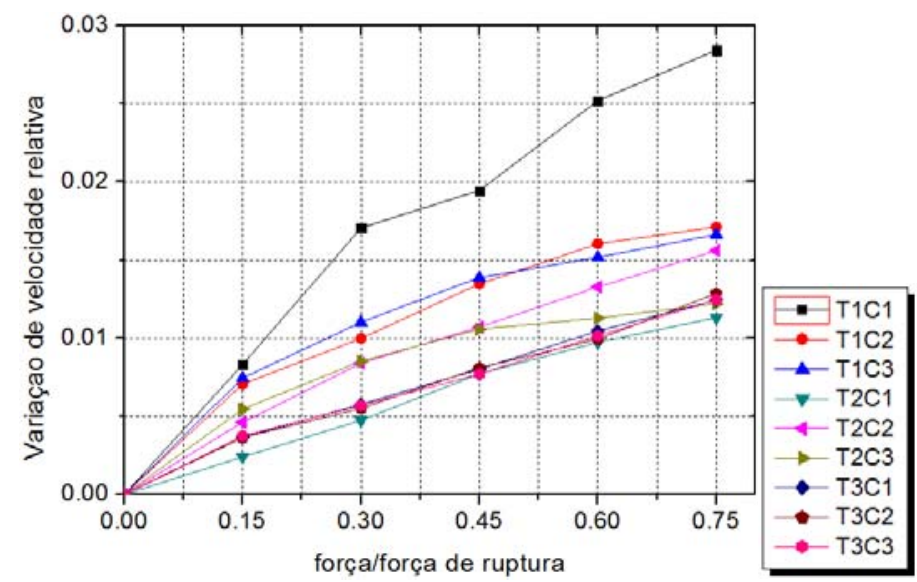

Figura 5. 26 - Comparação entre as médias obtidas para cada cilindro (ondas de cisalhamento)

As análises realizadas com as ondas longitudinais propagadas na direção 2 são mostradas nas figuras 5.27 e 5.28 . As médias obtidas são mostradas na figura 5.29 .

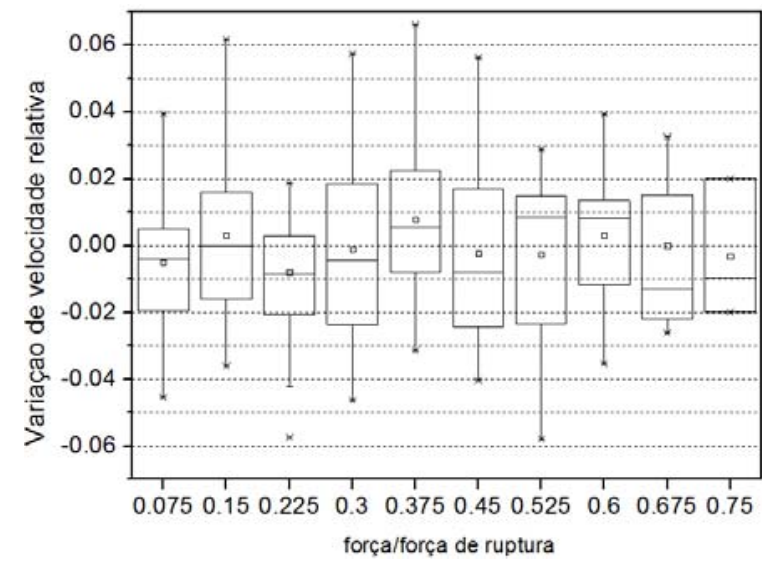

(a)

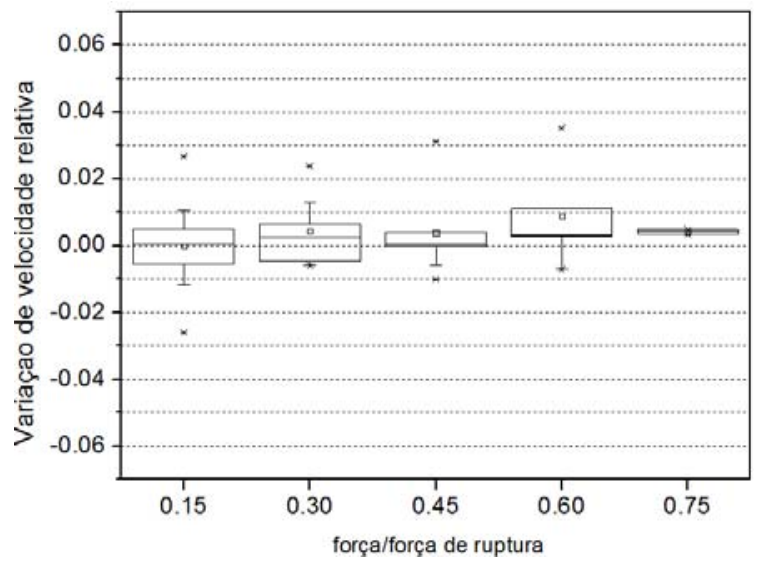

(b)

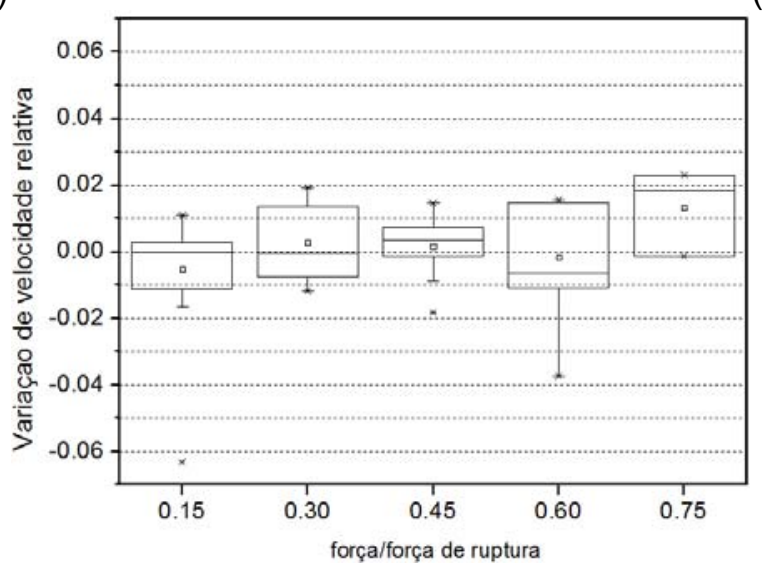

(c)

Figura 5. 27 - Dispersão de resultados para o traço 2, ondas longitudinais, direção 2: (a) cilindro 1; (b) cilindro 2; e (c) cilindro 3 


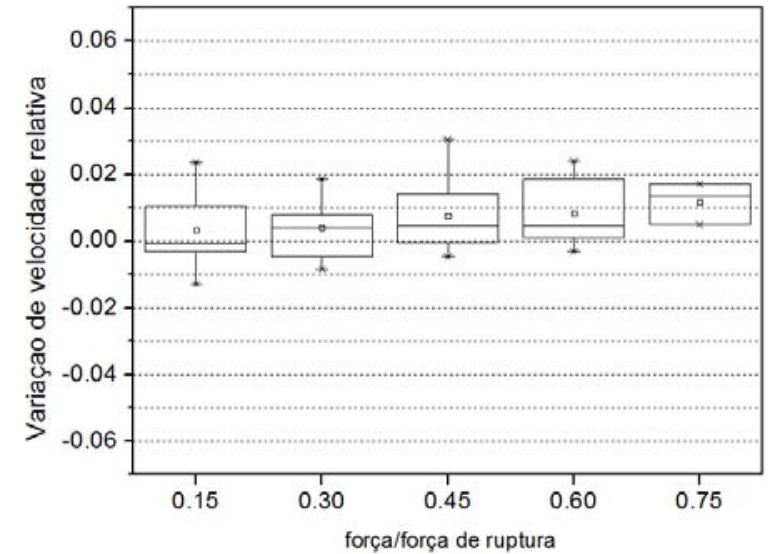

(a)

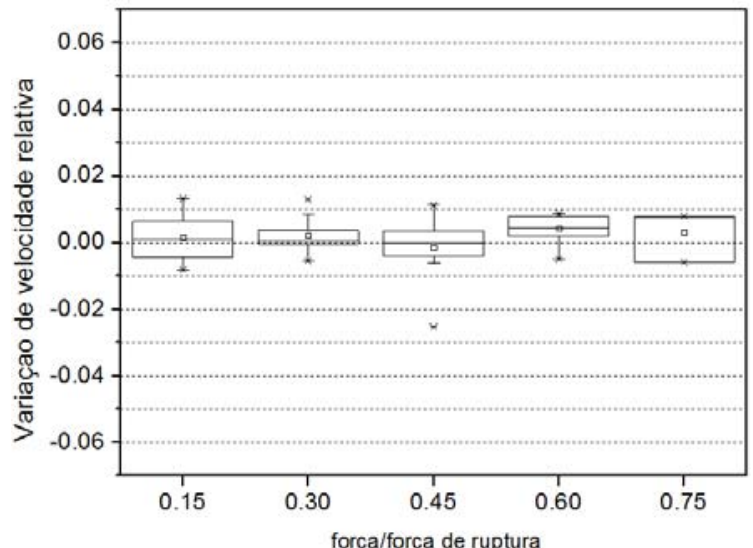

(b)

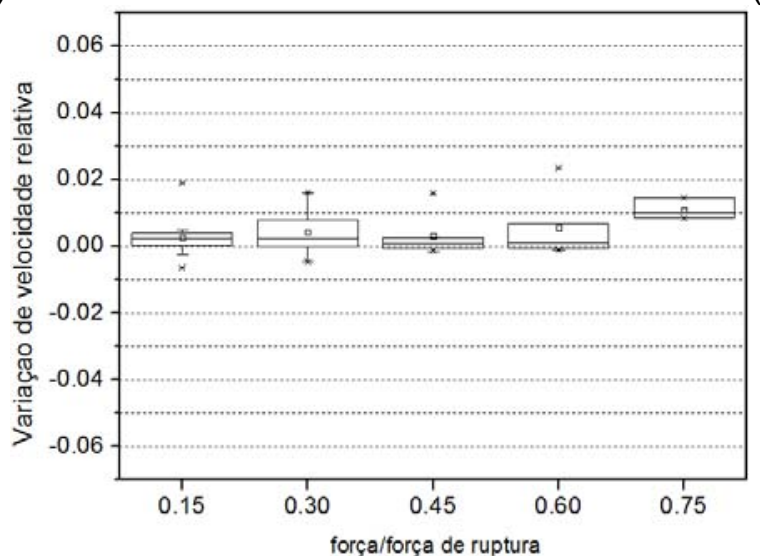

(c)

Figura 5. 28 - Dispersão de resultados para o traço 3, ondas longitudinais, direção 2: (a) cilindro 1; (b) cilindro 2; e (c) cilindro 3

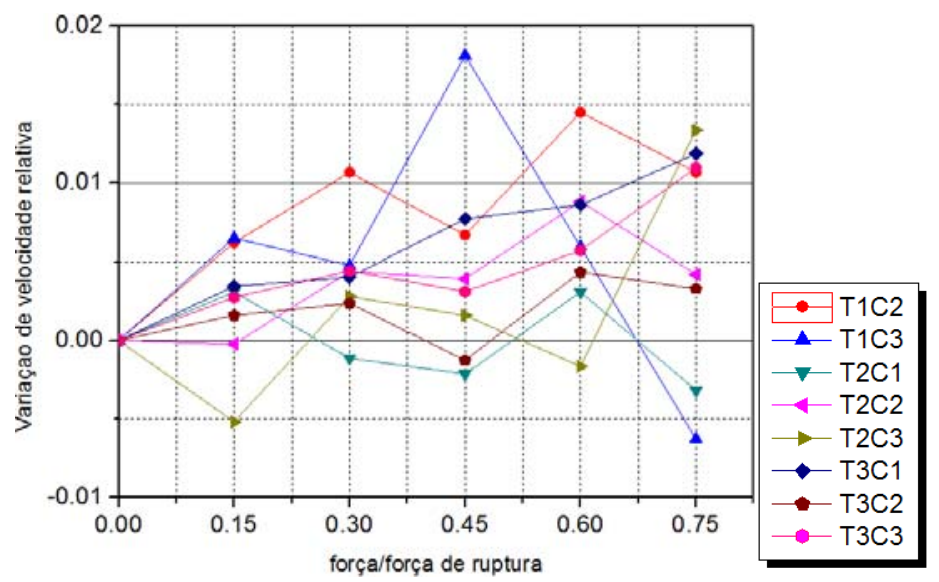

Figura 5. 29 - Comparação entre as médias obtidas para cada cilindro (ondas longitudinais 2)

Entre os resultados obtidos com as ondas longitudinais na direção 2, não é possível observar um padrão de variação de velocidade. Enquanto os resultados das ondas emitidas na direção 1 divergiam quanto à magnitude da variação de velocidade, todos eles tinham uma tendência crescente enquanto o carregamento aumentava. No entanto, quando as ondas longitudinais são avaliadas na direção perpendicular ao carregamento, os resultados deixam de ser curvas bem definidas. 
É sabido que o efeito acustoelástico é mais pronunciado quando a direção de propagação e/ou a de vibração das partículas é a mesma direção do carregamento. Popovics e Popovics (1991) realizaram ensaios de compressão para avaliar a acustoelasticidade em concreto e aplicaram a Velocidade de Pulso Ultrassônico apenas na direção 2. Os autores chegaram a concluir que a velocidade de propagação independe da tensão aplicada quando esta corresponde a até $70 \%$ da resistência a compressão. Embora seja claro que a conclusão de Popovics e Popovics (1991) não corresponda ao comportamento real do concreto e que o efeito acustoelástico exista na direção 2, esta referência ilustra a dificuldade de obtenção da variação de velocidade nesta direção devido ao seu valor ser muito pequeno.

A direção 2 apresenta ainda as desvantagens de ter a superfície curva (amostra cilíndrica) e da menor distância entre os transdutores. Conforme já foi mencionado, a superfície curva aumenta a variabilidade do ensaio. No ensaio VPU, a grandeza medida é o tempo necessário para que a onda se desloque de um transdutor a outro. Quanto maior este tempo, maior a sua variação quando a tensão é aplicada e, portanto, a medida da variação é mais facilmente obtida.

A partir das variações de velocidade analisadas, é possível obter os coeficientes acustoelásticos relativos a cada tipo de onda, conforme a tabela 5.2.

Tabela 5. 2 - Coeficientes acustoelásticos

\begin{tabular}{ccccc}
\hline Amostra & $\mathbf{A}_{11}$ & $\mathbf{R}^{\mathbf{2}}$ & $\mathbf{A} 12$ & $\mathbf{R}^{\mathbf{2}}$ \\
\hline T1P1 & 0.0221 & 0.8823 & 0.0064 & 0.9393 \\
T1P2 & 0.0224 & 0.9953 & -0.0011 & 0.0314 \\
T1P3 & 0.0177 & 0.9859 & 0.0151 & 0.9959 \\
T1C1 & 0.0698 & 0.8796 & 0.0372 & 0.9611 \\
T1C2 & 0.0329 & 0.9516 & 0.0221 & 0.9354 \\
T1C3 & 0.0252 & 0.8039 & 0.0208 & 0.8944 \\
T2C1 & 0.0203 & 0.8037 & 0.0155 & 0.9929 \\
T2C2 & 0.0187 & 0.7534 & 0.0203 & 0.978 \\
T2C3 & 0.0278 & 0.9052 & 0.0153 & 0.8757 \\
T3C1 & 0.0309 & 0.9939 & 0.0162 & 0.9907 \\
T3C2 & 0.028 & 0.9622 & 0.0163 & 0.9911 \\
T3C3 & 0.0356 & 0.9521 & 0.0159 & 0.9897 \\
\hline
\end{tabular}


Os coeficientes acustoelásticos estão apresentados na forma $A_{i j}$, onde $i$ corresponde à direção de propagação da onda e j corresponde à direção de vibração das partículas. Para cada coeficiente acustoelástico, é apresentado também seu coeficiente de determinação do modelo de regressão linear $\left(R^{2}\right)$.

Para obter os coeficientes acustoelásticos, cada uma das curvas mostradas nas Figuras 5.23 e 5.26 foi isolada a fim de aplicar-se uma função de regressão linear com o auxílio do Microsoft ${ }^{\circledR}$ Excel, versão 2013. As curvas foram consideradas em sua totalidade (com o carregamento variando de 0 a $75 \%$ da força de ruptura.

\section{3 Índice de Dano}

O Índice de Dano (D) é uma medida da quantidade de danificação sofrida pela amostra. Esta medida foi definida em função do módulo de elasticidade tangente inicial $\left(E_{0}\right)$ do corpo de prova e do módulo de elasticidade secante $\left(E_{S}\right)$ no nível de carregamento desejado, conforme equação 5.1 .

$$
D=1-\frac{E_{S}}{E_{0}}
$$

Conforme a amostra é solicitada, o módulo de elasticidade secante diminui e, consequentemente, o valor da danificação aumenta. Uma vez que a velocidade de pulso ultrassônico também pode ser definida em função do módulo de elasticidade (equação 5.2), as duas medidas podem ser relacionadas.

$$
V_{S}=\sqrt{\frac{E}{2 \rho(1+v)}}
$$

Por simplificação, as variações na densidade e no coeficiente de Poisson do material devido a aplicação do carregamento serão desprezadas e o Índice de Dano será descrito conforme a equação 5.3. 


$$
\begin{aligned}
& D=1-\frac{V^{2}}{V_{0}^{2}} \\
& D=\left(1+\frac{V}{V_{0}}\right)\left(1-\frac{V}{V_{0}}\right)
\end{aligned}
$$

A velocidade $V$ mostrada nas equações corresponde, por hipótese, à velocidade final medida $\left(V_{f}\right)$ descontada da parcela de variação referente à acustoelasticidade $\left(\Delta V_{A}\right)$, uma vez que esta reflete apenas a danificação do corpo de prova, conforme a equação 5.5 .

$$
\begin{aligned}
& V=V_{f}-\Delta V_{A} \\
& D=\left(1+\frac{V_{f}-\Delta V_{A}}{V_{0}}\right)\left(1-\frac{V_{f}-\Delta V_{A}}{V_{0}}\right)
\end{aligned}
$$

Como a variação de velocidade de pulso ultrassônico ocorre devido à danificação $\left(\Delta V_{D}\right)$ e à acustoelasticidade simultaneamente, podemos supor que a variação de velocidade medida $\left(\Delta V / V_{0}\right)$ corresponde à soma destas duas parcelas, conforme a equação 5.7 .

$$
\begin{aligned}
& \frac{\Delta V}{V_{0}}=\frac{\Delta V_{A}+\Delta V_{D}}{V_{0}} \\
& V_{f}-V_{0}=\Delta V_{A}+\Delta V_{D} \rightarrow V_{f}-\Delta V_{A}=V_{0}+\Delta V_{D}
\end{aligned}
$$

Substituindo a equação 5.8 na 5.6, podemos relacionar o Índice de Dano à variação de velocidade devido à danificação.

$$
\begin{aligned}
& D=\left(1+\frac{V_{0}+\Delta V_{D}}{V_{0}}\right)\left(1-\frac{V_{0}+\Delta V_{D}}{V_{0}}\right) \\
& D=\left(1+1+\frac{\Delta V_{D}}{V_{0}}\right)\left(1-1-\frac{\Delta V_{D}}{V_{0}}\right)
\end{aligned}
$$




$$
D=\left(2+\frac{\Delta V_{D}}{V_{0}}\right)\left(-\frac{\Delta V_{D}}{V_{0}}\right)=-2 \frac{\Delta V_{D}}{V_{0}}-\left(\frac{\Delta V_{D}}{V_{0}}\right)^{2}
$$

Escrevendo a variação de velocidade devido à danificação em função do Índice de Dano, temos:

$$
\frac{\Delta V_{D}}{V_{0}}=-1+\sqrt{1-D}
$$

Uma vez que o Índice de Dano permite que a parcela de variação de velocidade devido à danificação seja isolada, é possível encontrar a variação relativa de velocidade devido à acustoelasticidade por meio da equação 5.7 .

O módulo de elasticidade secante foi determinado apenas para os pontos de máxima tensão aplicada em cada ciclo de carregamento, segundo a equação 5.13, onde $\sigma_{M A ́ X i}$ representa a tensão máxima atingida no ciclo de carregamento i; $\varepsilon_{M A ́ X i}$ representa a deformação corresponde à tensão máxima no ciclo i; e $\varepsilon_{0 i-1}$ representa a deformação apresentada pela amostra sem aplicação de tensão após o ciclo de carregamento i-1.

$$
E_{S i}=\frac{\sigma_{M A ́ X i}}{\varepsilon_{M A X i}-\varepsilon_{0 i-1}}
$$

O módulo de elasticidade tangente inicial foi obtido por meio do gráfico tensão $x$ deformação referente ao primeiro ciclo de carregamento. $O$ gráfico foi plotado com o programa Microsoft Excel ${ }^{\circledR}$, versão 2013. Uma vez desenhado o gráfico, foi plotada uma equação de regressão do segundo grau. $O$ módulo de elasticidade adotado correspondeu ao valor da derivada da função de regressão quando a deformação é igual a 0 .

As figuras 5.30 a 5.41 mostram o Índice de Dano (a); a variação relativa de velocidade devido somente à danificação (b); e somente ao efeito acustoelástico (c). Os gráficos indicados pela letra (d) foram feitos a partir da equação 5.7. Sabendo-se que a variação de velocidade medida em ensaio é a soma das variações devido à 
danificação e à acustoelasticidade, podemos escrever todas as variações como uma razão da última, conforme a equação 5.14.

$$
\frac{\Delta V}{V_{0}}=\frac{\Delta V_{A}}{V_{0}}+\frac{\Delta V_{D}}{V_{0}} \rightarrow \Delta V_{A}=\Delta V+\left(-\Delta V_{D}\right) \rightarrow \frac{\Delta V}{\Delta V_{A}}+\left(-\frac{\Delta V_{D}}{\Delta V_{A}}\right)=1
$$

Logo, os gráficos (d) ilustram o quanto a danificação aumenta relativamente a variação de velocidade conforme os ciclos de carregamento são aplicados.

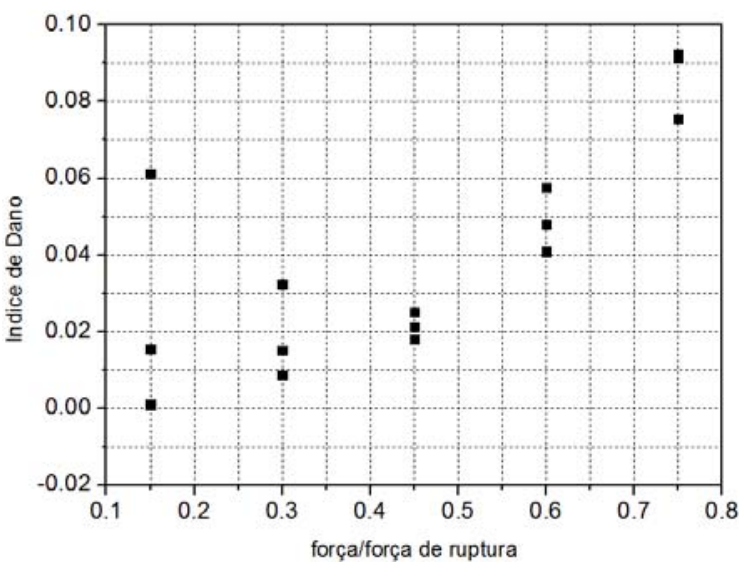

(a)

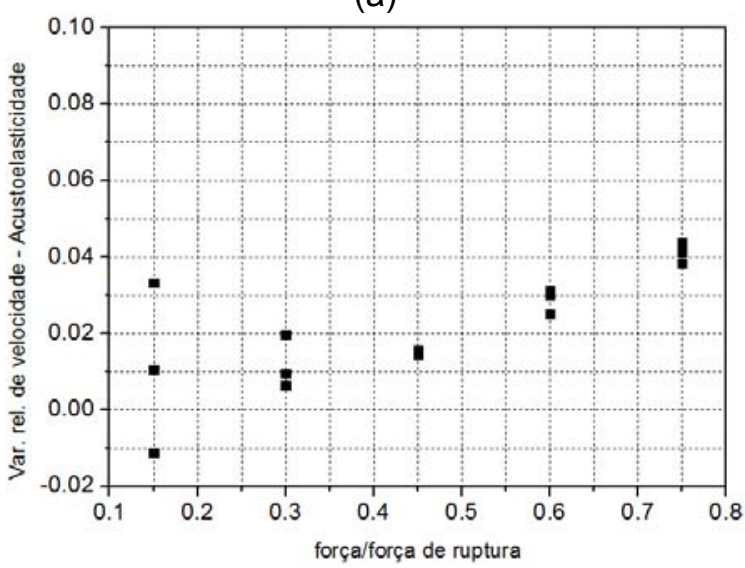

(c)

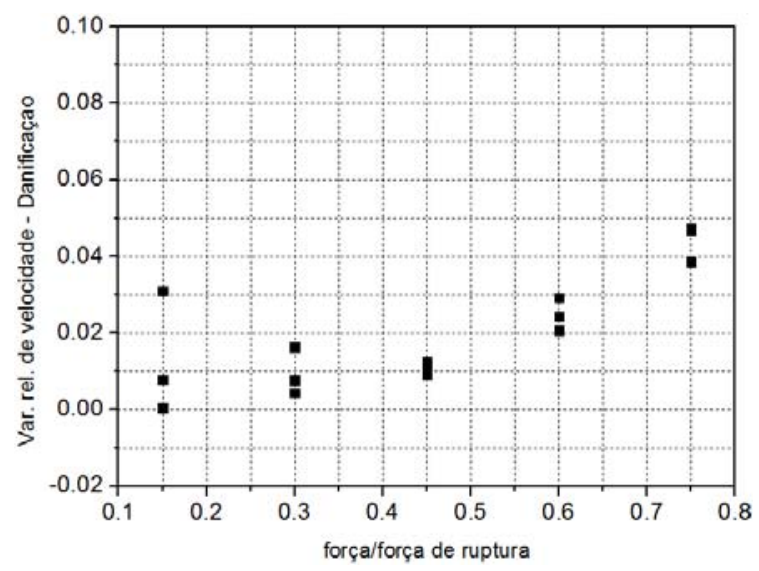

(b)

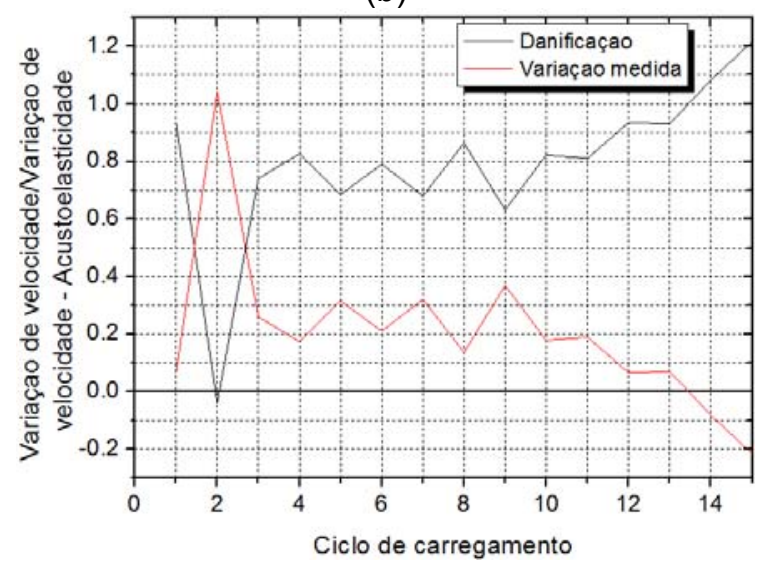

(d)

Figura 5. 30 - Prisma 1, traço 1: (a) Índice de Dano; (b) Variação relativa de velocidade devido à danificação; (c) Variação relativa de velocidade devido à acustoelasticidade; (d) influência da danificação sobre a variação de velocidade 


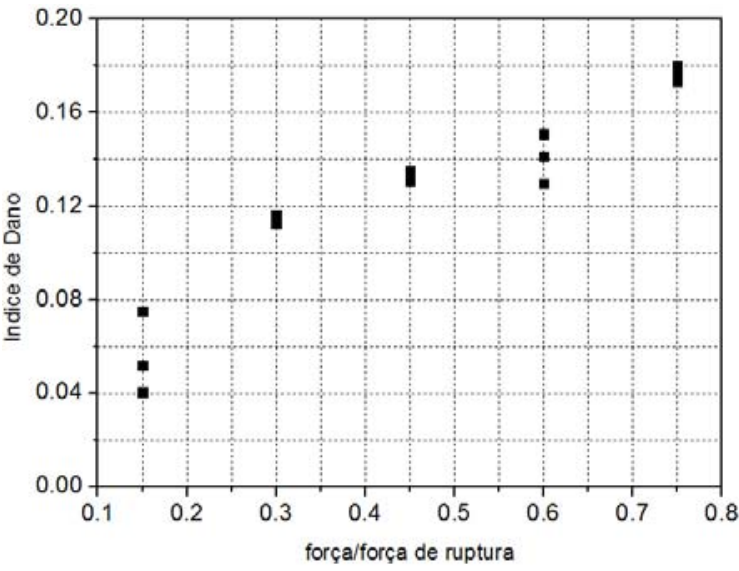

(a)

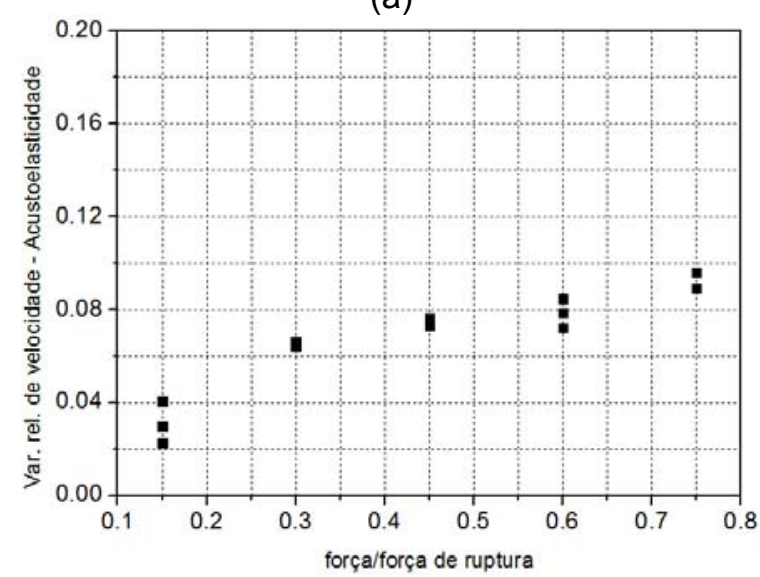

(c)

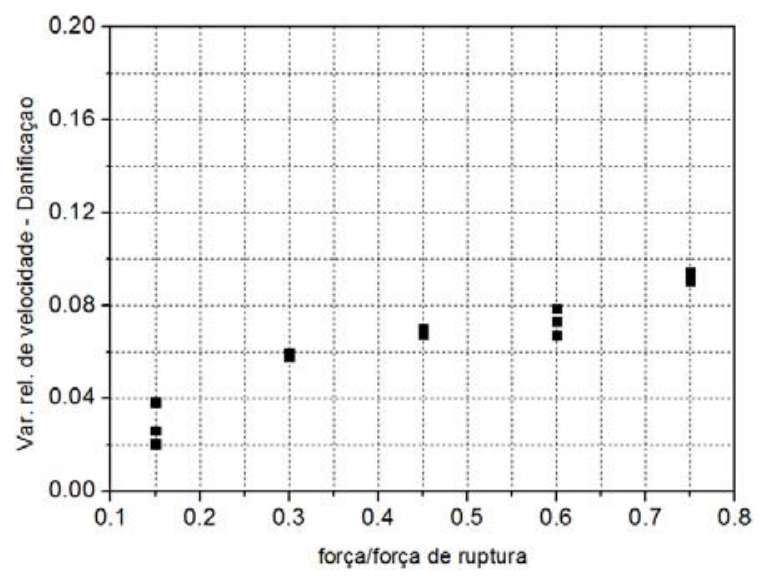

(b)

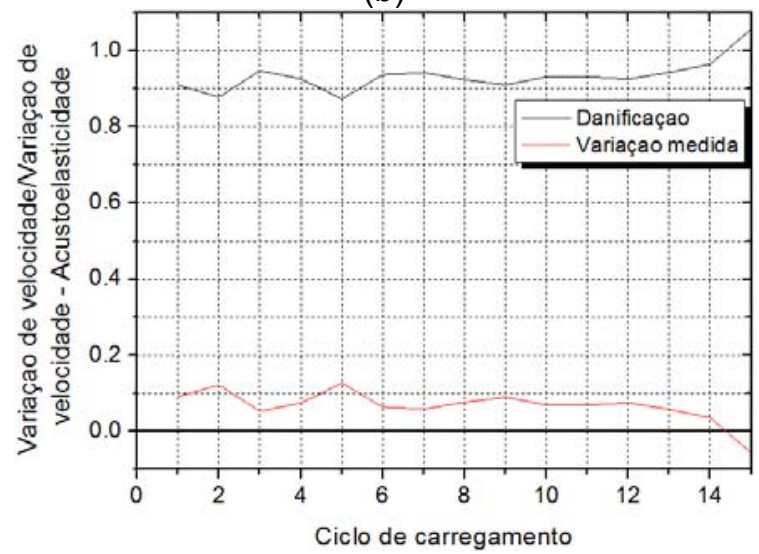

(d)

Figura 5. 31 - Prisma 2, traço 1: (a) Índice de Dano; (b) Variação relativa de velocidade devido à danificação; (c) Variação relativa de velocidade devido à acustoelasticidade; (d) influência da danificação sobre a variação de velocidade 


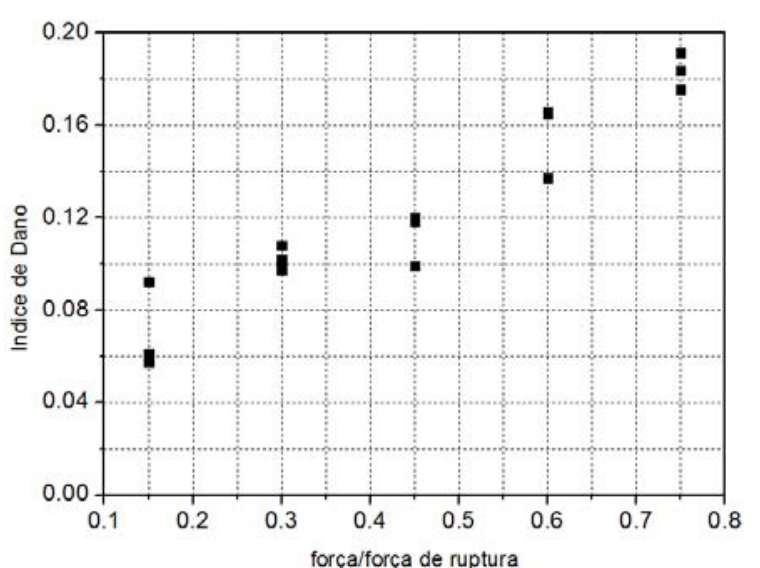

(a)

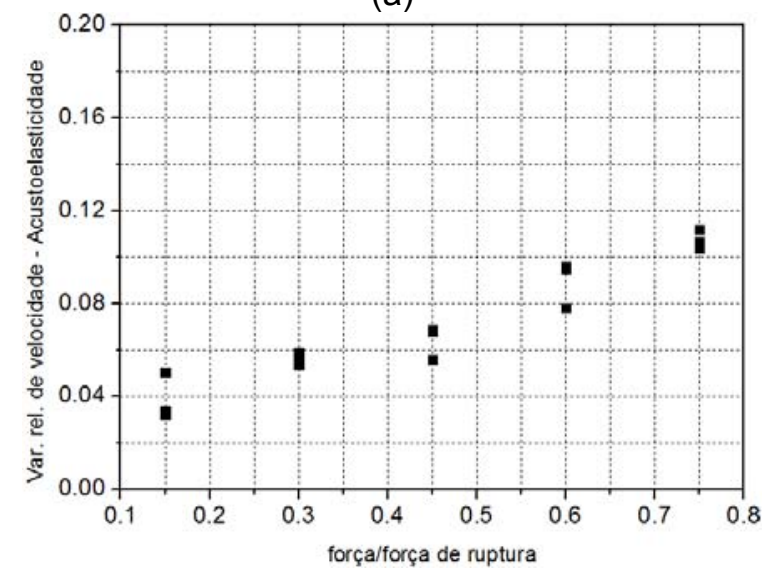

(c)

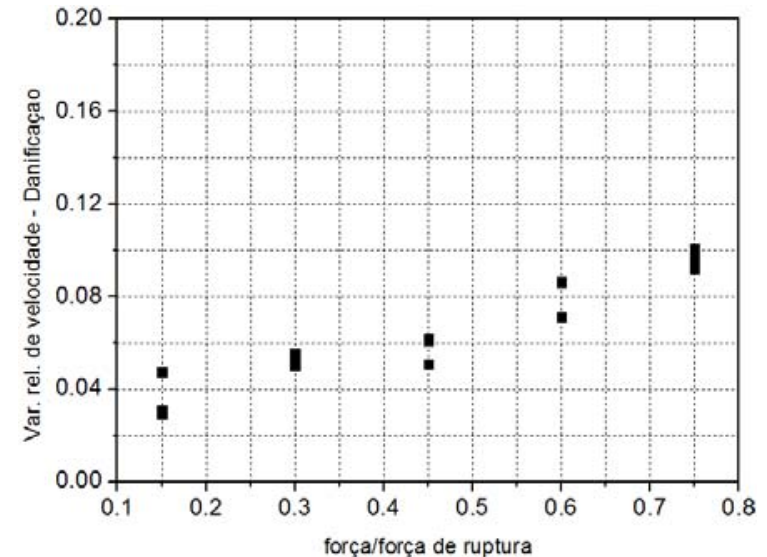

(b)

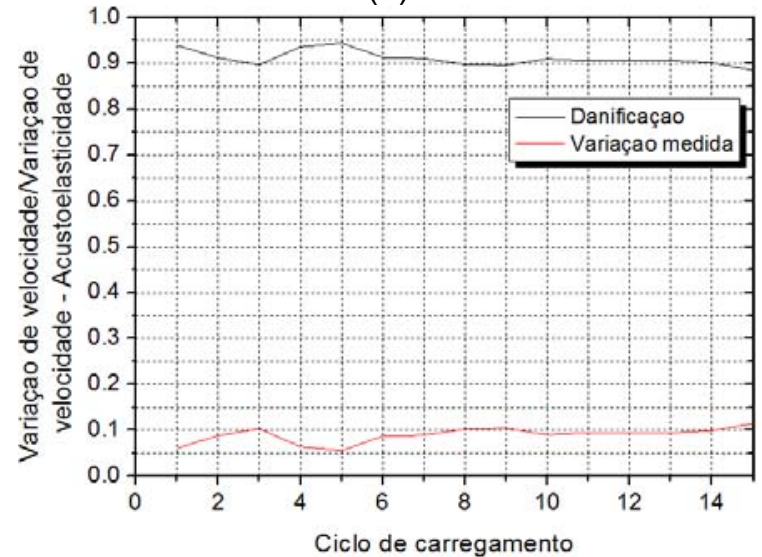

(d)

Figura 5. 32 - Prisma 3, traço 1: (a) Índice de Dano; (b) Variação relativa de velocidade devido à danificação; (c) Variação relativa de velocidade devido à acustoelasticidade; (d) influência da danificação sobre a variação de velocidade 


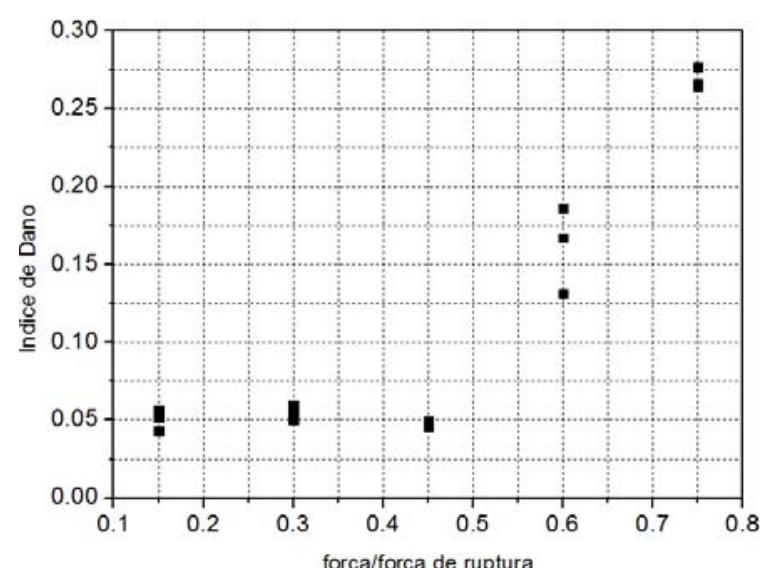

(a)

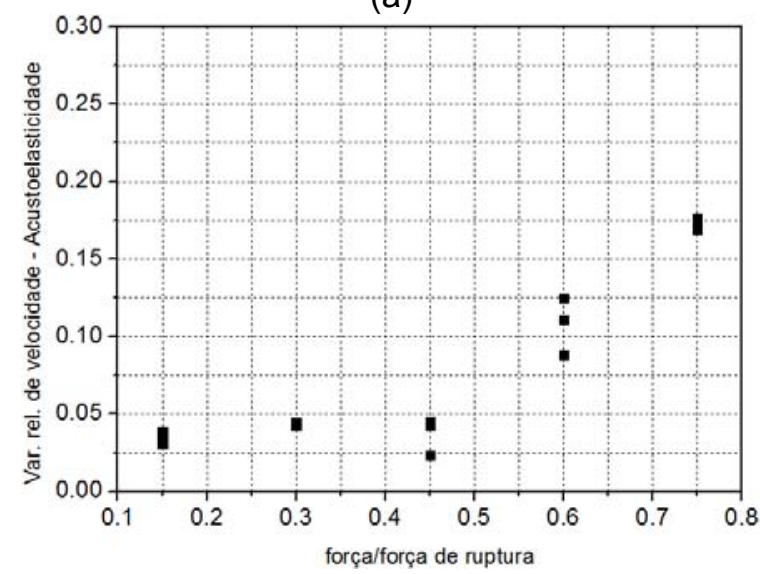

(c)

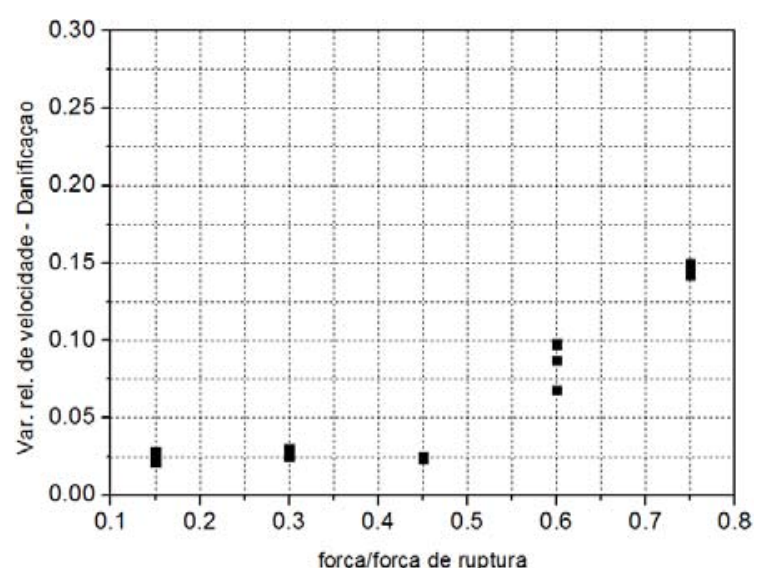

(b)

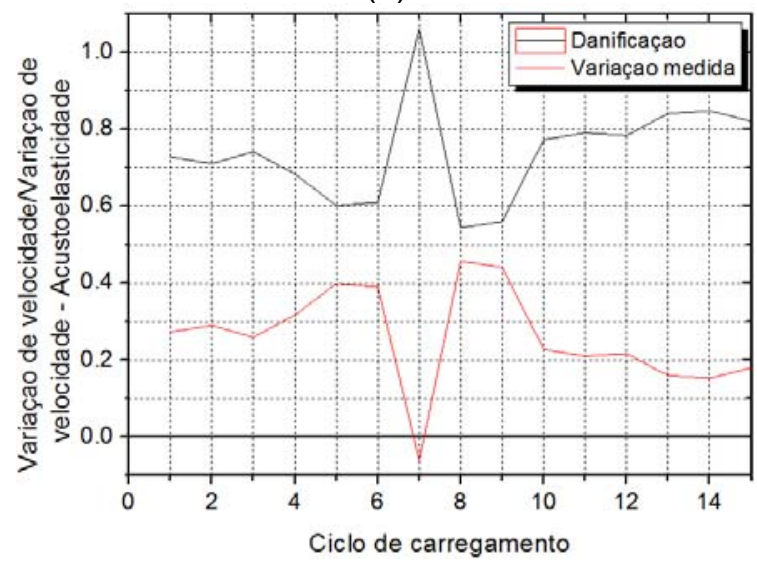

(d)

Figura 5. 33 - Cilindro 1, traço 1: (a) Índice de Dano; (b) Variação relativa de velocidade devido à danificação; (c) Variação relativa de velocidade devido à acustoelasticidade; (d) influência da danificação sobre a variação de velocidade 


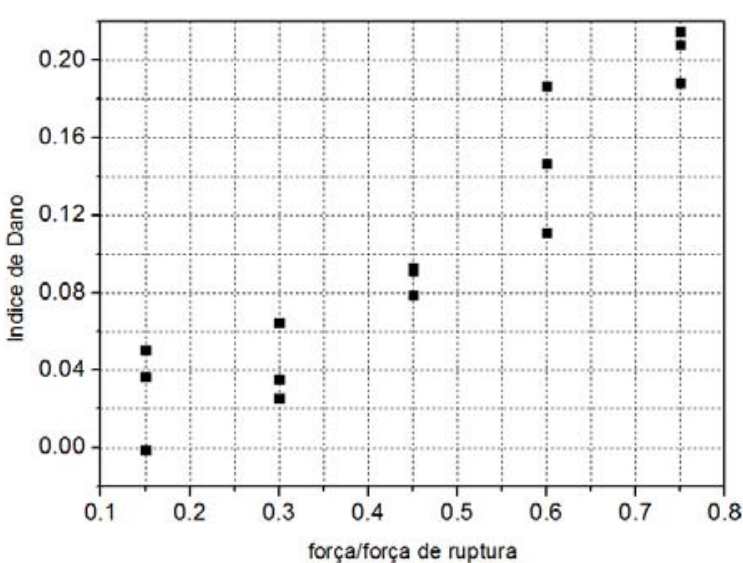

(a)

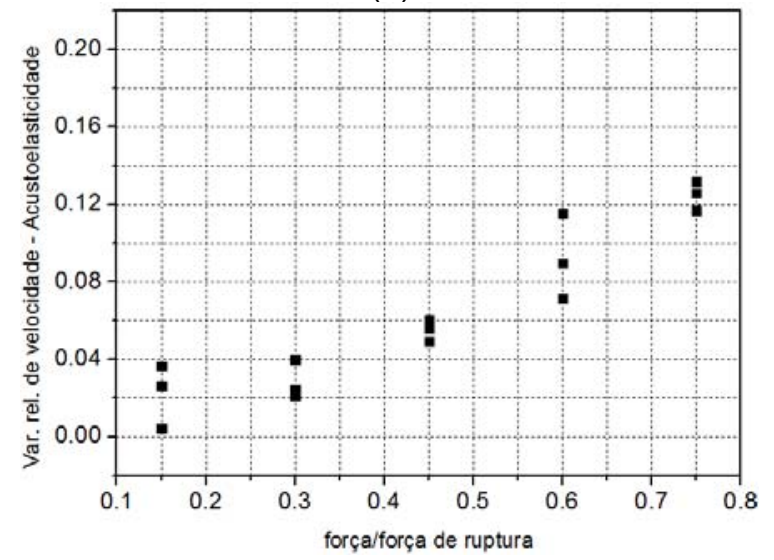

(c)

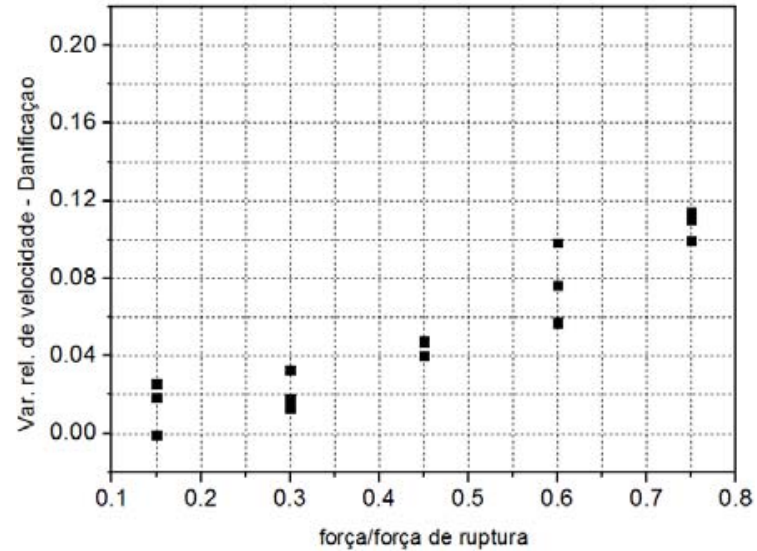

(b)

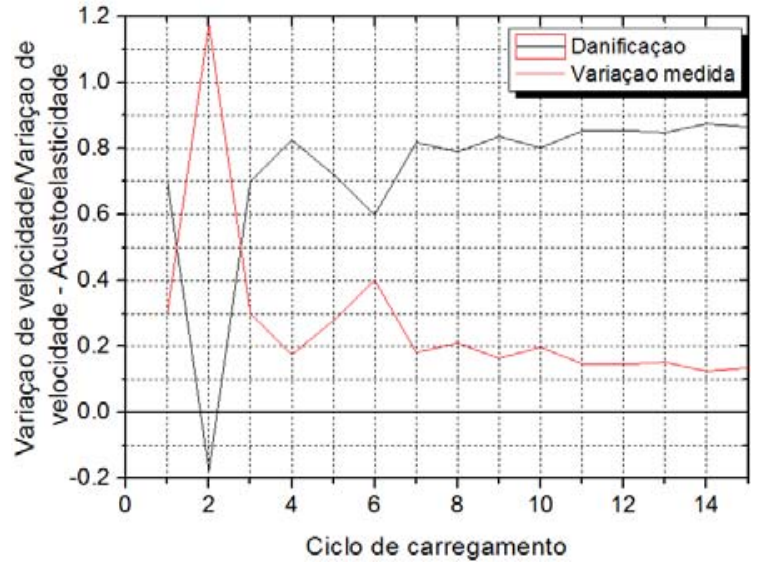

(d)

Figura 5. 34 - Cilindro 2, traço 1: (a) Índice de Dano; (b) Variação relativa de velocidade devido à danificação; (c) Variação relativa de velocidade devido à acustoelasticidade; (d) influência da danificação sobre a variação de velocidade 


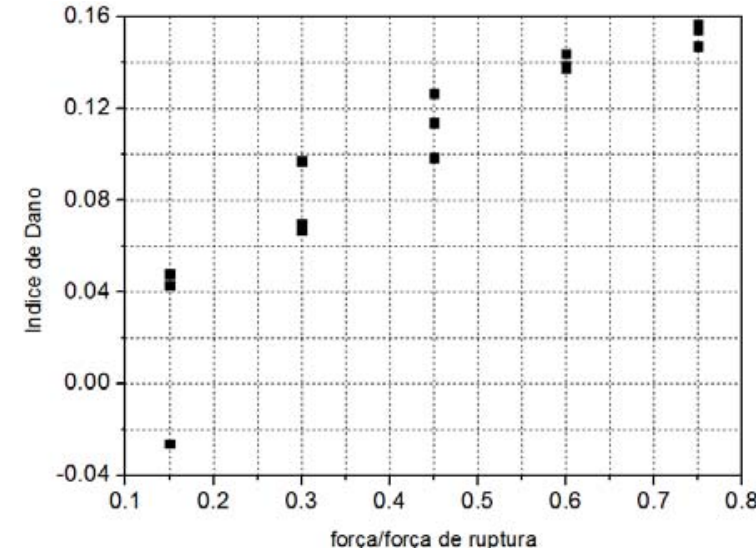

(a)

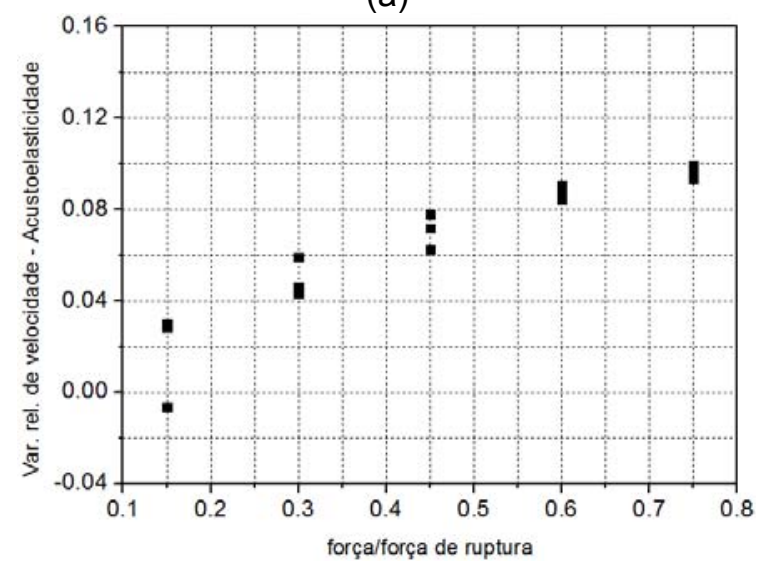

(c)

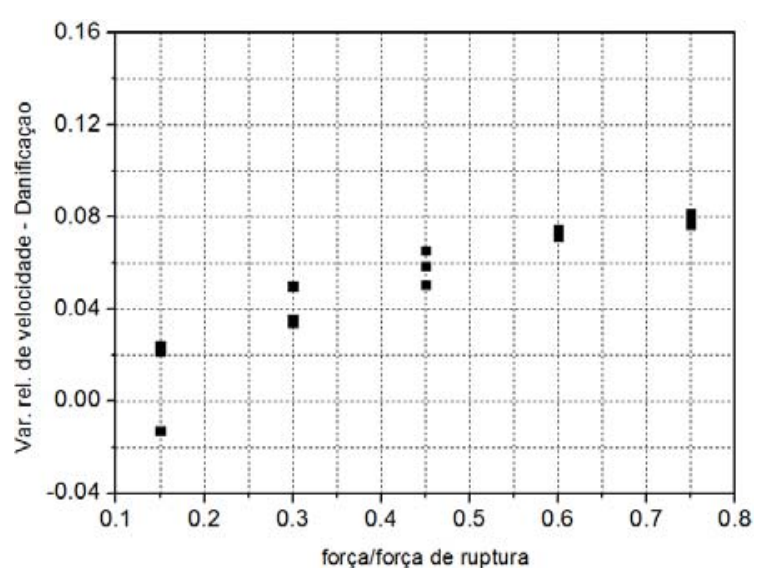

(b)

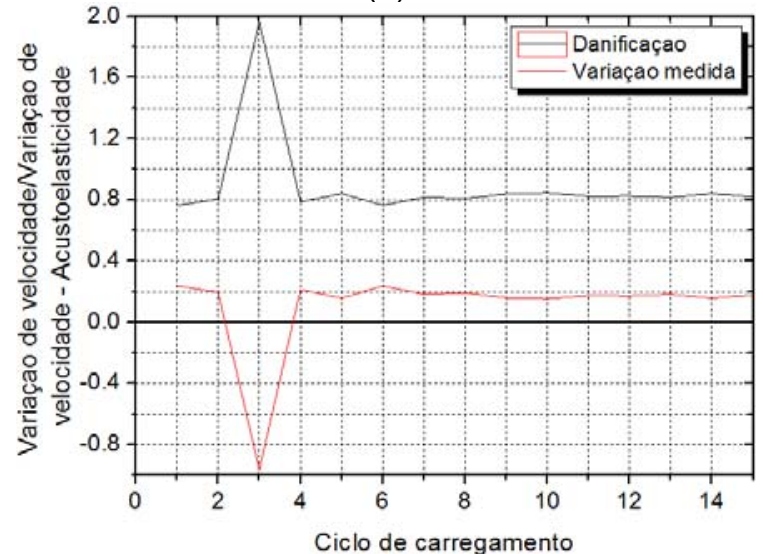

(d)

Figura 5. 35 - Cilindro 3, traço 1: (a) Índice de Dano; (b) Variação relativa de velocidade devido à danificação; (c) Variação relativa de velocidade devido à acustoelasticidade; (d) influência da danificação sobre a variação de velocidade 


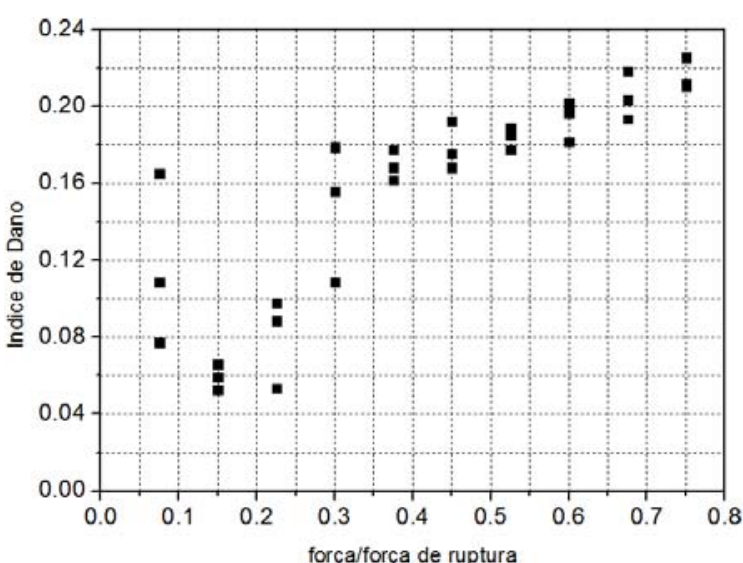

(a)

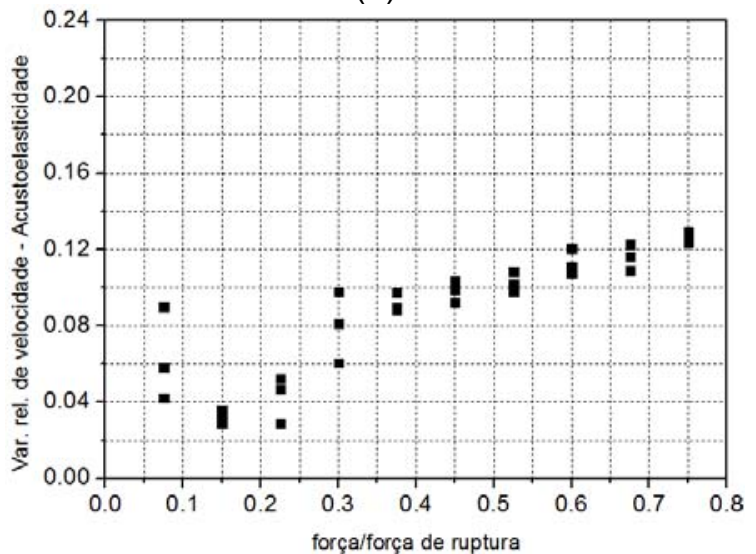

(c)

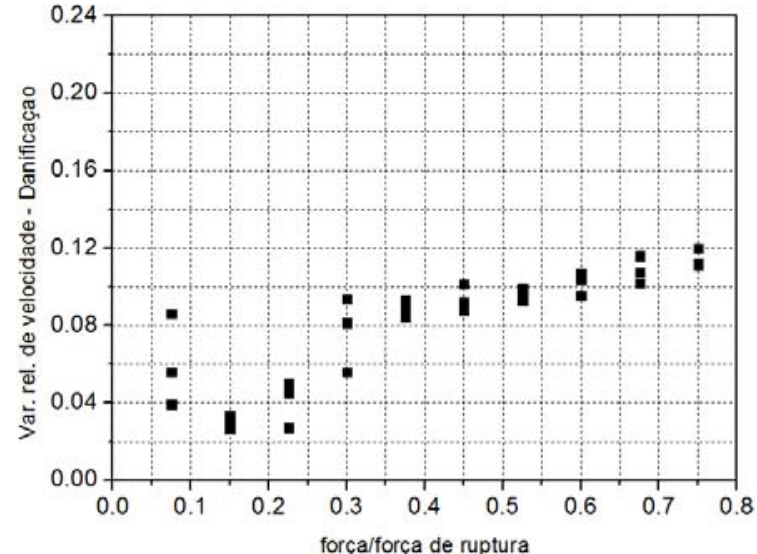

(b)

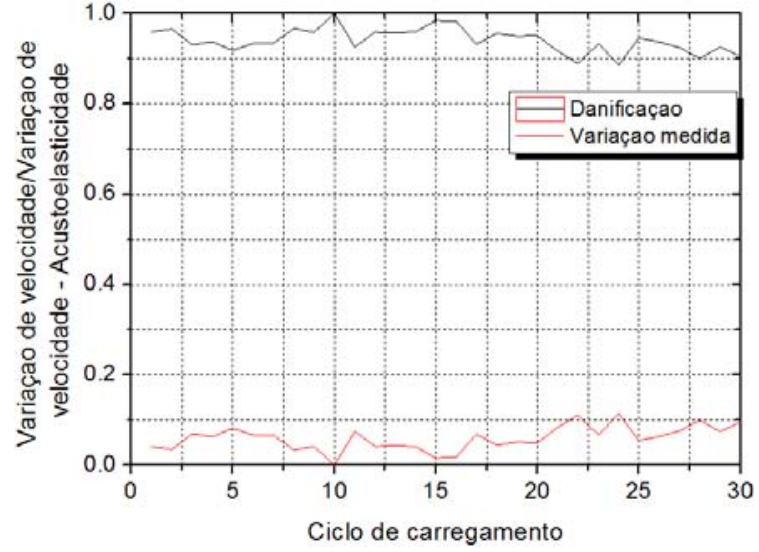

(d)

Figura 5. 36 - Cilindro 1, traço 2: (a) Índice de Dano; (b) Variação relativa de velocidade devido à danificação; (c) Variação relativa de velocidade devido à acustoelasticidade; (d) influência da danificação sobre a variação de velocidade 


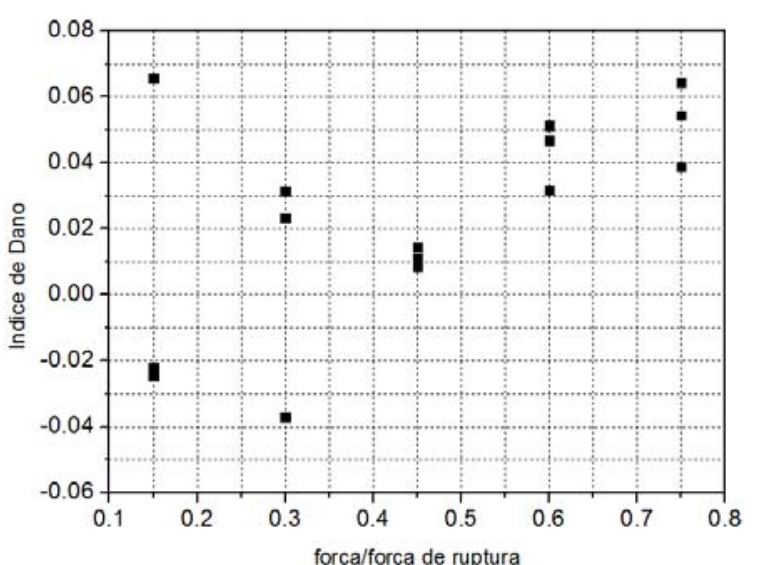

(a)

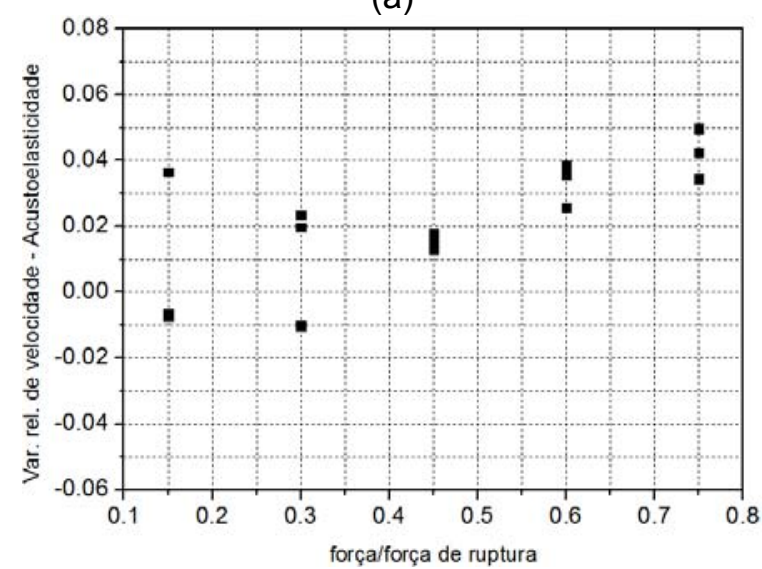

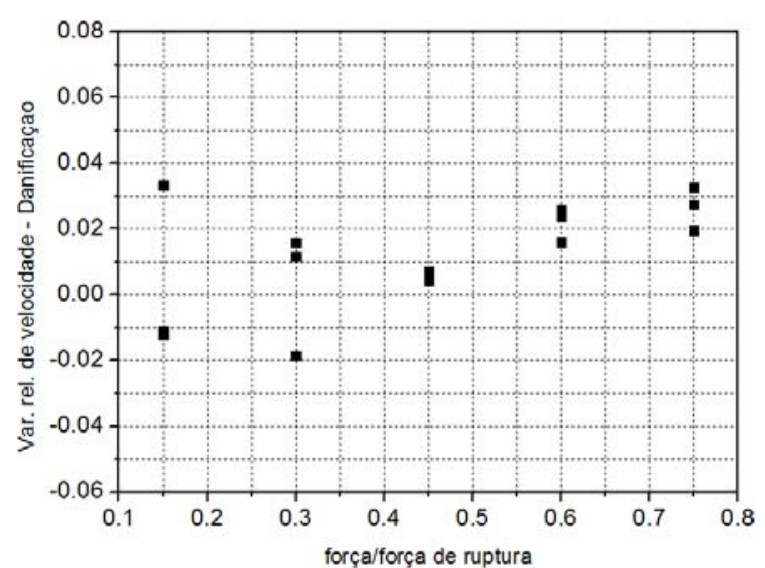

(b)

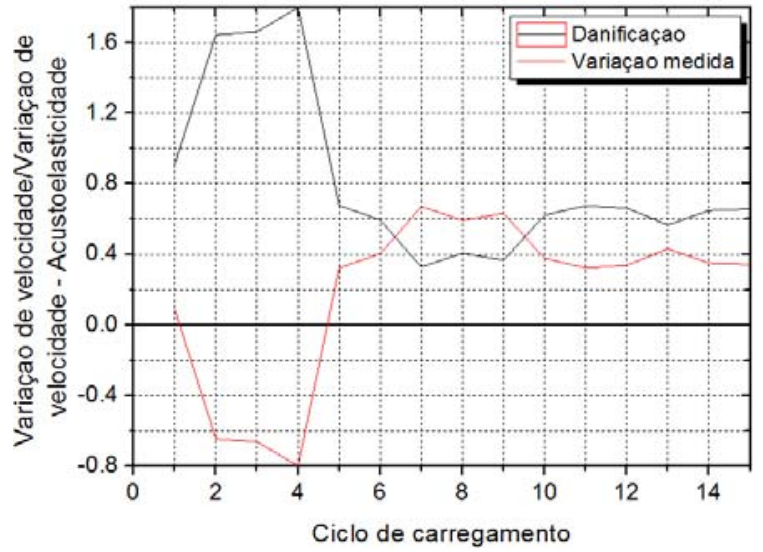

Figura 5. 37 - Cilindro 2, traço 2: (a) Índice de Dano; (b) Variação relativa de velocidade devido à danificação; (c) Variação relativa de velocidade devido à acustoelasticidade; (d) influência da danificação sobre a variação de velocidade 


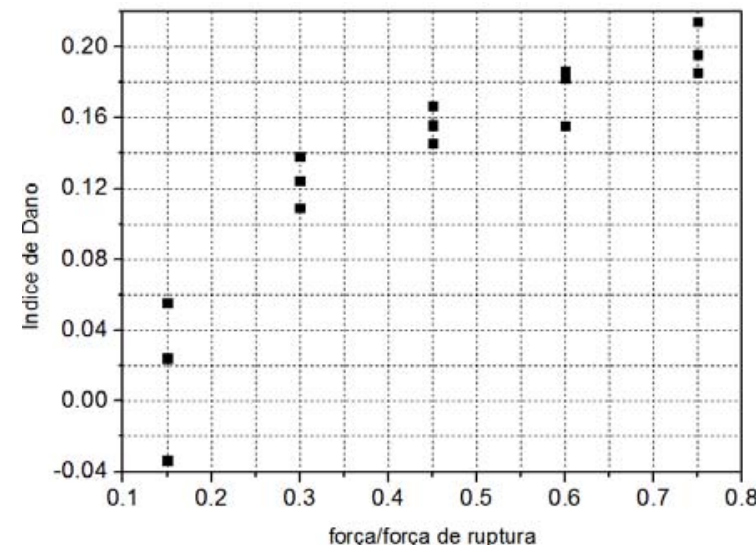

(a)

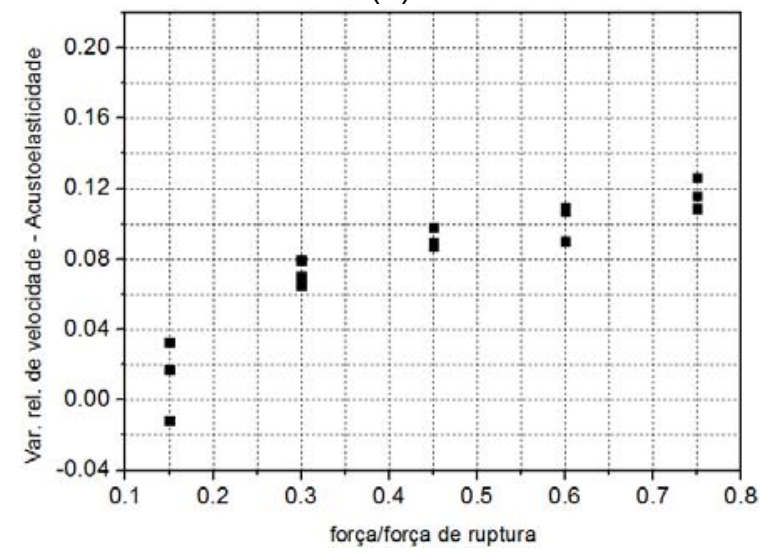

(c)

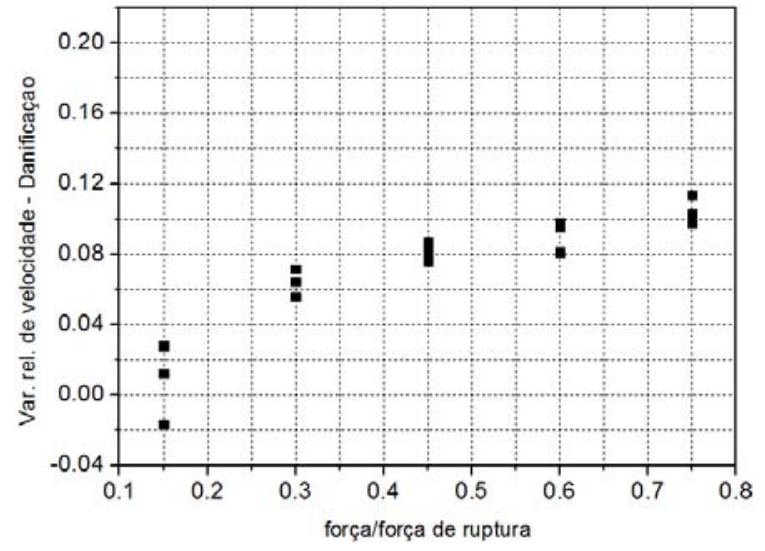

(b)

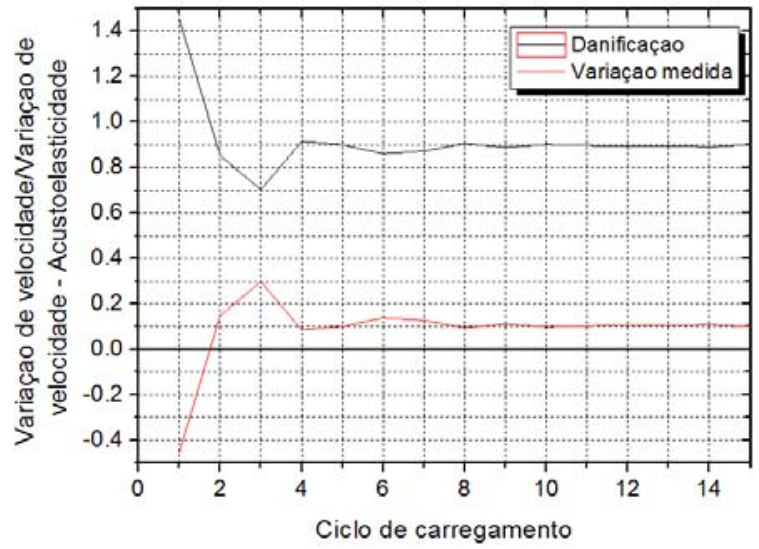

(d)

Figura 5. 38 - Cilindro 3, traço 2: (a) Índice de Dano; (b) Variação relativa de velocidade devido à danificação; (c) Variação relativa de velocidade devido à acustoelasticidade; (d) influência da danificação sobre a variação de velocidade 


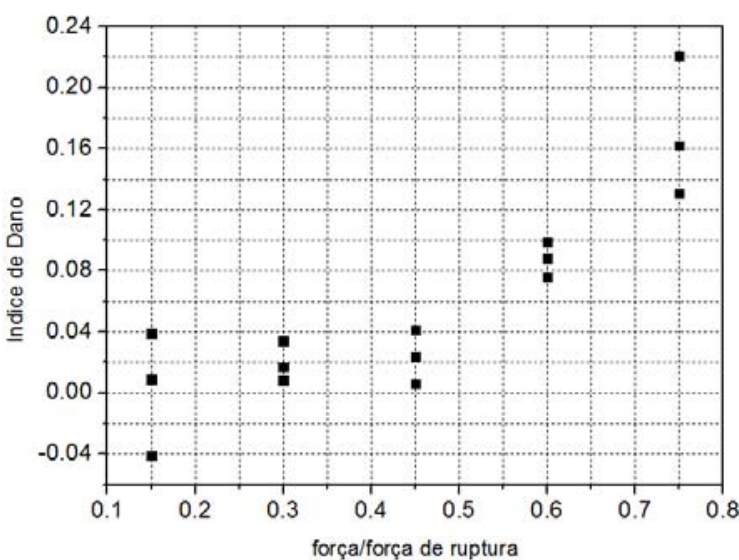

(a)

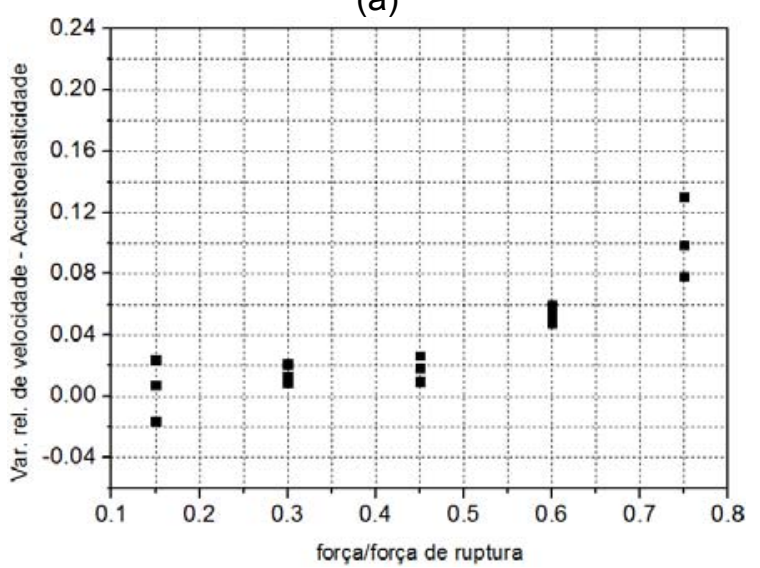

(c)

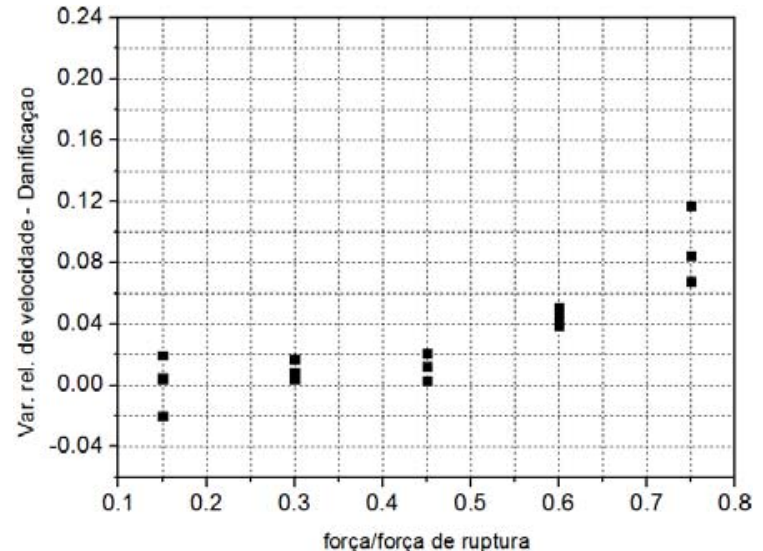

(b)

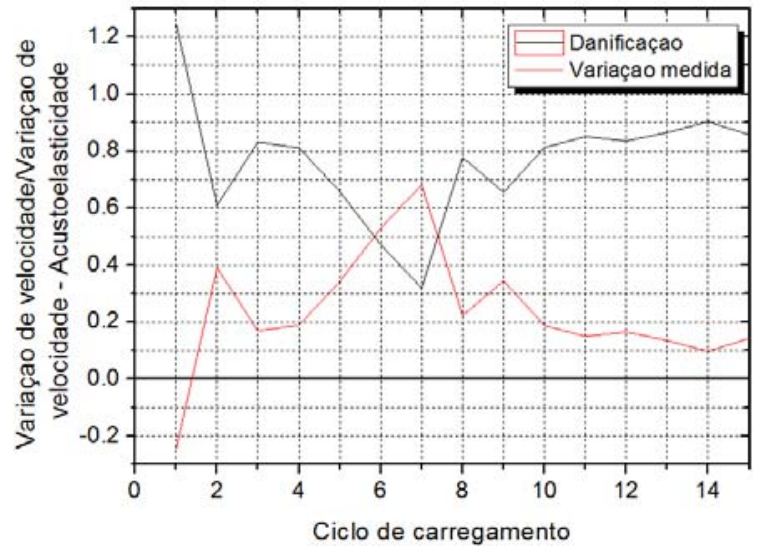

(d)

Figura 5. 39 - Cilindro 1, traço 3: (a) Índice de Dano; (b) Variação relativa de velocidade devido à danificação; (c) Variação relativa de velocidade devido à acustoelasticidade; (d) influência da danificação sobre a variação de velocidade 


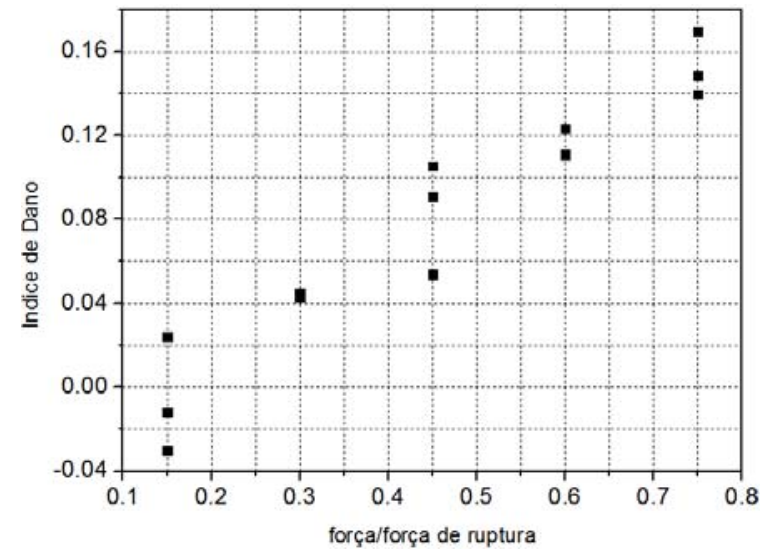

(a)

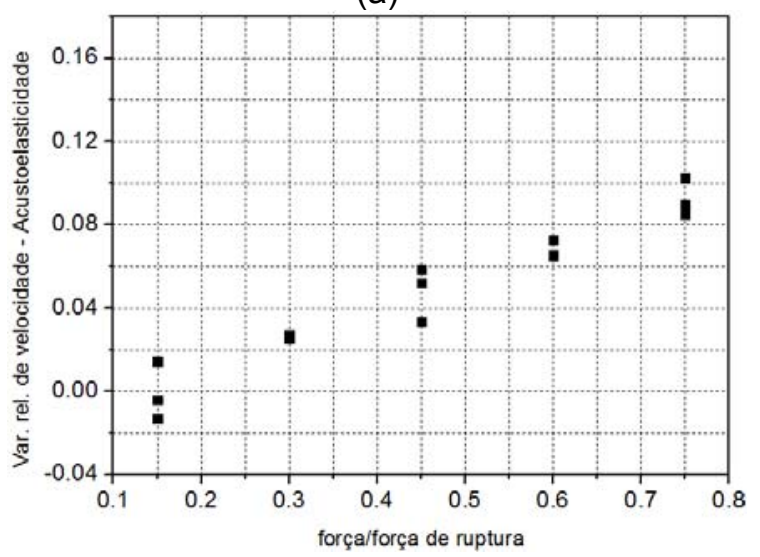

(c)

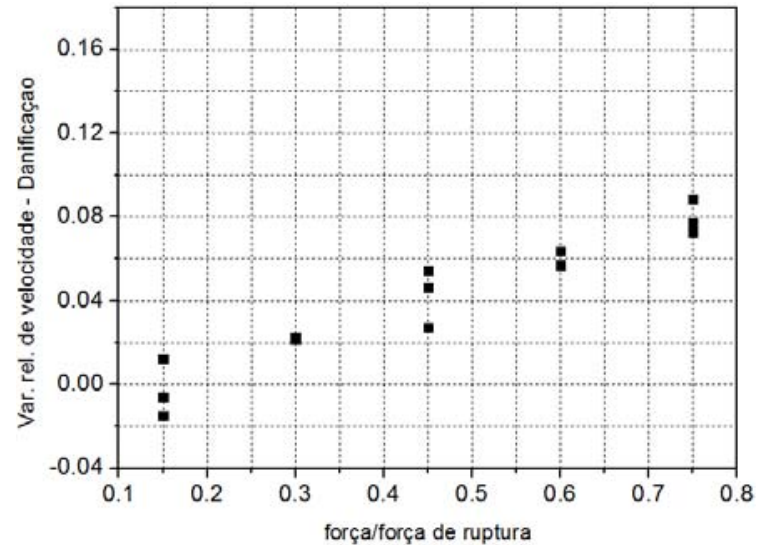

(b)

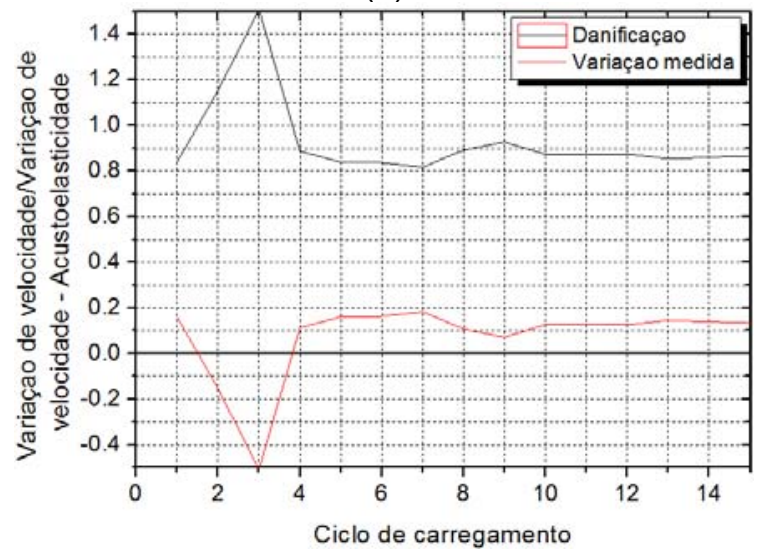

(d)

Figura 5. 40 - Cilindro 2, traço 3: (a) Índice de Dano; (b) Variação relativa de velocidade devido à danificação; (c) Variação relativa de velocidade devido à acustoelasticidade; (d) influência da danificação sobre a variação de velocidade 


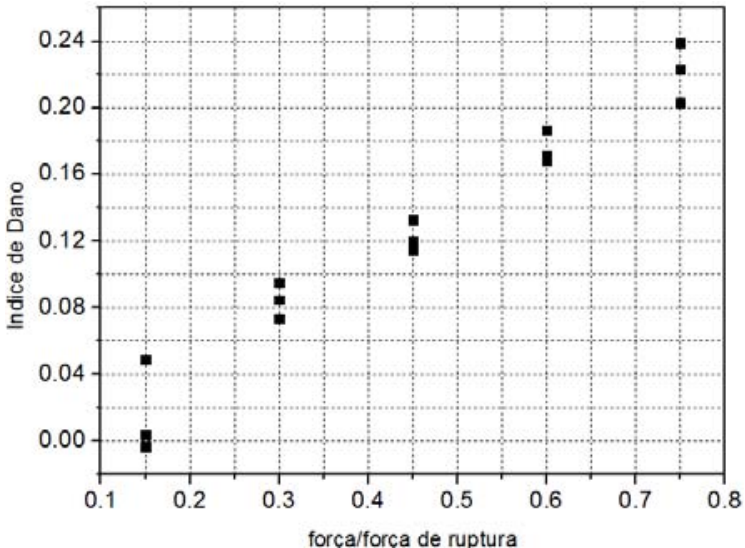

(a)

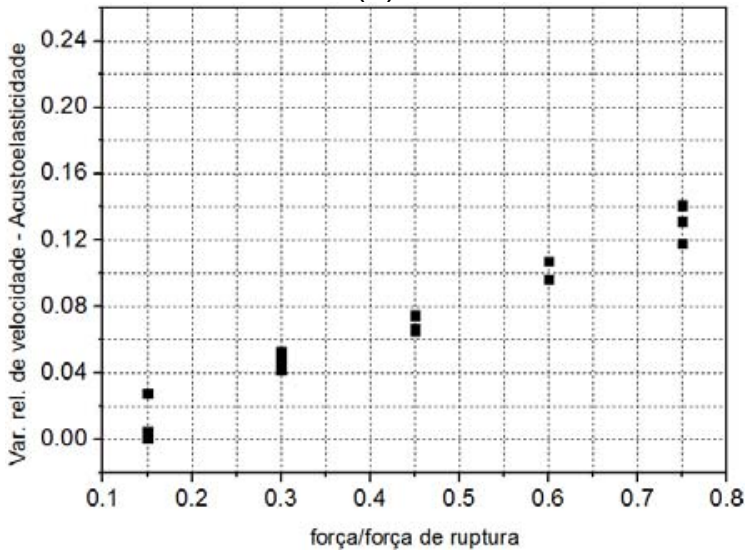

(c)

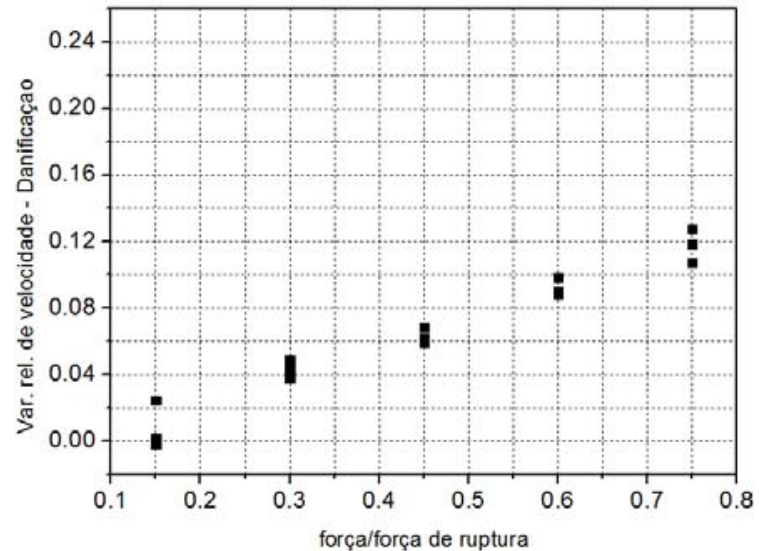

(b)

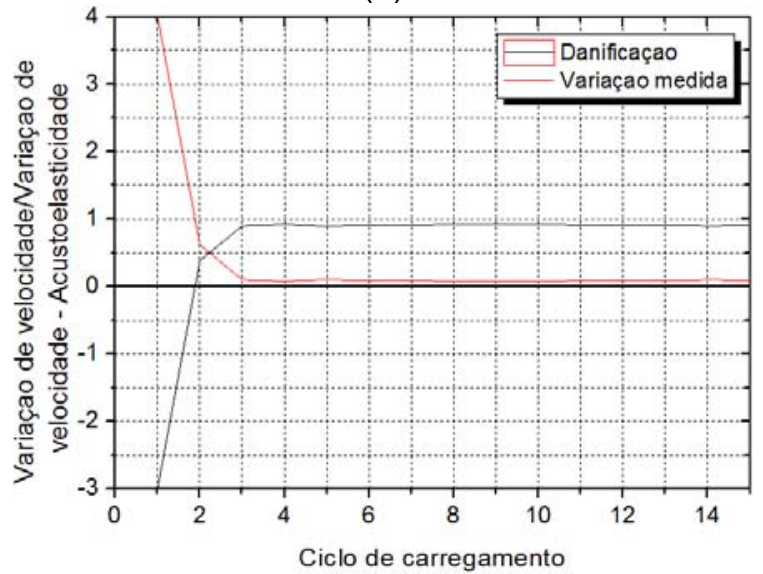

(d)

Figura 5. 41 - Cilindro 3, traço 3: (a) Índice de Dano; (b) Variação relativa de velocidade devido à danificação; (c) Variação relativa de velocidade devido à acustoelasticidade; (d) influência da danificação sobre a variação de velocidade

Conforme esperado, o Índice de Dano apresentou tendência crescente com o aumento do carregamento aplicado. Na maioria dos corpos de prova, é possível observar que o dano tem uma relação quase linear com a tensão aplicada até que aumenta consideravelmente após a aplicação de $60 \%$ da tensão de ruptura. Este comportamento explica o porquê da variação de velocidade medida começar a cair depois da aplicação deste nível de carregamento.

Comparando os gráficos (b) e (c) das figuras 5.30 a 5.41, pode ser observado que o efeito acustoelástico e a danificação afetam a variação de velocidade com, aproximadamente, a mesma grandeza, que é bem superior à medida durante o ensaio de Velocidade de Pulso Ultrassônico.

Por fim, analisando as figuras indicadas pela letra (d), podemos perceber que, como esperado, a influência da danificação aumenta com o passar dos ciclos de carregamento. 
Houve pontos isolados em que a variação de velocidade devido à danificação normalizada assumiu valores maiores que 1. Quando isto ocorreu para carregamentos baixos, o módulo de elasticidade secante encontrado foi superior ao módulo de elasticidade tangente inicial e, consequentemente, o valor do Índice de Dano foi negativo. Nos primeiros ciclos de carregamento, quase não houve variação do módulo de elasticidade porque o dano imposto à amostra foi muito pequeno. Portanto, a imprecisão típica do material e do ensaio podem ter levado a resultados incongruentes, como o aumento do módulo de elasticidade após o carregamento. Quando a danificação assumiu valores maiores que 1 para ciclos de carregamento maiores, a variação de velocidade medida em ensaio foi menor que zero. Nestes casos, é razoável supor que o efeito da danificação realmente foi preponderante sobre o efeito da acustoelasticidade.

A fim de verificar a qualidade do índice de dano para mensurar a variação de velocidade devido à danificação, decidiu-se encontrar a mesma por um outro método aproximado para que a ordem de grandeza entre as respostas fosse comparada. Para tanto, obteve-se a variação de velocidade entre o corpo de prova descarregado ao final de cada ciclo e o elemento íntegro em duas amostras (prisma 1 e cilindro T1C1) por meio da interferometria de cauda de onda. Os resultados são mostrados na figura 5.42 .

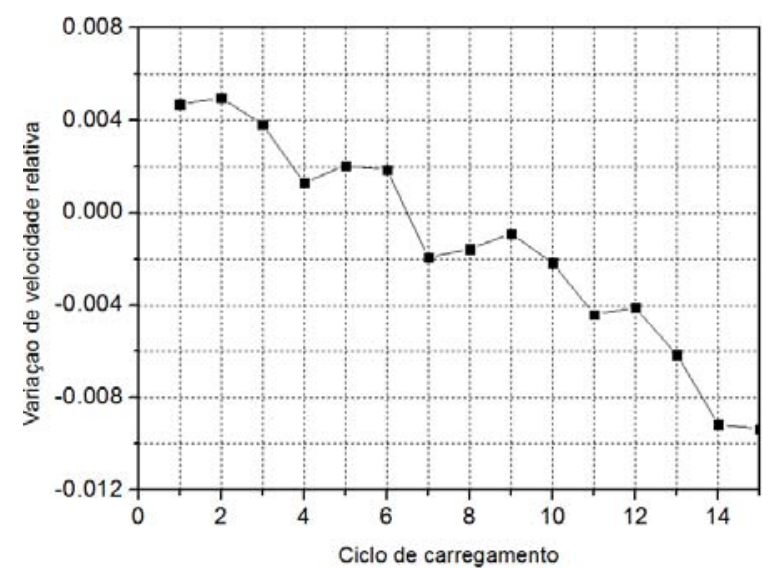

(a)

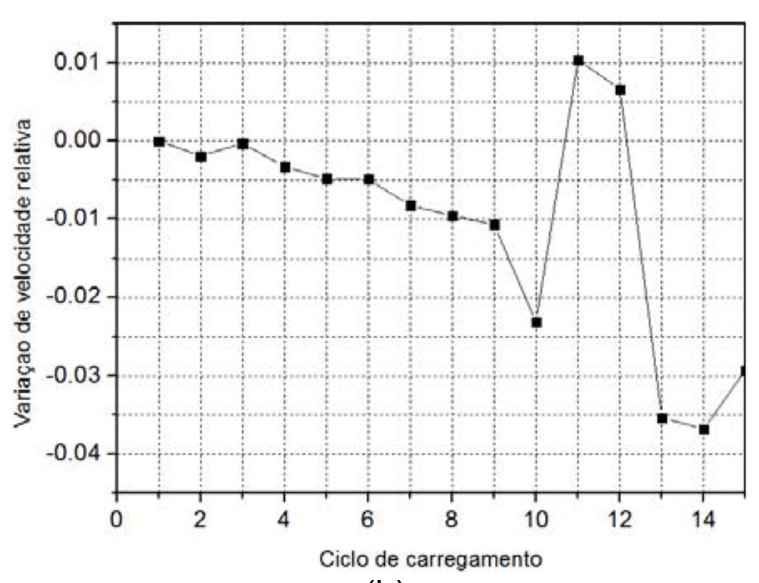

(b)

Figura 5. 42 - Variação de velocidade para a amostra descarregada: (a) prisma 1; e (b) cilindro T1C1

Comparando os gráficos das figuras $5.42 \mathrm{a}$ e $5.42 \mathrm{~b}$ aos das figuras $5.30 \mathrm{~b}$ e $5.33 \mathrm{~b}$, podemos perceber que os resultados obtidos com o Índice de Dano são cerca de quatro vezes maiores que os obtidos diretamente com a variação de velocidade. Além disso, no prisma 1, a danificação só começa a gerar resultados negativos de 
variação de velocidade a partir do sétimo ciclo de carregamento, equivalente a $45 \%$ da tensão de ruptura.

É importante ressaltar que as variações de velocidade mostradas na Figura 5.42 são aproximações. O primeiro fator de imprecisão é que a variação mostrada não leva em consideração a danificação reversível. Como resultados foram obtidos com as ondas propagadas nos corpos de prova descarregados, parte da microfissuração indicada pelo Índice de Dano já havia se fechado. O segundo fator de imprecisão é a não consideração da variação de velocidade devido às condições ambientais. Nos outros resultados apresentados, considerou-se esta variação desprezível devido ao curto intervalo de tempo decorrido entre a propagação das ondas comparadas (menos de uma hora). No entanto, na figura 5.42, a onda obtida no começo do ensaio (amostra íntegra) é comparada à onda obtida no fim do ensaio (fim do último ciclo de carregamento e descarregamento). Logo, há um intervalo de cerca de seis horas entre a primeira e a última medida.

Apesar da grande variação entre os gráficos das figuras $5.42 a$ e $5.42 b$ e as figuras 5.30b e 5.33b, acredita-se que a diferença pode ser explicada pelos fatores de imprecisão estabelecidos. 


\section{CONSIDERAÇÕES FINAIS}

\subsection{Conclusões}

O presente trabalho apresentou um estudo da influência da acustoelasticidade e da danificação sobre a velocidade de pulso ultrassônico em elementos de concreto submetidos a compressão uniaxial.

O primeiro passo para tanto foi definir a metodologia de análise de sinal que seria adotada para avaliação das ondas de cisalhamento. Neste sentido, avaliou-se a adequação da Interferometria de Cauda de Onda à determinação da variação entre dois sinais. Conforme mostrado no capítulo 4 , o método gerou bons resultados, com dispersão relativamente baixa. Concluiu-se, portanto, que o método é satisfatório para avaliação do efeito acustoelástico.

Posteriormente, elaborou-se um código computacional para aplicação da técnica do "alongamento", uma variação da Interferometria de Cauda de Onda tradicional. Comparando os resultados obtidos por meio das duas técnicas, observouse que o alongamento tem uma sensibilidade maior a alterações no meio ensaiado e menor variabilidade de resultados. Ademais, mostrou-se que a janela ideal para aplicação do método se encontra próxima à chegada estimada da onda de cisalhamento.

A partir da segunda etapa de ensaios, constatou-se que a variação de velocidade devido à danificação reversível tem magnitude muito próxima à resolução do aparelho. Por outro lado, mostrou-se que, dependendo da duração do ensaio e do fenômeno que se deseja observar, é fundamental que se considere a variação de velocidade devido a mudanças nas condições ambientais.

A terceira etapa de ensaios avaliou a influência da geometria da amostra e da composição do concreto sobre o efeito acustoelástico.

Com relação à geometria da amostra, observou-se que as amostras cilíndricas apresentaram maiores valores de variação de velocidade para uma mesma tensão aplicada e menor variabilidade de resultados quando a direção de propagação das ondas correspondia à direção de aplicação do carregamento. Acredita-se que isto se 
relacione à melhor distribuição de tensões no cilindro. Por outro lado, na direção 2, os resultados no cilindro tiveram qualidade muito inferior aos resultados no prisma. Este resultado se justifica pela diferença entre as superfícies laterais das duas geometrias. Devido à superfície lateral curva do corpo de prova, as medidas no cilindro estão sujeitas a maior variação.

Quanto à composição do concreto, ficou claro que as variações de velocidade se agrupam em torno de um mesmo traço. Entretanto, a composição de resistência intermediária apresentou os maiores valores de variação de velocidade. Logo, não é possível estabelecer uma relação direta entre a resistência do traço e a magnitude da resposta ao efeito acustoelástico.

Por fim, apresentou-se o Índice de Dano como uma proposta para identificar as variações de velocidades geradas pela danificação e pela acustoelasticidade. Os resultados obtidos mostraram que o efeito acustoelástico tem uma influência muito maior sobre a variação de velocidade que o valor medido em ensaio, uma vez que consegue superar a perda de velocidade causada pela fissuração do corpo de prova.

Conforme esperado, o Índice de Dano aumenta consideravelmente quando a tensão aplicada sobre os corpos de prova chega a $60 \%$ da tensão de ruptura. Ademais, para a maioria das amostras, pode ser visto que a influência da danificação sobre a variação de velocidade medida aumenta conforme a tensão aplicada é aumentada.

\subsection{Sugestões para trabalhos futuros}

A partir das discussões desenvolvidas neste trabalho, são sugeridas as seguintes investigações para trabalhos futuros:

- Realizar os ensaios da terceira etapa do programa experimental com os mesmos ciclos de carregamento, porém realizando o ensaio de Velocidade de Pulso Ultrassônico durante o carregamento e o descarregamento do corpo de prova.

- Expandir o estudo da relação entre acustoelasticidade e composição do concreto para um número maior de traços. 
- Simular numericamente a propagação das ondas mecânicas em prismas e cilindros sob tensão a fim de investigar melhor a influência da geometria no fenômeno.

- Investigar a influência da presença de armaduras nos resultados dos ensaios para avaliação da acustoelasticidade.

- Investigar a influência da danificação e da acustoelasticidade sobre a Velocidade de Pulso Ultrassônico em alvenaria. 


\section{REFERÊNCIAS}

ABRAHAM, O. et al. Non-contact, automated surface wave measurements for the mechanical characterization of concrete. Construction and Building Materials, v. 37, p.904-915, 2012.

AGGELIS, D. G. et al. Acoustic emission and ultrasound for damage characterization of concrete elements. ACI Materials Journal, v. 106, p.509-514, 2009.

AMERICAN SOCIETY FOR TESTING AND MATERIALS. ASTM C 597-09: Standard Test Method for Pulse Velocity through Concrete. West Conshohocken, 2009.

ANDREUCCI, R. Ensaio por ultrassom. São Paulo: Associação Brasileira de Ensaios Não Destrutivos - ABENDI, 2016.

ASSOCIAÇÃO BRASILEIRA DE NORMAS TÉCNICAS. NBR 8802: Concreto Endurecido - Determinação da velocidade de propagação de onda ultrassônica. Rio de Janeiro, 2013.

BLANCO, A. S. Acoustoelastic effects of surface waves in concrete subjected to compressive and bending stresses. 2015. 142p. Dissertação (Mestrado em Engenharia Civil) - University of Illinois, Urbana, 2015.

BUNGEY, J.H.; MILLARD, S.G.; GRANTHAM, M.G. Testing of concrete in structures. 4 ed. Nova York: Taylor \& Francis, 2006.

CARMO, D. C. do et al.; Identificação por ultra-som das regiões de tensões trativas e compressivas numa barra fletida. Tecnologia em Metalurgia e Materiais, v.4, p.1317, 2007.

CLEMEÑA, G.G. Short-pulse radar methods. In: MALHOTRA, V.M.; CARINO, N.J. Handbook on nondestructive testing of concrete. 2 ed. Boca Raton: CRC Press, 2004.

CRAWFORD, G. I. Guide to nondestructive testing of concrete. Washington:

Federal Highway Administration, 1997. 
DAPONTE, P; MACERI, F.; OLIVITO, R.S. Frequency-domain analysis of ultrasonic pulses for the measure of damage growth in structural materials. In: ULTRASONICS SYMPOSYUM PROCEEDINGS, 1990.

GOKHALE, S. Determination of applied stresses in rails using the acoustoelastic effect of ultrasonic waves. 2007. 100p. Dissertação (Mestrado em Engenharia Civil) - Texas A\&M University, College Station, 2007.

GRÊT, A.; SNIEDER, R.; SCALES, J. Time-lapse monitoring of rock properties with coda wave interferometry. Journal of Geophysical Research, v.3, 2006.

HAACH, V.G. CWI. São Carlos: [s.n.], 2016. Programa elaborado pelo professor Vladimir G. Haach.

HAACH, V. G.; JULIANI, L. M.; ROZ, M. R. Ultrasonic evaluation of mechanical properties of concretes produced with high early strength cement. Construction and Building Materials. v.96, p.1-10, 2015.

HUGHES, D.S.; KELLY, J.L. Second-order elastic deformation of solids. Physical Review. v.92, p.1145-1149, 1953.

INTERNATIONAL ATOMIC ENERGY AGENCY. Guidebook on nondestructive testing of concrete structures. Vienna, 2002.

JONES, R.; FACAOARU, I. Recommendations for testing concrete by the ultrasonic pulse method. Materials and Structures. v.2, p.275-284, 1969.

KLEITSA, D. et al. Assessment of metal strand wire pre-stress in anchor head by ultrasonics. NDT\&E International. v.43, p. 547-554, 2010.

KRAUTKRÄMER, J.; KRATKRÄMER, H. Ultrasonic testing of materials. 4 ed. Berlim: Springer-Verlag, 1990.

LAROSE, E.; HALL, S. Monitoring stress related velocity variation in concrete with a 2.10-5 relative resolution using diffuse ultrasound. Journal of the Acoustical Society of America, v. 125, p. 1853-1856, 2009. 
LAUER, K.R. Magnetic/electrical methods. In: MALHOTRA, V.M.; CARINO, N.J. Handbook on nondestructive testing of concrete. 2 ed. Boca Raton: CRC Press, 2004.

LILLAMAND, I. et al. Acoustoelastic effect in concrete material under uni-axial compressive loading. NDT\&E International, v. 43, p.655-660, 2010.

LUNDQVIST, P.; RYDÉN, N. Acoustoelastic effects on the resonance frequencies of prestressed concrete beams - Short-term measurements. NDT\&E International, v.50, p.36-41, 2012.

MALHOTRA, V.M. Surface hardness methods. In: MALHOTRA, V.M.; CARINO, N.J. Handbook on nondestructive testing of concrete. 2 ed. Boca Raton: CRC Press, 2004.

MALHOTRA, V.M.; CARETTE, G.G. Penetration resistance methods. In: MALHOTRA, V.M.; CARINO, N.J. Handbook on nondestructive testing of concrete. 2 ed. Boca Raton: CRC Press, 2004.

MALHOTRA, V.M.; SIVASUNDARAM, V. Resonant frequency methods. In: MALHOTRA, V.M.; CARINO, N.J. Handbook on nondestructive testing of concrete. 2 ed. Boca Raton: CRC Press, 2004.

MEHTA, P.K.; MONTEIRO, P.J.M. Concreto: microestrutura, propriedades e materiais. 3.ed. São Paulo: IBRACON, 2008.

MINDESS, S. Acoustic emission methods. In: MALHOTRA, V.M.; CARINO, N.J. Handbook on nondestructive testing of concrete. 2 ed. Boca Raton: CRC Press, 2004.

MIRMIRAN, A.; WEI, Y. Damage assessment of FRP-encased concrete using ultrasonic pulse velocity. Journal of Enginnering Mechanics, v.127, p.126-135, 2001.

MURNAGHAN, F. D. Finite deformations of an elastic solid. American Journal of Mathematics, v. 59, p. 235-260, 1937.

NAIK, T.R. The break-off test method. In: MALHOTRA, V.M.; CARINO, N.J. Handbook on nondestructive testing of concrete. 2 ed. Boca Raton: CRC Press, 2004. 
NAIK, T.R.; MALHOTRA, V.M.; POPOVICS, J.S. The ultrasonic pulse velocity method. In: MALHOTRA, V.M.; CARINO, N.J. Handbook on nondestructive testing of concrete. 2 ed. Boca Raton: CRC Press, 2004.

PAYAN, C. et al. Determination of nonlinear elastic constants and stress monitoring in concrete by coda wave analysis. In: NON-DESTRUCTIVE TESTING IN CIVIL ENGINEERING, 2009, Nantes.

PLANĖS, T.; LAROSE, E. A review of ultrasonic Coda Wave Interferometry in concrete. Cement and Concrete Research, v. 53, p.248-255, 2013.

POPOVICS, S.; POPOVICS, J.S. Effect of stresses on the ultrasonic pulse velocity in concrete. Materials and Structures, v. 24, p.15-23, 1991.

SAINT-PIERRE, F. et al. Concrete Quality Designation based on Ultrasonic Pulse Velocity. Construction and Building Materials, v.125, p.1022-1027, 2016.

SCHIAVON, K.F.B. Estudo da aplicação de ultrassom na medição de tensões em estruturas de concreto. 2015. 130p. Dissertação (Mestrado em Estruturas) - Escola de Engenharia de São Carlos, Universidade de São Paulo, São Carlos, 2015.

SCHNEIDER, E. Ultrasonic techniques. In: Structural and residual stress analysis by nondestructive methods. Amsterdam: Elsevier Science B. V., 1997.

SCHURR, D. P. et al. Damage detection in concrete using coda wave interferometry. NDT\&E International, v.44, p.728-735, 2011.

SHOKOUHI, P. et al. Surface wave velocity-stress relationship in uniaxially loaded concrete. ACI Materials Journal, v.109, p.141-148, 2012.

SHOKOUHI, P.; ZOËGA, A.; WIGGENHAUSER, H. Nondestructive investigation of stress-induced damage in concrete. Advances in Civil Engineering, p. 1-9, 2010.

SNIEDER, R. et al. Coda Wave Interferometry for estimating nonlinear behavior in seismic velocity. Science, v. 295, p. 2253-2255, 2002. 
STÄHLER, S. C.; SENS-SCHÖNFELDER, C.; NIEDERLEITHINGER, E. Monitoring stress changes in a concrete bridge with coda wave interferometry. Journal of the Acoustical Society of America, v.129, p.1945-1952, 2011.

VASCONCELOS, J.S.; SOUZA, L.C.L. de; TEIXEIRA, B.A. do N. Comportamento térmico em uma fração urbana no município de São Carlos. In: IV Congresso Brasileiro de Gestão Ambiental, Salvador, 2013.

WEIL, G.J. Infrared thermographic techniques. In: MALHOTRA, V.M.; CARINO, N.J. Handbook on nondestructive testing of concrete. 2 ed. Boca Raton: CRC Press, 2004.

ZHANG, Y. et al. Study of stress-induced velocity variation in concrete under direct tensile force and monitoring of damage level by using thermally-compensated Coda Wave Interferometry. Ultrasonics, v.52, p.1038-1045, 2012. 